UNIVERSIDADE DE SÃO PAULO

INSTITUTO DE GEOCIÊNCIAS

\title{
QUIMIOESTRATIGRAFIA ISOTÓPICA (C, O, Sr) E GEOCRONOLOGIA (U-Pb, Sm-Nd) DAS ROCHAS DA FORMAÇÃO SETE LAGOAS, GRUPO BAMBUÍ
}

Gustavo Macedo de Paula Santos

Orientadora: $\operatorname{Prof}^{\mathrm{a}}$. Dr ${ }^{\mathrm{a}}$. Marly Babinski

DISSERTAÇÃO DE MESTRADO

Programa de Pós Graduação em Geoquímica e Geotectônica

SÃO PAULO

2012 
"O cabra que não gosta de Geologia é um..."

(Benjamin Bley de Brito Neves) 


\section{AGRADECIMENTOS}

Quem esteve comigo nestes últimos dois anos sabe o quanto minha vida mudou. Talvez o período entre o fim da graduação e o depósito desta dissertação tenha sido aquele em que mais fui submetido à emoções extremas, fossem elas alegres ou de sofrimento. Por isto escrever estes agradecimentos tem um significado especial para mim. Então chega de lenga lenga e vamos ao que interessa.

Ainda que possam achar ruim, vou começar agradecendo à Elisa, pessoa que compartilhou três anos de sua vida comigo. Pessoa que me ensinou o real significado de estar com alguém, de ser cúmplice, parceiro ou qualquer coisa mais que um simples namorado. Ela definitivamente mudou minha vida, sem volta. Peço sinceras desculpas, não pelo que fiz, mas como fiz. Prometo jamais agir de tal maneira em nenhum outro momento da minha vida. Os mesmos agradecimentos e as desculpas também se direcionam à sua família, que me tratou como um verdadeiro filho. Lamento ter quebrado sua confiança.

Passo agora ao pessoal de casa, o Cativeiro. Agradeço Fyona, Indigente, Charula e Funga pela contribuição "intelectual” dada à elaboração deste trabalho. Pode parecer estranho, mas se esta dissertação tivesse sido escrita no silêncio de uma sala privada, seu conteúdo geológico teria sido altamente penalizado pela ausência da falácia e da sapiência destes que são, certamente, os caras mais qualificados ao título de "geólogos competentes". Agradeço também aos adendos da república (Dé, Dante, Flor, Gargalo e outros) por eventuais contribuições dadas.

Também devo agradecer aqui meus parceiros de campo, Alemão e Craca. Estas figuras foram de fundamental importância neste trabalho, visto que sem eles simplesmente não haveria amostras!! Quantas pessoas subiriam aqueles morros de Lagoa Santa mais íngremes que os prédios da Avenida Paulista e rodeados de carrapatos? Garanto que as pessoas xingadas durante a subida não.

Um obrigado especial também ao pessoal do CPGeo: Vasco, Maurício, Márcio, Helen, Ivone, Solange, Lili, Walter e outros me ajudaram e muito na obtenção dos dados deste trabalho.

Muito obrigado Marly, a Babinski, por sua orientação impecável. Mais que isso, obrigado por me aturar todo este tempo, pois pode não parecer, mas já são seis anos. Sei que já disse isto, mas quero repetir o quão é inevitável enxergar a figura de minha mãe nesta mulher, não só pela semelhança na forma de ser, mas pela forma de me tratar. Na parte de orientação, também deixo um agradecimento especial para Mr. Thomas, Teixeira e Boggiani 
pelas dicas dadas. E não me esqueço de Bley, proferidor das mais sábias palavras geológicas desde James Huton.

Dando sequência, quero agradecer à minha família. Obrigado mãe e pai por tudo o que fizeram por mim. Não só nestes dois anos de mestrado, mas desde o parto deste que vos escreve, naquele momento denominado de rã pela própria mãe (que se assustou com a aparência do filho similar ao anfíbio). Tudo que fui, sou ou serei é obra de vocês. Agradeço também aos meus avós (Stella, Henrique, Olívia e Zé), tios (em especial Márcia e Shell) e irmãs (Flávia e Fernanda) por terem me apoiado após tudo o que aconteceu no dia da minha Formatura. Mesmo reconhecendo meu erro, nunca duvidaram do meu caráter.

Quase por fim, agradeço Carolina Barnez Gramcianinov. Sim, a minha trakinas!! Nunca tinha batido os olhos em alguém e ficado apaixonado tão rapidamente. Você fez minha vida girar uns $2113^{\circ}$ em uma velocidade impossível de ser aferida por qualquer instrumento conhecido pelo homem. Cada dia ao seu lado é uma oportunidade inigualável de conhecer ainda mais aquela que é minha companheira, minha amiga, meu amor. Tenha certeza de que tudo pelo que passamos nos fez ainda mais unidos e apaixonados. Agradeço também a sua família, em especial à Rosana, Wanda, Guilherme e Arcádio, que me acolheram como um filho e não como apenas mais um.

Finalizo agradecendo ao Shade. Pode ser ridículo agradecer um cachorro, ainda mais um com problemas na vista, no rim e no reto, mas a afinidade que criei com este vira-lata foi algo fundamental para me manter em pé nos momentos tristes. Ele é a prova de que tudo na natureza é capaz de trazer satisfação e alegria, mesmo que apareça fedendo e vagando sem rumo em uma rua qualquer.

Despeço-me aqui, sem mais. Desculpe os que esqueci de mencionar. Podem ter certeza que sou grato a todos, mas se continuar, esta seção vai ficar muito longa. Aliás, já está maior que o resumo... 


\section{SUMÁRIO}

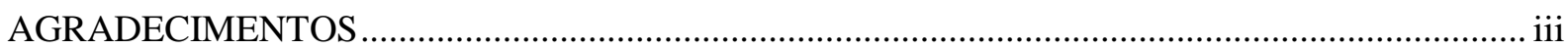

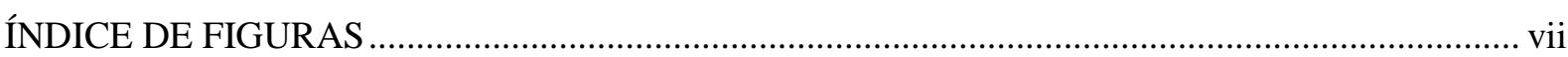

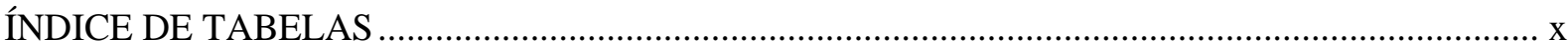

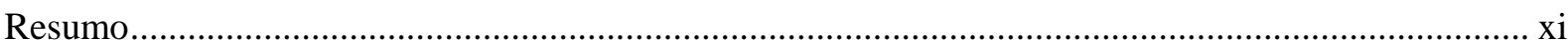

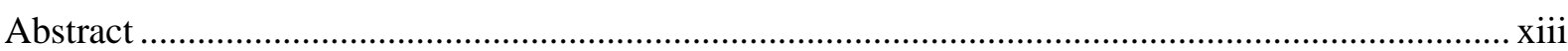

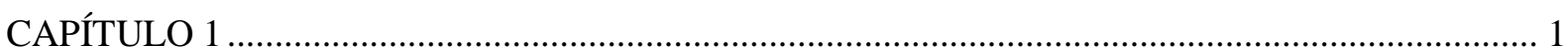

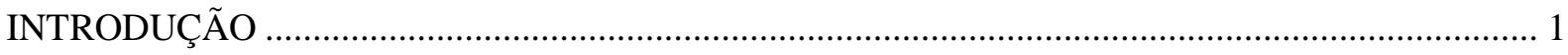

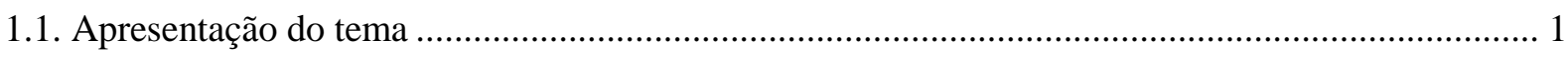

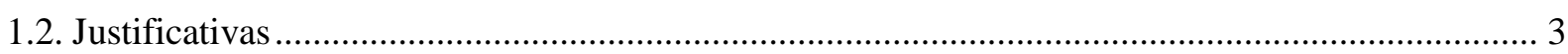

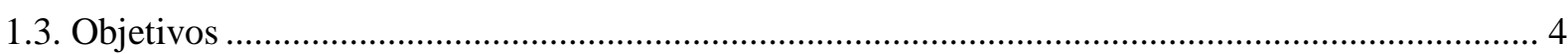

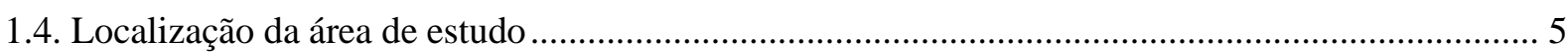

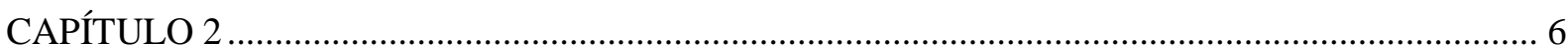

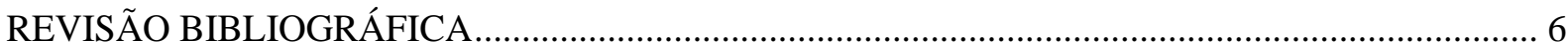

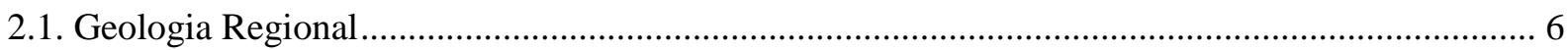

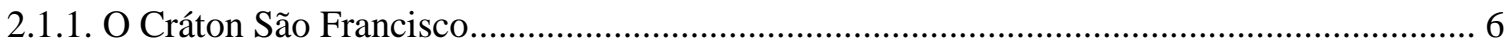

2.1.2. As sequências deposicionais proterozoicas do CSF ........................................................... 7

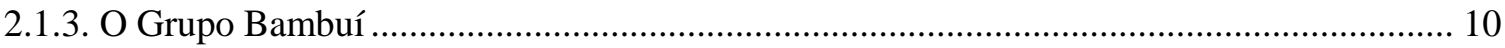

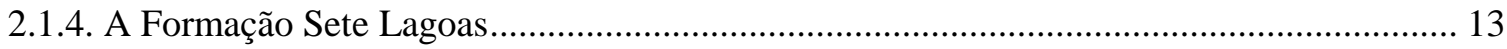

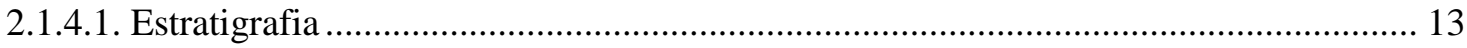

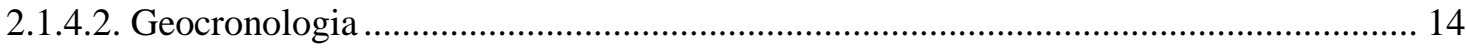

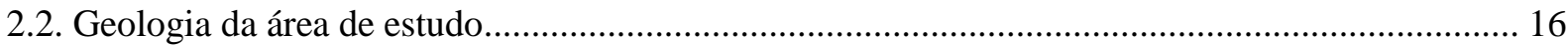

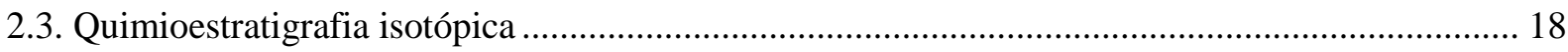

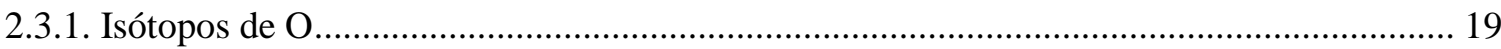

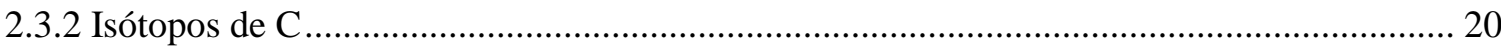

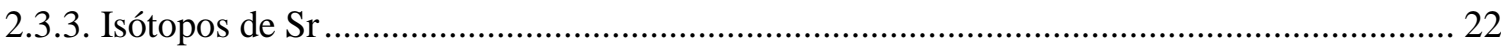

2.3.4. Aspectos a serem considerados para aplicação da quimioestratigrafia isotópica................. 22

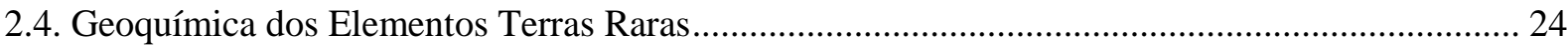

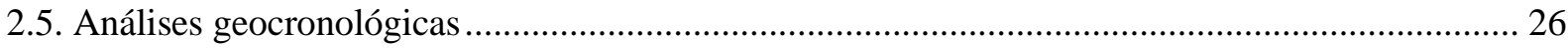

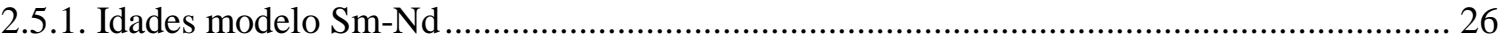

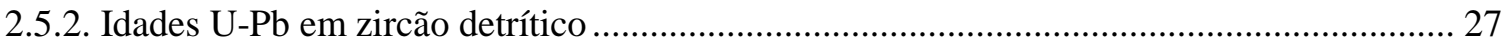

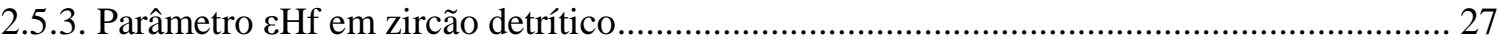

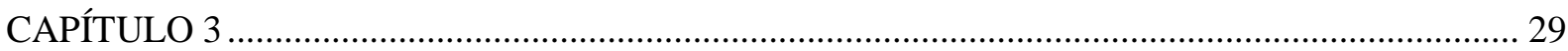

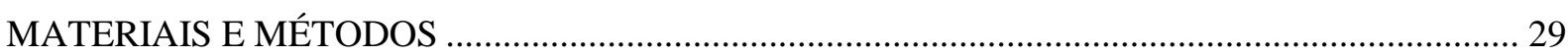

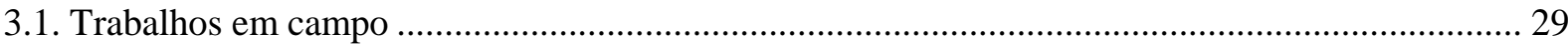

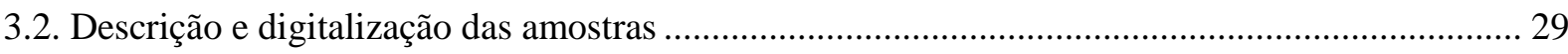




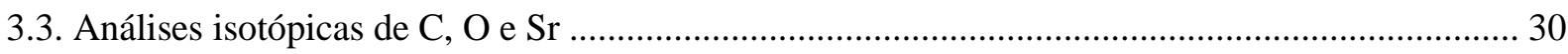

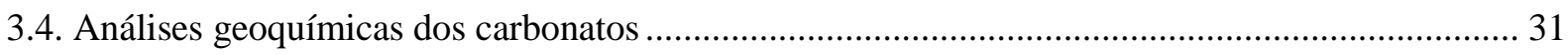

3.5. Separação de zircão detrítico para datação U-Pb e análises isotópicas de Hf ................................. 32

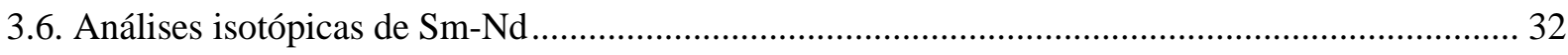

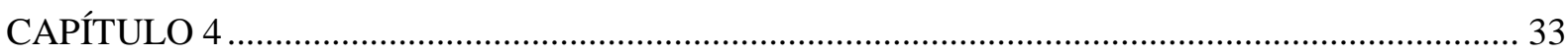

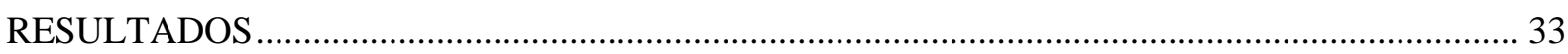

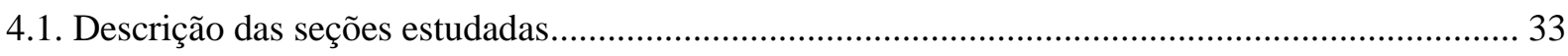

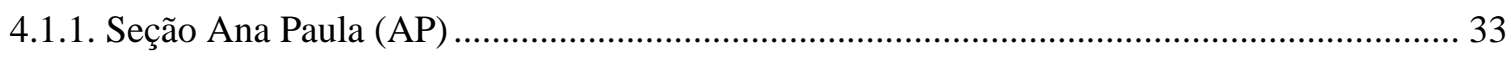

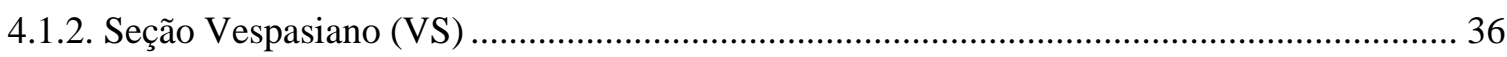

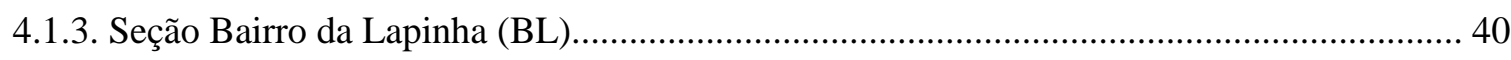

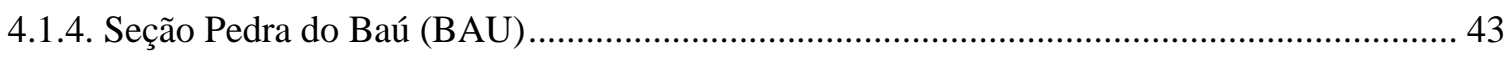

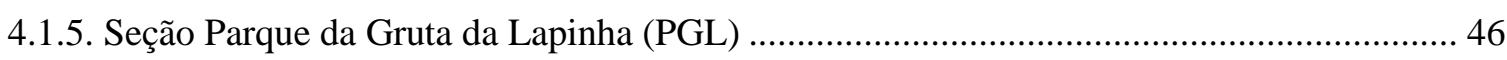

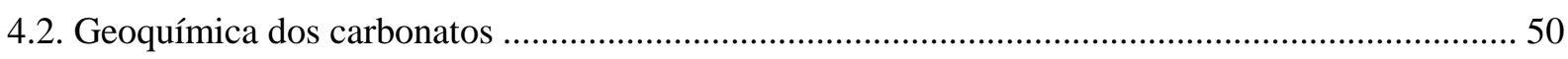

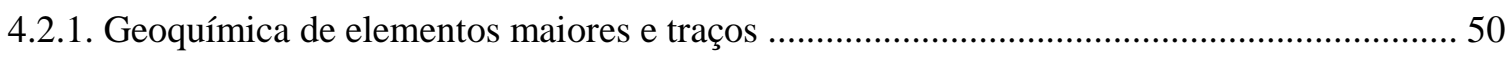

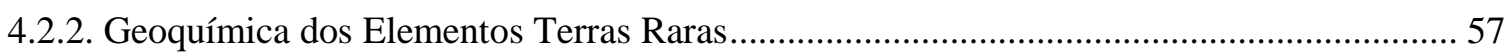

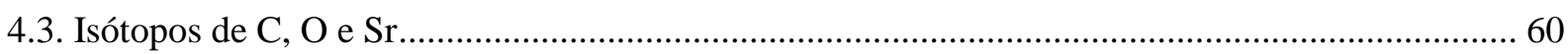

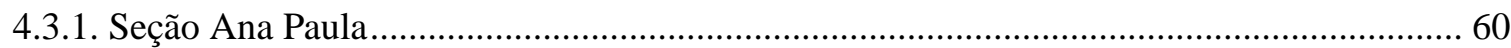

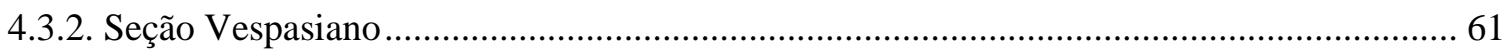

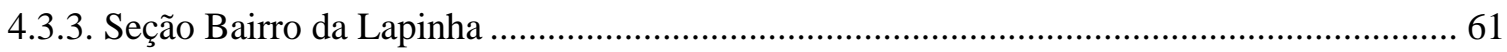

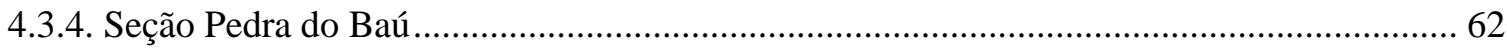

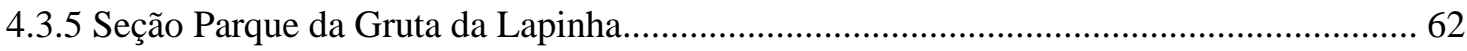

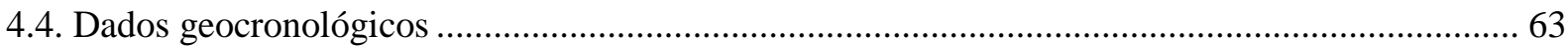

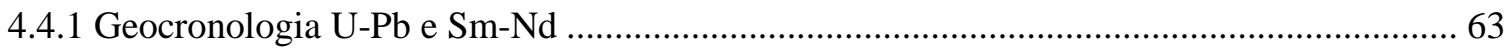

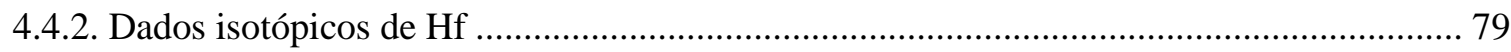

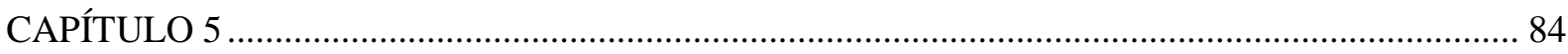

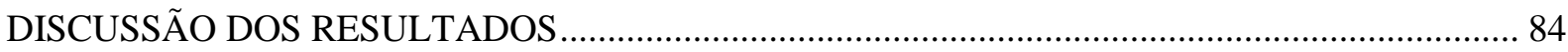

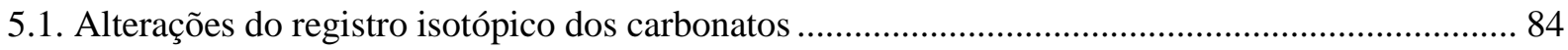

5.2. Representatividade dos dados de Elementos Terras Raras........................................................... 91

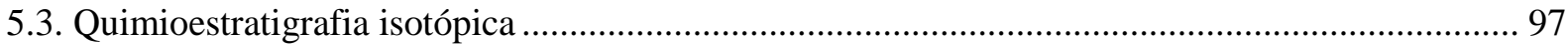

5.4. Proveniência sedimentar e idade deposicional da Formação Sete Lagoas .................................... 106

5.5. Implicações geotectônicas e paleoambientais das idades obtidas ................................................. 112

5.6. Significado das razões ${ }^{87} \mathrm{Sr} /{ }^{86} \mathrm{Sr}$ nos carbonatos do Grupo Bambuí .......................................... 117

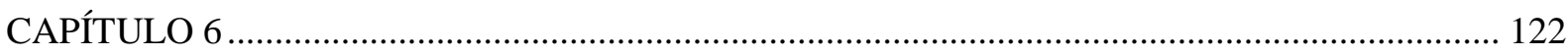

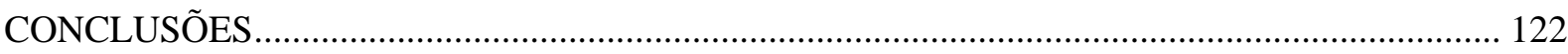

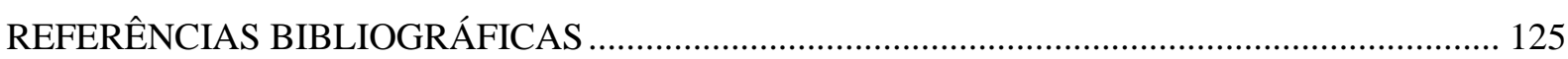




\section{ÍNDICE DE FIGURAS}

Fig. 1 - Mapa de localização da área de estudo com as principais vias de acesso..

Fig. 2 - Mapas de localização, geológico e morfotectônico do Cráton São Francisco (modificado de Santos et al., 2000 e Alkmim \& Martins-Neto, 2012).

Fig. 3 - As sequências proterozoicas de primeira ordem do CSF e correlatos nas faixas Brasília, Araçuaí, West Congo e Cráton do Congo (modificado de Alkmim \& Martins-Neto, 2012). 10

Fig. 4 - Estratigrafia do Supergrupo São Francisco baseada em Dardenne (1978) e Iglesias \& Uhlein (2009).

Fig. 5 - Estratigrafia da Formação Sete Lagoas baseada em Schöll (1976) e Vieira et al. (2007a, b), com as idades recentemente publicadas e seu perfil isotópico de $\mathrm{C}$ esquemático. 15

Fig. 6 - Mapa geológico da área de estudo com as localizações das seções descritas neste estudo (modificado de Projeto VIDA, 2003).

Fig. 7 - Curva de evolução da composição isotópica de C dos oceanos durante o Neoproterozoico e início do Cambriano (modificado de Halverson et al., 2005).

Fig. 8 - Curva de evolução da composição isotópica de Sr dos oceanos durante o Neoproterozoico e Cambriano (modificado de Halverson et al., 2010).

Fig. 9 - Coluna estratigráfica da seção Ana Paula com as curvas isotópicas de $\mathrm{C}$ e $\mathrm{O}$ obtidas e a razão ${ }^{87} \mathrm{Sr} /{ }^{86} \mathrm{Sr}$ da amostra 11-AP-14.

Fig. 10 - Imagens da seção Ana Paula que exibem: A) Afloramento de marga amostrado para geocronologia; B) Calcissiltito com lâminas compostas por dolomita (amostra 11-AP-14); C) Doloarenito muito fino com lâminas submilimétricas de sericita (amostra 11-AP-18); D) Fotomicrografia de doloarenito muito fino a fino com mais de $20 \%$ de sedimentos detríticos (nicóis // e $X$ da esquerda para a direita, objetiva de 1,25x, amostra 11-AP-03); E) Fotomicrografia de calcissiltito com litoclasto sigmoide (nicóis // e X da esquerda para a direita, objetiva de 4x, amostra 11-AP-01)

Fig. 11 - Coluna estratigráfica da seção Vespasiano com as curvas isotópicas de $\mathrm{C}$ e $\mathrm{O}$ obtidas e as razões ${ }^{87} \mathrm{Sr} /{ }^{86} \mathrm{Sr}$ das amostras $11-\mathrm{VS}-01$ e 16.

Fig. 12 - Imagens da seção Vespasiano que exibem: A) Vista geral da base da seção; B) calcissiltito grosso com laminação planar (amostra 11-VS-01); C) Brecha tectônica dolomitizada (amostra 11-VS03); D) Falha de empurrão com dobras de arrasto (vareta tem $1 \mathrm{~m}$ de comprimento); E) Doloarenito fina da porção central (amostra 11-VS-12); F) Afloramento de marga amostrado para geocronologia; G) Fotomicrografia de calcissiltito recristalizado (nicóis // e X da esquerda para a direita, objetiva de 4x, amostra 11-VS-01). 40

Fig. 13 - Coluna estratigráfica da seção BL com as curvas isotópicas de C, O e Sr obtidas

Fig. 14 - Imagens da seção Bairro da Lapinha exibindo: A) Calcarenito muito fino, rico em matéria orgânica e com possível laminação convoluta; B) Calcissiltito rico em matéria orgânica (amostra 11BL-15); C) Calcarenito muito fino com vênulas preenchidas por calcita branca // $\mathrm{S}_{0}$ (amostra 11-BL12); D) Fotomicrografia de calcarenito muito fino, com matriz recristalizada e anel carbonático (nicóis //, objetiva de 10x, amostra 11-BL-05).

Fig. 15 - Coluna estratigráfica da seção Pedra do Baú com suas curvas isotópicas de C, O e Sr. 44

Fig. 16 - Imagens da Seção Pedra do Baú exibindo: A) Vista Geral da seção; B) calcário cinza com teor moderado de matéria orgânica (amostra 11-BAU-30); C) calcário cinza escuro rico em matéria 
orgânica (amostra 11-BAU-26); D) calcário cinza com mancha mais escura à direita (amostra 11BAU-27); E) Afloramento mostrando horizontalidade dos estratos; F) Fotomicrografia com estilólito em leito com aspecto protomilonítico (nicóis X, objetiva de 4x, amostra 11-BAU-08); G) Fotomicrografia com vênula preenchida por calcita, rompendo estilólito em leito protomilonítico (nicóis //, objetiva de 4x, amostra 11-BAU-45).

Fig. 17 - Coluna estratigráfica da seção PGL com suas curvas isotópicas de C, O e Sr.

Fig. 18 - Imagens da seção do Parque da Gruta da Lapinha exibindo: A) Vista da base da seção; B) Calcarenito muito fino, cinza escuro (amostra 11-PGL11); C) Calcarenito muito fino com lâminas compostas por dolomita (amostra 11-PGL-33); D) Calcissiltito negro e rico em matéria orgânica (amostra 11-PGL-18); E) Camada mais espessa de marga (entre linhas pontilhadas vermelhas martelo tem $38 \mathrm{~cm}$ de comprimento); F) Fotomicrografia que mostra contato poligonizado entre os grãos de carbonato e orientação dos mesmos (nicóis X, objetiva de 2,5x, amostra 11-PGL-29); G) Fotomicrografia de calcário com aspecto protomilonítico com vênula truncando foliação $S_{1}$ (nicóis $X$, objetiva de 10x, amostra 11-PGL-37). .

Fig. 19 - Gráfico de dispersão de teores $\mathrm{Sr} v s$. Rb, exibindo a distinção entre os grupos 1 e 2 . Notar que somente a amostra 11-PGL-33 está fora de seu grupo designado.

Fig. 20 - Distribuição normalizada de ETR em relação ao padrão PAAS obtidos em carbonatos da Formação Sete Lagoas das seções Bairro da Lapinha (BL), Pedra do Baú (BAU) e Parque da Gruta da Lapinha (PGL).

Fig. 21 - Gráfico de dispersão dos valores de $\delta^{13} \mathrm{C}$ e $\delta^{18} \mathrm{O}$, exibindo a distinção entre os carbonatos dos grupos 1 e 2. As amostras de calcário com lâminas de dolomita da seção PGL estão dentro da elipse do grupo 2, o que sugere alteração pós-deposicional.

Fig. 22 - Imagens de catodoluminescência dos grãos de zircão detrítico obtidos da amostra 11-AP-05.

Fig. 23 - Diagrama Concórdia Tera \& Wasserburg (1972) para a amostra 11-AP-05, com detalhe para o intervalo entre 620-560 Ma, onde foi obtida a idade concórdia de 592,9 \pm 1,7 Ma.

Fig. 24 - Imagens de catodoluminescência dos grãos de zircão detrítico obtidos da amostra 11-VS-13.

Fig. 25 - Diagrama Concórdia Tera \& Wasserburg (1972) para a amostra 11-VS-13 com detalhe para o intervalo entre 1600-400 Ma.

Fig. 26 - Histograma obtido com os dados geocronológicos de zircão detrítico da amostra 11-VS-13. Foram utilizadas somente idades ${ }^{207} \mathrm{~Pb} /{ }^{206} \mathrm{~Pb}$ com concordância entre $90-110 \%$. Não foram considerados os grãos de idade paleoproterozoica e arqueana.

Fig. 27 - Imagens de catodoluminescência dos grãos de zircão detrítico obtidos da amostra 11-PGLPEL

Fig. 28 - Imagens de catodoluminescência dos grãos de zircão detrítico obtidos da amostra 11-PGLPEL

Fig. 29 - Diagrama Concórdia Tera \& Wasserburg (1972) para a amostra 11-PGL-PEL com detalhe para o intervalo entre 750-350 Ma.

Fig. 30 - Histograma obtido com os dados geocronológicos de zircão detrítico da amostra 11-PGLPEL. Foram utilizadas somente idades ${ }^{238} \mathrm{U} /{ }^{206} \mathrm{~Pb}$ com concordância entre $90-110 \%$. 78

Fig. 31 - Idades Modelo Sm-Nd obtidas em análises de Rocha Total das amostras 11-AP-05, 11-VS13, 11-PGL-PEL. 
Fig. 32 - Gráficos de dispersão entre $\mathrm{Mg} / \mathrm{Ca}$ e $\mathrm{Mn} / \mathrm{Sr}$ vs. $\delta^{13} \mathrm{C}$ e $\delta^{18} \mathrm{O}$. Nota-se que amostra 11-PGL-33 difere geoquimicamente das demais.

Fig. 33 - Gráfico de dispersão entre as razões $\mathrm{Mn} / \mathrm{Sr}$ vs. $\mathrm{Mg} / \mathrm{Ca}$ das amostras de carbonatos. 89

Fig. 34 Gráfico de dispersão entre os teores de $\mathrm{Sr} / \mathrm{Ca}$ vs. Mn. Nota-se que a diminuição das razões $\mathrm{Sr} / \mathrm{Ca}$ não é acompanhada de incorporação de Mn na química dos carbonatos.

Fig. 35 - Diagramas de teores $\Sigma$ ETR vs. Zr, Al vs. $\Sigma$ ETR e Al vs.Th, nos quais se observa correlação positiva entre os constituintes de minerais terrígenos e o conteúdo de ETR dos carbonatos analisados.

Fig. 36 - Diagramas de distribuição normalizada das amostras de carbonatos considerados representativos da composição de ETR do ambiente de deposição.

Fig. 37 - Diagramas de distribuição normalizada das amostras de carbonatos considerados não representativos da composição de ETR do ambiente de deposição.

Fig. 38 - Correlação quimioestratigráfica entre a Seção VS deste trabalho e as seções Lontra (LO), Sambra (SA), Paraíso (PA), Tatiana (TA) e Cauê (CE) de Vieira et al. (2007b). A seção AP foi posicionada abaixo do salto isotópico da Formação Sete Lagoas por estratigrafia convencional. ..... 102

Fig. 39 - Correlação quimioestratigráfica entre a Seção VS deste trabalho e as seções de Santos et al. (2004) e Kuchenbecker (2011).

Fig. 40 - Correlação quimioestratigráfica entre a Seções BL, BAU e PGL deste trabalho e as seções Canaã (CA), Mata Grande (MG) e Cauê (CE) do trabalho de Vieira et al. (2007b). 104

Fig. 41 - Correlação quimioestratigráfica entre a Seções BL, BAU e PGL deste trabalho e as seções de Santos et al. (2004).

Fig. 42 - Histogramas de distribuição das idades para as amostras 11-VS-13 e 11-PGL-PEL com as prováveis fontes dos sedimentos terrígenos.

Fig. 43 - Esquema estratigráfico e geocronológico da Formação Sete Lagoas baseado em dados disponíveis na literatura e obtidos neste trabalho. 112

Fig. 44 - Esquema da evolução tectônica do CSF entre 750-530 Ma com a deposição do Grupo Bambuí neste intervalo (modificado de Martins-Neto, 2009 e Kuchenbecker, 2011). 116

Fig. 45 - Mapa da área de estudo com indicação dos elementos que sugerem que a Faixa Araçuaí estava edificada a E durante a deposição do Grupo Bambuí e atuou como fonte dos sedimentos detríticos desta unidade. 116

Fig. 46 - Curva de evolução da composição isotópica de $\mathrm{Sr}$ dos oceanos durante o Neoproterozoico e Cambriano. A elipse vermelha indica a faixa de razões ${ }^{87} \mathrm{Sr} /{ }^{86} \mathrm{Sr}$ mais representativas obtidas para a Formação Sete Lagoas (modificado de Halverson et al., 2010). 117

Fig. 47 - Esquema do fluxo de Sr fluvial para os mares nos dias atuais (baseado em Palmer \& Edmond, 1992) e no CSF no início do Cambriano. 


\section{ÍNDICE DE TABELAS}

Tabela 1 - Teores dos elementos maiores dos carbonatos analisados.

Tabela 2 - Teores de $\mathrm{Rb}$ e $\mathrm{Sr}$, razões geoquímicas, valores isotópicos de $\mathrm{C}$ e $\mathrm{O}$ e razões ${ }^{87} \mathrm{Sr} /{ }^{86} \mathrm{Sr}$ obtidos nos calcários analisados.

Tabela 3 - Teores de Elementos Terras Raras e Zr, razões Y/Ho e parâmetros Ce/Ce* e $\mathrm{Pr} / \mathrm{Pr} *$ dos carbonatos analisados das seções BL, BAU e PGL. 58

Tabela 4 - Dados de LA-ICP-MS U/Pb dos grãos de zircão detríticos das amostras 11-AP05 . . .66

Tabela 5 - Dados de LA-ICP-MS U/Pb dos grãos de zircão detríticos das amostras 11-VS13. .66

Tabela 6 - Dados de LA-ICP-MS U/Pb dos grãos de zircão detríticos das amostras 11-PGLPEL . .70

Tabela 7 - Dados isotópicos de Sm-Nd obtidos para as amostras de marga das seções AP, VS e PGL. 79

Tabela 8 - Dados isotópicos de Hf obtidos nos grãos de zircão detrítico das amostras 11-AP-05, 11VS-13 e 11-PGL-PEL. 81 


\section{Resumo}

Idades radiométricas absolutas recentemente publicadas levantaram questões sobre a evolução deposicional da Formação Sete Lagoas (FSL). Esta unidade é composta predominantemente por carbonatos com rochas siliciclásticas subordinadas e constitui a unidade basal do Grupo Bambuí, sobreposta aos depósitos glaciogênicos da Formação Jequitaí no Cráton São Francisco (CSF). Este estudo combina quimioestratigrafia isotópica (C, O e Sr) e geocronologia (U-Pb e Hf em zircão detrítico e Sm-Nd em rocha total) em amostras de cinco seções da FSL na região de Lagoa Santa, MG, sul do CSF, com a finalidade de responder a tais questionamentos.

As seções Vespasiano (VS) e Ana Paula (AP) são constituídas por calcários cinzas e dolomitos beges, com altos teores de sedimentos terrígenos e pobres em matéria orgânica. Os valores de $\delta^{13} \mathrm{C}$ mais representativos do ambiente deposicional oscilam em uma estreita faixa ao redor de 0\%o. Estes dados permitem posicionar estas seções na primeira sequência deposicional da FSL, acima dos carbonatos de capa Sturtianos ( 740 Ma) da base desta unidade. As seções Bairro da Lapinha (BL), Pedra do Baú (BAU) e Parque da Gruta da Lapinha (PGL) são compostas por calcários de coloração cinza escura a negra, pobres em sedimentos detríticos e ricos em matéria orgânica. São caracterizados por valores de $\delta^{13} \mathrm{C}$ bastante positivos (> 6\%o) e razões ${ }^{87} \mathrm{Sr} /{ }^{86} \mathrm{Sr}$ próximas de 0,7075. Estas seções estão posicionadas na segunda sequência deposicional da FSL.

Zircões detríticos foram separados de três amostras de marga das seções VS, AP e PGL e datados pelo método U-Pb. Os resultados indicam que os sedimentos siliciclásticos da FSL na área de estudo provêm de fontes de longa residência crustal do Orógeno AraçuaíOeste Congo. A população expressiva mais jovem tem 557 Ma e determina a idade máxima de deposição para a segunda sequência da unidade e para a maior parte do Grupo Bambuí. Além disso, grãos de zircão concordantes mais jovens com idades de $537 \pm 4$ Ma e $506 \pm 7$ Ma para a primeira e segunda sequência, respectivamente, refutam a existência de um hiato deposicional expressivo entre as duas sequências, como recentemente proposto, e endossam uma idade deposicional do limite Ediacarano/Cambriano para a FSL. Se existe uma discordância, esta está posicionada entre os carbonatos de capa Sturtianos e as seções com valores de $\delta^{13} \mathrm{C}$ ao redor de 0\%. Estas idades indicam que grande parte do Grupo Bambuí foi depositada em uma bacia de foreland, após o fechamento do Oceano Adamastor que culminou com a edificação da Faixa Araçuaí a leste do CSF.

As razões ${ }^{87} \mathrm{Sr} /{ }^{86} \mathrm{Sr}$ obtidas nos carbonatos da FSL contrastam com as recentes curvas de evolução de Sr para os oceanos, especialmente no Cambriano, quando razões maiores que 
0,7085 são esperadas. É provável que esta unidade tenha sido depositada em um mar epicontinental restrito e a correlação global por meio de isótopos de Sr não é confiável nestes casos.

Palavras-chave: Carbonatos, Isótopos Estáveis, Geocronologia, Grupo Bambuí, Cráton São Francisco 


\section{Abstract}

Recently published geochronological data has arisen questions on the Sete Lagoas Formation (SLF) depositional evolution. This unit is mainly composed by carbonate rocks with subordinated pelitic intercalations and represents the basal unit of the Bambuí Group, which overlies the glacial deposits of the Jequitaí Formation in the São Francisco Craton (SFC). This study combines isotope chemostratigraphy $(\mathrm{C}, \mathrm{O}, \mathrm{Sr})$ and geochronology $(\mathrm{U}-\mathrm{Pb}$ and Hf on detrital zircons and Sm-Nd on whole rock samples) in five sections of the SLF in the Lagoa Santa (MG) region, southern part of SFC, in order to answer such questions.

Vespasiano (VS) and Ana Paula (AP) sections are composed by gray limestones and beige dolostones, with high contents of detrital sediments and poor in organic matter. The most representative $\delta^{13} \mathrm{C}$ values obtained oscillate within a narrow range around $0 \%$. These data allow positioning these sections in the first depositional sequence of the SLF, above the basal Sturtian cap carbonates ( 740 Ma) of this unit. Bairro da Lapinha (BL), Pedra do Baú (BAU) and Parque da Gruta da Lapinha (PGL) sections comprises dark gray to black limestones, with low detrital sediments contents and rich in organic matter. They are characterized by very positive $\delta^{13} \mathrm{C}$ values $\left(>6 \%\right.$ ) and ${ }^{87} \mathrm{Sr} /{ }^{86} \mathrm{Sr}$ ratios close to 0.7075 . These sections belong to the second sequence of the SLF.

Detrital zircons were retrieved from three marl samples from sections VS, AP and PGL and dated by the U-Pb method. The results indicate that the siliciclastic sediments of the SLF come from sources of long crustal residence time located in the Araçuaí-West Congo Orogen. The youngest population is $557 \mathrm{Ma}$ aged and sets the maximum depositional age for the second sequence of SLF and most of the Bambuí Group. Furthermore, younger concordant zircon grains with ages of $537 \pm 4 \mathrm{Ma}$ and $506 \pm 7 \mathrm{Ma}$ for the first and second sequence, respectively, refute the hypothesis of a major sedimentation gap between the sequences, as recently proposed, and endorse an Ediacaran/Cambrian age for the SLF. If such gap does exist, it lies between the Sturtian cap carbonates and the sections with $\delta^{13} \mathrm{C}$ around 0\%. These ages also indicate that the deposition of most of the Bambuí Group took place in a foreland basin, after the closure of the Adamastor Ocean which led to the edification of the Araçuaí Belt to the east of the SFC.

The ${ }^{87} \mathrm{Sr} /{ }^{86} \mathrm{Sr}$ ratios obtained on the SLF carbonates contrast with the recently proposed $\mathrm{Sr}$ evolution curves, especially for the Cambrian, from where ratios higher than 0.7085 would be expected. It is possible that the SLF was deposited on a restricted eipiric sea and global correlations based on $\mathrm{Sr}$ isotopes are not reliable in such cases. 
Keywords: Carbonates, Stable Isotopes, Geochronology, Bambuí Group, São Francisco Craton 


\section{CAPÍTULO 1}

\section{$\underline{\text { INTRODUCÃO }}$}

A idade deposicional da Formação Sete Lagoas é objeto de grande discussão na literatura atual. Reconhecer os diferentes estágios evolutivos desta unidade e suas cronologias tem grande importância não só para a geologia brasileira, mas também para avaliar sua correlação com outras seções carbonáticas espalhadas pelo globo. Isto se torna ainda mais importante visto que os dados geoquímicos e isotópicos guardados nestas seções podem ser fundamentais para desvendar os processos pelos quais o planeta passou no Neoproterozoico e Cambriano, e que podem ter sido cruciais para a evolução biológica.

\subsection{Apresentação do tema}

Sucessões carbonáticas neoproterozoicas sobrepostas a depósitos glaciais têm despertado a atenção de diversos pesquisadores nas últimas décadas. Elas sugerem uma rápida transição entre períodos de glaciação e efeito estufa que caracterizaram os últimos 200 My do Eon Proterozoico. Mais que isto, estudos paleomagnéticos realizados nos diamictitos glaciogênicos (Williams, 1975; Schmidt \& Willians, 1995; Evans, 2000) revelaram que estes foram depositados em baixas latitudes, sugerindo que as geleiras atingiram regiões próximas ao equador. Com base nestes dados, Kirschvink (1992) propôs a hipótese do Snowball Earth, segundo a qual a Terra teria permanecido completamente coberta por gelo.

Tão intrigante quanto os dados paleomagnéticos dos depósitos glaciais, são as assinaturas isotópicas dos carbonatos. Estas rochas exibem fortes anomalias negativas de $\delta^{13} \mathrm{C}$, interpretadas como representativas de profundas mudanças de caráter químico e biológico nos oceanos (Kaufman et al., 1991, 1997). Hoffman et al. (1998) e Hoffman \& Schrag (2002) retomaram de forma mais robusta a hipótese do Snowball Earth com a proposta de que as glaciações globais teriam isolado os oceanos da atmosfera, o que teria inibido a atividade de organismos fotossintéticos. Como estes são os principais responsáveis pelo fracionamento dos isótopos de $\mathrm{C}$ nos oceanos, tal processo teria gerado um acúmulo de

${ }^{12} \mathrm{C}$ neste ambiente e, consequentemente, as anomalias de $\delta^{13} \mathrm{C}$ negativas. Com o posterior recuo das geleiras e transgressão marinha, os carbonatos imediatamente depositados após o período glacial (carbonatos de capa) guardaram tal assinatura. 
Esta nova perspectiva sobre as glaciações neoproterozoicas levantou a tese de que estes eventos teriam funcionado como um "gargalo" evolutivo que conduziu o planeta à chamada "Explosão de Vida do Cambriano". Tal pensamento foi combatido por Corsetti et al. (2006) que demonstrou que os registros fossilíferos pré, sin e pós-glaciais, ainda que escassos, permaneceram inalterados. Além disso, muitos pesquisadores combateram a hipótese do Snowball Earth e apresentaram modelos alternativos. Eyles \& Januszczak (2004) elaboraram a hipótese do Zipper Rift, na qual sugerem que poucos dos diamictitos caracterizados tinham uma origem glacial segura e muitos destes seriam, na verdade, produtos de fluxos gravitacionais sin-rift e diacrônicos gerados pela quebra do supercontinente Rodínia, iniciada por volta de $750 \mathrm{Ma}$. Entretanto, este modelo não explica de forma convincente as anomalias de $\delta^{13} \mathrm{C}$ registradas nos carbonatos que capeiam estas rochas. Outro modelo alternativo é o Slushball Earth (Hyde et al., 2000), cuja proposta também envolve períodos glaciais globais, entretanto com uma faixa de $40 \%$ próximo do equador descoberta, que serviu de refúgio para organismos fotossintetizantes. As anomalias isotópicas de $\mathrm{C}$ seriam resultado da liberação de metano durante as conseguintes transgressões que inundaram as bacias com água de degelo (Kennedy et al., 2001).

Considerando que de fato ocorreram glaciações, Halverson et al. (2005) propõem que três foram os períodos glaciais de escala global: Sturtiano ( 725 Ma), Marinoano ( 635 Ma) e Gaskierano ( $\sim 582 \mathrm{Ma})$. No Brasil, ocorrem unidades litoestratigráficas representantes destes eventos na Faixa Paraguai e sobre o Cráton do São Francisco (CSF) e áreas adjacentes.

Situada na borda sudoeste do Cráton Amazônico, a Faixa Paraguai guarda o registro de duas glaciações. A Formação Puga, sotoposta aos carbonatos do Grupo Araras, é constituída de diamictitos glaciais e rochas associadas correspondentes ao evento Marinoano (Alvarenga et al., 2004, 2008; Figueiredo, 2010). Já a Formação Serra Azul é composta por depósitos glaciais correlatos ao evento Gaskiers (Figueiredo et al., 2008).

Sobre o CSF, ocorrem os depósitos glaciais da Formação Jequitaí com diversas unidades correlatas nas faixas móveis que rodeiam o cráton e no Aulacógeno do Paramirim. As idades máximas de deposição destas rochas glaciogênicas, obtidas por datação U-Pb em zircão detrítico, são da ordem de 864 Ma (Buchwaldt et al., 1999, Pedrosa-Soares et al., 2000, 2008) e 880 Ma (Rodrigues, 2008) e pouco dizem sobre o período glacial neoproterozoico em que se encaixam. Entretanto estas unidades são sobrepostas pelas rochas carbonáticas e siliciclásticas do Grupo Bambuí, cujos estudos geocronológicos recentes abriram uma grande discussão sobre sua evolução sedimentar e geotectônica. Babinski et al. (2007) obtiveram uma idade $\mathrm{Pb}-\mathrm{Pb}$ de $740 \pm 22 \mathrm{Ma}$ para a capa carbonática da Formação Sete Lagoas, unidade basal do Grupo Bambuí, e correlacionaram-na ao evento glacial Sturtiano. Para esta mesma 
Formação, Vieira et al. (2007a, b) propuseram uma evolução sedimentar em duas sequências deposicionais separadas por uma pronunciada discordância na curva de $\delta^{13} \mathrm{C}$, e reafirmaram a idade Sturtiana com base em quimioestratigrafia de isótopos de C, metodologia pouco confiável segundo Melezhik et al. (2001). Rodrigues (2008) e Pimentel et al. (2011) obtiveram uma idade máxima U-Pb em zircão detrítico de $610 \mathrm{Ma}$, atribuída à segunda sequência, gerando uma ampla discussão sobre a possível existência de dois eventos glaciais no CSF e até mesmo de dois estágios evolutivos com estilos bacinais diferentes para o Grupo Bambuí (Babinski et al., 2012; Alkmim \& Martins-Neto, 2012). Estes dados tornaram necessários estudos geocronológicos acompanhados de quimioestratigrafia isotópica, a fim de averiguar o significado geológico deste salto isotópico e do limite de sequências, essenciais no entendimento da evolução geológica do Grupo Bambuí. Este trabalho foi realizado observando esta lacuna.

\subsection{Justificativas}

A idade deposicional da Formação Sete Lagoas tornou-se objeto de grande discussão, ainda mais com evidências da existência de uma importante discordância dentro desta unidade. Caracterizar geocronologicamente cada uma de suas sequências deposicionais significa compreender os diferentes estilos bacinais e a evolução do Grupo Bambuí. Isto porque a idade de $740 \pm 22$ Ma obtida para a capa carbonática (Babinski et al., 2007) representa uma fase com um oceano entre o CSF e Oeste-Congo, enquanto que a idade máxima de 610 Ma (Rodrigues, 2008; Pimentel et al., 2011) obtida para a segunda sequência sugere uma deposição em uma bacia do tipo foreland já com a Faixa Araçuaí edificada a leste do CSF. Este conhecimento pode ser importante não só para o meio acadêmico, mas também para a elaboração de modelos na prospecção de hidrocarbonetos, visto que ocorrências de gás foram observadas no CSF.

A aplicação de quimioestratigrafia com isótopos de C, O e Sr é fundamental para o posicionamento correto dos estratos siliciclásticos selecionados para datação U-Pb na estratigrafia da Formação Sete Lagoas, principalmente se for considerado o fato de que a unidade em questão possui um perfil isotópico de $\mathrm{C}$ bastante característico e bem distinto para as duas sequências propostas por Vieira et al. (2007). A correlação por estratigrafia convencional é menos precisa devido à grande extensão da bacia do São Francisco que recobre o CSF, fato que implica em um grande número de sistemas deposicionais, depocentros e controles estruturais. Além disso, a capa carbonática com forte excursão negativa, na qual foi obtida a idade mais antiga, representa apenas os $20 \mathrm{~m}$ basais dos quase 
$100 \mathrm{~m}$ da primeira sequência (Vieira et al., 2007a, b) e suas relações geológicas com os demais carbonatos, diamictitos basais e embasamento são desconhecidas. O estudo em conjunto de quimioestratigrafia isotópica e geocronologia permitiu caracterizar idades máximas de deposição para estratos posicionados mais ao topo da primeira sequência.

Os dados geocronológicos e de isótopos de $\mathrm{C}, \mathrm{O}$ e $\mathrm{Sr}$ também representam uma boa oportunidade para averiguar a competência da quimioestratigrafia isotópica como instrumento de posicionamento temporal de seções carbonáticas neoproterozoicas. Atualmente, isto é amplamente realizado pela simples comparação de dados com curvas de evolução da composição isotópica dos oceanos no Neoproterozoico e início do Cambriano propostas na literatura (e. g. Halverson et al., 2005, 2007, 2010). Ainda que a aplicação de múltiplos isótopos, seguindo padrões que garantam qualidade das análises e de suas interpretações, torne este método bastante confiável (Melezhik et al., 2001), há a necessidade de obtenção de idades absolutas para correlação temporal segura das unidades carbonáticas, bem como calibrar tais curvas evolutivas.

A área de estudo situa-se entre os municípios mineiros de Lagoa Santa e Vespasiano, próximos à capital Belo Horizonte. Esta foi selecionada por possuir afloramentos de rochas de ambas as sequências deposicionais da Formação Sete Lagoas e com leitos siliciclásticos intercalados nos carbonatos. Isto propiciou obter os dados necessários para as discussões deste trabalho e concluir seus objetivos.

\subsection{Objetivos}

Este trabalho tem como objetivo determinar idades máximas de deposição das diferentes sequências deposicionais da Formação Sete Lagoas. As idades foram obtidas por datação U-Pb em grãos de zircão detríticos de rochas siliciclásticas e as posições estratigráficas corretas dos estratos datados foram determinadas por meio de quimioestratigrafia com isótopos de $\mathrm{C}, \mathrm{O}$ e $\mathrm{Sr}$.

Os dados obtidos neste estudo permitiram: (i) averiguar idades tão jovens quanto 540 Ma abaixo do salto isotópico encontrado na Formação Sete Lagoas; (ii) correlacionar as seções estudadas com outras disponíveis na literatura para o CSF; (iii) caracterizar temporalmente as anomalias isotópicas da unidade basal do Grupo Bambuí; e (iv) discutir as curvas de evolução isotópica dos oceanos do Neoproterozoico e Cambriano propostas na literatura. 


\subsection{Localização da área de estudo}

A área de estudo localiza-se entre os municípios de Lagoa Santa e Vespasiano, estado de Minas Gerais, na região metropolitana de Belo Horizonte (Fig. 1). Vespasiano dista cerca de $29 \mathrm{~km}$ a norte da capital mineira, a partir de onde pode ser acessada utilizando a rodovia pavimentada MG-010 (Linha Verde). Já Lagoa Santa está a cerca de $38 \mathrm{Km}$ a norte de Belo Horizonte e seu acesso a partir da capital pode ser feito utilizando a MG-010 até Vespasiano, seguindo pela rodovia pavimentada BR-424.

As seções estudadas podem ser acessadas pelas rodovias MG-010 e BR-424, além de vias asfaltadas (ruas e avenidas) de Lagoa Santa.

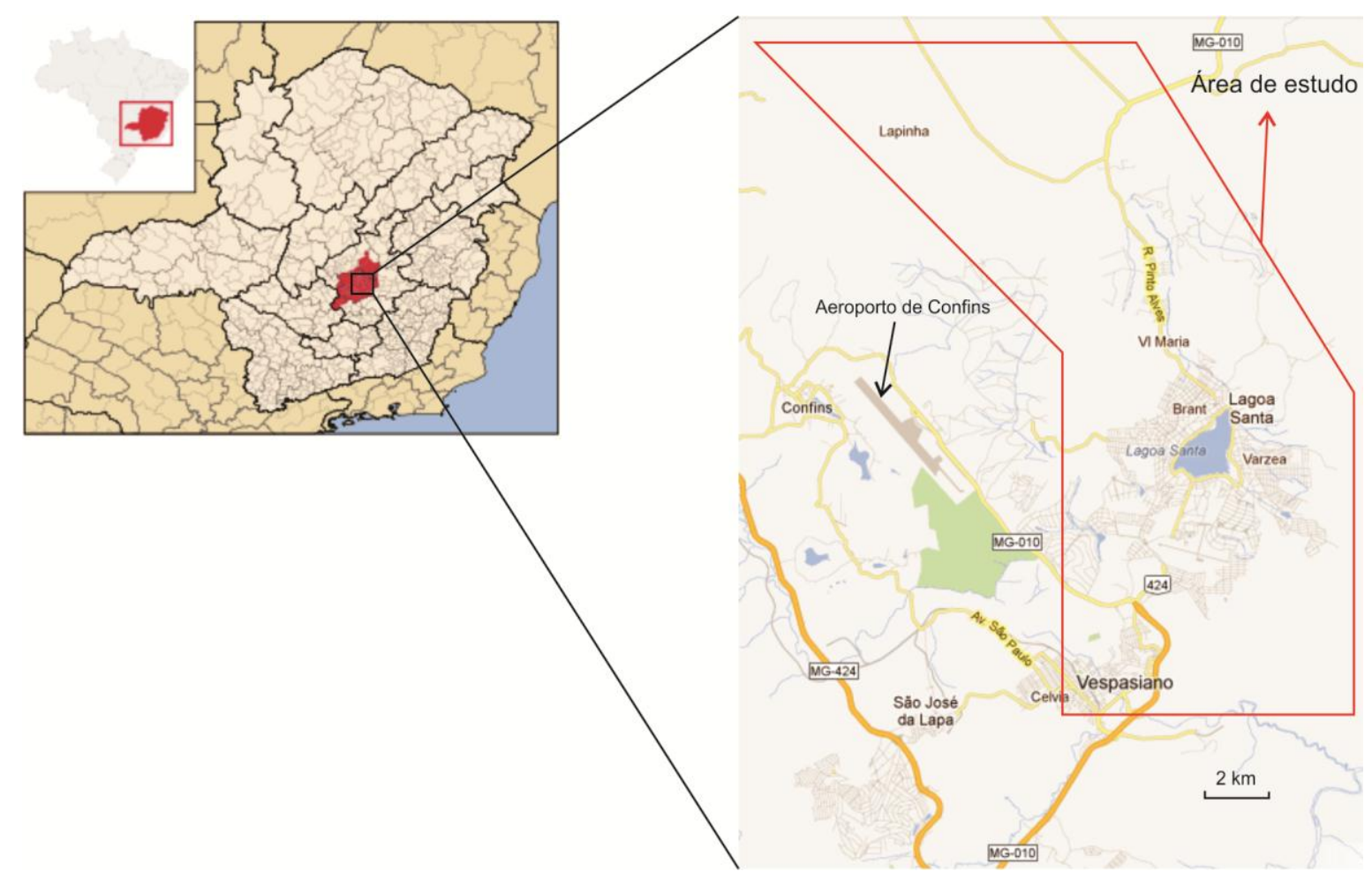

Fig. 1 - Mapa de localização da área de estudo com as principais vias de acesso. 


\section{CAPÍTULO 2}

\section{REVISÃO BIBLIOGRÁFICA}

A Formação Sete Lagoas é a unidade basal do Grupo Bambuí, que por sua vez compõe o Supergrupo São Francisco. Juntamente com outras unidades litoestratigráficas, este supergrupo constitui a Bacia do São Francisco que recobre grande parte do cráton homônimo. Neste capítulo será apresentada uma compilação com dados geológicos das unidades envolvidas no estudo. Também serão abordados alguns aspectos sobre quimioestratigrafia com isótopos de $\mathrm{C}, \mathrm{O}$ e $\mathrm{Sr}$, necessários para a compreensão das assinaturas isotópicas obtidas nos carbonatos da Formação Sete Lagoas ao longo de sua estratigrafia, e sobre os métodos U$\mathrm{Pb}, \mathrm{Sm}-\mathrm{Nd}$ e Lu-Hf utilizados neste trabalho.

\subsection{Geologia Regional}

\subsubsection{O Cráton São Francisco}

O Cráton São Francisco (CSF - Fig. 2) corresponde à parte interna e estável de uma das placas envolvidas na amalgamação diacrônica do continente Gondwana ocidental ao final do Neoproterozoico (Brito-Neves et al., 1999; Campo-Neto, 2000; Alkmim \& Martins-Neto, 2012). Devido à residência neste continente, o CSF permaneceu ligado ao cráton africano do Congo até a abertura do oceano Atlântico durante o Cretáceo. Deste fato decorre que estes crátons possuem diversas sequências sedimentares de primeira ordem correlatas entre si (Alkmim \& Martins-Neto, 2012).

As faixas móveis neoproterozoicas Araçuaí (a E do cráton), Sergipana (NE), Riacho do Pontal (N), Rio Preto (NW) e Brasília (W) circundam o CSF em sua atual configuração. Seu embasamento está exposto a $\mathrm{S}$ e a NE e a maior parte do cráton está encoberto por três unidades morfotectônicas (Alkmim, 2004): a Bacia do São Francisco, o Aulacógeno do Paramirim e parte do Rifte Recôncavo-Tucano-Jatobá, sendo os dois primeiros hospedeiros principais das coberturas proterozoicas e fanerozoicas do cráton e, portanto, de maior importância para este trabalho.

O embasamento exposto ao sul do CSF (Fig. 2) é constituído por um núcleo arqueano e por uma faixa paleoproterozoica formada há cerca de 2,1 Ga denominada Cinturão Mineiro (Teixeira \& Figueiredo, 1991; Teixeira et al., 2000). Tal cinturão envolve o núcleo arqueano, unidades bacinais paleoproterozoicas e um grande volume de granitoides com idades entre 
2,55 e 2,04 Ga (Noce et al., 2000). O embasamento exposto a NE é representado por um fragmento de um orógeno acrescionário edificado há cerca de 2,0 Ga, constituído pelos blocos do Gavião, Jequié e Serrinha, além do Cinturão Itabuna-Salvador-Curuçá (Teixeira et al. 2000).

A Bacia do São Francisco ocupa grande parte do segmento N-S do CSF, cobre uma área de aproximadamente $500.000 \mathrm{Km}^{2}$ pelos estados de Minas Gerais, Bahia e Goiás (Alkmim, 2004 - Fig. 2), e é composta pelo Supergrupo São Francisco. O Aulacógeno do Paramirim é a feição morfotectônica do N do CSF que compreende a Serra do Espinhaço Setentrional, os vales do Paramirim e do São Francisco e a Chapada Diamantina (Cruz \& Alkmim, 2004). As unidades litoestratigráficas que o constituem são os Supergrupos Espinhaço e São Francisco.

As unidades proterozoicas da Bacia do São Francisco foram deformadas durante o ciclo orogênico brasiliano (Neoproterozoico) pelas faixas móveis que o rodeiam. Como produto deste evento, formaram-se cinturões epidérmicos de antepaís com vergência centrípeta para o CSF (Alkmim et al., 1996). Tais cinturões apresentam falhas de empurrão e dobras com características diferenciadas nos compartimentos W e E: enquanto próximo à Faixa Brasília as falhas atingem apenas a cobertura, nas adjacências da Faixa Araçuaí as falhas afetam o embasamento e provocaram metamorfismo de baixo grau (Coelho et al., 2008). As porções mais interiores da bacia apresentam-se indeformadas.

\subsubsection{As sequências deposicionais proterozoicas do CSF}

As sequências deposicionais proterozoicas foram subdivididas em quatro sequências deposicionais de primeira ordem por Alkmim \& Martins-Neto (2012), baseado nos diferentes registros tectônicos da evolução geológica do CSF que guardam. São elas as sequências Minas-Itacolomi, Espinhaço, Macaúbas e Bambuí (Fig. 3).

A sequência Minas-Itacolomi registra um ciclo completo de Ciclo de Wilson ocorrido ao sul do CSF entre 2,5 e 2,0 Ga (Alkmim \& Marshak, 1998). É constituído de 8000 m de espessura de sedimentos de margem passiva e de bacia do tipo foreland do Supergrupo Minas e de sedimentos depositados em grabens do Grupo Itacolomi. Outras unidades correlatas a esta sequência são o Grupo Jacobina, no E da Bahia, e Grupos Ogoué, Nyong, Ayna e Francevillian, no Gabão (Fig. 3). 


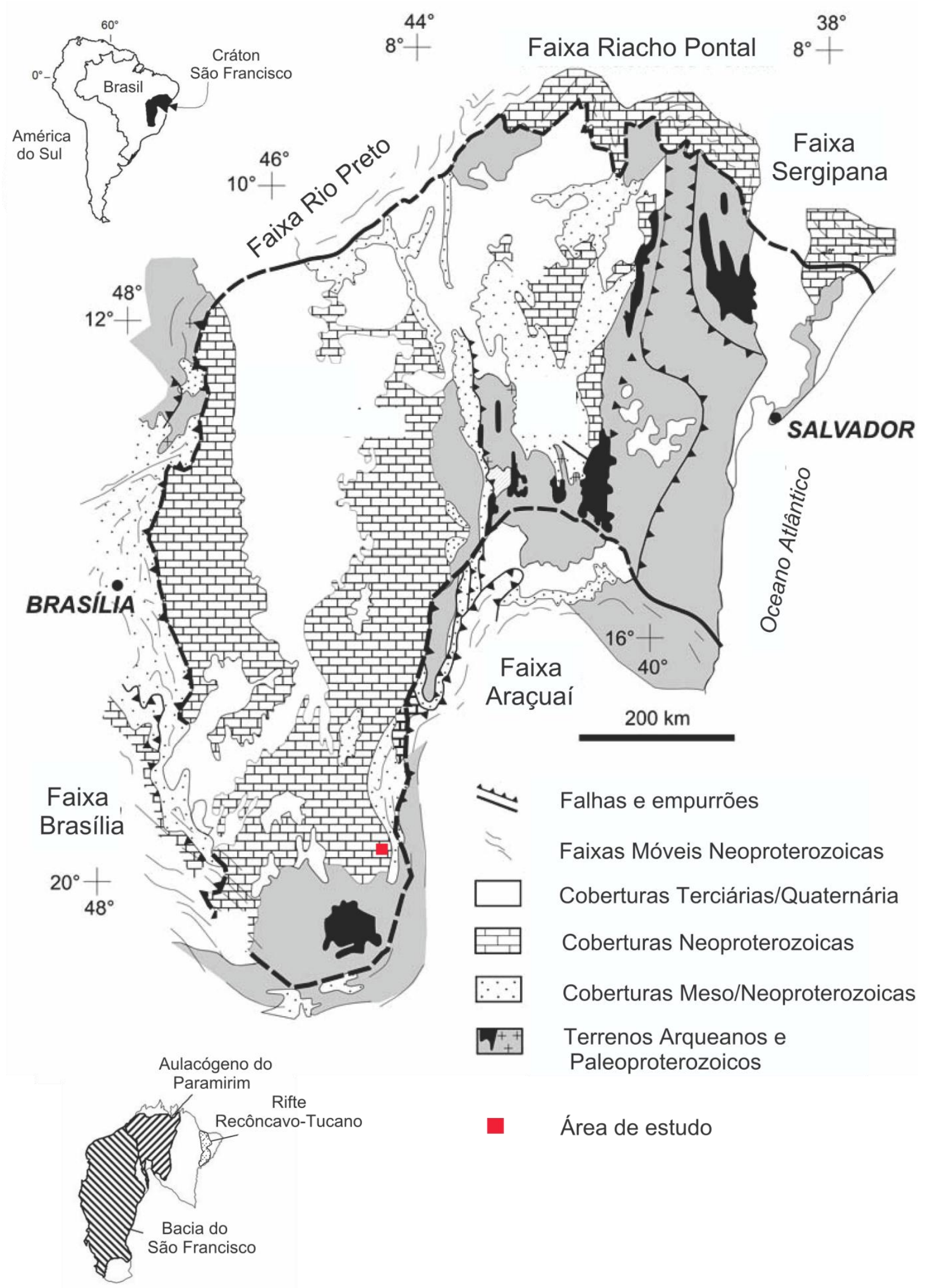

Fig. 2 - Mapas de localização, geológico e morfotectônico do Cráton São Francisco (modificado de Santos et al., 2000 e Alkmim \& Martins-Neto, 2012). 
A sequência Espinhaço é predominantemente constituída de quartzo arenitos depositados em uma bacia do tipo rifte com núcleo na massa continental outrora formada pelo CSF e Cráton do Congo (Alkmim \& Martins-Neto, 2012). O início do rifte teria ocorrido por volta de 1,75 Ga como sugerem rochas vulcânicas desta idade datadas por Babinski et al. (1994) e Schobbenhaus et al. (1994). As rochas desta sequência pertencem ao Supergrupo Espinhaço, cuja área tipo ocorre na Serra do Espinhaço, Faixa Araçuaí. É o principal preenchimento do Aulacógeno do Paramirim e ocorre também em alguns núcleos antiformais da Bacia do São Francisco. Outras unidades correlatas são os Grupos Araí (Faixa Brasília) e Rio Preto (Faixa Rio Preto), além do Grupo Chela e Supergrupo Kibaran (Cráton do Congo Fig. 3).

A sequência Macaúbas é representada por depósitos glaciogênicos continentais e siliciclásticos com lentes carbonáticas de margem passiva, que ocorrem no CSF e sua margem leste, respectivamente (Alkmim \& Martins-Neto, 2012). Representa uma sucessão pré-rifte, rifte, transicional e margem passiva instalada entre a península do São Francisco e cráton do Congo, cujo início é marcado por um evento magmático ocorrido há cerca 990-900 Ma na África (Tack et al., 2001) e com registros de 850 Ma no CSF (Pedrosa-Soares et al., 2008; Silva et al., 2008; Danderfer et al., 2009). A idade máxima da sequência é dada pela idade isocrônica $\mathrm{Pb}-\mathrm{Pb}$ de $740 \pm 22 \mathrm{Ma}$ dos carbonatos depositados imediatamente acima dos depósitos glaciogênicos (Babinski et al., 2007). As suas unidades correspondentes são o Grupo Macaúbas (Faixa Araçuaí), Formação Jequitaí (Bacia do São Francisco) e Formação Bebedouro (Aulacógeno do Paramirim - Fig. 3). Os grupos Canastra e Vazante e a Formação Cubatão, na Faixa Brasília, também podem ser unidades pertencentes à sequência em questão, embora Dias et al. (2011) considerem esta última unidade como depósitos de leques aluviais de frente de cavalgamento.

A mais jovem das sequências proterozoicas é a Bambuí, que marca um período de elevado nível relativo do mar que submergiu o CSF há cerca de $650 \mathrm{Ma}$, transformando-o em uma bacia do tipo foreland da Faixa Brasília com deposição de carbonatos e siliciclastos (Alkmim \& Martins-Neto, 2012). A parte W da bacia de foreland (foredeep) foi preenchida principalmente por siliciclastos, enquanto que a rampa flexural a E e o Aulacógeno do Paramirim, por carbonatos de águas rasas com intercalações de sedimentos siliciclásticos finos. O Grupo Bambuí é a principal unidade desta sequência, bem como da Bacia do São Francisco, e também ocorre em grandes sinformas do Aulacógeno do Paramirim. A Formação Sete Lagoas, base desta unidade tem sido subdividida em duas partes (Alkmim \& MartinsNeto, 2012; Babinski et al., 2012): a primeira constituída pelo conglomerado Carrancas e a porção basal desta formação, correlata à glaciação global Sturtiana, e a segunda constituída 
pelas porções central e de topo da mesma com idade máxima deposicional de $610 \mathrm{Ma}$ (Rodrigues, 2008; Pimentel et al., 2011). Esta divisão levanta questionamentos sobre a possibilidade de correlação da parte basal com os depósitos glaciais da sequência Macaúbas (Alkmim \& Martins-Neto, 2012). O topo do Grupo Oeste Congo é o correlato do Grupo Bambuí no cráton do Congo (Fig. 3).

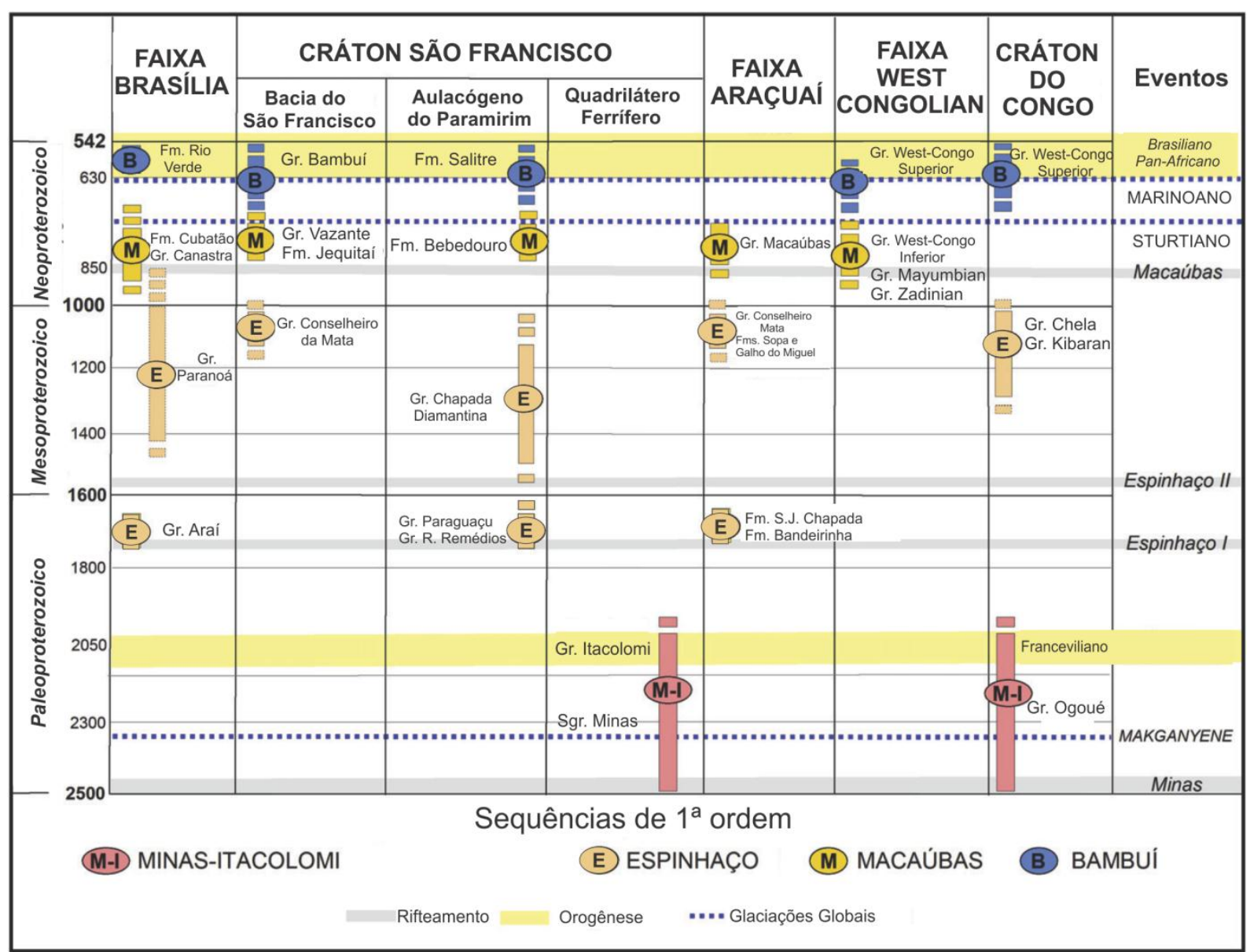

Fig. 3 - As sequências proterozoicas de primeira ordem do CSF e correlatos nas faixas Brasília, Araçuaí, West Congo e Cráton do Congo (modificado de Alkmim \& Martins-Neto, 2012).

\subsubsection{O Grupo Bambuí}

O Grupo Bambuí é uma unidade composta por carbonatos marinhos e rochas siliciclásticas e sobreposta aos depósitos glaciais da Formação Jequitaí no CSF e aos seus correlatos nas faixas móveis e Aulacógeno do Paramirim (Dardenne, 1978). Ainda no cráton, pode estar sobreposta ao conglomerado Carrancas (Dardenne, 1978; Vieira et al., 2007a, b). As unidades glaciogênicas em conjunto com o Grupo Bambuí constituem o Supergrupo São Francisco (Fig. 4). 
A unidade basal do Supergrupo São Francisco compreende diamictitos, conglomerados suportados pela matriz, arenitos maciços e ritmitos compostos por sedimentos finos depositados em ambiente glácio-marinho (Formação Jequitaí), com ocorrências de depósitos glácio-terrestres (Rocha-Campos et al., 1981). Na região proposta para este trabalho ocorre o Conglomerado Carrancas, correlato à Formação Jequitaí, que é polimítico com matriz carbonática, depositado com geometria lenticular sobre o embasamento paleoproterozoico (Martins-Neto et al., 2001; Vieira et al., 2007a, b). Caxito et al. (2012) interpretaram o Conglomerado Carrancas como produto de ressedimentação da Formação Sete Lagoas próxima a altos estruturais.

A sucessão carbonática do Grupo Bambuí foi subdividida em cinco unidades litoestratigráficas por Dardenne (1978 - Fig. 4). Estas são da base para o topo: i) Formação Sete Lagoas, constituída por dolomitos e calcários estromatolíticos com folhelhos intercalados (espessura máxima de 500 m); ii) Formação Serra de Santa Helena, composta por folhelhos, siltitos, lentes de calcário e arenitos subordinados (640 m); iii) Formação Lagoa do Jacaré, formada por siltitos, margas e calcários pretos (140 m); iv) Formação Serra da Saudade, constituída por folhelhos verdes, pelitos, siltitos e lentes de calcário (100 m); e v) Formação Três Marias, composta por siltitos e arcóseos $(100 \mathrm{~m})$. As espessuras máximas de cada unidade, indicadas entre parênteses, foram estimadas por Iglesias \& Uhlein, 2009. As quatro unidades inferiores foram depositadas em ambiente marinho raso, enquanto que a unidade superior em ambiente marinho raso a aluvial (Dardenne, 1978; Iglesias \& Uhlein, 2009).

As rochas do Grupo Bambuí registram uma grande transgressão marinha e um regime flexural no interior cratônico, decorrente da sobrecarga exercida pelas faixas móveis que o rodeiam, em especial a Faixa Brasília (Martins-Neto et al., 2001; Alkmim \& Martins-Neto, 2012). Desta forma, a região de maior profundidade da bacia de foreland (foredeep) instalada no CSF se encontra a W, onde o Grupo Bambuí se interdigita com os conglomerados molássicos da Formação Samburá (Martins-Neto et al., 2001). 


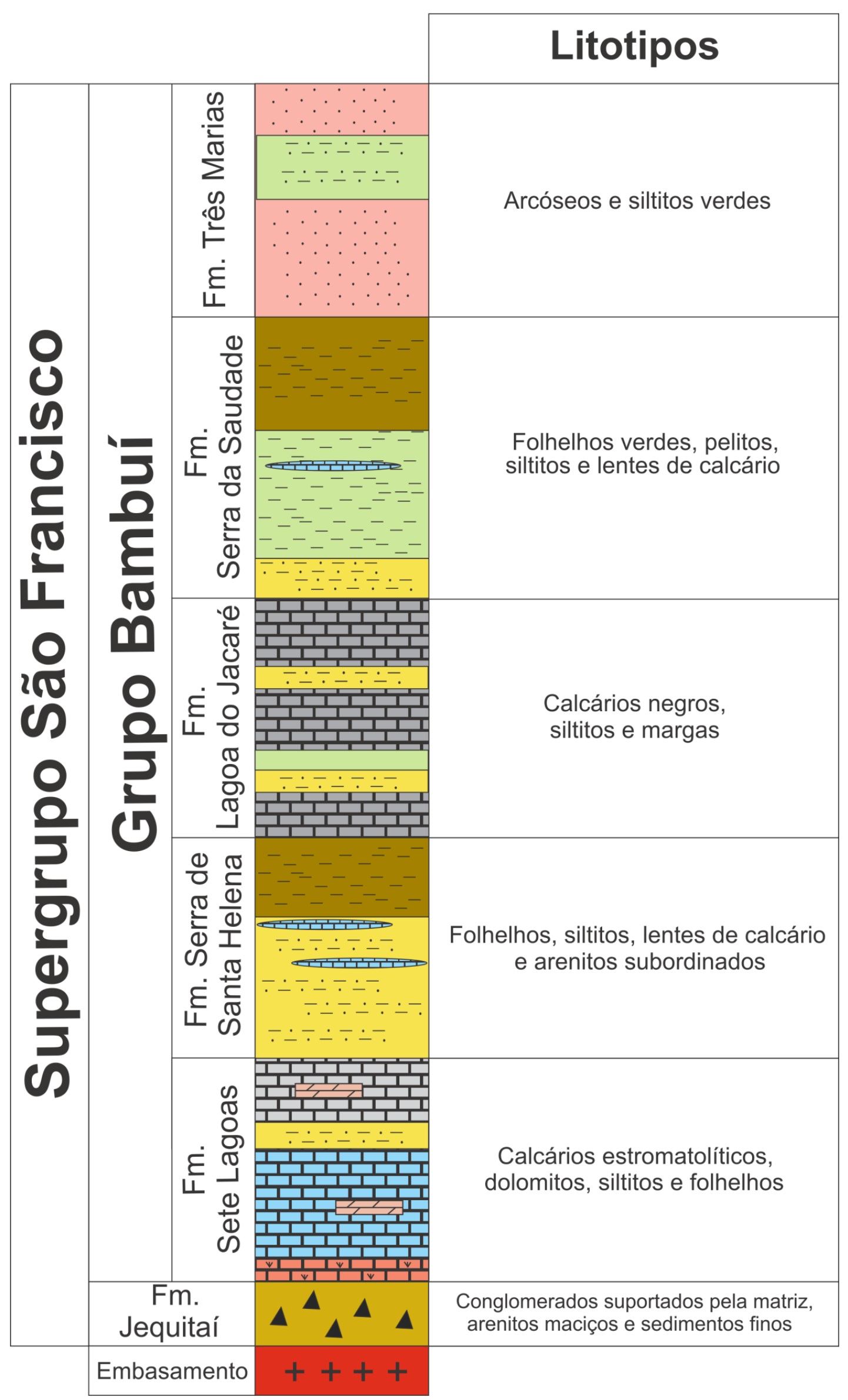

Fig. 4 - Estratigrafia do Supergrupo São Francisco baseada em Dardenne (1978) e Iglesias \& Uhlein (2009). 


\subsubsection{A Formação Sete Lagoas}

\subsubsection{Estratigrafia}

A Formação Sete Lagoas é a unidade basal do Grupo Bambuí, constituída por carbonatos e pelitos, embora alguns pesquisadores tenham colocado o Conglomerado Carrancas como parte desta formação (e. g. Schöll, 1976; Caxito et al., 2012). Provavelmente isto é decorrente da dificuldade de correlação destes conglomerados com as unidades glaciais do CSF e suas adjacências. De qualquer maneira, serão considerados como parte da Formação Sete Lagoas somente os litotipos carbonáticos e pelíticos conforme outros trabalhos mais recentes (e. g. Vieira et al., 2007a, b; Iglesias \& Uhlein, 2009).

Schöll (1976) estimou uma espessura máxima de 250 m para a Formação Sete Lagoas, subdividindo-a em duas fácies da base para o topo (Fig. 5):

(i) Fácies Pedro Leopoldo com espessura variando entre 40 e 100 m, constituída de margas, calcários impuros e calcários dolomíticos impuros. Esta fácies grada para siltitos e filitos na borda W da bacia do São Francisco, onde a separação entre esta e a Formação Serra de Santa Helena é difícil.

(ii) Fácies Lagoa Santa constituída de calcários puros, com matéria orgânica, laminação rítmica e espessura variável de 100 a 150 m.

Embora antiga, esta divisão é de grande aplicação em trabalhos de campo, visto que a distinção entre estas duas fácies é relativamente fácil.

Vieira et al. (2007a, b) estimaram a espessura desta unidade em $200 \mathrm{~m}$ e propuseram uma subdivisão em duas sequências deposicionais (Fig. 5). A sequência basal inicia-se com precipitados de fundo oceânico sob a forma de pseudomorfos de aragonita, além de lama e cimento carbonático, que apresentam valores de $\delta^{13} \mathrm{C}$ negativos que chegam a -4,5\%o. Estas características sedimentares e isotópicas são típicas de carbonatos de capa (Grotzinger \& Knoll, 1995; Kennedy, 1996; Hoffman \& Schrag, 2002). Encerram esta sequência basal, depósitos carbonáticos de granulometria mais grossa (areia, silte) com laminação planar, por vezes hummocky, que gradam lateralmente para calcários com laminação planar, que podem apresentar estruturas heterolíticas e climbing ripples. Estas fácies foram depositadas, respectivamente, em rampa dominada por tempestade e rampa dominada por maré e possuem valores de $\delta^{13} \mathrm{C}$ próximos a $0 \%$. A segunda sequência inicia-se com ritmitos de calcário com pelitos que gradam em direção ao topo para calcários negros com laminação planar ou truncada de baixo ângulo, depositados em rampa profunda. $\mathrm{O}$ início desta segunda sequência é caracterizado por um pronunciado salto isotópico na curva de $\delta^{13} \mathrm{C}$ de valores levemente 
positivos para valores da ordem de $+8 \%$. Encerram esta sequência, calcários negros com laminação truncada e presença de estromatólitos, depositados em rampa dominada por ondas, que gradam lateralmente para calcários negros com laminação convoluta, indicando inclinação pronunciada do substrato. Os valores de $\delta^{13} \mathrm{C}$ neste trecho são amplamente positivos e podem chegar a $+14 \%$ (Iyer et al., 1995; Vieira et al., 2007a) .

Os trabalhos de Vieira et al. (2007a, b) por serem mais detalhados, envolver a utilização de isótopos estáveis para caracterização dos estratos e terem sido realizados em áreas próximas a deste estudo (ver itens 1.4. e 2.2.), serão utilizados como guias neste trabalho. Também é importante notar que os carbonatos da primeira sequência não possuem matéria orgânica como impureza ao contrário dos calcários negros da segunda, fator que também os distinguem na subdivisão de Schöll (1976) e facilita sua separação em campo. Por fim, é importante mencionar que diversos leitos de dolomitos de origem primária, diagenética ou metamórfica, podem ocorrer ao longo da Formação Sete Lagoas (Schöll, 1976; Iglesias \& Uhlein, 2009).

\subsubsection{Geocronologia}

A presença de fácies sedimentares típicas de carbonatos de capa na base com forte excursão negativa de $\mathrm{C}$ e o fato de estar sobreposta a diamictitos glaciais chamaram a atenção de diversos pesquisadores para a Formação Sete Lagoas. Isto levantou a possibilidade desta unidade ser uma das sucessões carbonáticas neoproterozoicas, pós-glaciais e de ocorrência global, cujo estudo é fundamental para compreensão dos processos que podem ter levado à explosão de vida no Cambriano.

Neste contexto, as datações U-Pb em grãos de zircão detrítico dos conglomerados sotopostos aos carbonatos mostraram-se ineficientes. Pedrosa-Soares et al. (2000) obtiveram uma idade máxima de ca. de 864 Ma para o Grupo Macaúbas; Rodrigues (2008) relataram idade máxima de ca. 880 Ma para a Formação Jequitaí e de ca. 1431 Ma (Fig. 5) para o Conglomerado Carrancas; Figueiredo et al. (2009) obtiveram a idade máxima de ca. $875 \mathrm{Ma}$ para a Formação Bebedouro. Estas idades não permitem correlacionar com precisão estas unidades a umas das glaciações globais neoproterozoicas. 


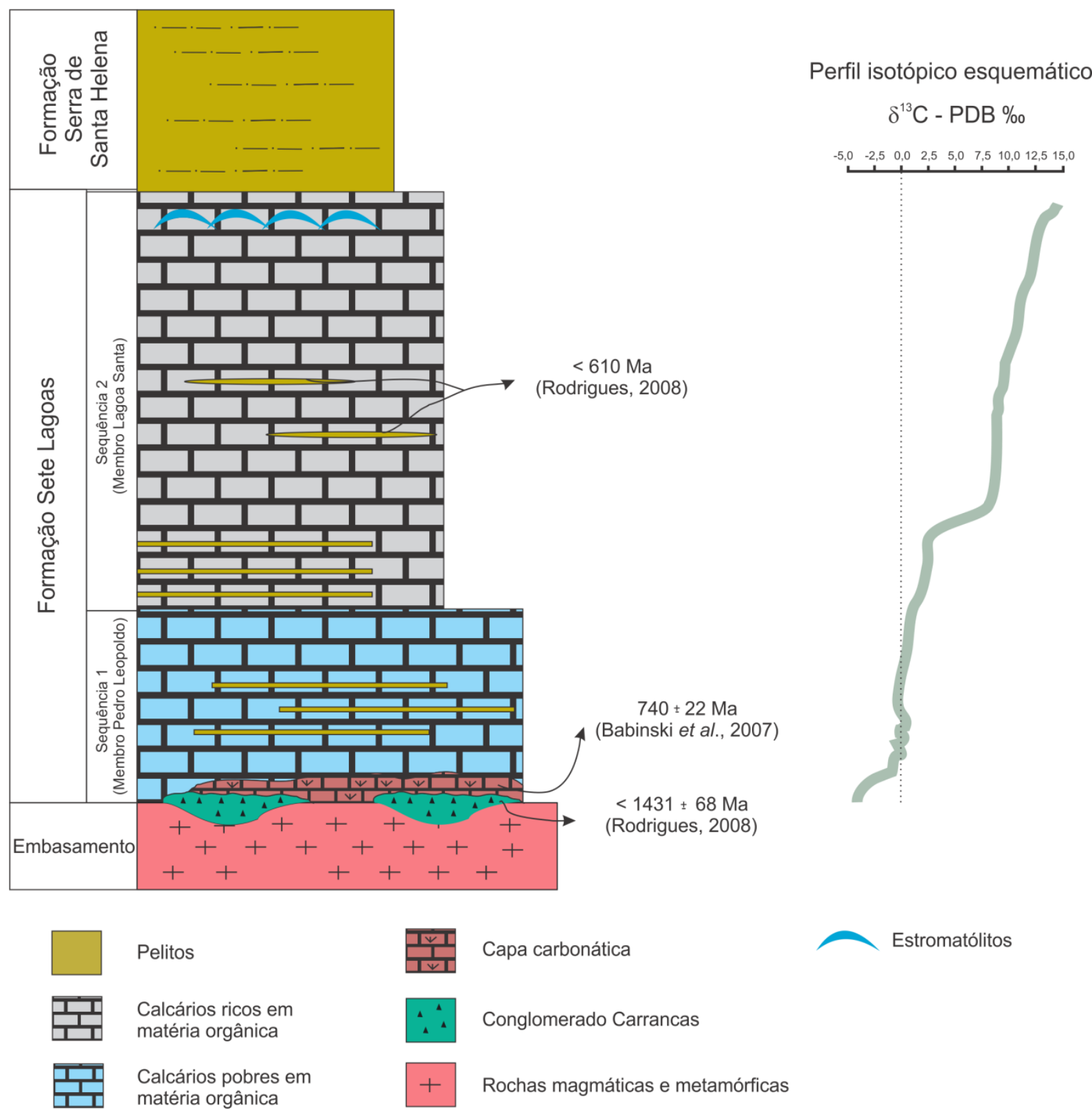

Fig. 5 - Estratigrafia da Formação Sete Lagoas baseada em Schöll (1976) e Vieira et al. (2007a, b), com as idades recentemente publicadas e seu perfil isotópico de $\mathrm{C}$ esquemático.

Idades isocrônicas $\mathrm{Pb}-\mathrm{Pb}$ obtidas nos carbonatos tiveram mais sentido geológico. Babinski et al. (2007) obtiveram a idade de $740 \pm 22$ Ma nos carbonatos de capa e correlacionaram a Formação Sete Lagoas e os diamictitos basais ao evento Sturtiano (Fig. 5). Entretanto, Rodrigues (2008) e Pimentel et al. (2011) encontraram populações de zircão importantes com idade de 645 e 610 Ma em intercalações de pelitos da segunda sequência deposicional da unidade (Fig. 5). Dado o limite de sequências abaixo dos estratos estudados e o pronunciado salto isotópico no início da segunda sequência, levantou-se a possibilidade de existir uma expressiva discordância na Formação Sete Lagoas (Alkmim \& Martins-Neto, 2012; Babinski et al., 2012). Também é importante ressaltar que Babinski et al. (1999) obtiveram idades isocrônicas $\mathrm{Pb}-\mathrm{Pb}$ mais jovens que $600 \mathrm{Ma}$ em rochas da segunda 
sequência, mas consideram estas como resultado de reequilíbrio isotópico entre os carbonatos e fluídos tectônicos.

Caxito et al. (2012) propuseram que a Formação Sete Lagoas seria uma sucessão carbonática depositada após o evento glacial Marinoano ( 635 Ma), baseando-se em elementos sedimentológicos e em dados quimioestratigráficos de Sr. Segundo os autores, as razões ${ }^{87} \mathrm{Sr} /{ }^{86} \mathrm{Sr}$ constantes, por volta de 0,7075 , obtidas para a unidade ao longo de toda sua estratigrafia (e. g. Babinski et al., 2007; Misi et al., 2007; Kuchenbecker, 2011) indicam uma idade criogeniana superior, quando confrontadas com a curva de evolução de Sr proposta por Halverson et al. (2010). Além disso, feições sedimentares como os leques de pseudomorfos de aragonita, dolomitos peloidais e mega ripples apresentadas pela capa carbonática basal, ocorrem somente em outras capas carbonáticas pós-Marinoanas espalhadas pelo globo. Vieira et al. (2007a) argumentaram que esta semelhança se deve ao fato de o Grupo Bambuí ter sido depositado em ambientes mais rasos que outras sucessões Sturtianas, atribuindo uma idade criogeniana inferior para a Formação Sete Lagoas.

Estas idades têm grande relevância geotectônica na evolução do Grupo Bambuí. Para a idade mais antiga, sua sedimentação teria ocorrido ainda sem a Faixa Araçuaí edificada a E, ao passo que o contrário é assumido para a sequência mais jovem.

Embora Rodrigues (2008) tenha discutido essa possibilidade, parece pouco provável que o Grupo Bambuí registre duas glaciações, no caso uma Sturtiana e outra Marinoana, já que não são conhecidos dois níveis de diamictitos, tampouco duas excursões negativas de $\delta^{13} \mathrm{C}$ nos carbonatos.

\subsection{Geologia da área de estudo}

$\mathrm{Na}$ área de estudo afloram rochas das Formações Sete Lagoas e Serra de Santa Helena (Grupo Bambuí - Schöll, 1976; Vieira et al., 2007a, b; Projeto VIDA, 2003), além de migmatitos e gnaisses do embasamento e depósitos quaternários ao longo das principais drenagens (Projeto VIDA, 2003 - Fig. 6). Próximo a Vespasiano, há ocorrência pontual do Conglomerado Carrancas (Vieira et al., 2007 a, b). Um mapeamento realizado na região retomou a subdivisão de Schöll (1976) que separa a Formação Sete Lagoas em Membro Pedro Leopoldo e Membro Lagoa Santa (Projeto VIDA, 2003). Os litotipos se assemelham muito aos das sequências 1 e 2 de Vieira et al. (2007a, b), respectivamente, e às fácies homônimas propostas por Schöll (1976).

As rochas do embasamento são constituídas de migmatitos com estruturas diversas, granitoides e gnaisses indiferenciados que, por vezes, são intrudidos por corpos alongados de 
rochas básicas (Projeto VIDA, 2003). Ocorrem amplamente no SE da área de estudo, próximo ao município de Vespasiano.

O Membro Pedro Leopoldo é constituído por calcissiltitos, margas, microespatitos/espatitos, micritos, estromatólitos, além de calcarenitos muito finos e milonitos protoderivados (Projeto VIDA, 2003), diretamente sobrepostos ao embasamento no SE da área. Também se apresenta na forma de um corpo alongado na direção N-S, que se estende da região entre Confins e Lagoa Santa até o $\mathrm{N}$ da área, e às margens do Rio das Velhas.

O Membro Lagoa Santa é composto principalmente por calcarenitos com intercalações de calcissiltitos, microespatitos/espatitos, micritos, localmente brechados, estromatolíticos ou milonitizados (Projeto VIDA, 2003). Dispõe-se amplamente no NW da área, ocorrendo também às margens do Ribeirão da Mata na região dos municípios de Vespasiano e São José da Mata.

A Formação Serra de Santa Helena é formada por siltitos e argilitos com arenitos e lentes carbonáticas subordinadas. Ocorre principalmente ao redor do aeroporto de Confins e da Lagoa Santa, aflorando com menor expressividade no NE da área.

A região apresenta deformações, caracterizada por um sistema de compressão de baixo ângulo, decorrentes da evolução da Faixa Araçuaí a E do CSF (Marshak \& Alkmim, 1989). As rochas do Grupo Bambuí apresentam foliação $S_{1}$, que constitui uma xistosidade de transposição paralela a $S_{0}$ de atitude sub-horizontal (Projeto VIDA, 2003). Nesta superfície, ocorre uma lineação de orientação E-W resultante de cisalhamento intraestratal. Nos pelitos também se observa uma lineação de crenulação de igual orientação. Veios de calcita paralelos à xistosidade e boudinados são comumente encontrados. Dado a existência de um descolamento entre embasamento e cobertura, em alguns locais são observadas falhas de cavalgamento, com empurrão para W, que atingem o Membro Pedro Leopoldo (Magalhães, 1988). Em algumas localidades, ocorrem dobras de eixo N-S como produto do cavalgamento, feições típicas dos cinturões de epidérmicos de antepaís das margens do CSF (Alkmim et al., 1996). Também ocorre descolamento basal no contato entre as unidades do Grupo Bambuí. O metamorfismo na área é de baixo grau, observado pela mineralogia composta por sericita e clorita nos níveis pelíticos (Projeto VIDA, 2003).

Embora apresentem deformação e recristalização, as relações estratigráficas originais da deposição das rochas não foram obliteradas na maioria das vezes (Vieira et al., 2007b). 


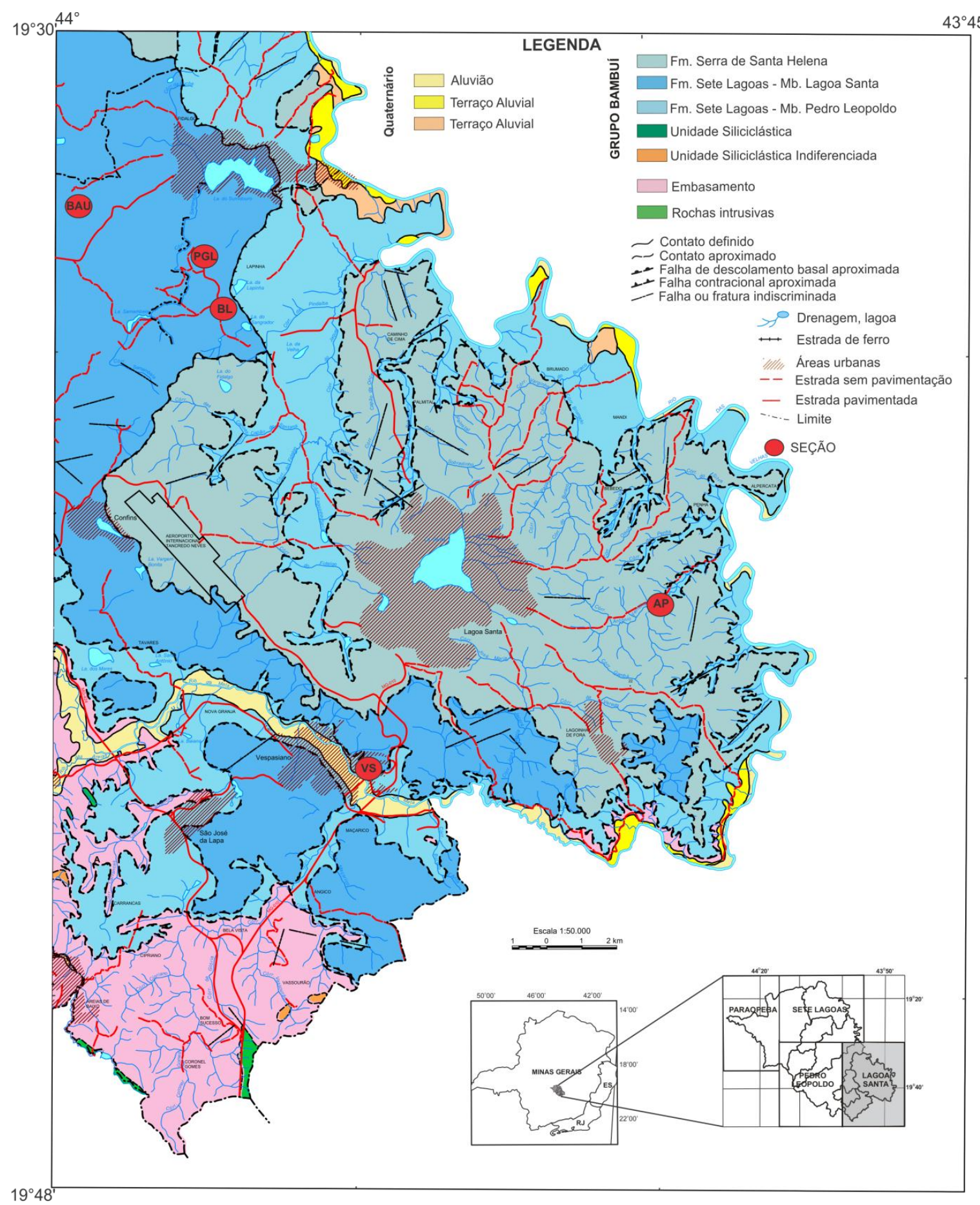

Fig. 6 - Mapa geológico da área de estudo com as localizações das seções descritas neste estudo (modificado de Projeto VIDA, 2003).

\subsection{Quimioestratigrafia isotópica}

A quimioestratigrafia, ou estratigrafia química, é o estudo das variações na composição química dos sedimentos (Halverson et al., 2010). Em geral, os dados geoquímicos estudados são indicadores das condições paleoambientais no momento da deposição dos sedimentos ou pouco depois desta, ou são indicadores de proveniência sedimentar. Uma aplicação muito comum da quimioestratigrafia é correlação intrabacinal e 
global de seções sedimentares espalhadas pelo planeta, em especial as pré-cambrianas, cujo registro fossilífero é extremamente escasso, dificultando a aplicação de bioestratigrafia (Knoll \& Walter, 1992). Desta forma, integrar dados geoquímicos, isotópicos e sedimentares para estas seções permite investigar as condições do ambiente deposicional e variações tectônicas tanto sob o aspecto temporal quanto espacial (Halverson et al., 2010).

As sucessões carbonáticas marinhas estão entre as rochas sedimentares pré-cambrianas mais estudadas, visto que registram mudanças climáticas e de regimes tectônicos de vital importância no entendimento da evolução da dinâmica interna e externa do nosso planeta. $\mathrm{O}$ estudo destas sucessões teve grande incentivo a partir da proposição de alternância entre períodos glaciais e de efeito estufa durante o Neoproterozoico pela hipótese do Snowball Earth (Kirschvink, 1992; Hoffman et al., 1998). Estas mudanças teriam causado distúrbios na composição isotópica dos oceanos desta Era, cujo significado é amplamente debatido pela comunidade científica atualmente. Trabalhos mais recentes também apontam registros de variações isotópicas significativas em carbonatos pós-glaciais paleoproterozoicos (e.g. Bekker et al., 2003).

Os isótopos mais utilizados em estudos quimioestratigráficos de sucessões carbonáticas pré-cambrianas são os $\mathrm{C}, \mathrm{O}$ e Sr. Os dois primeiros fornecem informações sobre as condições químicas e biológicas do paleoambiente deposicional dos carbonatos, enquanto que os de Sr registram importantes eventos tectônicos como tafrogêneses e orogenias.

A interpretação correta do significado destes isótopos e a aplicação eficaz da quimioestratigrafia isotópica em sucessões carbonáticas passam pelo conhecimento dos mecanismos de fracionamento isotópico no ambiente marinho, das fontes destes elementos, das características do ambiente deposicional e de parâmetros de alteração pós-deposicional destas rochas.

\subsubsection{Isótopos de $\mathrm{O}$}

Para estudos isotópicos de $\mathrm{O}$ em carbonatos são utilizados valores de $\delta^{18} \mathrm{O}$ relativos ao padrão SMOW (Standard Mean Ocean Water), uma amostra de água marinha representativa da composição isotópica atual do oceano, ou PDB, padrão da concha Bellemnite da Formação Pee Dee, Estados Unidos, dados em partes por mil (\%). O valor $\delta^{18} \mathrm{O}$ pode ser calculado pela equação:

$$
\delta^{18} \mathrm{O}=\left\{\left[\left({ }^{18} \mathrm{O} /{ }^{16} \mathrm{O}\right)_{\text {amostra }}-\left({ }^{18} \mathrm{O} /{ }^{16} \mathrm{O}\right)_{\text {padrão }}\right] /\left({ }^{18} \mathrm{O} /{ }^{16} \mathrm{O}\right)_{\text {padrão }}\right\} \times 1000 .
$$

Um dos mecanismos de fracionamento do $\mathrm{O}$ mais relevantes no ambiente marinho é a evaporação. Neste processo, o ${ }^{16} \mathrm{O}$ fica preferencialmente na fase gasosa, enquanto que o ${ }^{18} \mathrm{O}$ 
fica na fase líquida. Desta forma, quanto maior a taxa de evaporação no ambiente marinho, mais positivos serão os valores de $\delta^{18} \mathrm{O}$ registrados nos carbonatos precipitados a partir da água do mar, o que poderia auxiliar na identificação de ambientes evaporíticos ou restritos. Entretanto, a presença de fluidos no interstício dos sedimentos durante a diagênese, dolomitização ou metamorfismo de rochas carbonáticas leva a um decréscimo nos valores de $\delta^{18} \mathrm{O}$ destes litotipos (Banner \& Hanson, 1990). Isto dificulta interpretações paleoambientais e correlações estratigráficas globais baseadas em isótopos de oxigênio, visto que é comum a influência de águas de degelo ou meteóricas na composição isotópica de rochas carbonáticas pré-cambrianas, de tal forma que esta dificilmente corresponde à composição isotópica original da água do mar no momento da deposição.

Desta forma, os isótopos de oxigênio são utilizados como sensíveis marcadores de alteração pós-deposicional em sucessões carbonáticas pré-cambrianas. Segundo Kaufman \& Knoll (1995), carbonatos neoproterozoicos com valores de $\delta^{18} \mathrm{O}$ entre -10 e $-5 \%$ guardam o registro isotópico original do mar na época da deposição.

\subsubsection{Isótopos de $\mathrm{C}$}

Para estudos isotópicos de $\mathrm{C}$ em carbonatos são utilizados valores de $\delta^{13} \mathrm{C}$ calculados com base no padrão PDB, anteriormente citado, dados em partes por mil (\%o). O valor de $\delta^{13} \mathrm{C}$ de uma amostra pode ser calculado com base na seguinte equação:

$\delta^{13} \mathrm{C}=\left\{\left[\left({ }^{13} \mathrm{C} /{ }^{12} \mathrm{C}\right)_{\text {amostra }}-\left({ }^{13} \mathrm{C} /{ }^{12} \mathrm{C}\right)_{\text {padrão }}\right] /\left({ }^{13} \mathrm{C} /{ }^{12} \mathrm{C}\right)_{\text {padrão }}\right\} \times 1000$.

O principal mecanismo de fracionamento do $\mathrm{C}$ no ambiente marinho é biológico. Durante a fotossíntese, os organismos fotossintéticos consomem preferencialmente o isótopo ${ }^{12} \mathrm{C}$ na sintetização da glicose, enquanto que o ${ }^{13} \mathrm{C}$ tende a permanecer na água. Desta forma, carbonatos precipitados em oceanos com alta bioprodutividade fotossintética registram valores de $\delta^{13} \mathrm{C}$ positivos. Eventos de rápido soterramento de carbono orgânico também geram este efeito. Já carbonatos depositados em ambientes de baixa bioprodutividade fotossintética tendem a possuir valores de $\delta^{13} \mathrm{C}$ negativos.

A reconstrução do registro global da evolução da composição isotópica de C nos oceanos pré-cambrianos é amplamente debatida na comunidade científica nos últimos anos. Esta discussão é mais pronunciada para o Neoproterozoico quando, após uma monotonia relativa no Mesoproterozoico com valores de $\delta^{13} \mathrm{C}$ ao redor de 0\%o (Buick et al., 1995), ocorrem grandes variações, desde valores muito negativos até valores bastante positivos (Fig. 7), que seriam decorrentes das variações climáticas extremas propostas na hipótese do Snowball Earth (Kirschvink, 1992; Hoffman et al., 1998). Halverson et al. (2010) realizaram 
uma compilação de dados e publicaram uma curva de evolução da composição isotópica de $\mathrm{C}$ para o Neoproterozoico (Fig. 7). A comparação de dados de $\delta^{13} \mathrm{C}$ de uma determinada sucessão carbonática neoproterozoica com as desta curva e com de outras seções espalhadas pelo mundo, permitiria a realização da quimioestratigrafia isotópica e o posicionamento temporal da seção estudada.

Entretanto, a geoquímica do $\mathrm{C}$ nos oceanos tornam estas correlações quimioestratigráficas um tanto imprecisas. O tempo de residência do $\mathrm{C}$ no oceano, calculado por Frimmel (2010), baseado em dados de Houghton (2005), é de aproximadamente 433 anos. Este tempo é muito curto se comparado àquele da homogeneização do oceano que é da ordem de $10^{5}$ anos (Jacobsen \& Kaufman, 1999), o que torna a concentração deste elemento suscetível a fatores locais. De fato, durante o Fanerozoico, e mesmo nos oceanos atuais, as variações de $\delta^{13} \mathrm{C}$ podem chegar a $5 \%$ (Veizer et al., 1999) entre a plataforma rasa e o mar profundo. Isto dificulta assumir a continuidade lateral das anomalias isotópicas de C encontradas nas sucessões carbonáticas e suas correlações quimioestratigráficas apenas com valores de $\delta^{13} \mathrm{C}$, mas faz deste elemento um bom instrumento de reconstrução da composição química do mar. Melezhik et al. (2001) também apontam a escassez de dados geocronológicos como motivo de imprecisão do posicionamento correto das variações de $\delta^{13} \mathrm{C}$ no tempo geológico.

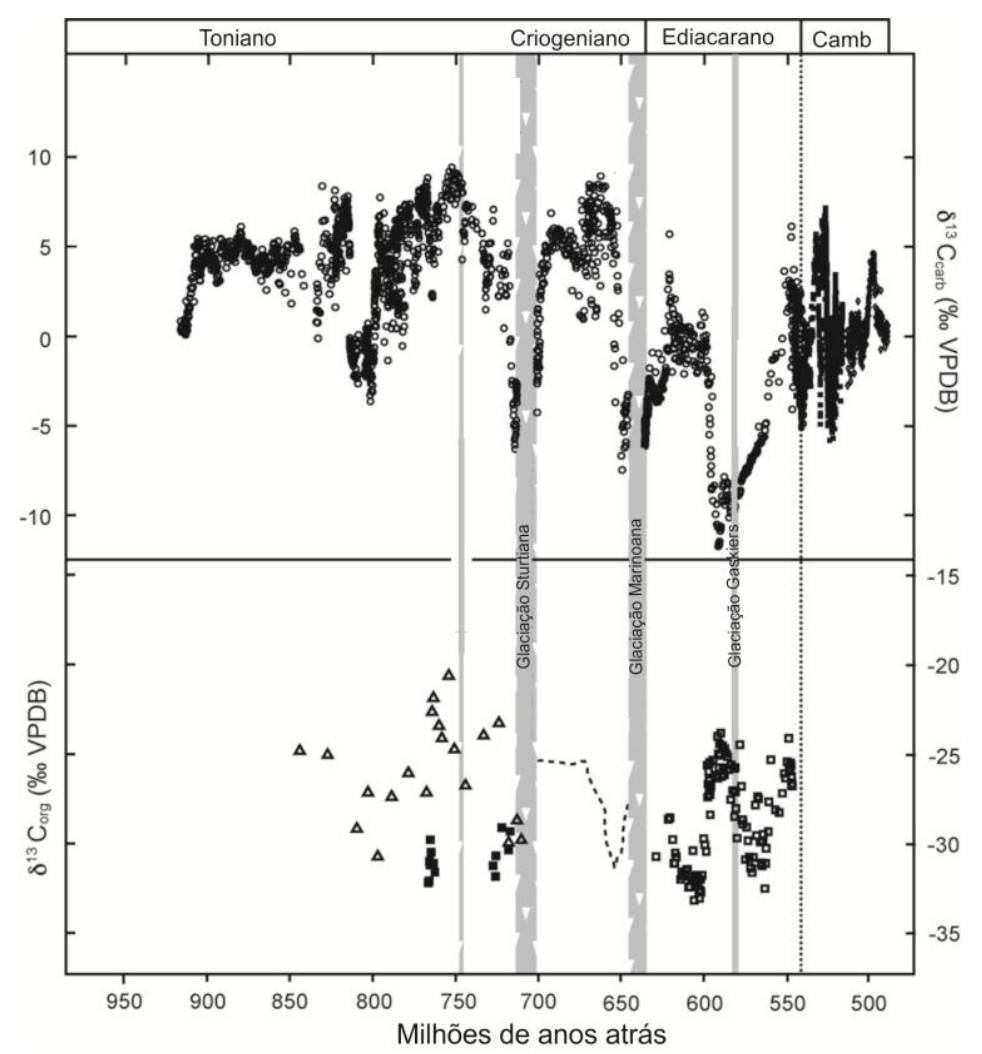

Fig. 7 - Curva de evolução da composição isotópica de C dos oceanos durante o Neoproterozoico e início do Cambriano (modificado de Halverson et al., 2005). 


\subsubsection{Isótopos de $\mathrm{Sr}$}

A razão isotópica ${ }^{87} \mathrm{Sr} /{ }^{86} \mathrm{Sr}$ registrada em carbonatos marinhos é uma mistura do $\mathrm{Sr}$ oriundo do intemperismo de rochas continentais que chega ao oceano, do Sr proveniente da interação da água do mar com o assoalho oceânico, e daquele proveniente da dissolução de carbonatos nos continentes e nas plataformas continentais (Faure \& Mensing, 2005). A alta capacidade do ambiente marinho em homogeneizar sua composição química e isotópica e o elevado tempo de residência do Sr no mar ( 2,4 Ma - Jones \& Jenkyns, 2001) fazem das razões ${ }^{87} \mathrm{Sr} /{ }^{86} \mathrm{Sr}$ excelentes registros de eventos temporais ocorridos em bacias oceânicas conectadas, como as glaciações propostas na hipótese da Snowball Earth (Kirschvinck, 1992; Hoffman et al., 1998), bem como eficientes ferramentas de correlação entre seções carbonáticas depositadas em uma mesma bacia oceânica. Entretanto, é importante salientar que o Sr é mais suscetível a alterações pós-deposicionais que o $\mathrm{C}$, visto que é um elemento traço na constituição dos carbonatos e ocorre em teores da ordem de centenas a milhares de ppm.

Halverson et al. (2010) publicaram a mais recente curva de evolução da composição isotópica de Sr para o oceano neoproterozoico (Fig. 8). Observa-se que a evolução da razão ${ }^{87} \mathrm{Sr} /{ }^{86} \mathrm{Sr}$ é mais homogênea que a de $\delta^{13} \mathrm{C}$, o que o torna um instrumento mais eficaz no posicionamento temporal das seções estudadas. Outro aspecto notável é que as razões ${ }^{87} \mathrm{Sr} /{ }^{86} \mathrm{Sr}$ são mais baixas durante a tafrogênese do supercontinente Rodínia (iniciada entre 900-850 Ma) e mais altas ao final do Neoproterozoico e início do Cambriano quando ocorreram diversos eventos orogênicos, mostrando que as rochas carbonáticas também registram importantes eventos resultantes da dinâmica interna do planeta. Também é perceptível uma pequena queda destas razões durante os eventos glaciais que teriam isolado o oceano através de uma espessa camada de gelo, impedindo a chegada de Sr mais radiogênico oriundo dos continentes (Kirschvink, 1992; Hoffman et al., 1998).

Mesmo sendo ferramentas eficazes de correlação entre seções carbonáticas e bons marcadores de eventos tectônicos, as razões ${ }^{87} \mathrm{Sr} /{ }^{86} \mathrm{Sr}$ devem ser corretamente posicionadas no tempo geológico por meio de geocronologia. Desta forma, a quimioestratigrafia por meio de isótopos de Sr torna-se bastante confiável (Melezhik et al., 2001).

\subsubsection{Aspectos a serem considerados para aplicação da quimioestratigrafia isotópica}

Antes de aplicar a quimioestratigrafia isotópica como ferramenta de correlação global entre seções carbonáticas pré-cambrianas, é necessário realizar estudos sedimentológicos e 
geoquímicos que permitam, respectivamente, identificar o ambiente deposicional e possíveis processos pós-deposicionais que possam alterar o registro isotópico destas rochas (Melezhik et al., 2001).

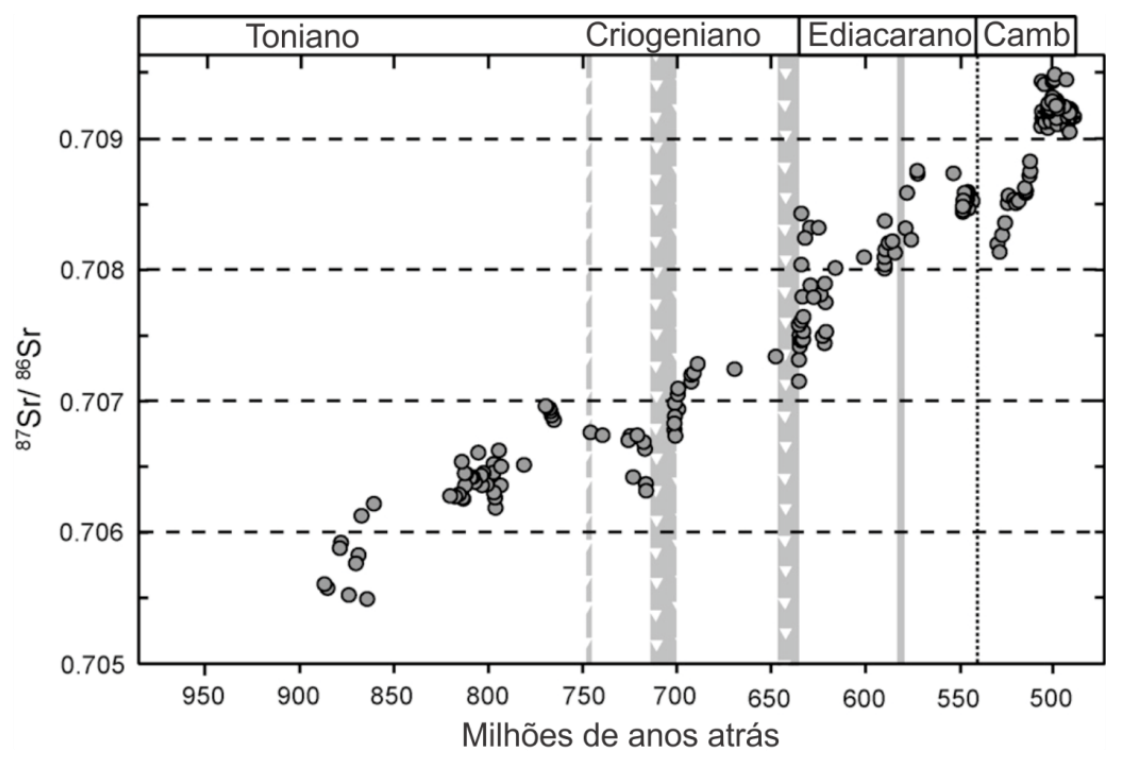

Fig. 8 - Curva de evolução da composição isotópica de $\mathrm{Sr}$ dos oceanos durante o Neoproterozoico e Cambriano (modificado de Halverson et al., 2010).

Como observado pelas características geoquímicas dos isótopos comumente utilizados para correlação global, a quimioestratigrafia isotópica só pode ser aplicada para correlacionar seções carbonáticas que tenham sido depositadas em uma mesma bacia oceânica ou bacias oceânicas conectadas no momento da deposição dos sedimentos. Somente desta forma haveria homogeneização isotópica antes da precipitação dos carbonatos. Assim, é de fundamental importância a identificação do ambiente deposicional por meio de uma detalhada análise de fácies sedimentares. Identificado um ambiente restrito, deve-se considerar que este não tem a mesma composição isotópica de outro ambiente, visto que não há homogeneização isotópica entre estes.

Como exemplo, se o $\mathrm{Rb}$ lixiviado das rochas continentais fosse totalmente inserido em um ambiente restrito, este seria enriquecido em ${ }^{87} \mathrm{Rb}$ (comum nas rochas crustais potássicas) que decai para ${ }^{87} \mathrm{Sr}$. Como não haveria homogeneização isotópica, os carbonatos depositados neste ambiente possuiriam uma razão ${ }^{87} \mathrm{Sr} /{ }^{86} \mathrm{Sr}$ mais radiogênica que os de uma bacia oceânica contemporânea. Assim a quimioestratigrafia isotópica baseada em $\mathrm{Sr}$ destes carbonatos com seções de outras bacias seria incorreta e sem significado geológico.

Outra etapa importante para garantir a confiabilidade de um estudo quimioestratigráfico é o reconhecimento de alterações pós-deposicionais do registro isotópico original dos carbonatos por meio de estudos geoquímicos. Isto é especialmente importante para os elementos traço, como o $\mathrm{Sr}$, que são mais facilmente lixiviados da rocha se comparados aos constituintes majoritários, como o C. Para isto são utilizadas razões 
geoquímicas como parâmetros de identificação destas alterações, visto que a presença de fluidos durante a diagênese, dolomitização ou metamorfismo de rochas carbonáticas leva a um aumento nas razões $\mathrm{Mn} / \mathrm{Sr}, \mathrm{Fe} / \mathrm{Sr}, \mathrm{Rb} / \mathrm{Sr}$ e ${ }^{87} \mathrm{Sr} /{ }^{86} \mathrm{Sr}$, bem como a um decréscimo nos valores de $\delta^{18} \mathrm{O}$ e $\delta^{13} \mathrm{C}$ destes litotipos (Banner \& Hanson, 1990). Trabalhos recentes (Frimmel et al., 2006) têm se baseado nos parâmetros de verificação de processos de alteração da razão ${ }^{87} \mathrm{Sr} /{ }^{86} \mathrm{Sr}$ utilizados por Fölling \& Frimmel (2002): $\mathrm{Rb} / \mathrm{Sr}<0,001, \mathrm{Mn} / \mathrm{Sr}<0,5, \mathrm{Fe} / \mathrm{Sr}$ $<3$ e $\mathrm{Sr} / \mathrm{Ca}>0,001$, além de $\delta^{18} \mathrm{O}>-10 \%$. Halverson et al. (2007) propõe que amostras de carbonatos com teores de Sr maiores que 300 ppm sejam utilizados para análises isotópicas de Sr. Já valores isotópicos de $\delta^{13} \mathrm{C}$ próximos ao da água do mar na época da deposição são encontrados em carbonatos com razões $\mathrm{Mn} / \mathrm{Sr}<10, \mathrm{Fe} / \mathrm{Sr}<50$ e valores de $\delta^{18} \mathrm{O}>-10 \%$ (PDB - Fölling \& Frimmel, 2002). Entretanto, estas razões geoquímicas não são válidas para o Paleoproterozoico, visto que os oceanos desta Era eram mais enriquecidos em $\mathrm{Mn}$ e Fe (Veizer et al., 1989).

Outra forma de verificar a confiabilidade dos dados isotópicos é analisar a coerência destes ao longo da estratigrafia da seção estudada. Valores isotópicos de C e O que desviem muito dos demais da coluna estratigráfica tendem a ser não representativos. Neste ponto, a alta resolução de um estudo quimioestratigráfico, com amostras coletadas de metro em metro na escala vertical, é fundamental para a comparação de resultados de amostras imediatamente sobrepostas e sotopostas. Além disto, a correlação positiva entre dados de $\delta^{18} \mathrm{O}$ e $\delta^{13} \mathrm{C}$ de uma mesma sucessão pode indicar alteração diagenética da assinatura isotópica original (Derry, 2010).

Identificados o ambiente deposicional não restrito e carbonatos com registro isotópico original, a quimioestratigrafia pode ser aplicada para correlação intrabacinal e global de seções carbonáticas pré-cambrianas. A obtenção de idades radiométricas que possam posicionar as variações isotópicas corretamente no tempo e a realização de análises isotópicas em alíquotas de amostras obtidas pela técnica de microdrill nos carbonatos ajudam a aumentar a confiabilidade do estudo.

\subsection{Geoquímica dos Elementos Terras Raras}

Os Elementos Terras Raras (ETR) em sucessões carbonáticas do Neoproterozoico e Cambriano têm sido objeto de vários estudos recentes (e.g. Frimmel, 2009; Zhao et al., 2009; Ling et al., 2011). Embora o banco de dados ainda seja escasso e necessite de aperfeiçoamento, algumas características importantes chamam a atenção. 
De acordo com Zhang \& Nozaki (1996), os sedimentos marinhos atuais são caracterizados pelo empobrecimento em ETR leves, enriquecimento em La, empobrecimento em Ce, pouco enriquecimento em Gd e pronunciada anomalia positiva de $\mathrm{Y}$ em diagramas de distribuição normalizada em relação ao padrão PAAS (post-Archean Australian shale) de Taylor \& McLennan (1985). Estas características diferem significativamente daquelas de águas fluviais que tendem a apresentar diagramas de distribuição com tendência planar e apenas um leve empobrecimento em ETR leves + Y (Lawrence et al., 2006). Outra diferença significativa entre as águas destes dois reservatórios está na sua razão Y/Ho: enquanto os oceanos modernos possuem esta razão entre 60 e 90 (Lawrence et al., 2006), os rios tendem a possuir razões próximas a da crosta continental superior que variam entre 27 e 30 (Kamber et al., 2005).

Frimmel (2010) identificou três padrões de características de ETR em carbonatos neoproterozoicos, os quais diferem da composição do oceano moderno: (i) diagramas de distribuição normalizada com fraca anomalia positiva de La, anomalia positiva fraca ou ausente de Ce, fraca anomalia positiva de Gd e anomalia positiva de Y com empobrecimento geral de ETR em relação ao PAAS; (ii) diagramas de distribuição com amplas tendências planares, leve empobrecimento em ETR leves e razões Y/Ho próximas às da crosta superior; (iii) carbonatos com diagramas de distribuição similares a (i) e (ii), mas com anomalias de Eu. O mais interessante é que estes padrões estão diretamente ligados aos ambientes deposicionais destas rochas. Os carbonatos depositados em ambientes distais apresentam o padrão (i), que tende a ser os mais representativo da composição da água do mar, embora difiram dos oceanos modernos. Já carbonatos depositados em ambientes proximais tendem a apresentar diagramas do padrão (ii), semelhantes aos de águas fluviais. Frimmel $(2009,2010)$ interpretou isto como mistura de água doce com a marinha que influenciou a composição de ETR das rochas carbonáticas. Zhao et al. (2009) levantam a hipótese que as águas doces podem ser oriundas de degelo, no caso de carbonatos pós-glaciais. O terceiro tipo de padrão está ligado a carbonatos com evidência de mineralização hidrotermal (Frimmel, 2009; 2010).

Outro trabalho importante é o de Ling et al. (2011), realizado em rochas carbonáticas na área do Yangtze Gorges, sul da China. Os carbonatos deste estudo apresentaram anomalias negativas de Ce pronunciadas. Nas águas oxigenadas dos oceanos modernos, o Ce tende a ocorrer no estado mais oxidado, com valência +4 . Neste estado, o Ce é facilmente adsorvido e removido da água do mar por óxidos e hidróxidos de Fe-Mn (Bau et al., 1996), de forma que os sedimentos precipitados nestas águas tendem a apresentar uma anomalia negativa deste elemento. Coerentemente, esta anomalia negativa de Ce é ausente em carbonatos arqueanos, quando os oceanos não estavam suficientemente oxigenados (Bau \& Dulski, 1996). Baseado 
nisto, Ling et al. (2011) interpretaram as anomalias dos carbonatos da Formação Dengying como um evento de oxigenação do ambiente marinho no limite Ediacarano-Cambriano.

Tais quais os isótopos de $\mathrm{C}, \mathrm{O}$ e $\mathrm{Sr}$, os estudos de ETR devem ser acompanhados de cuidados para avaliar se estes são representativos da composição das águas nas quais se precipitaram os sedimentos carbonáticos. Os ETR dificilmente são mobilizados durante a diagênese o que faz com que os efeitos deste processo na composição dos carbonatos sejam mínimos, mesmo que ocorra dolomitização (Banner \& Hanson, 1990; Webb et al., 2009). Assim, a principal causa de alteração do registro original se relaciona aos sedimentos detríticos presentes nos carbonatos, que durante os processos analíticos de dissolução tendem a enriquecer os lixiviados em ETR (Frimmel, 2009; Zhao et al., 2009; Ling et al., 2011). Para verificar quais composições são representativas do ambiente deposicional, serão aplicados parâmetros rigorosos utilizados nos trabalhos de Frimmel (2009) e Ling et al. (2011). São estes: $\mathrm{Zr}<4$ ppm, $\mathrm{Al}<0,35 \%, \mathrm{Fe}<0,45 \%$, Th $<0,5$ ppm, $\mathrm{Sc}<2$ ppm, $\Sigma$ ETR $<12$ ppm e razões $\mathrm{Y} / \mathrm{Ho}>36$.

\subsection{Análises geocronológicas}

\subsubsection{Idades modelo Sm-Nd}

Os elementos terras raras $\mathrm{Sm}$ e $\mathrm{Nd}$ são incompatíveis e possuem comportamento geoquímico semelhante. Dos sete isótopos naturais de $\mathrm{Sm}$, apenas o ${ }^{147} \mathrm{Sm}$ possui decaimento mensurável, quando por emissão $\alpha$ forma o ${ }^{143} \mathrm{Nd}$. Em processos geológicos de extração de magmas do manto o Sm tende a ficar no resíduo sólido, enquanto que o $\mathrm{Nd}$ passa ao líquido de fusão parcial. Desta forma, o manto tende a ficar empobrecido em $\mathrm{Nd}$ em relação ao Sm, e com maior razão ${ }^{143} \mathrm{Nd} /{ }^{144} \mathrm{Nd}$.

As idades modelo utilizadas neste trabalho foram obtidas de acordo com o modelo depleted mantle (DM, manto empobrecido) de DePaolo (1981). De acordo com este modelo, que se baseia nos aspectos geoquímicos acima descritos, idades $\mathrm{T}_{\mathrm{DM}} \mathrm{e}$ o parâmetro $\varepsilon_{\mathrm{Nd}}$ podem ser obtidos pelas equações abaixo:

$$
\begin{aligned}
& \left({ }^{143} \mathrm{Nd} /{ }^{144} \mathrm{Nd}\right)_{\text {inicial }}=\left({ }^{143} \mathrm{Nd} /{ }^{144} \mathrm{Nd}\right)_{\text {amostra }}-\left({ }^{147} \mathrm{Sm} /{ }^{144} \mathrm{Nd}\right)_{\text {amostra }} \mathrm{x}\left(\mathrm{e}^{\lambda^{\mathrm{t}}}\right), \\
& \varepsilon \mathrm{Nd}(\mathrm{t})=\left[\left({ }^{143} \mathrm{Nd} /{ }^{144} \mathrm{Nd}\right) \operatorname{amostra}(\mathrm{t}) /\left({ }^{143} \mathrm{Nd} /{ }^{144} \mathrm{Nd}\right) \text { CHUR (t) - } 1\right] \times 10000,
\end{aligned}
$$

onde $\lambda$ é a constante de desintegração do ${ }^{147} \mathrm{Sm}$ e igual a $6,54 \times 10^{-12}$ ano ${ }^{-1}$, e t é a idade calculada. 
Ao contrário da extração de magmas do manto, processos exógenos não fracionam Sm e Nd (McLennan, 1989), o que aliado à baixa solubilidade destes elementos em água, faz com que o $\mathrm{T}_{\mathrm{DM}}$ de uma rocha sedimentar seja o resultado da mistura dos diferentes $\mathrm{T}_{\mathrm{DM}}$ de suas fontes. Isto torna o método Sm-Nd um bom auxiliar na procura das fontes de uma bacia sedimentar. Mas visto que as idades $\mathrm{T}_{\mathrm{DM}}$ representam a idade de extração do protólito de uma rocha do manto e que, portanto, podem ser bastante diferentes de uma idade de cristalização ou metamorfismo, utilizar este método para definição de uma idade máxima de deposição é pouco preciso.

\subsubsection{Idades U-Pb em zircão detrítico}

O zircão é um mineral pesado e, como tal, é resistente às intempéries físicas e químicas praticadas pelos processos exógenos, fazendo-o comum na maioria dos depósitos sedimentares. Seu sistema isotópico dificilmente é aberto, mesmo em processos metamórficos de alta temperatura (Faure \& Mensing, 2005), e possui baixa velocidade de difusão intracristalina de íons (Cherniak \& Watson, 2000). Estas características favorecem a preservação da composição isotópica deste mineral ao longo do tempo e o faz um alvo ideal para estudo de proveniência sedimentar.

Dadas as características químicas e cristalográficas do zircão, estes possui elevados teores de $\mathrm{U}$ e baixos teores de $\mathrm{Pb}$. Isto resulta em altas razões $\mathrm{U} / \mathrm{Pb}$ que torna a sensibilidade dos geocronômetros do método U-Pb bastante apurada. Além disso, o desenvolvimento de técnicas analíticas modernas como LA-ICP-MS (Laser Ablation - Inductively Coupled Plasma - Mass Spectrometry, utilizada neste trabalho) e SHRIMP (Sensitive High Resolution Ion Probe) ampliaram ainda mais a confiabilidade e importância deste método.

Devido às altas temperaturas de bloqueio do zircão, a idade U-Pb obtida neste mineral representa a idade de cristalização das rochas fontes. Mesmo que estas rochas representem diversos estágios de retrabalhamento de um mesmo protólito (e tenham, portanto a mesma idade $\mathrm{T}_{\mathrm{DM}}$ ), a cada processo de fusão e cristalização a idade do evento é registrada no zircão. Assim a datação de grãos de zircão detrítico é mais eficiente que o método Sm-Nd tanto na procura da fontes de uma rocha sedimentar, quanto na determinação de sua idade máxima de deposição.

\subsubsection{Parâmetro $\varepsilon H f$ em zircão detrítico}


Lu e Hf são elementos terras raras e o isótopo radioativo ${ }^{176} \mathrm{Lu}$ decai para ${ }^{176} \mathrm{Hf}$, por emissão $\beta$, com uma constante de decaimento igual a $1,94 \times 10^{-11} \mathrm{ano}^{-1}$. As propriedades destes elementos são semelhantes às de $\mathrm{Sm}$ e $\mathrm{Nd}$, de forma que em um processo de fusão mantélica o $\mathrm{Hf}$ tende a ficar na parte líquida, enquanto o $\mathrm{Lu}$, no sólido residual (Faure \& Mensing, 2005).

Devido à similaridade dos raios iônicos de $\mathrm{Hf}$ e $\mathrm{Zr}(0,81$ e $0,80 \AA$, respectivamente), minerais como o zircão possuem altos teores de Hf. Como o raio iônico do Lu é maior $(0,93$ Å), sua admissão no retículo cristalino deste mineral é difícil, o que resulta em baixas razões Lu/Hf em zircão e praticamente exclui a necessidade de correção da razão ${ }^{176} \mathrm{Hf} /{ }^{177} \mathrm{Hf}$ medida, pelo fato de não haver geração de Hf radiogênico. Mais ainda, estas características fazem com que o zircão guarde a razão $\left({ }^{176} \mathrm{Hf} /{ }^{177} \mathrm{Hf}\right)_{\text {inicial }}$ do magma do qual foi derivado (Hawkesworth \& Kemp, 2006). Através do parâmetro عHf, adiciona-se uma ferramenta a mais à idade U-Pb na busca das fontes da rocha sedimentar em questão e em estudos de evolução crustal.

O parâmetro $\varepsilon H f$ é obtido pela comparação da razão ${ }^{176} \mathrm{Hf} /{ }^{177} \mathrm{Hf}$ medida no zircão com aquela proposta no modelo de evolução da composição de Hf do planeta baseada em um reservatório condrítico uniforme (chondritic uniform resevoir - CHUR; Patchett \& Tatsumoto, 1980) para um determinado tempo t, conforme a equação abaixo:

$\mathcal{E}^{\mathrm{t}} \mathrm{Hf}=\left[\left({ }^{176} \mathrm{Hf} /{ }^{177} \mathrm{Hf}\right)_{\mathrm{amostra}} /\left({ }^{176} \mathrm{Hf} /{ }^{177} \mathrm{Hf}\right)_{\mathrm{CHUR}}-1\right] \times 10^{-4}$, onde o tempo t utilizado é aquele obtido por datação U-Pb no mesmo grão de zircão.

Um zircão com $\varepsilon$ Hf positivo é enriquecido em ${ }^{176} \mathrm{Hf}$ radiogênico em relação ao CHUR e, portanto deve ter se cristalizado em uma rocha com maior razão Lu/Hf que o reservatório condrítico, como por exemplo, uma acresção magmática juvenil. Pelo mesmo raciocínio, um zircão com este parâmetro negativo deve ter se cristalizado em uma rocha com longa residência crustal.

As análises isotópicas de Hf deste trabalho foram realizadas pela técnica LA-ICP-MS em spots adjacentes aos realizados para datação U-Pb. Esta técnica contorna diversos problemas analíticos como a dificuldade de separação de $\mathrm{Hf}$ e $\mathrm{Zr}$ em solução e o alto potencial de ionização do Hf (Faure \& Mensing, 2005). 


\section{CAPÍTULO 3}

\section{MATERIAIS E MÉTODOS}

Para este trabalho, foram coletadas 158 amostras de rochas carbonáticas para o estudo de quimioestratigrafia isotópica ( $\mathrm{C}, \mathrm{O}$ e $\mathrm{Sr})$ e 3 amostras de pelitos da Formação Sete Lagoas para geocronologia U-Pb e Sm-Nd. Adicionalmente, 12 amostras de veios preenchendo falhas e intercalados entre os estratos sedimentares tiveram suas composições isotópicas de $\mathrm{C}$ e $\mathrm{O}$ analisadas.

Os procedimentos utilizados neste trabalho são descritos a seguir.

\subsection{Trabalhos em campo}

Foram realizadas três etapas de trabalhos de campo no ano de 2011. A primeira foi realizada em Março com a finalidade de selecionar possíveis afloramentos-alvo para o estudo. A segunda, realizada em Julho, foi a etapa principal, em que quatro seções geológicas da Formação Sete Lagoas (três em Lagoa Santa e uma em Vespasiano) foram descritas com coleta de amostras em intervalos de aproximadamente $1 \mathrm{~m}$ entre si na escala vertical sempre que possível. Durante a terceira etapa, em setembro, foi descrita uma última seção no município de Lagoa Santa com a mesma resolução amostral da segunda etapa.

\subsection{Descrição e digitalização das amostras}

As amostras de carbonato e de pelitos foram inicialmente descritas para reconhecimento dos litotipos e das fácies sedimentares. Além disso, foram identificadas estruturas pós-deposicionais como veios, vênulas, recristalizações minerais, dissoluções e contatos litológicos que devem ser evitadas durante a microamostragem para estudos isotópicos. Estas estruturas representam superfícies e áreas de percolação de fluidos diagenéticos ou de metamorfismo, possíveis fontes de alteração do registro isotópico original da rocha. As rochas carbonáticas foram serradas e polidas, com o auxílio de uma politriz, perpendicularmente à superfície $\mathrm{S}_{1} / / \mathrm{S}_{0}$ para permitir melhor visualização das estruturas sedimentares. A seleção da área para amostragem por microdrilling foi realizada sob lupa binocular.

Antes dos procedimentos de coleta de material para análises geoquímicas e isotópicas das rochas carbonáticas, que implicam na total destruição das amostras, estas foram 
digitalizadas por meio de um scanner para criação de um banco de dados para posterior consulta.

Lâminas petrográficas de 29 amostras de carbonatos e de dois pelitos foram confeccionadas para descrição sob microscópio de luz polarizada modelo Olympus BX-50.

\subsection{Análises isotópicas de $\mathrm{C}, \mathrm{O}$ e $\mathrm{Sr}$}

Em cada amostra foi selecionada a área mais homogênea, sem veios, vênulas, recristalizações minerais e estilólitos por meio de avaliação macroscópica e microscópica com auxílio de microscópio petrográfico ou lupa binocular. Nestas áreas, foi realizada coleta do material para análises de $\mathrm{C}, \mathrm{O}$ e Sr pela técnica de microdrilling com pequenas brocas de tungstênio. Esta metodologia ajuda a minimizar ou até eliminar a influência de alterações pósdeposicionais na coleta de alíquotas pulverizadas de carbonato, aumentando a confiabilidade dos resultados como representativos da água do mar na época da deposição.

As análises de $\mathrm{C}$ e $\mathrm{O}$ foram realizadas através da reação do pó coletado por microdrill em cada amostra com $\mathrm{H}_{3} \mathrm{PO}_{4} 100 \%$, rapidamente aquecido e manipulado por um braço mecânico. Este processo ocorre em atmosfera de He. $\mathrm{O} \mathrm{CO}_{2}$ liberado foi analisado no espectrômetro de massa Delta Advantage do Centro de Pesquisas Geocronológicas da USP (CPGeo). Os valores de $\delta^{18} \mathrm{O}$ e $\delta^{13} \mathrm{C}$ de cada amostra foram determinados com base nas equações dos itens 2.3.1 e 2.3.2, respectivamente. Os resultados são dados em partes por mil (\%o) com erro analítico de $\pm 0,05 \%$ para $\delta^{13} \mathrm{C}$ e $\pm 0,07 \%$ para $\delta^{18} \mathrm{O}$.

Para as análises isotópicas de $\mathrm{Sr}$ foram selecionadas amostras de carbonatos com teores de Sr superiores a 300 ppm, em acordo com o proposto por Halverson et al. (2007). As razões isotópicas ${ }^{87} \mathrm{Sr} /{ }^{86} \mathrm{Sr}$ foram obtidas por lixiviação de cerca de $100 \mathrm{mg}$ de carbonato pulverizado, adquiridos no processo de microdrill, com $2 \mathrm{ml}$ de $\mathrm{HCl}$ 0,1 $\mathrm{N}$ durante uma hora. O sobrenadante é retirado e a amostra é centrifugada e lavada três vezes com água Milli Q de forma a obter o primeiro lixiviado, o qual é descartado. Em seguida, são adicionadas à amostra seca $2 \mathrm{ml}$ de $\mathrm{HCl} 1 \mathrm{~N}$, deixando reagir durante 30 minutos. Novamente esta é centrifugada e lavada três vezes, e esta solução constitui o segundo lixiviado. A solução é submetida a um processo de purificação do Sr através da técnica de cromatografia de troca iônica e, em seguida, tem suas razões determinadas no espectrômetro de massa Finnigan MAT 262 do Centro de Pesquisas Geocronológicas (CPGeo) do Instituto de Geociências da USP. As razões ${ }^{87} \mathrm{Sr} /{ }^{86} \mathrm{Sr}$ foram normalizadas para o valor de ${ }^{86} \mathrm{Sr} /{ }^{88} \mathrm{Sr}$ igual a 0,1194 . O valor médio da razão ${ }^{87} \mathrm{Sr} /{ }^{86} \mathrm{Sr}$ do padrão NBS-987 determinado durante o estudo foi de $0,710251 \pm$ 0,000043 . 
Pelo fato de alguns carbonatos terem $\mathrm{Rb}$, o qual pode gerar $\mathrm{Sr}$ radiogênico, as razões isotópicas de $\mathrm{Sr}$ medidas foram recalculadas para a época de sua deposição (t) através da equação:

$$
\left({ }^{87} \mathrm{Sr} /{ }^{86} \mathrm{Sr}\right)_{\mathrm{t}}=\left({ }^{87} \mathrm{Sr} /{ }^{86} \mathrm{Sr}\right)_{\mathrm{m}}-{ }^{87} \mathrm{Rb} /{ }^{86} \mathrm{Sr} \times\left(\mathrm{e}^{\lambda \mathrm{t}}-1\right),
$$

onde: $\left({ }^{87} \mathrm{Sr} /{ }^{86} \mathrm{Sr}\right)_{\mathrm{t}}$ é a razão recalculada para a idade de deposição $(\mathrm{t}),\left({ }^{87} \mathrm{Sr} /{ }^{86} \mathrm{Sr}\right)_{\mathrm{m}}$ a razão medida na amostra, ${ }^{87} \mathbf{R b} /{ }^{86} \mathrm{Sr}$ é a razão calculada em função das razões isotópicas de $\mathrm{Sr}$ medidas e dos teores de $\mathrm{Rb}$ e $\mathrm{Sr}$ determinados, $\lambda$ é a constante de decaimento radioativo de ${ }^{87} \mathrm{Rb}$ para ${ }^{87} \mathrm{Sr}$ e igual a $1,42 \times 10^{-11} \mathrm{a}^{-1} \mathbf{t}$ é a idade em que os sedimentos carbonáticos foram depositados (540 Ma).

\subsection{Análises geoquímicas dos carbonatos}

As amostras de carbonato foram pulverizadas em um moinho de anéis de carbeto de tungstênio do Laboratório de Preparação de Amostras do CPGeo. Uma alíquota de aproximadamente $10 \mathrm{~g}$ da amostra pulverizada foi enviada para determinação dos teores de $\mathrm{Rb}$ e $\mathrm{Sr}$ pela técnica de fluorescência de raios-X, no espectrômetro de raios-X Philips PW 2510 do Laboratório de Fluorescência / ICP-OES do Instituto de Geociências da USP.

As análises de elementos maiores, demais traços e terras raras foram realizadas pelo Laboratório Acme (Canadá). O teor de óxidos de elementos maiores e dos elementos traços foi determinado a partir da fusão de $0,2 \mathrm{~g}$ de amostra com metaborato/tetraborato de lítio, com posterior ataque com ácido nítrico diluído e análise por ICP-OES. A perda ao fogo foi dada pela diferença de peso após fusão a $1000^{\circ} \mathrm{C}$. Metais preciosos e metais base foram determinados após digestão de 0,5 g de amostra com Água Régia seguida de análise em ICPMS.

Os resultados de elementos terras raras obtidos foram normalizados em relação ao padrão post-Archean Australian shale (PAAS - Taylor \& McLennan, 1985). O parâmetro $\mathrm{Ce} / \mathrm{Ce}^{*}$, de interesse deste trabalho foi calculado para cada amostra pela equação $\mathrm{Ce} / \mathrm{Ce}^{*}=$ $\mathrm{Ce}_{\mathrm{n}} /\left(\mathrm{Pr}_{\mathrm{n}}{ }^{2} / \mathrm{Nd}_{\mathrm{n}}\right)$, proposta por Lawrence et al. (2006), onde $\mathrm{n}$ indica a composição de cada elemento já normalizada ao PAAS. Esta equação evita anomalias aparentes de Ce devidas à abundância de La dos sistemas aquáticos em geral. Adicionalmente, também foi calculado o parâmetro $\operatorname{Pr} / \mathrm{Pr}^{*}=2 \mathrm{Pr}_{\mathrm{n}} /\left(\mathrm{Ce}_{\mathrm{n}}+\mathrm{Nd}_{\mathrm{n}}\right)$ para auxiliar na identificação da anomalia aparente já citada. 


\subsection{Separação de zircão detrítico para datação U-Pb e análises isotópicas de Hf}

As amostras de pelitos foram reduzidas a fragmentos de aproximadamente $2 \mathrm{~cm}$ de lado maior com a utilização de um martelo. A etapa seguinte de cominuição foi feita em um britador de mandíbulas, onde os fragmentos foram reduzidos até dimensões milimétricas. Finalizando, as amostras foram levadas a um moinho de discos e o material final foi peneirado, de forma a separar as frações maior e menor que 0,149 $\mathrm{mm}$. Tais frações foram colocadas em uma mesa de separação (Wiffley Table) para concentração dos minerais pesados. O material resultante foi passado em separador magnético e posteriormente em líquidos pesados (bromofórmio e iodeto de metileno) para obtenção dos cristais de zircão. Os grãos de cada amostra foram separados por catação sob lupa binocular e arranjados em um molde vítreo sobre uma fita adesiva dupla face. $\mathrm{O}$ molde foi recoberto com resina epóxi e polido.

Após a preparação, estes moldes foram recobertos com uma película de C para obtenção de imagens de catodo luminescência e posterior datação pelo método U-Pb e análises isotópicas Hf, através da técnica de Laser Ablation ICPMS no equipamento Neptune do CPGeo.

\subsection{Análises isotópicas de Sm-Nd}

As amostras de pelitos foram inicialmente fragmentadas com um martelo. Estes fragmentos foram pulverizados em um moinho de anéis de tungstênio do Laboratório de Preparação de amostras do CPGeo.

Aproximadamente $50 \mathrm{mg}$ de cada amostra foi dissolvida em uma mistura de ácidos concentrados 3:1 de $\mathrm{HF} / \mathrm{HNO}_{3}$ com adição de Spike (concentração ${ }^{150} \mathrm{Nd}=0,510999 \mu \mathrm{g} / \mathrm{g}$ e ${ }^{149} \mathrm{Sm}=0,740918 \mu \mathrm{g} / \mathrm{g}$ ). Após secas, foram adicionados de $5 \mathrm{ml}$ de $\mathrm{HCl} 6 \mathrm{~N}$ às amostras e evaporadas. Em seguida, foram diluídas em $2 \mathrm{ml}$ de $\mathrm{HNO}_{3} 1 \mathrm{~N}$ e os elementos foram separados em dois estágios. No primeiro, foram coletados os elementos terras raras em coluna de resina RE Spec, com $\mathrm{HNO}_{3}$ 0,05 N. A solução foi evaporada e o resíduo foi novamente diluído em 0,2 ml de $\mathrm{HCl}$ 0,26 N. No segundo estágio, os elementos Sm e Nd foram coletados em coluna de resina $\mathrm{LN}$ Spec, com $\mathrm{HCl} 0,55 \mathrm{~N}$ e 0,026 N, respectivamente. As razões isotópicas de $\mathrm{Sm}$ e Nd foram medidas no espectrômetro de massa Finnigan MAT-262. O branco analítico é de ca. $80 \mathrm{pg}$ para $\mathrm{Nd}$ e de ca. $20 \mathrm{pg}$ para $\mathrm{Sm}$. As idades $\mathrm{T}_{\mathrm{DM}}$ foram

calculadas com base no modelo de DePaolo (1981). O valor médio para a razão ${ }^{143} \mathrm{Nd} /{ }^{144} \mathrm{Nd}$ do padrão JNdi medido durante a realização das análises foi de 0,512098 \pm 0,000013. 


\section{CAPÍTULO 4}

\section{$\underline{\text { RESULTADOS }}$}

Foram estudadas cinco seções geológicas da Formação Sete Lagoas entre os municípios mineiros de Vespasiano e Lagoa Santa (Fig. 6). São elas: Ana Paula (AP), Vespasiano (VS), Bairro da Lapinha (BL), Parque Gruta da Lapinha (PGL) e Pedra do Baú (BAU). As duas últimas se encontram dentro de Unidades de Conservação (UC) do Estado de Minas Gerais gerenciadas pelo Instituto Estadual de Florestas (IEF). As autorizações para entrada e coleta de amostras de rocha nas UC foram devidamente fornecidas pelo IEF.

Embora as rochas de todas as seções descritas apresentem recristalização da matriz carbonática, as relações estratigráficas originais não foram obliteradas. As análises realizadas forneceram resultados petrográficos e estratigráficos, de isótopos de $\mathrm{C}, \mathrm{O}$ e $\mathrm{Sr}$, geocronológicos e geoquímicos que estão detalhados neste capítulo.

\subsection{Descrição das seções estudadas}

\subsubsection{Seção Ana Paula (AP)}

Esta seção está localizada na cidade de Lagoa Santa, cerca de $5 \mathrm{~km}$ a W da lagoa que dá nome ao município (UTM 622776 / 7827181 - Fig. 6). Os afloramentos ocorrem em um morro de aproximadamente $50 \mathrm{~m}$ de altura situado atrás da sede de uma pequena chácara, cuja proprietária se chama Ana Paula. As exposições de rochas da Formação Sete Lagoas não são muito boas e em geral se encontram bastante intemperisadas e descontínuas.

A seção tem $46 \mathrm{~m}$ de espessura e é principalmente constituída por calcissiltitos grossos e doloarenitos muito finos a finos, passando a doloarenitos médios no topo (Fig. 9). Ocorrem três leitos subordinados de $1 \mathrm{~m}$ de espessura de margas e o mais basal destes foi amostrado para geocronologia (amostra 11-AP-05 - Fig. 10A), dado seu aspecto menos intemperisado. $\mathrm{Na}$ altura de 32,3 m, ocorre uma camada de brecha tectônica dolomitizada, com clastos de até $2 \mathrm{~cm}$ de lado maior e diversos veios preenchidos por calcita branca. Imediatamente acima da brecha ocorrem algumas falhas de empurrão de rejeito inferior a $5 \mathrm{~cm}$, de plano axial de direção N-S com vergência do deslocamento para W.

Os calcissiltitos possuem coloração cinza e laminações irregulares truncadas como estrutura sedimentar predominante, com um nível próximo ao topo onde ocorrem laminações plano-paralelas. Tais laminações são de até $1 \mathrm{~cm}$ de espessura e recobertas por lâminas sub- 
milimétricas de sericita. Algumas lâminas intercaladas nestes calcários apresentam coloração bege e são constituídas por dolomita (Fig. 10B). Os doloarenitos possuem coloração bege a marrom e estrutura sedimentar predominante composta por laminações de até $1 \mathrm{~cm}$ de espessura, irregulares truncadas e que são recobertas por lâminas submilimétricas de sericita (Fig. 10C). À altura de $8 \mathrm{~m}$ ocorre um leito com laminações plano-paralelas e os doloarenitos médios do topo apresentam estratificação cruzada. As margas apresentam lâminas de até $2 \mathrm{~cm}$ compostas por grãos carbonáticos na fração areia muito fina a fina recobertos por lâminas de até $1 \mathrm{~mm}$ de siltito. O leito mais basal apresenta laminações com cavalgamento supercrítico (climbing ripples), enquanto que os dois mais superiores exibem laminação irregular truncada.

Ao microscópio petrográfico, observa-se que os calcários e dolomitos são bastante impuros e contém entre 20 e $30 \%$ de sedimentos detríticos compostos principalmente por grãos de quartzo e feldspato na fração areia muito fina, litoclastos félsicos na fração areia fina, óxido/hidróxido de ferro, além das lâminas submilimétricas de sericita que representam leitos de argila metamorfisados em grau baixo (Fig. 10D). Estes terrígenos apresentam seleção moderada e são sub-angulosos. Os doloarenitos médios do topo da seção apresentam igual teor de sedimentos siliciclásticos, mas não exibem os leitos micáceos. Na amostra 11-AP-01, observaram-se alguns litoclastos félsicos rotacionados e com formato sigmoide (Fig. 10E). A matriz carbonática corresponde 70 a $80 \%$ do volume destas rochas e os contatos entre seus grãos se dispõem poligonizados por recristalização. Os minerais carbonáticos apresentam orientação pela recristalização que caracteriza uma xistosidade oblíqua ao acamamento $\mathrm{S}_{0}$ $\left(\mathrm{S}_{1}\right)$. Nos leitos mais micáceos, os grãos apresentam pronunciado estiramento e a rocha adquire um aspecto protomilonítico. Observam-se também diversas vênulas paralelas a $\mathrm{S}_{0} \mathrm{e}$ preenchidas por calcita. As margas exibem as mesmas feições e constituição dos carbonatos, porém com teores de sedimentos terrígenos entre 40 e 50\%. Todos os litotipos descritos possuem porosidade inferior a $0,5 \%$.

A ritmicidade de lâminas de silte e areia recoberta pelas lâminas submilimétricas de mica, sugerem alternância entre períodos de tração e suspensão que podem ser controlados por correntes de maré. As laminações irregulares truncadas que dominam a seção, além da estratificação cruzada no topo e das climbing ripples exibidas por um nível de marga, apontam para um ambiente raso e energético, abaixo do nível de ondas e tempestades. Estes elementos permitem interpretar um ambiente deposicional de planície de maré, próximo à linha de costa e com influência de ondas.

A presença de uma foliação oblíqua a $S_{0}$ indica deformação tectônica imposta sobre as rochas da seção Ana Paula. As atitudes de plano axial obtidas possuem vergência para W e sugerem que o tectonismo pode ter sido decorrente do empurrão do orógeno Araçuaí sobre o 
CSF. Além disso, a presença de sericita e falhas de empurrão de baixo rejeito e que afetam níveis restritos de camadas sedimentares apontam para deformações em níveis crustais rasos, provavelmente geradas pela formação do cinturão epidérmico na região do antepaís da Faixa Araçuaí. Estes esforços devem ter sido mais pronunciados nos leitos rochosos com mica, dada a constituição mais permissiva a deslizes intraestratais dos sedimentos originais, que resultou na milonitização dos carbonatos.

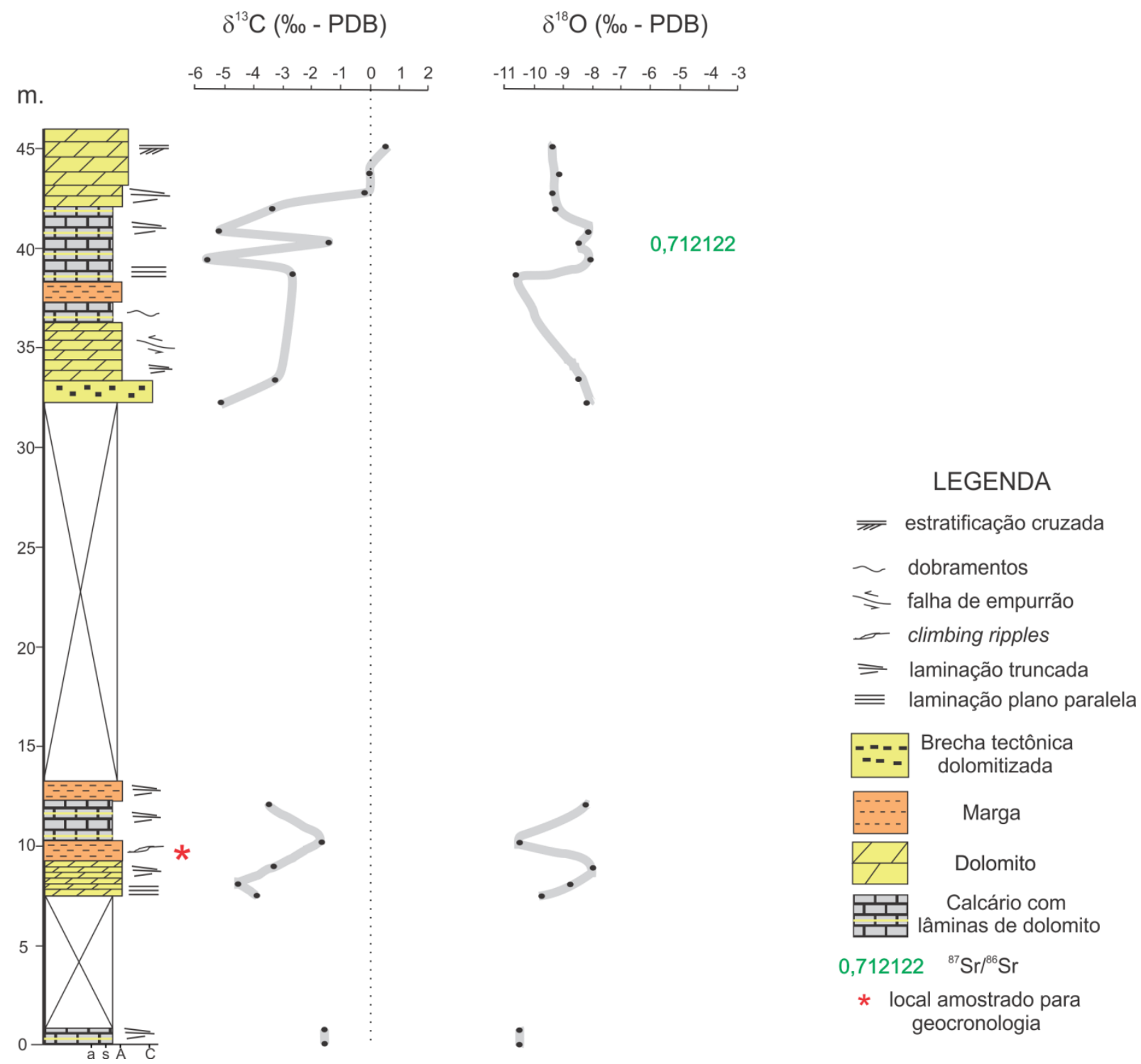

Fig. 9 - Coluna estratigráfica da seção Ana Paula com as curvas isotópicas de $\mathrm{C}$ e $\mathrm{O}$ obtidas e a razão ${ }^{87} \mathrm{Sr} /{ }^{86} \mathrm{Sr}$ da amostra 11-AP-14. 

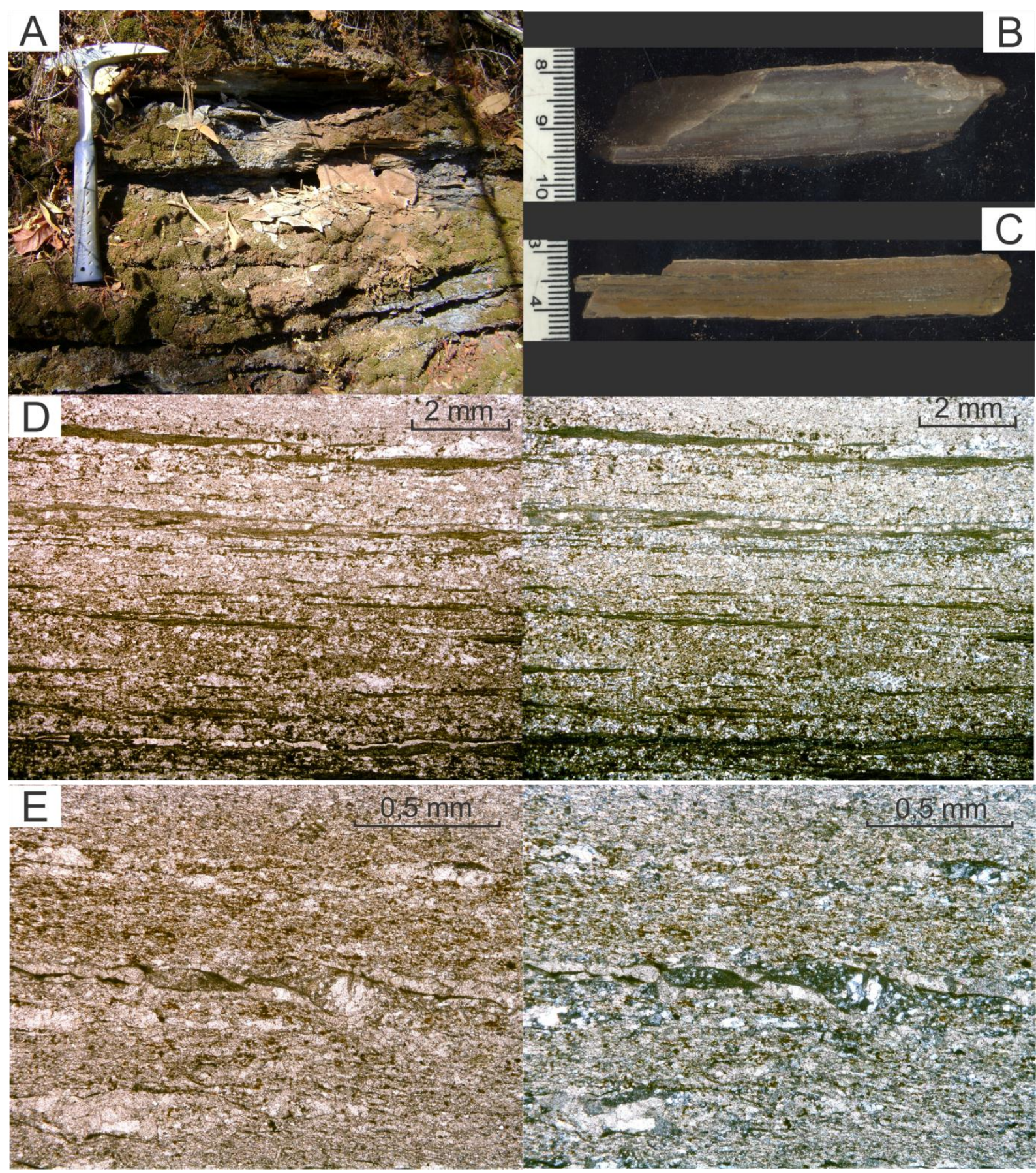

Fig. 10 - Imagens da seção Ana Paula que exibem: A) Afloramento de marga amostrado para geocronologia; B) Calcissiltito com lâminas compostas por dolomita (amostra 11-AP-14); C) Doloarenito muito fino com lâminas submilimétricas de sericita (amostra 11-AP-18); D) Fotomicrografia de doloarenito muito fino a fino com mais de $20 \%$ de sedimentos detríticos (nicóis // e X da esquerda para a direita, objetiva de 1,25x, amostra 11-AP-03); E) Fotomicrografia de calcissiltito com litoclasto sigmoide (nicóis // e X da esquerda para a direita, objetiva de 4x, amostra 11-AP-01).

\subsubsection{Seção Vespasiano (VS)}

Esta seção está localizada na cidade de Vespasiano, ao lado da pista da MG-010 (Linha Verde) sentido Belo Horizonte (UTM 613881 / 7821915 - Fig. 6). Os afloramentos 
ocorrem em cortes de estrada e em um bloco acima de um morro com baixo grau de intemperismo. Foram descritos três porções distintas separadas por hiatos de exposição: basal, central e superior. A espessura da Seção Vespasiano é de cerca de 37 m (Fig. 11).

A porção basal tem $6 \mathrm{~m}$ de espessura (Fig. 12A) e é constituída de calcissiltitos grossos / calcarenitos muito finos cinza claros a cinza (Fig. 12B), que gradam para calcarenitos médios no topo. Na altura de $2 \mathrm{~m}$, foi descrita uma camada de $90 \mathrm{~cm}$ de espessura de brecha tectônica dolomitizada (Fig. 12C), com clastos de até 0,5 cm de lado maior e diversos veios de calcita branca. Esta camada ocorre na base de uma falha de empurrão "cega" e com rejeito de $20 \mathrm{~cm}$, que desloca camadas restritas a uma espessura de 2,5 m sem que a deformação atinja níveis abaixo ou acima (Fig. 12D). Esta falha tem direção N-S com mergulho de $20^{\circ}$ para E. Acima da brecha, os calcários apresentam algumas lâminas beges compostas por dolomita. A estrutura sedimentar dominante é a laminação plano-paralela e diversos veios preenchidos por calcita branca e concordantes a $S_{0}$ foram descritos.

A porção central é composta por $6 \mathrm{~m}$ de espessura de doloarenitos finos a médios, de coloração bege (Fig. 12E), e com lâminas e estratos irregulares truncados. Estes dolomitos são capeados por uma camada de um metro de espessura de marga, que foi amostrada para análises geocronológicas (amostra 11-VS-13 - Fig. 12F). Abaixo da marga, ocorrem estratos boudinados preenchidos por calcita branca sem orientação mineral, que evidencia um preenchimento pós-deformacional. Esta porção é separada da basal por um hiato de exposição de $7 \mathrm{~m}$.

A porção superior tem cerca de $4 \mathrm{~m}$ de espessura e é constituída de calcissiltitos grossos/calcarenitos muito finos cinza claro a cinza, com algumas lâminas beges com dolomita e laminações irregulares truncadas na base e laminação plano paralela no topo. Esta porção está separada da central por um hiato de exposição de $15 \mathrm{~m}$. Em todas as porções notam-se que as lâminas com carbonato na fração silte grosso / areia muito fina e os estratos de areia média são recobertos por lâminas submilimétricas de argila. Por toda a seção Vespasiano foram observadas lineações de deslize intraestratal de direção E-W sobre o acamamento $\mathrm{S}_{0}$ de direção ESE-WNW e mergulho não superior a $2^{\circ}$.

Ao microscópio petrográfico observa-se que a matriz carbonática representa entre 93 e 95\% do volume da rocha e seus grãos apresentam contato poligonizado por recristalização (Fig. 12G). Nota-se uma orientação dos grãos carbonáticos oblíqua a $S_{0}$ que define uma foliação $S_{2}$. Esta foliação é semelhante àquela observada na seção $\mathrm{AP}$, mas não tão pronunciada o que dificulta seu reconhecimento algumas vezes. Os sedimentos terrígenos compõem cerca de $7 \%$ do volume da rocha e são constituídos de quartzo na fração silte, fragmentos líticos félsicos na fração areia muito fina, além de mica de cerca de $0,1 \mathrm{~mm}$ de 
lado maior. Estes sedimentos são subangulosos a subarredondados e possuem boa seleção. A porosidade dos litotipos é quase nula, atingindo $0,1 \%$ em alguns casos.
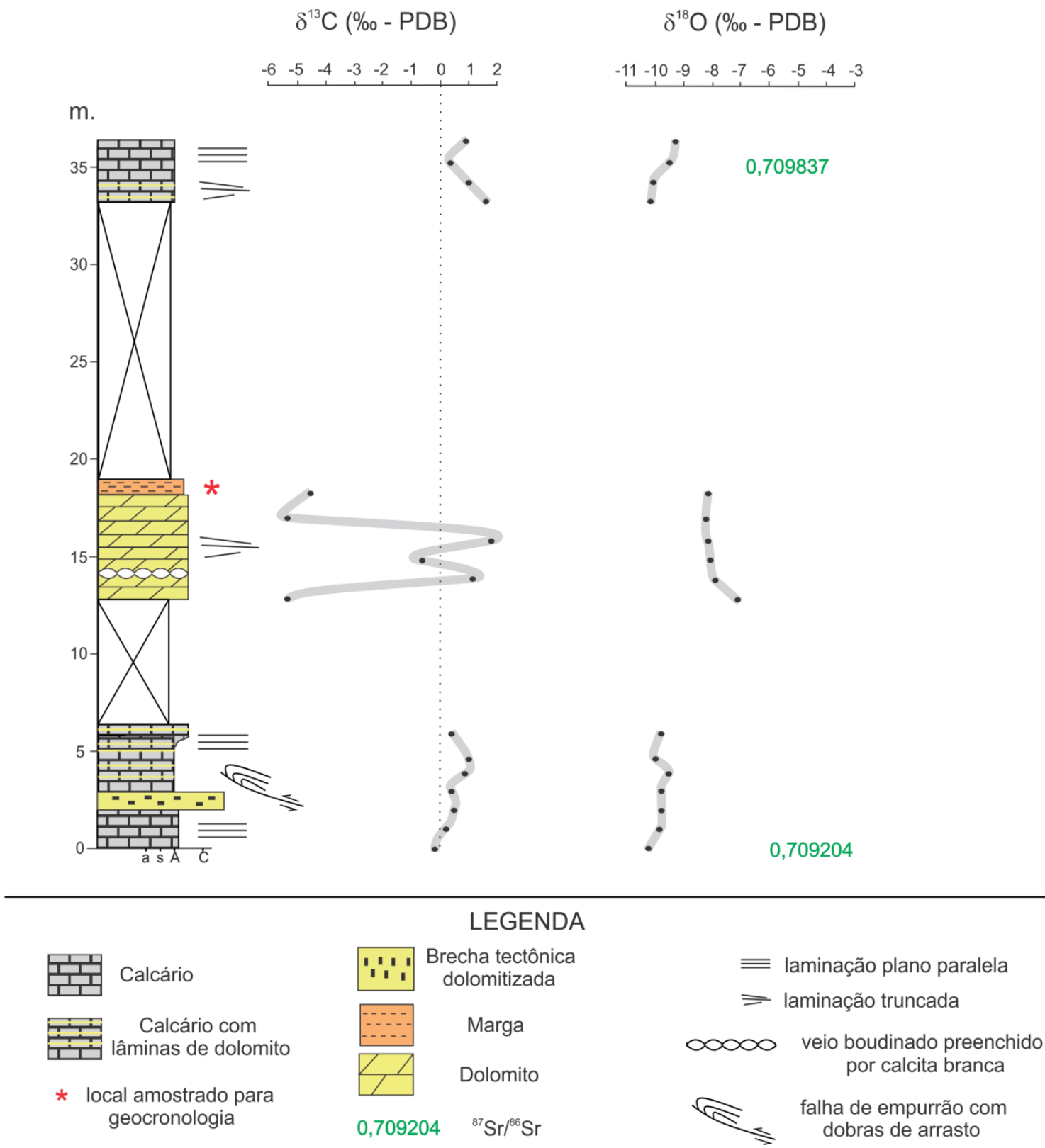

Fig. 11 - Coluna estratigráfica da seção Vespasiano com as curvas isotópicas de C e O obtidas e as razões ${ }^{87} \mathrm{Sr} /{ }^{86} \mathrm{Sr}$ das amostras 11 -VS-01 e 16.

A ritmicidade de lâminas de silte/areia recobertos por uma camada submilimétrica de argila, sugere alternância de períodos de tração e suspensão que podem ser controlados por correntes de maré. A influência de ondas e tempestades é menor nos carbonatos da seção VS, dado o predomínio de laminações plano-paralelas. Estes elementos permitem interpretar que os carbonatos foram depositados em planície de maré, porém em região mais distal que a seção AP. 
A falha de empurrão com vergência para $\mathrm{W}$ e as lineações de deslize intraestratal de direção E-W sugerem que o tectonismo observado na seção foi decorrente do empurrão da Faixa Araçuaí sobre o CSF.

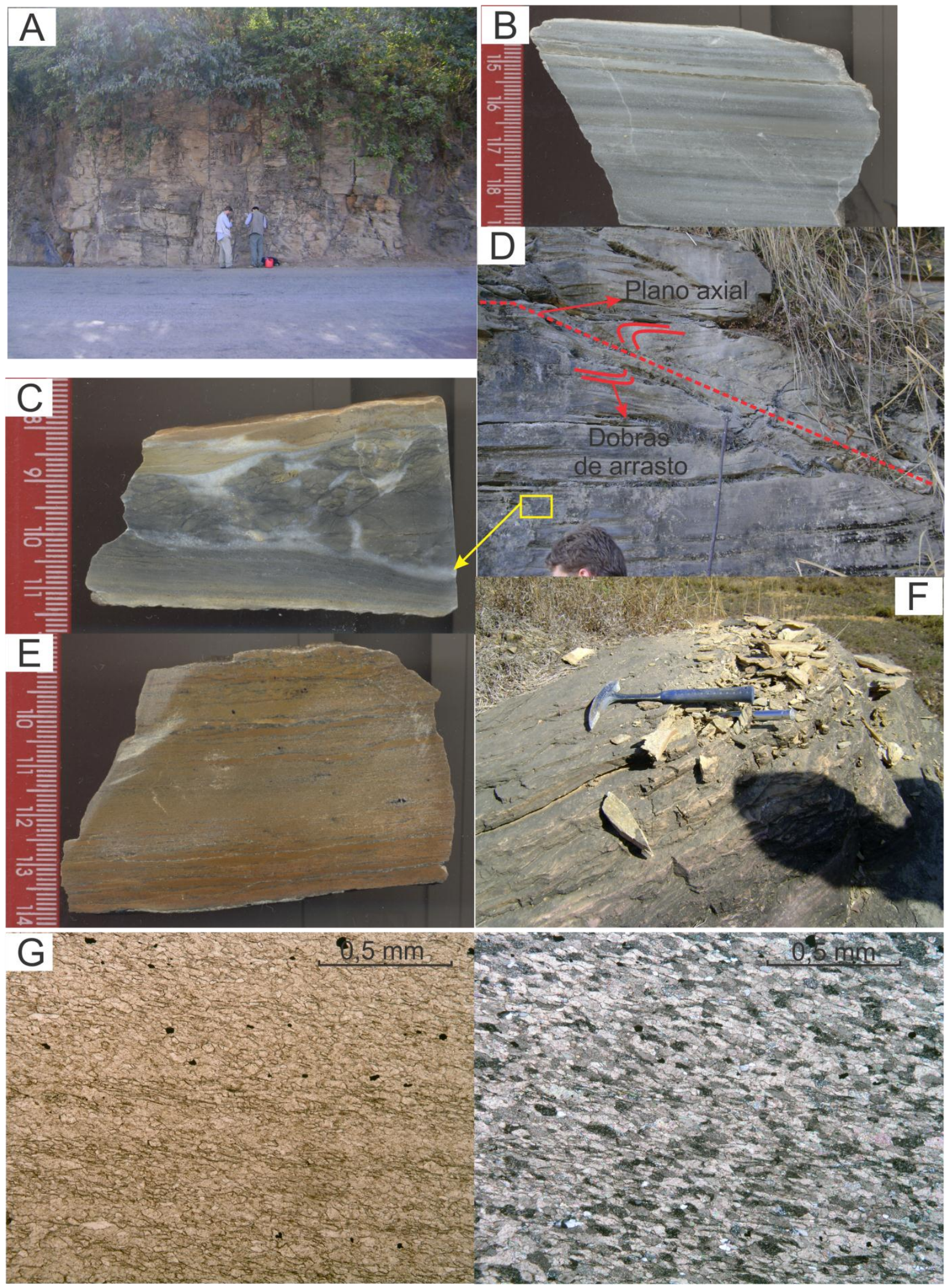


Fig. 12 - Imagens da seção Vespasiano que exibem: A) Vista geral da base da seção; B) calcissiltito grosso com laminação planar (amostra 11-VS-01); C) Brecha tectônica dolomitizada (amostra 11-VS-03); D) Falha de empurrão com dobras de arrasto (vareta tem $1 \mathrm{~m}$ de comprimento); E) Doloarenito fina da porção central (amostra 11-VS-12); F) Afloramento de marga amostrado para geocronologia; G) Fotomicrografia de calcissiltito recristalizado (nicóis // e X da esquerda para a direita, objetiva de 4x, amostra 11-VS-01).

\subsubsection{Seção Bairro da Lapinha (BL)}

Esta seção está localizada no município de Lagoa Santa e dista cerca de $6 \mathrm{~km}$ a NE da lagoa que dá nome à cidade e 1 km a S da UC Parque da Gruta da Lapinha (UTM 609864 / 7835563 - Fig. 6). Os afloramentos ocorrem em um grande maciço rochoso de frente para uma igreja no Bairro da Lapinha, com exposição constante e baixo grau de intemperismo, à exceção dos dois metros basais que se apresentam carstificados. Como tal maciço se encontra em duas propriedades particulares, somente os primeiros $14 \mathrm{~m}$ de espessura foram amostrados, visto que apenas um dos proprietários forneceu autorização para entrada.

A seção BL tem $14 \mathrm{~m}$ de espessura (Fig. 13) e é dominantemente composta por calcarenitos muito finos a finos, de coloração cinza escura a negra, ricos em matéria orgânica (Fig. 14A) e que gradam no topo para um pacote de $1 \mathrm{~m}$ de espessura de calcissiltitos com as mesmas características (Fig. 14B). A estrutura sedimentar dominante é laminação planoparalela, com apenas um leito de $1 \mathrm{~m}$ de espessura com laminações irregulares truncadas na altura de $4 \mathrm{~m}$. Na base, ocorrem leitos deformados que parecem corresponderem à laminações convolutas (Fig. 14A). Nota-se a abundância de veios de espessura variando de milimétrica até $1 \mathrm{~cm}$ preenchidos por calcita branca (Fig. 14C). Estas estruturas são paralelas ao acamamento $S_{0}$ de direção ESE-WNW e mergulho não superior a $3^{\circ}$ que, por vezes, se apresentam sob a forma de dobras recumbentes restritas de pequeno porte de direção aproximada N-S ou boudinadas. Também foram descritas diversas lineações de deslize intraestratal de direção E-W e mergulho de $1^{\circ}$.

Ao microscópio petrográfico observa-se que a matriz carbonática corresponde a aproximadamente $98,5 \%$ do volume da rocha, com porosidade quase nula e com grãos em contato poligonizado que indica recristalização (Fig. 14D). Há uma orientação dos grãos oblíqua ao acamamento $\mathrm{S}_{0}$ que define uma xistosidade $\mathrm{S}_{2}$. Os sedimentos terrígenos correspondem a, no máximo, $1 \%$ da rocha, são predominantemente constituídos por clinozoizita, feldspato e quartzo na fração areia muito fina, apresentam seleção muito boa e são subarredondados. Há também cerca de $0,5 \%$ de pirita autigênica. As porcentagens não levam em conta o teor de matéria orgânica, que é de difícil estimativa. 
Também foi descrita uma estrutura carbonática distinta, que corresponde a um anel carbonático de cerca de $0,5 \mathrm{~mm}$ de diâmetro e que se apresenta recristalizada junto com a matriz carbonática (Fig. 14D). Esta estrutura é semelhante a um corte transversal do metazoário Cloudina e está dentro da faixa de tamanho para a variedade $C$. lucianoi. A difícil descrição e a escassez de mais exemplares (foi observada nas amostras 11-BL-05 e 15) tornam difícil sua interpretação como um fóssil, embora seja algo bastante sugestivo.

As características sedimentares das rochas da seção BL sugerem um ambiente deposicional de baixa energia, abaixo do nível de ondas e tempestades. Os grandes teores de matéria orgânica sugerem elevada bioprodutividade no ambiente, gerando ao menos uma faixa de águas redutoras e propícias à precipitação de pirita autigênica.

As lineações de deslize intraestratal E-W, bem como a direção N-S dos planos axiais das pequenas dobras recumbentes, sugerem que as estruturas tectônicas observadas (foliações e boudins) podem ser resultados do empurrão do orógeno Araçuaí sobre o CSF. Os altos teores de matéria orgânica podem ter funcionado como espécie de "sabão", favorecendo o deslize intraestratal e fornecendo condições reológicas para formação da dobras recumbentes.

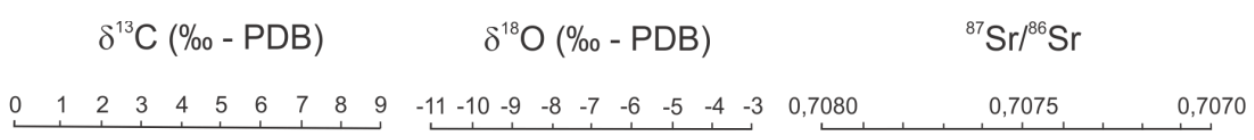

$\mathrm{m}$.
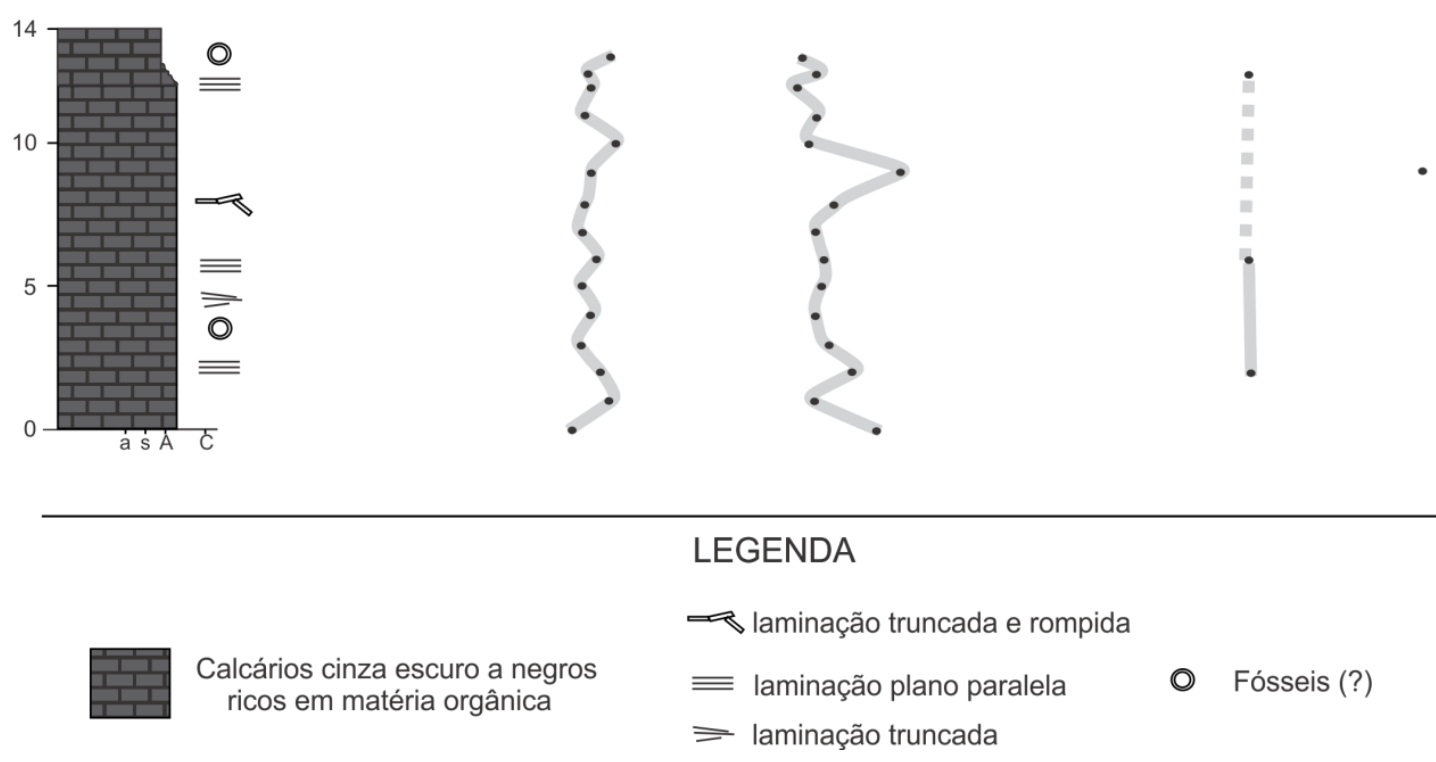

Fig. 13 - Coluna estratigráfica da seção BL com as curvas isotópicas de C, O e Sr obtidas. 


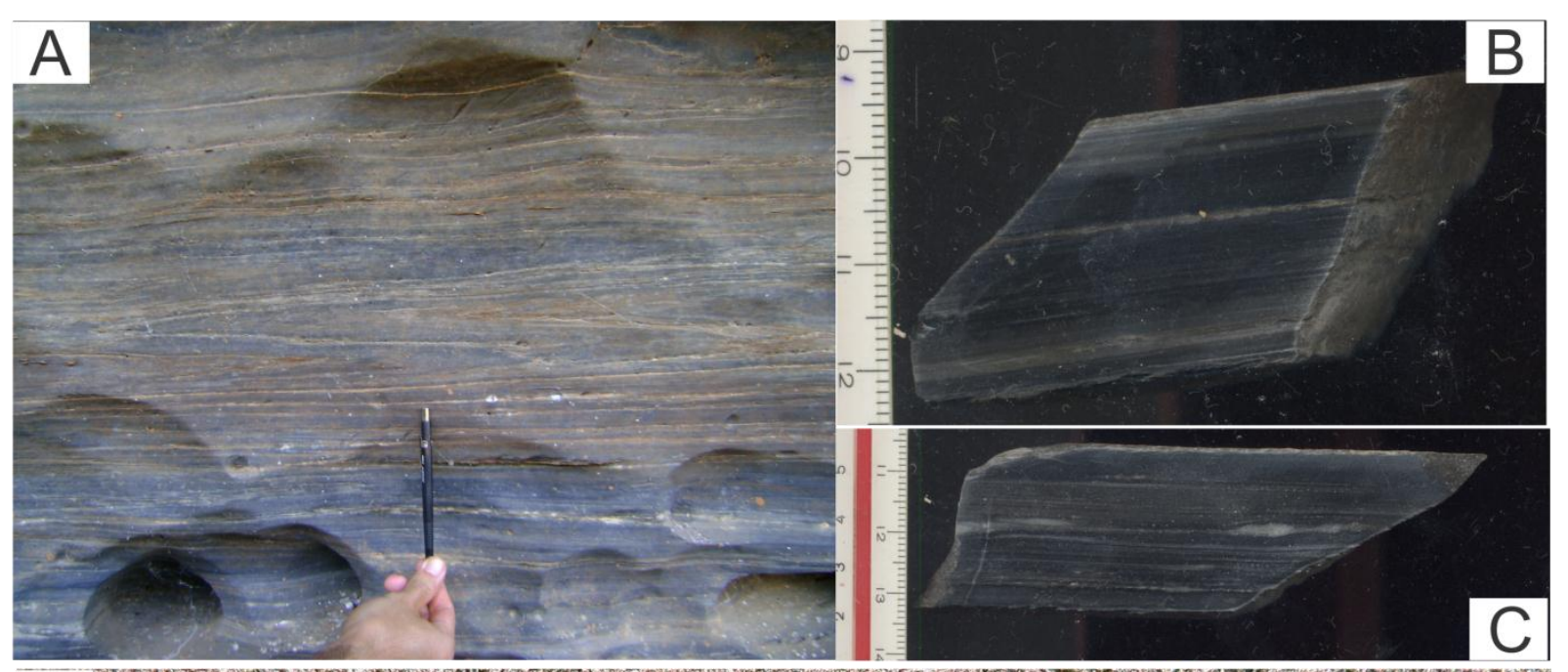

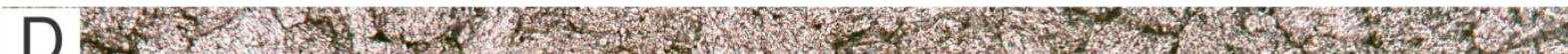

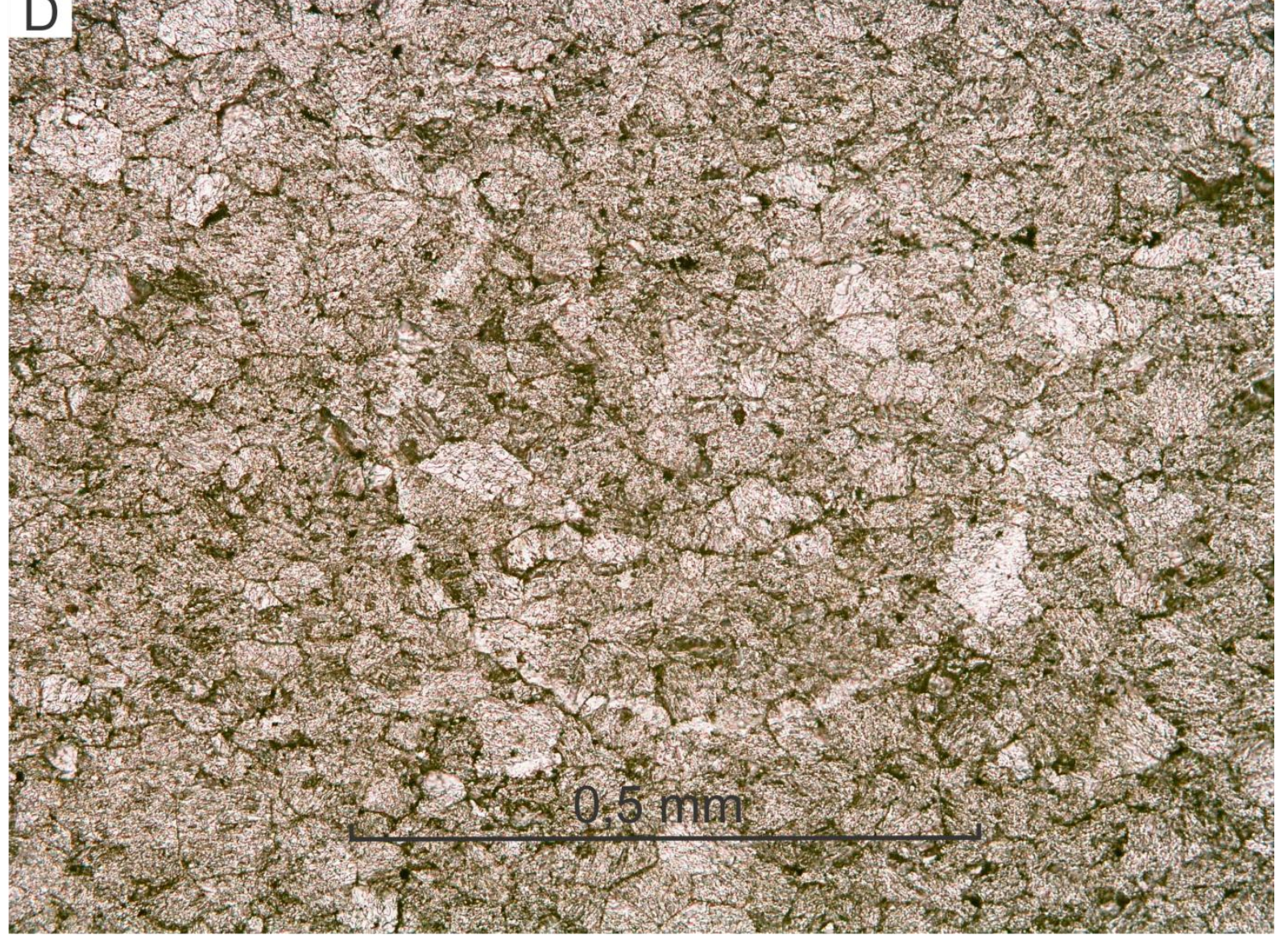

Fig. 14 - Imagens da seção Bairro da Lapinha exibindo: A) Calcarenito muito fino, rico em matéria orgânica e com possível laminação convoluta; B) Calcissiltito rico em matéria orgânica (amostra 11-BL-15); C) Calcarenito muito fino com vênulas preenchidas por calcita branca // $\mathrm{S}_{0}$ (amostra 11-BL-12); D) Fotomicrografia de calcarenito muito fino, com matriz recristalizada e anel carbonático (nicóis //, objetiva de 10x, amostra 11-BL$05)$. 


\subsubsection{Seção Pedra do Baú (BAU)}

Esta seção está localizada na região NE do município de Lagoa Santa e dista cerca de 5 km a E da Lagoa do Sumidouro (UTM 606138 / 7838200 - Fig. 6). Os afloramentos da Formação Sete Lagoas ocorrem em um grande maciço rochoso carstificado, com boas exposições contínuas e situadas no setor E da UC Parque da Gruta da Lapinha.

A seção BAU tem $64 \mathrm{~m}$ de espessura e é composta dominantemente por calcarenitos muito finos com alguns níveis de calcissiltitos (Fig. 15; vista geral na Fig. 16A). Estes calcários podem possuir duas colorações distintas: uma cinza (Fig. 16B) e outra cinza escura a negra (Fig. 16C). No primeiro caso estes litotipos possuem um teor moderado de matéria orgânica, enquanto que no segundo são bastante ricos. Nas alturas de 27 e 62 m ocorrem manchas escuras ricas em matéria orgânica (Fig. 16D). Próximo ao trecho com seção encoberta, os calcários apresentam lâminas milimétricas de cor bege e compostas por dolomita. Predomina a laminação plano-paralela como estrutura sedimentar (Fig. 16E), embora ocorram diversos leitos de espessura métrica com laminação irregular truncada. Foram descritos diversos veios de espessura milimétrica a até $1 \mathrm{~cm}$ preenchidos por calcita branca paralelos ao acamamento $S_{0}$ de direção ESE-WNW e mergulho não superior a $2^{\circ}$. Estas estruturas, por vezes, se apresentam sob a forma de dobras recumbentes restritas de pequeno porte de direção aproximada N-S ou boudinadas. Em alguns níveis, estes veios se dispõem rompidos e formam uma "laminação" truncada. Também foram descritas diversas lineações de deslize intraestratal de direção E-W e mergulho de $1^{\circ}$.

Ao microscópio petrográfico observa-se que a matriz carbonática corresponde entre 98 e 99,5\% do volume da rocha e seus grãos possuem contato poligonizado que indica recristalização. Ocorre orientação dos grãos de carbonato oblíqua a $S_{0}\left(S_{2}\right)$. Nos leitos mais ricos em matéria orgânica, esta foliação apresenta amplo estiramento de minerais e aparenta um aspecto protomilonítico. Nestes mesmos leitos ocorrem estilólitos em abundância (Fig. 16F). Os veios de calcita branca truncam esta foliação e se aproveitaram das superfícies de dissolução para percolação (Fig. 16G). Isto sugere que a matéria orgânica permitiu um deslize intraestratal mais intenso, que gerou milonitização e dissolução dos carbonatos e criou superfícies de fraqueza favoráveis à percolação de fluidos.

O teor de sedimentos detríticos diminui de 1,5\% na base, para quase $0 \%$ no topo. Estes são constituídos de clinozoizita, feldspato, quartzo e raros fragmentos líticos félsicos, todos na fração areia fina. A seleção dos terrígenos é muito boa e estes são subarredondados. Ocorrem também $0,5 \%$ de pirita autigênica e um mineral azulado semelhante à glauconita na amostra 11-BAU-39. 
$\mathrm{m}$.
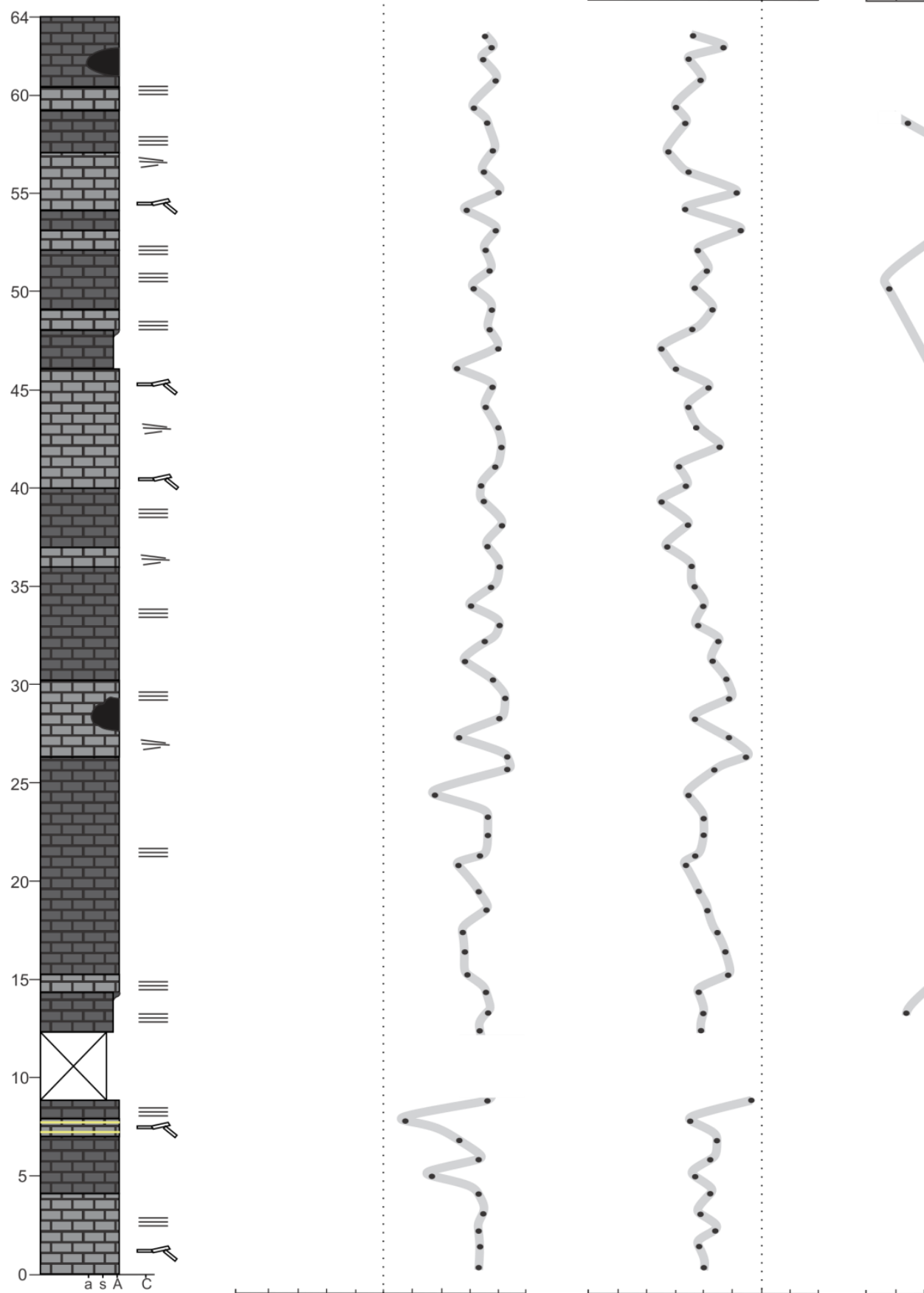


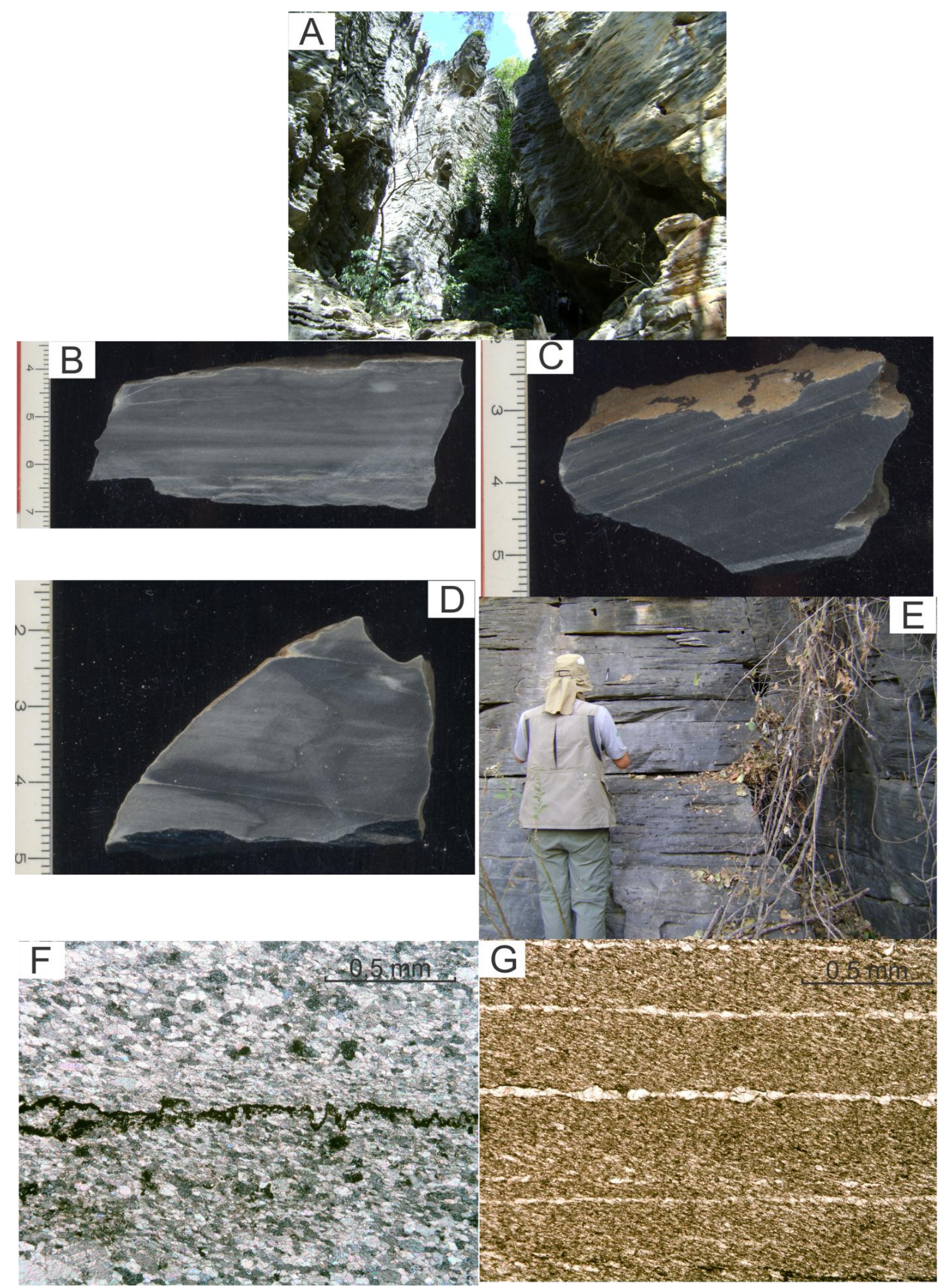

Fig. 16 - Imagens da Seção Pedra do Baú exibindo: A) Vista Geral da seção; B) calcário cinza com teor moderado de matéria orgânica (amostra 11-BAU-30); C) calcário cinza escuro rico em matéria orgânica (amostra 11-BAU-26); D) calcário cinza com mancha mais escura à direita (amostra 11-BAU-27); E) Afloramento mostrando horizontalidade dos estratos; F) Fotomicrografia com estilólito em leito com aspecto protomilonítico (nicóis X, objetiva de 4x, amostra 11-BAU-08); G) Fotomicrografia com vênula preenchida por calcita, rompendo estilólito em leito protomilonítico (nicóis //, objetiva de 4x, amostra 11-BAU-45). 
As feições sedimentares sugerem um ambiente deposicional de energia moderada a baixa, com eventuais influências de ondas ou tempestades. A matéria orgânica sugere elevada bioprodutividade no ambiente, que pode ter gerado ao menos uma faixa de águas redutoras e propícias à precipitação de pirita autigênica. A glauconita sugere um ambiente de profundidade rasa a moderadamente profunda com diagênese precoce. As manchas de matéria orgânica sugerem mobilização desta e pode representar geração de pequena quantidade de querogênio.

As lineações de deslize intraestratal E-W sugerem que o tectonismo observado na seção BAU foi decorrente do empurrão do orógeno Araçuaí sobre o CSF.

\subsubsection{Seção Parque da Gruta da Lapinha (PGL)}

Esta seção situa-se na região NE do município de Lagoa Santa, $3,5 \mathrm{~km}$ a $\mathrm{S}$ da lagoa do Sumidouro (UTM 609088 / 7836803 - Fig. 6). Os afloramentos ocorrem em um maciço rochoso, poucos metros após adentrar a entrada principal da UC Parque da Gruta da Lapinha. As exposições são contínuas e apresentam baixo grau de intemperismo.

A seção PGL possui cerca de 46 m de espessura (Fig. 17 e Fig. 18A) e é constituída predominantemente por calcarenitos muito finos, de coloração cinza escura e ricos em matéria orgânica (Fig. 18B). Próximo a altura de 34 m, há um nível em que estes calcários possuem lâminas de até $2 \mathrm{~mm}$ de coloração bege e compostas por dolomita (Fig. 18C). Subordinadamente ocorrem: um pacote de $2 \mathrm{~m}$ de espessura de calcissiltito grosso, de cor negra e mais rico em matéria orgânica (na altura de $18 \mathrm{~m}$ - Fig. 18D); dois pacotes de até $1 \mathrm{~m}$ de espessura de calcarenitos médios (alturas de 30 e $45 \mathrm{~m}$ ); diversos leitos de margas de menos de $50 \mathrm{~cm}$ de espessura e um de $1,15 \mathrm{~m}$ de espessura (a $31 \mathrm{~m}$ ), o qual foi amostrado para geocronologia (amostra 11-PGL-PEL - Fig. 18E). A estrutura sedimentar dominante é a laminação plano-paralela, embora ocorram diversos leitos de espessura métrica com laminação irregular truncada. Na seção PGL também foram descritos diversos veios de espessura milimétrica a até $30 \mathrm{~cm}$ preenchidos por calcita branca paralelos ao acamamento $\mathrm{S}_{0}$ de direção ESE-WNW e mergulho não superior a $2^{\circ}$. Estas estruturas por vezes se exibiam como dobras recumbentes restritas de pequeno porte de direção aproximada N-S ou boudinadas. Em alguns níveis, estes veios se dispõem rompidos e formam uma espécie de "laminação" truncada. Novamente ocorrem lineações de deslize intraestratal de direção E-W e mergulho de $1^{\circ}$.

Ao microscópio petrográfico observa-se amplo predomínio da matriz carbonática, que corresponde entre 97 e $99 \%$ do volume da rocha. A porosidade nestas rochas é nula e os grãos 
de carbonatos apresentam contato poligonizados entre si, que indicam recristalização (Fig. 18F). Estes grãos também possuem orientação oblíqua a $S_{0}$ que define uma xistosidade $S_{1}$ (Fig. 18F). Assim como na seção BAU, nota-se que os leitos mais ricos em matéria orgânica apresentam amplo estiramento mineral e aspecto protomilonítico. Nestes mesmos leitos os estilólitos são mais abundantes e os veios de calcita branca truncam a foliação, aproveitandose das superfícies de dissolução para percolação (Fig. 18G). Isto reforça a interpretação de que a matéria orgânica permitiu um deslize intraestratal mais intenso, que culminou em milonitização, dissolução dos carbonatos e criação de superfícies de fraqueza favoráveis à percolação de fluidos.

Os sedimentos detríticos correspondem entre 0,5 e $2 \%$ do volume das rochas e são constituídos de clinozoizita e quartzo em fração areia fina. A seleção dos terrígenos é muito boa e estes são subarredondados. Ocorre também $1 \%$ de pirita autigênica.

As estruturas sedimentares sugerem um ambiente deposicional de energia moderada a baixa, com eventuais influências de ondas ou tempestades. A matéria orgânica sugere elevada bioprodutividade no ambiente, que gerou ao menos uma faixa de águas redutoras propícias à precipitação de pirita autigênica.

Esta é mais uma seção que apresenta as lineações de deslize intraestratal E-W, que sugerem que o tectonismo observado na seção PGL foi decorrente do empurrão do orógeno Araçuaí sobre o CSF. 

$\delta^{13} \mathrm{C}(\%$ - PDB)
$\delta^{18} \mathrm{O}(\% \circ-\mathrm{PDB})$
${ }^{87} \mathrm{Sr} /{ }^{86} \mathrm{Sr}$

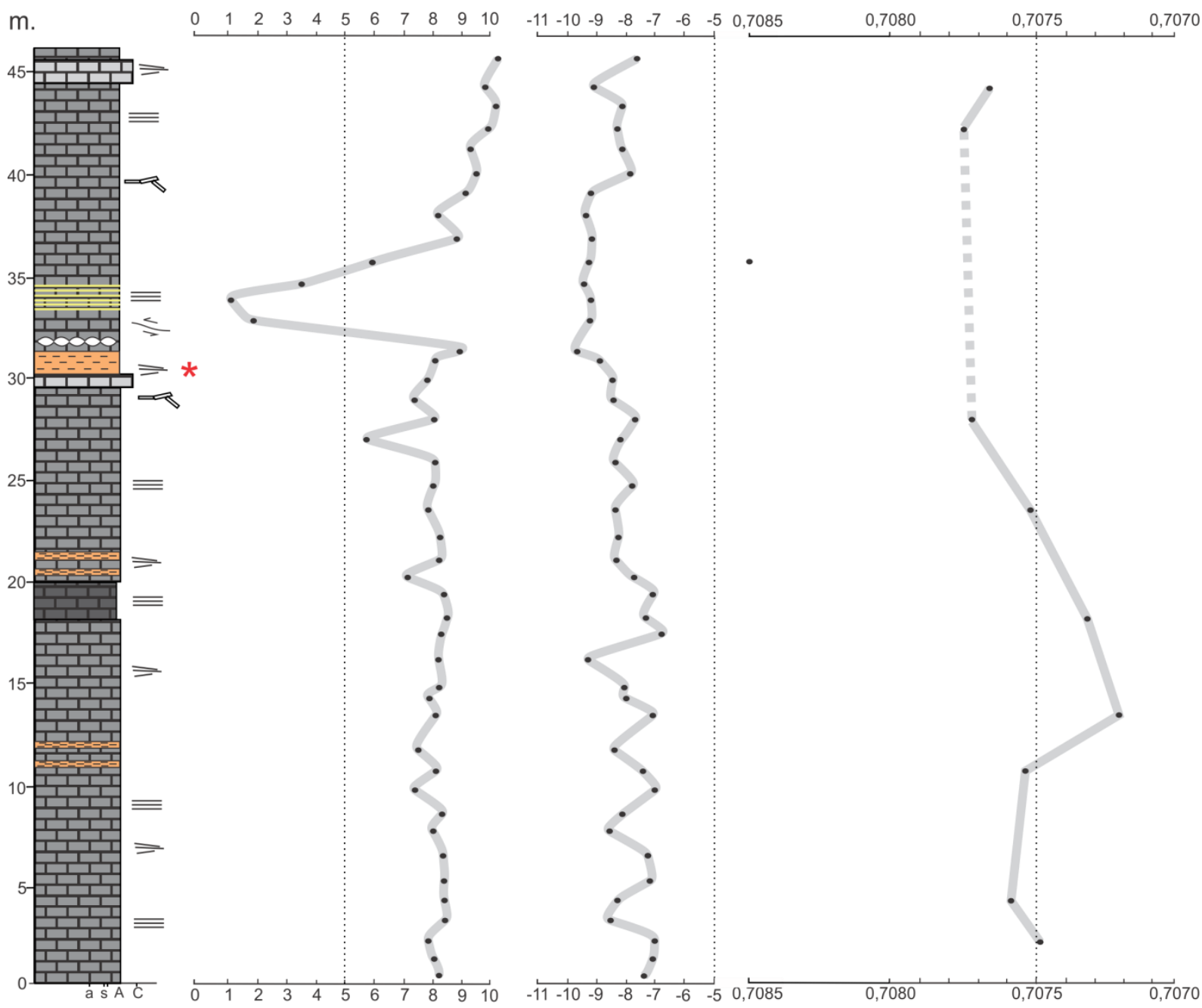

\begin{tabular}{|c|c|c|c|}
\hline & & LEGENDA & laminação truncada e rompida \\
\hline 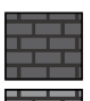 & $\begin{array}{l}\text { Calcários cinza escuro a negros } \\
\text { ricos em matéria orgânica }\end{array}$ & $\begin{array}{c}\text { Calcários cinza com teor } \\
\text { moderado de matéria orgânica } \\
\text { e lâminas de dolomito }\end{array}$ & $\begin{array}{l}\equiv \text { laminação plano paralela } \\
\equiv \text { laminação truncada }\end{array}$ \\
\hline 童 & $\begin{array}{l}\text { Calcários cinza com teor } \\
\text { moderado de matéria orgânica }\end{array}$ & $\begin{array}{l}\text { Calcários cinza claros com } \\
\text { Pry }\end{array}$ & $\begin{array}{l}\infty \infty \infty \text { veio boudinado espesso } \\
\text { preenchido por calcita branca }\end{array}$ \\
\hline & geocronologia & & $\leqslant \quad$ falha de empurrão \\
\hline
\end{tabular}

Fig. 17 - Coluna estratigráfica da seção PGL com suas curvas isotópicas de C, O e Sr. 


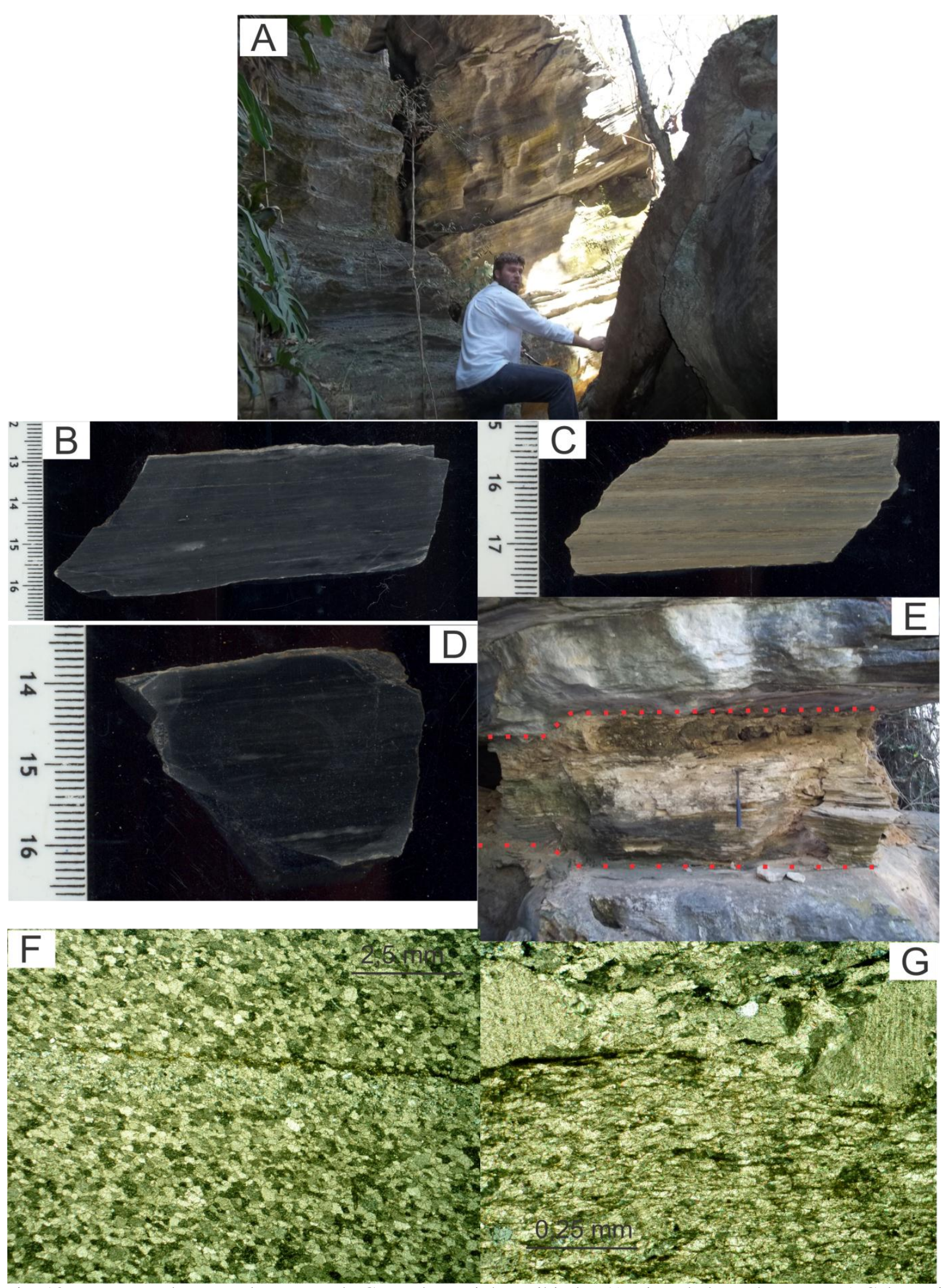

Fig. 18 - Imagens da seção do Parque da Gruta da Lapinha exibindo: A) Vista da base da seção; B) Calcarenito muito fino, cinza escuro (amostra 11-PGL11); C) Calcarenito muito fino com lâminas compostas por dolomita (amostra 11-PGL-33); D) Calcissiltito negro e rico em matéria orgânica (amostra 11-PGL-18); E) Camada mais espessa de marga (entre linhas pontilhadas vermelhas - martelo tem $38 \mathrm{~cm}$ de comprimento); F) Fotomicrografia que mostra contato poligonizado entre os grãos de carbonato e orientação dos mesmos (nicóis X, objetiva de 2,5x, amostra 11-PGL-29); G) Fotomicrografia de calcário com aspecto protomilonítico com vênula truncando foliação $S_{1}$ (nicóis $X$, objetiva de 10x, amostra 11-PGL-37). 


\subsection{Geoquímica dos carbonatos}

A Tabela 1 exibe os resultados dos teores de elementos maiores e a Tabela 2, dos elementos traço e razões geoquímicas de interesse obtidas. Um total de 34 amostras foram analisadas.

O objetivo principal das análises geoquímicas dos carbonatos foi selecionar amostras adequadas para determinação de razões ${ }^{87} \mathrm{Sr} /{ }^{86} \mathrm{Sr}$. Isto foi inicialmente realizado através de teores dos elementos traços $\mathrm{Rb}$ e $\mathrm{Sr}$, este último em acordo com o proposto por Halverson et al. (2007). A análise destes teores também permitiu separar as seções em dois grupos (Fig. 19): (1) seções AP e VS com carbonatos com teores de $\mathrm{Sr}$ inferiores a $550 \mathrm{ppm}$ e de $\mathrm{Rb}$ superiores a 10 ppm; (2) seções BL, BAU e PGL com teores de Sr superiores a 1000 ppm e de $\mathrm{Rb}$ inferiores a $10 \mathrm{ppm}$.

As seções do grupo 2 tiveram seus teores de elementos maiores de elementos terras raras analisados, ao passo que as do grupo 1 não. Explica-se este critério pela maior expressividade da mineralogia detrítica na composição dos carbonatos das seções AP e VS. Como reflexo disto, estes litotipos apresentariam elevados teores de $\mathrm{Si}$ e $\mathrm{Al}$, além de $\mathrm{Zr}$ que seriam sugestivas de contaminação de rochas siliciclásticas (Frimmel et al., 2006, 2009), dificultando interpretações sobre a composição química original destas rochas.

\subsubsection{Geoquímica de elementos maiores e traços}

Os carbonatos do grupo 1 apresentaram teores de $\mathrm{Rb}$ entre 13 e 27 ppm e de $\mathrm{Sr}$ entre 272 e 533 ppm (Tabela 2). As razões Rb/Sr estão entre 0,02 e 0,10. As amostras 11-AP-14 e 11-VS-01 apresentaram os maiores teores de Sr e os menores de Rb. Estas e a amostra 11-VS16 foram selecionadas para análises isotópicas de $\mathrm{Sr}$.

Se comparados aos carbonatos do grupo 2 estes apresentam menores teores de $\mathrm{Sr}$ e mais elevados de $\mathrm{Rb}$, o que pode ser explicado por dois motivos. Primeiro porque as seções AP e VS apresentam mais estratos dolomíticos e mesmo os calcários mais calcíticos apresentam lâminas compostas por dolomita. Dado à afinidade geoquímica entre $\mathrm{Ca}$ e $\mathrm{Sr}$, calcários calcíticos tendem a admitir uma quantidade maior de Sr no retículo cristalino. Como tal afinidade não é observada entre $\mathrm{Mg}$ e $\mathrm{Sr}$, quanto maior a quantidade de dolomita na composição do carbonato, menor tende a ser a quantidade de $\mathrm{Sr}$ em seu retículo. O segundo motivo é o maior volume de sedimentos terrígenos na composição destes carbonatos, principalmente de minerais que contenham $\mathrm{K}$, como feldspatos potássicos e micas. $\mathrm{O} \mathrm{K}$ tem 
afinidade geoquímica com $\mathrm{Rb}$, de forma que carbonatos ricos em terrígenos tendem a apresentar maiores teores de $\mathrm{Rb}$.

Os carbonatos das seções do grupo 2 apresentaram bastante uniformidade quanto à composição geoquímica de elementos maiores e traços (Tabela 2). Os teores de Si e Al são baixos e variam entre 0,11 e $1,16 \%$ e entre 0,01 e $0,36 \%$, respectivamente. Isto reflete o baixo conteúdo em sedimentos detríticos presentes nestes carbonatos. A mesma observação pode ser feita para os elementos $\mathrm{Na}$, K e Ti que variam de uma faixa abaixo do limite de detecção até 0,04, 0,22 e 0,04\%, respectivamente. Estes litotipos também apresentam baixos volumes de P que estão dentro da faixa 0,03 - 0,09\%. Também foram observados altos teores de Ca dentro da faixa 37,49 - 39,78\% que, em conjunto com os baixos teores de Mg dentro do intervalo $0,11-0,26 \%$, resultaram em razões $\mathrm{Mg} / \mathrm{Ca}$ abaixo de 0,01 . Estas razões permitem classificar estes carbonatos em calcários calcíticos, em acordo com a classificação utilizada por Figueiredo (2006). Os teores de Mn e Fe também são reduzidos e variam entre <0,01 - 0,03\% e $<0,01-0,29 \%$. Os teores de Sr são elevados e estão compreendidos entre 1045 e 3650 ppm e os teores de $\mathrm{Rb}$ são muito baixos, entre 2 e $10 \mathrm{ppm}$, de tal forma que quase todas as amostras (à exceção da 11-PGL-33) tiveram suas composições isotópicas de Sr analisadas. Com estes dados, foram obtidas razões $\mathrm{Rb} / \mathrm{Sr}$ menores que $0,01, \mathrm{Mn} / \mathrm{Sr}$ abaixo de $0,12, \mathrm{Fe} / \mathrm{Sr}$ abaixo de 1,10 e $\mathrm{Ca} / \mathrm{Sr}$ entre 100 - 380 nos carbonatos.

Uma única amostra de carbonato do grupo 2 destoou destas características. A amostra 11-PGL-33 apresentou teores de $\mathrm{Si}, \mathrm{Al}, \mathrm{K}$ e Fe mais elevados, 4,71, 0,94, 0,62 e 0,77\% respectivamente (Tabela 1). Os teores de Ca e Mg também são distintos, 31,37 e 2,01\% respectivamente, o que resultou em uma razão $\mathrm{Mg} / \mathrm{Ca}$ de 0,06 , dentro do intervalo de calcário magnesiano (Figueiredo, 2006). Os demais teores de elementos maiores são semelhantes às demais amostras. Estas características geoquímicas podem ser o reflexo do maior conteúdo de terrígenos e/ou da presença de lâminas compostas de dolomita reconhecidas na petrografia. Deste segundo fato decorre também o teor de $\mathrm{Rb}$ mais elevado (26 ppm) e de $\mathrm{Sr}$ mais baixo (462 ppm - Fig. 19), dadas à baixa afinidade geoquímica entre $\mathrm{Mg}$ e $\mathrm{Sr}$ e a afinidade entre K e $\mathrm{Rb}$, já mencionadas para os carbonatos do grupo 1 . 


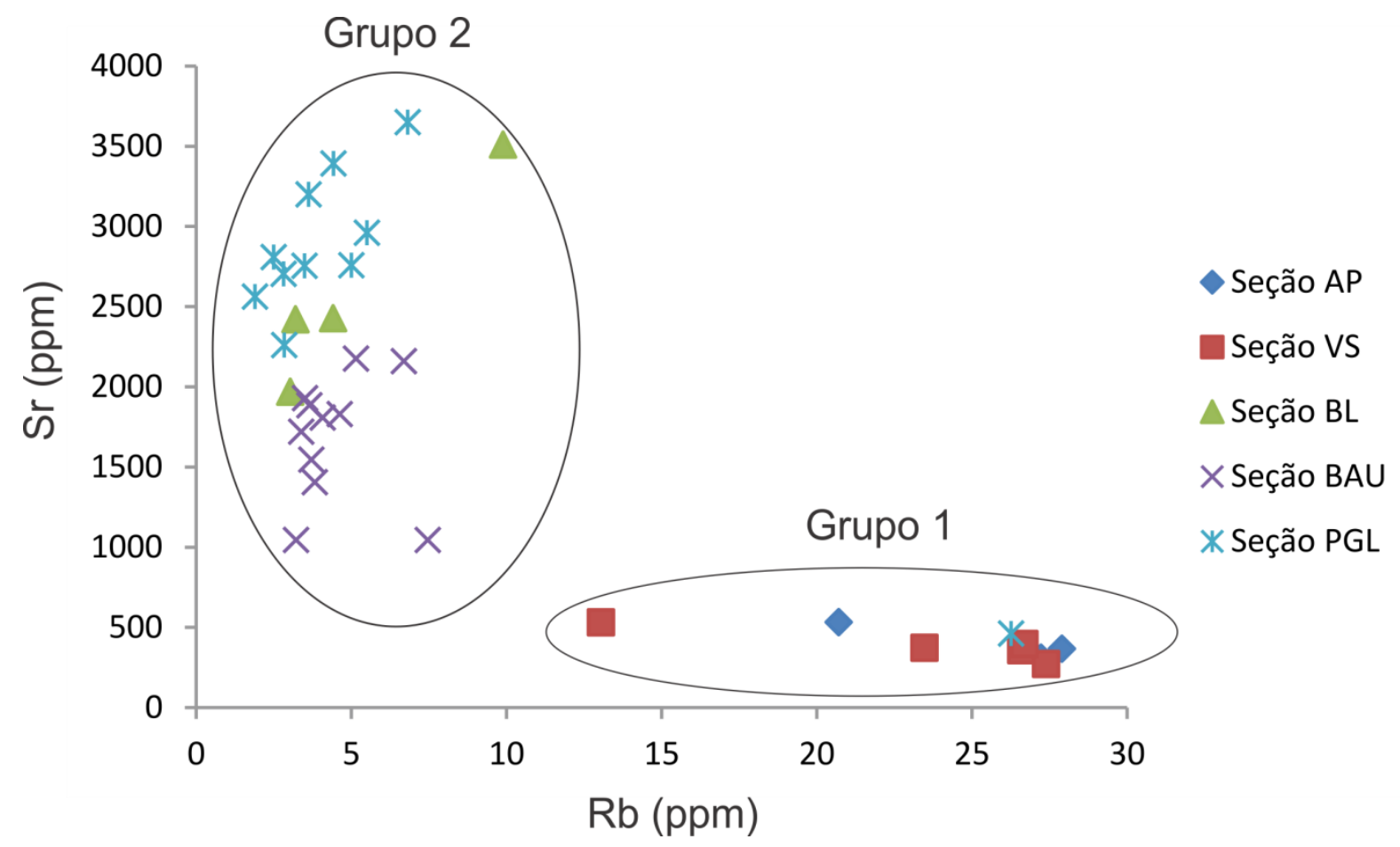

Fig. 19 - Gráfico de dispersão de teores Sr vs. Rb, exibindo a distinção entre os grupos 1 e 2. Notar que somente a amostra 11-PGL-33 está fora de seu grupo designado. 
Tabela 1 - Teores dos elementos maiores dos carbonatos analisados.

\begin{tabular}{|c|c|c|c|c|c|c|c|c|c|c|c|c|}
\hline & Amostra & m. & Si (\%) & Al (\%) & Mn (\%) & $\mathrm{Mg}(\%)$ & $\mathrm{Ca}(\%)$ & $\mathrm{Na}(\%)$ & $\mathrm{K}(\%)$ & $\mathrm{Ti}(\%)$ & $\mathbf{P}(\%)$ & $\mathrm{Fe}(\%)$ \\
\hline \multirow{3}{*}{ 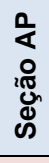 } & 11-AP-01 & 0,0 & n.a. & n.a. & n.a. & n.a. & n.a. & n.a. & n.a. & n.a. & n.a. & n.a. \\
\hline & 11-AP-06 & 10,3 & n.a. & n.a. & n.a. & n.a. & n.a. & n.a. & n.a. & n.a. & n.a. & n.a. \\
\hline & 11-AP-14 & 38,3 & n.a. & n.a. & n.a. & n.a. & n.a. & n.a. & n.a. & n.a. & n.a. & n.a. \\
\hline \multirow{5}{*}{ 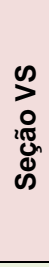 } & $11-V S-01$ & 0,0 & n.a. & n.a. & n.a. & n.a. & n.a. & n.a. & n.a. & n.a. & n.a. & n.a. \\
\hline & 11-VS-06 & 4,6 & n.a. & n.a. & n.a. & n.a. & n.a. & n.a. & n.a. & n.a. & n.a. & n.a. \\
\hline & 11 -VS-07 & 5,8 & n.a. & n.a. & n.a. & n.a. & n.a. & n.a. & n.a. & n.a. & n.a. & n.a. \\
\hline & $11-V S-14$ & 33,2 & n.a. & n.a. & n.a. & n.a. & n.a. & n.a. & n.a. & n.a. & n.a. & n.a. \\
\hline & 11-VS-16 & 35,2 & n.a. & n.a. & n.a. & n.a. & n.a. & n.a. & n.a. & n.a. & n.a. & n.a. \\
\hline \multirow{4}{*}{ 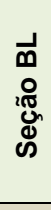 } & 11-BL-03 & 2,0 & 1,06 & 0,36 & 0,02 & 0,26 & 37,94 & 0,01 & 0,22 & 0,04 & 0,09 & 0,29 \\
\hline & 11-BL-07 & 5,9 & 0,42 & 0,04 & 0,02 & 0,17 & 39,17 & $<0,01$ & 0,02 & 0,02 & 0,05 & 0,14 \\
\hline & $11-B L-10$ & 9,0 & 0,23 & 0,07 & 0,02 & 0,17 & 39,03 & $<0,01$ & 0,05 & 0,02 & 0,07 & 0,16 \\
\hline & 11-BL-14 & 12,4 & 1,16 & 0,12 & 0,03 & 0,21 & 38,36 & 0,01 & 0,07 & 0,03 & 0,03 & 0,26 \\
\hline \multirow{11}{*}{ 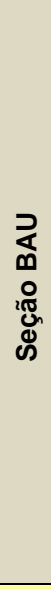 } & 11-BAU-06 & 5,0 & 0,72 & 0,13 & $<0,01$ & 0,22 & 38,66 & $<0,01$ & 0,04 & 0,03 & 0,09 & 0,17 \\
\hline & 11-BAU-09 & 7,8 & 0,69 & 0,13 & 0,01 & 0,24 & 39,05 & 0,02 & 0,07 & 0,03 & 0,09 & 0,19 \\
\hline & 11-BAU-12 & 13,3 & 0,29 & 0,05 & 0,01 & 0,20 & 39,32 & 0,01 & 0,04 & 0,02 & 0,05 & 0,13 \\
\hline & 11-BAU-15 & 16,4 & 0,17 & 0,02 & 0,01 & 0,19 & 39,62 & 0,01 & 0,02 & 0,02 & 0,04 & 0,11 \\
\hline & 11-BAU-18 & 19,5 & 0,89 & 0,03 & 0,01 & 0,20 & 38,95 & $<0,01$ & 0,02 & 0,02 & 0,05 & 0,11 \\
\hline & 11-BAU-29 & 30,2 & 0,24 & 0,03 & 0,01 & 0,24 & 39,52 & 0,01 & 0,01 & 0,00 & 0,03 & 0,00 \\
\hline & 11-BAU-37 & 38,1 & 0,68 & 0,17 & $<0,01$ & 0,23 & 38,55 & $<0,01$ & 0,10 & 0,03 & 0,04 & 0,19 \\
\hline & 11-BAU-41 & 42,1 & 0,20 & 0,03 & 0,02 & 0,18 & 39,78 & $<0,01$ & 0,02 & 0,02 & 0,04 & 0,15 \\
\hline & 11-BAU-49 & 50,1 & 0,26 & 0,06 & 0,02 & 0,21 & 39,42 & $<0,01$ & 0,04 & 0,02 & 0,07 & 0,15 \\
\hline & 11-BAU-54 & 55,0 & 0,14 & 0,01 & 0,01 & 0,11 & 39,62 & 0,02 & 0,00 & 0,02 & 0,04 & 0,11 \\
\hline & 11-BAU-57 & 58,3 & 0,11 & 0,02 & 0,02 & 0,22 & 39,08 & 0,01 & 0,02 & 0,02 & 0,03 & 0,13 \\
\hline \multirow{11}{*}{ 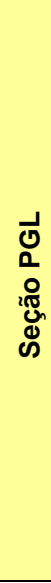 } & 11-PGL-03 & 2,0 & 0,22 & 0,04 & 0,02 & 0,15 & 39,65 & $<0,01$ & 0,02 & 0,02 & 0,06 & 0,13 \\
\hline & 11-PGL-05 & 4,0 & 0,56 & 0,13 & 0,02 & 0,20 & 38,87 & $<0,01$ & 0,07 & 0,03 & 0,06 & 0,20 \\
\hline & 11-PGL-11 & 10,4 & 0,59 & 0,12 & 0,02 & 0,22 & 38,98 & $<0,01$ & 0,03 & 0,02 & 0,05 & 0,19 \\
\hline & 11-PGL-13 & 12,9 & 0,58 & 0,13 & 0,02 & 0,17 & 38,84 & $<0,01$ & 0,07 & 0,03 & 0,05 & 0,18 \\
\hline & 11-PGL-18 & 17,9 & 0,81 & 0,18 & 0,02 & 0,21 & 38,49 & $<0,01$ & 0,10 & 0,03 & 0,05 & 0,24 \\
\hline & 11-PGL-23 & 23,2 & 1,78 & 0,26 & 0,02 & 0,22 & 37,49 & $<0,01$ & 0,16 & 0,04 & 0,07 & 0,21 \\
\hline & 11-PGL-27 & 27,6 & 0,19 & 0,04 & 0,02 & 0,17 & 39,39 & 0,02 & 0,02 & 0,02 & 0,04 & 0,14 \\
\hline & 11-PGL-33 & 33,6 & 4,71 & 0,94 & 0,02 & 2,01 & 31,37 & $<0,01$ & 0,62 & 0,08 & 0,04 & 0,77 \\
\hline & 11-PGL-35 & 35,6 & 0,34 & 0,07 & 0,02 & 0,14 & 39,12 & 0,04 & 0,04 & 0,02 & 0,07 & 0,20 \\
\hline & 11-PGL-41 & 42,0 & 0,37 & 0,11 & 0,02 & 0,17 & 38,87 & 0,02 & 0,07 & 0,03 & 0,06 & 0,15 \\
\hline & 11-PGL-43 & 44,1 & 0,97 & 0,23 & 0,02 & 0,22 & 37,99 & 0,02 & 0,12 & 0,04 & 0,06 & 0,24 \\
\hline
\end{tabular}

Nota - n.a. = não analisado 
Tabela 2 - Teores de $\mathrm{Rb}$ e Sr, razões geoquímicas, valores isotópicos de C e O e razões ${ }^{87} \mathrm{Sr} /{ }^{86} \mathrm{Sr}$ obtidos nos calcários analisados.

\begin{tabular}{|c|c|c|c|c|c|c|c|c|c|c|c|c|c|}
\hline & Amostra & m. & $\mathrm{Rb}$ (ppm) & $\mathrm{Sr}(\mathrm{ppm})$ & $\mathrm{Mg} / \mathrm{Ca}$ & $\mathrm{Rb} / \mathrm{Sr}$ & $\mathrm{Mn} / \mathrm{Sr}$ & $\mathrm{Fe} / \mathrm{Sr}$ & $\mathrm{Ca} / \mathrm{Sr}$ & $\delta^{13} \mathrm{C}(\%$ - PDB $)$ & $\delta^{18} \mathrm{O}(\% 0$ - PDB) & ${ }^{87} \mathrm{Sr} /{ }^{86} \mathrm{Sr}$ & erro $(2 \sigma)$ \\
\hline \multirow{20}{*}{ 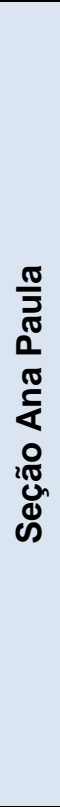 } & 11-AP-01 & 0,0 & 27 & 311 & - & 0,087 & - & - & - & $-1,6$ & $-10,5$ & n.a. & n.a. \\
\hline & 11-AP-02 & 0,9 & - & - & - & - & - & - & - & $-1,6$ & $-10,5$ & n.a. & n.a. \\
\hline & 11-AP-03 & 7,5 & - & - & - & - & - & - & - & $-3,9$ & $-9,8$ & n.a. & n.a. \\
\hline & 11-AP-04 & 8,3 & - & - & - & - & - & - & - & $-4,6$ & $-8,8$ & n.a. & n.a. \\
\hline & 11-AP-05 & 9,3 & - & - & - & - & - & - & - & $-3,3$ & $-8,0$ & n.a. & n.a. \\
\hline & 11-AP-06 & 10,3 & 28 & 367 & - & 0,076 & - & - & - & $-1,8$ & $-10,5$ & n.a. & n.a. \\
\hline & 11-AP-07 & 12,3 & - & - & - & - & - & - & - & $-3,5$ & $-8,3$ & n.a. & n.a. \\
\hline & 11-AP-08 & 32,3 & - & - & - & - & - & - & - & $-5,1$ & $-8,2$ & n.a. & n.a. \\
\hline & 11-AP-09 & 33,4 & - & - & - & - & - & - & - & $-3,3$ & $-8,5$ & n.a. & n.a. \\
\hline & 11-AP-10 & 34,3 & - & - & - & - & - & - & - & $<\mathrm{LD}$ & $<L D$ & n.a. & n.a. \\
\hline & 11-AP-11 & 35,3 & - & - & - & - & - & - & - & $<\mathrm{LD}$ & $<\mathrm{LD}$ & n.a. & n.a. \\
\hline & 11-AP-12 & 36,3 & - & - & - & - & - & - & - & $<L D$ & $<L D$ & n.a. & n.a. \\
\hline & 11-AP-14 & 38,3 & 21 & 533 & - & 0,039 & - & - & - & $-2,7$ & $-10,7$ & 0,712122 & 0,000072 \\
\hline & 11-AP-15 & 39,3 & - & - & - & - & - & - & - & $-5,6$ & $-8,1$ & n.a. & n.a. \\
\hline & 11-AP-16 & 40,5 & - & - & - & - & - & - & - & $-1,4$ & $-8,5$ & n.a. & n.a. \\
\hline & 11-AP-17 & 41,5 & - & - & - & - & - & - & - & $-5,2$ & $-8,2$ & n.a. & n.a. \\
\hline & 11-AP-18 & 42,2 & - & - & - & - & - & - & - & $-3,4$ & $-9,3$ & n.a. & n.a. \\
\hline & 11-AP-19 & 43,2 & - & - & - & - & - & - & - & $-0,2$ & $-9,4$ & n.a. & n.a. \\
\hline & 11-AP-20 & 44,2 & - & - & - & - & - & - & - & $-0,1$ & $-9,2$ & n.a. & n.a. \\
\hline & 11-AP-21 & 45,2 & - & - & - & - & - & - & - & 0,5 & $-9,4$ & n.a. & n.a. \\
\hline \multirow{17}{*}{ 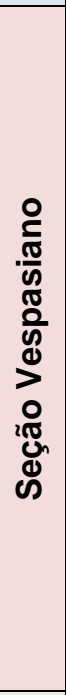 } & 11-VS-01 & 0,0 & 13 & 532 & - & 0,025 & - & - & - & $-0,1$ & $-10,2$ & 0,709204 & 0,000066 \\
\hline & 11-VS-02 & 1,0 & - & - & - & - & - & - & - & 0,1 & $-9,9$ & n.a. & n.a. \\
\hline & 11 -VS-03 & 2,0 & - & - & - & - & - & - & - & 0,4 & $-9,8$ & n.a. & n.a. \\
\hline & 11-VS-04 & 2,9 & - & - & - & - & - & - & - & 0,3 & $-9,8$ & n.a. & n.a. \\
\hline & 11-VS-05 & 3,8 & - & - & - & - & - & - & - & 0,9 & $-9,6$ & n.a. & n.a. \\
\hline & 11 -VS-06 & 4,6 & 23 & 373 & - & 0,063 & - & - & - & 1,0 & $-10,0$ & n.a. & n.a. \\
\hline & 11 -VS-07 & 5,8 & 27 & 358 & - & 0,074 & - & - & - & 0,3 & $-9,8$ & n.a. & n.a. \\
\hline & 11 -VS-08 & 12,8 & - & - & - & - & - & - & - & $-5,3$ & $-7,1$ & n.a. & n.a. \\
\hline & 11 -VS-09 & 13,8 & - & - & - & - & - & - & - & 1,1 & $-7,9$ & n.a. & n.a. \\
\hline & $11-V S-10$ & 14,7 & - & - & - & - & - & - & - & $-0,7$ & $-8,1$ & n.a. & n.a. \\
\hline & $11-V S-11$ & 15,7 & - & - & - & - & - & - & - & 1,8 & $-8,2$ & n.a. & n.a. \\
\hline & $11-V S-12$ & 17,0 & - & - & - & - & - & - & - & $-5,3$ & $-8,3$ & n.a. & n.a. \\
\hline & 11 -VS-13 & 18,3 & - & - & - & - & - & - & - & $-4,6$ & $-8,2$ & n.a. & n.a. \\
\hline & 11-VS-14 & 33,2 & 27 & 272 & - & 0,101 & - & - & - & 1,6 & $-10,2$ & n.a. & n.a. \\
\hline & 11-VS-15 & 34,2 & - & - & - & - & - & - & - & 1,0 & $-10,1$ & n.a. & n.a. \\
\hline & $11-V S-16$ & 35,2 & 27 & 397 & - & 0,067 & - & - & - & 0,3 & $-9,6$ & 0,709837 & 0,000062 \\
\hline & 11 -VS-17 & 36,4 & - & - & - & - & - & - & - & 0,9 & $-9,3$ & n.a. & n.a. \\
\hline \multirow{15}{*}{ 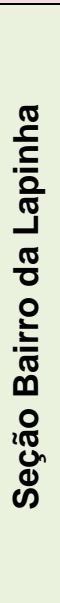 } & 11-BL-01 & 0,0 & - & - & - & - & - & - & - & 7,5 & $-6,1$ & n.a. & n.a. \\
\hline & 11-BL-02 & 1,0 & - & - & - & - & - & - & - & 8,4 & $-7,7$ & n.a. & n.a. \\
\hline & 11-BL-03 & 2,0 & 10 & 3510 & 0,007 & 0,003 & 0,066 & 0,837 & 108 & 8,2 & $-6,7$ & 0,707547 & 0,000062 \\
\hline & 11-BL-04 & 3,0 & - & - & - & - & - & - & - & 7,7 & $-7,3$ & n.a. & n.a. \\
\hline & 11-BL-05 & 4,0 & - & - & - & - & - & - & - & 8,0 & $-7,7$ & n.a. & n.a. \\
\hline & 11-BL-06 & 5,0 & - & - & - & - & - & - & - & 7,7 & $-7,5$ & n.a. & n.a. \\
\hline & 11-BL-07 & 5,9 & 3 & 1969 & 0,004 & 0,002 & 0,118 & 0,710 & 199 & 8,1 & $-7,4$ & 0,707556 & 0,000063 \\
\hline & 11-BL-08 & 6,8 & - & - & - & - & - & - & - & 7,7 & $-7,7$ & n.a. & n.a. \\
\hline & 11-BL-09 & 7,8 & - & - & - & - & - & - & - & 7,8 & $-7,2$ & n.a. & n.a. \\
\hline & 11-BL-10 & 9,0 & 3 & 2421 & 0,004 & 0,001 & 0,064 & 0,665 & 161 & 8,0 & $-5,6$ & 0,707122 & 0,000047 \\
\hline & 11-BL-11 & 10,0 & - & - & - & - & - & - & - & 8,6 & $-7,9$ & n.a. & n.a. \\
\hline & 11-BL-12 & 11,0 & - & - & - & - & - & - & - & 7,8 & $-7,7$ & n.a. & n.a. \\
\hline & 11-BL-13 & 12,0 & - & - & - & - & - & - & - & 8,0 & $-8,1$ & n.a. & n.a. \\
\hline & 11-BL-14 & 12,4 & 4 & 2428 & 0,006 & 0,002 & 0,128 & 1,066 & 158 & 7,9 & $-7,7$ & 0,707557 & 0,000053 \\
\hline & 11-BL-15 & 13,0 & - & - & - & - & - & - & - & 8,5 & $-8,0$ & n.a. & n.a. \\
\hline
\end{tabular}


Tabela 2 - Continuação.

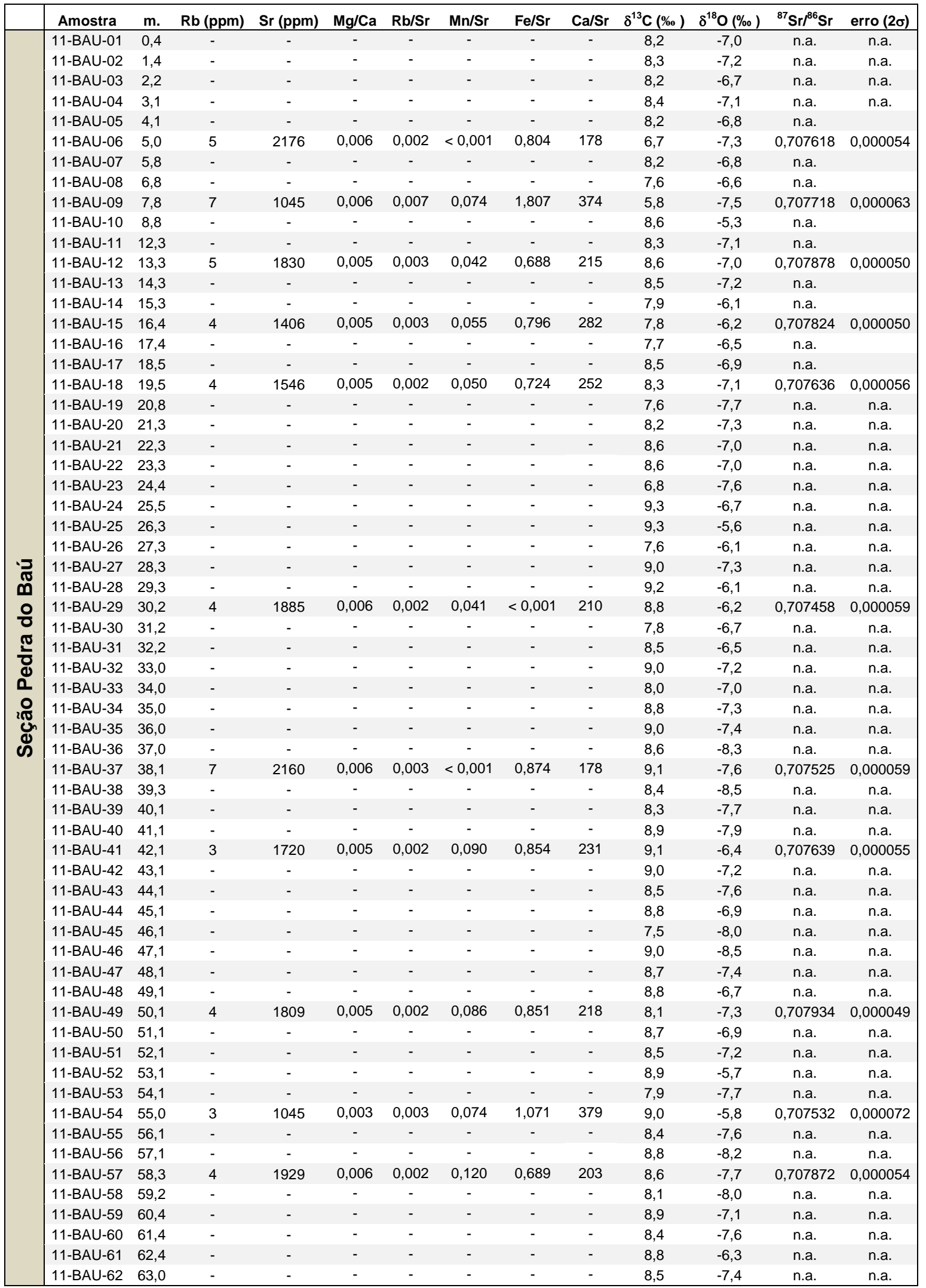


Tabela 2 - Continuação.

\begin{tabular}{|c|c|c|c|c|c|c|c|c|c|c|c|c|c|}
\hline & Amostra & m. & Rb (ppm) & $\mathrm{Sr}(\mathrm{ppm})$ & $\mathrm{Mg} / \mathrm{Ca}$ & $\mathrm{Rb} / \mathrm{Sr}$ & $\mathrm{Mn} / \mathrm{Sr}$ & $\mathrm{Fe} / \mathrm{Sr}$ & $\mathrm{Ca} / \mathrm{Sr}$ & $\delta^{13} \mathrm{C}(\% \circ)$ & $\delta^{18} \mathrm{O}(\%)$ & ${ }^{87} \mathrm{Sr} /{ }^{86} \mathrm{Sr}$ & erro $(2 \sigma)$ \\
\hline \multirow{44}{*}{ 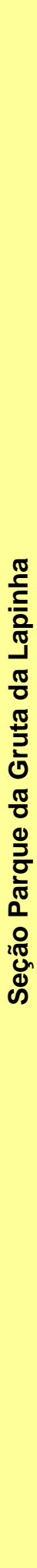 } & 11-PGL-01 & 0,0 & - & - & - & - & - & - & - & 8,2 & $-7,4$ & n.a. & n.a. \\
\hline & 11-PGL-02 & 1,0 & - & - & - & - & - & - & - & 8,1 & $-7,1$ & n.a. & n.a. \\
\hline & 11-PGL-03 & 2,0 & 2 & 2563 & 0,004 & 0,001 & 0,060 & 0,519 & 155 & 7,9 & $-7,1$ & 0,707489 & 0,000064 \\
\hline & 11-PGL-04 & 3,0 & - & - & - & - & - & - & - & 8,4 & $-8,5$ & n.a. & n.a. \\
\hline & 11-PGL-05 & 4,0 & 3 & 2755 & 0,005 & 0,001 & 0,056 & 0,711 & 141 & 8,4 & $-8,3$ & 0,707588 & 0,000066 \\
\hline & 11-PGL-06 & 5,0 & - & - & - & - & - & - & - & 8,4 & $-7,2$ & n.a. & n.a. \\
\hline & 11-PGL-07 & 6,0 & - & - & - & - & - & - & - & 8,3 & $-7,3$ & n.a. & n.a. \\
\hline & 11-PGL-08 & 7,2 & - & - & - & - & - & - & - & 8,0 & $-8,5$ & n.a. & n.a. \\
\hline & 11-PGL-09 & 8,2 & - & - & - & - & - & - & - & 8,3 & $-8,1$ & n.a. & n.a. \\
\hline & 11-PGL-10 & 9,2 & - & - & - & - & - & - & - & 7,4 & $-7,0$ & n.a. & n.a. \\
\hline & 11-PGL-11 & 10,4 & 2 & 2809 & 0,006 & 0,001 & 0,055 & 0,672 & 139 & 8,0 & $-7,5$ & 0,707532 & 0,000065 \\
\hline & 11-PGL-12 & 11,4 & - & - & - & - & - & - & - & 7,5 & $-8,4$ & n.a. & n.a. \\
\hline & 11-PGL-13 & 12,9 & 4 & 3393 & 0,005 & 0,001 & 0,046 & 0,536 & 114 & 8,2 & $-7,1$ & 0,707212 & 0,000062 \\
\hline & 11-PGL-14 & 13,9 & - & - & - & - & - & - & - & 7,8 & $-8,0$ & n.a. & n.a. \\
\hline & 11-PGL-15 & 14,9 & - & - & - & - & - & - & - & 8,3 & $-8,1$ & n.a. & n.a. \\
\hline & 11-PGL-16 & 15,9 & - & - & - & - & - & - & - & 8,4 & $-9,3$ & n.a. & n.a. \\
\hline & 11-PGL-17 & 16,9 & - & - & - & - & - & - & - & 8,4 & $-6,8$ & n.a. & n.a. \\
\hline & 11-PGL-18 & 17,9 & 5 & 2758 & 0,005 & 0,002 & 0,056 & 0,862 & 140 & 8,5 & $-7,4$ & 0,707332 & 0,000075 \\
\hline & 11-PGL-19 & 18,9 & - & - & - & - & - & - & - & 8,4 & $-7,1$ & n.a. & n.a. \\
\hline & 11-PGL-20 & 19,8 & - & - & - & - & - & - & - & 7,2 & $-7,7$ & n.a. & n.a. \\
\hline & 11-PGL-21 & 20,8 & - & - & - & - & - & - & - & 8,2 & $-8,3$ & n.a. & n.a. \\
\hline & 11-PGL-22 & 21,8 & - & - & - & - & - & - & - & 8,2 & $-8,3$ & n.a. & n.a. \\
\hline & 11-PGL-23 & 23,2 & 7 & 3650 & 0,006 & 0,002 & 0,064 & 0,575 & 103 & 7,8 & $-8,4$ & 0,707513 & 0,000072 \\
\hline & 11-PGL-24 & 24,4 & - & - & - & - & - & - & - & 8,0 & $-7,8$ & n.a. & n.a. \\
\hline & 11-PGL-25 & 25,5 & - & - & - & - & - & - & - & 8,1 & $-8,4$ & n.a. & n.a. \\
\hline & 11-PGL-26 & 26,6 & - & - & - & - & - & - & - & 5,8 & $-8,2$ & n.a. & n.a. \\
\hline & 11-PGL-27 & 27,6 & 3 & 2260 & 0,004 & 0,001 & 0,069 & 0,619 & 174 & 8,1 & $-7,7$ & 0,707723 & 0,000063 \\
\hline & 11-PGL-28 & 28,6 & - & - & - & - & - & - & - & 7,4 & $-8,5$ & n.a. & n.a. \\
\hline & 11-PGL-29 & 29,6 & - & - & - & - & - & - & - & 7,8 & $-8,5$ & n.a. & n.a. \\
\hline & 11-PGL-30 & 30,1 & - & - & - & - & - & - & - & 8,1 & $-8,9$ & n.a. & n.a. \\
\hline & 11-PGL-31 & 31,6 & - & - & - & - & - & - & - & 8,9 & $-9,7$ & n.a. & n.a. \\
\hline & 11-PGL-32 & 32,6 & - & - & - & - & - & - & - & 1,9 & $-9,3$ & n.a. & n.a. \\
\hline & 11-PGL-33 & 33,6 & 26 & 462 & 0,064 & 0,057 & 0,503 & 16,655 & 679 & 1,2 & $-9,3$ & n.a. & n.a. \\
\hline & 11-PGL-34 & 34,6 & - & - & - & - & - & - & - & 3,6 & $-9,4$ & n.a. & n.a. \\
\hline & 11-PGL-35 & 35,6 & 3 & 2704 & 0,004 & 0,001 & 0,086 & 0,750 & 145 & 6,0 & $-9,3$ & 0,708593 & 0,000076 \\
\hline & 11-PGL-36 & 36,6 & - & - & - & - & - & - & - & 8,9 & $-9,2$ & n.a. & n.a. \\
\hline & 11-PGL-37 & 37,8 & - & - & - & - & - & - & - & 8,2 & $-9,3$ & n.a. & n.a. \\
\hline & 11-PGL-38 & 38,8 & - & - & - & - & - & - & - & 9,1 & $-9,2$ & n.a. & n.a. \\
\hline & 11-PGL-39 & 39,8 & - & - & - & - & - & - & - & 9,5 & $-7,9$ & n.a. & n.a. \\
\hline & 11-PGL-40 & 41,0 & - & - & - & - & - & - & - & 9,3 & $-8,1$ & n.a. & n.a. \\
\hline & 11-PGL-41 & 42,0 & 4 & 3200 & 0,005 & 0,001 & 0,048 & 0,481 & 121 & 9,9 & $-8,3$ & 0,707745 & 0,000062 \\
\hline & 11-PGL-42 & 43,1 & - & - & - & - & - & - & - & 10,2 & $-8,1$ & n.a. & n.a. \\
\hline & 11-PGL-43 & 44,1 & 6 & 2961 & 0,006 & 0,002 & 0,052 & 0,803 & 128 & 9,8 & $-9,1$ & 0,707672 & 0,000068 \\
\hline & 11-PGL-44 & 45,4 & - & - & - & - & - & - & - & 10,2 & $-7,6$ & n.a. & n.a. \\
\hline
\end{tabular}

Nota - Os valores de $\delta^{13} \mathrm{C}$ e $\delta^{18} \mathrm{O}$ são dados em relação ao padrão PDB. n.a. = não analisado, - = sem parâmetros para cálculo. O erro analítico é de $\pm 0,05 \%$ para $\delta^{13} \mathrm{C}$ e $\pm 0,07 \%$ para $\delta^{18} \mathrm{O}$. 


\subsubsection{Geoquímica dos Elementos Terras Raras}

A Tabela 3 mostra os teores de Elementos Terras Raras (ETR) e outros elementos obtidos em 26 amostras de carbonato das seções BL, BAU, PGL, além da razão Y/Ho e dos parâmetros $\mathrm{Ce} / \mathrm{Ce}$ * e $\mathrm{Pr} / \mathrm{Pr}$ *. Os diagramas de distribuição dos ETR normalizados em relação ao padrão PAAS são apresentados na Fig. 20.

Os carbonatos analisados da seção BL são ligeiramente empobrecidos em ETR leves relativamente aos ETR médios e pesados. Todas as amostras são empobrecidas em terras raras em relação ao padrão PAAS. O diagrama da seção na Fig. 20 mostra uma tendência planar da distribuição, principalmente para as amostras 11-BL-03 e 11-BL-14. As demais amostras possuem um desnível maior entre os ETR leves dos demais. As razões Y/Ho decrescem de 39,3 para 26,7 da base para o topo. Os parâmetros $\mathrm{Ce} / \mathrm{Ce} *$ calculados variam de 0,83 a 1,01 e os parâmetros $\operatorname{Pr} / \operatorname{Pr}^{*}$, entre 0,92 e 1,04.

As amostras da seção BAU também são empobrecidas em relação ao PAAS. Os carbonatos analisados desta seção são empobrecidos em ETR leves em relação aos médios e pesados, e possuem menor tendência planar que as amostras das seções BL e PGL (Fig. 20). Exceção a estes padrões faz-se a amostra 11-BAU-29. As razões Y/Ho variam de 31,1 a 50, sendo que as amostras 11-BAU-54 e 57 possuem teores de Ho abaixo do limite de detecção (razões Y/Ho não calculadas). Os parâmetros $\mathrm{Ce} / \mathrm{Ce} e^{*}$ calculados variam de 0,59 a 1,50. As amostras 11-BAU-54 e 57 possuem valores normalizados de $\mathrm{Nd}$ muito próximos a zero e tais parâmetros não foram calculados, mas tenderiam a zero pela equação de Lawrence et al. (2006). Os parâmetros $\mathrm{Pr} / \mathrm{Pr}^{*}$ variam de 0,63 a 2,48.

Os carbonatos da seção PGL tendem a apresentar distribuição normalizada planar, com pouco empobrecimento em ETR leves e empobrecimento geral em relação ao padrão PAAS. Exceções são feitas às amostras 11-PGL-03 e 27, que possuem empobrecimento mais proeminente de ETR leves comparado aos médios e pesados. As razões Y/Ho variam de 25 a 45,7. Os parâmetros $\mathrm{Ce} / \mathrm{Ce}^{*}$ calculados variam de 0,53 a 1,90 e os parâmetros $\mathrm{Pr} / \mathrm{Pr}$, entre 0,68 e 1,37 . 
Tabela 3 - Teores de Elementos Terras Raras e Zr, razões Y/Ho e parâmetros Ce/Ce* e Pr/Pr* dos carbonatos analisados das seções BL, BAU e PGL.

\begin{tabular}{|c|c|c|c|c|c|c|c|c|c|c|c|c|c|c|c|c|c|c|c|c|c|c|c|c|}
\hline & Amostra & m. & $\begin{array}{c}\mathrm{Ce} \\
(\mathrm{ppm})\end{array}$ & $\begin{array}{c}\text { Dy } \\
(\mathrm{ppm})\end{array}$ & $\begin{array}{c}\mathrm{Er} \\
(\mathrm{ppm})\end{array}$ & $\begin{array}{c}\text { Eu } \\
(\mathrm{ppm})\end{array}$ & $\begin{array}{c}\text { Gd } \\
(\text { ppm) }\end{array}$ & $\begin{array}{c}\text { Ho } \\
(\mathrm{ppm})\end{array}$ & $\begin{array}{c}\text { La } \\
(\mathrm{ppm})\end{array}$ & $\begin{array}{c}\text { Lu } \\
\text { (ppm) }\end{array}$ & $\begin{array}{c}\begin{array}{c}\mathbf{N d} \\
(\mathrm{ppm})\end{array} \\
\end{array}$ & $\begin{array}{c}\mathrm{Pr} \\
(\mathbf{p p m})\end{array}$ & $\begin{array}{c}\text { Sc } \\
(\mathbf{p p m})\end{array}$ & $\begin{array}{c}\text { Sm } \\
(\text { ppm) }\end{array}$ & $\begin{array}{c}\text { Tb } \\
(\mathrm{ppm})\end{array}$ & $\begin{array}{c}\text { Th } \\
\text { (ppm) }\end{array}$ & 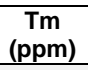 & $\begin{array}{c}\mathbf{Y} \\
(\mathbf{p p m})\end{array}$ & $\begin{array}{c}\mathrm{Yb} \\
(\mathrm{ppm})\end{array}$ & EETR & $\begin{array}{c}\mathrm{Zr} \\
(\mathrm{ppm})\end{array}$ & $\mathrm{Y} / \mathrm{Ho}$ & $\mathrm{Ce} / \mathrm{Ce}^{*}$ & $\mathrm{Pr} / \mathrm{Pr}^{*}$ \\
\hline \multirow{4}{*}{ 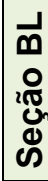 } & 11-BL-03 & 2,0 & 8,4 & 0,68 & 0,46 & 0,23 & 1,04 & 0,15 & 4,4 & 0,08 & 5,7 & 1,23 & $<1$ & 1,3 & 0,17 & 0,7 & 0,08 & 5,9 & 0,34 & 30,16 & 9,1 & 39,3 & 0,91 & 1,02 \\
\hline & 11-BL-07 & 5,9 & 0,7 & 0,21 & 0,13 & 0,07 & 0,19 & 0,04 & 0,5 & 0,04 & 0,7 & 0,12 & $<1$ & 0,15 & 0,05 & $<0,2$ & 0,04 & 1,3 & 0,12 & 4,36 & 1,8 & 32,5 & 0,98 & 0,92 \\
\hline & 11-BL-10 & 9,0 & 1,4 & 0,12 & 0,09 & 0,07 & 0,27 & 0,07 & 0,8 & 0,05 & 1 & 0,2 & $<1$ & 0,14 & 0,06 & $<0,2$ & 0,04 & 2 & 0,15 & 6,46 & 2,1 & 28,6 & 1,01 & 0,96 \\
\hline & 11-BL-14 & 12,4 & 3,7 & 0,33 & 0,23 & 0,15 & 0,57 & 0,12 & 2,6 & 0,07 & 3 & 0,62 & $<1$ & 0,45 & 0,1 & 0,3 & 0,05 & 3,2 & 0,13 & 15,32 & 3,2 & 26,7 & 0,83 & 1,04 \\
\hline \multirow{11}{*}{ 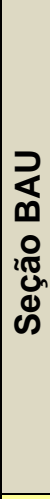 } & 11-BAU-06 & 5,0 & 2,4 & 0,41 & 0,21 & 0,07 & 0,36 & 0,07 & 1,1 & 0,03 & 1 & 0,29 & $<1$ & 0,31 & 0,07 & $<0,2$ & 0,05 & 3,2 & 0,19 & 9,76 & 2,8 & 45,7 & 0,82 & 1,10 \\
\hline & 11-BAU-09 & 7,8 & 1,3 & 0,17 & 0,1 & 0,06 & 0,24 & 0,03 & 0,8 & 0,03 & 0,4 & 0,16 & $<1$ & 0,13 & 0,04 & $<0,2$ & 0,02 & 1,5 & 0,06 & 5,04 & 3,8 & 50,0 & 0,59 & 1,29 \\
\hline & 11-BAU-12 & 13,3 & 1,3 & 0,17 & 0,12 & 0,02 & 0,2 & 0,05 & 0,7 & 0,03 & 0,6 & 0,15 & $<1$ & 0,15 & 0,04 & 0,3 & 0,03 & 1,7 & $<0,05$ & 5,26 & 1,7 & 34,0 & 1,00 & 1,00 \\
\hline & 11-BAU-15 & 16,4 & 0,7 & 0,14 & 0,13 & 0,04 & 0,25 & 0,03 & 0,4 & 0,02 & 0,6 & 0,09 & $<1$ & 0,12 & 0,04 & $<0,2$ & 0,02 & 1,5 & 0,09 & 4,17 & 0,9 & 50,0 & 1,50 & 0,77 \\
\hline & 11-BAU-18 & 19,5 & 1,2 & 0,16 & 0,17 & 0,05 & 0,21 & 0,05 & 0,8 & 0,03 & 0,4 & 0,14 & $<1$ & 0,1 & 0,04 & $<0,2$ & 0,01 & 2 & 0,11 & 5,47 & 0,4 & 40,0 & 0,71 & 1,18 \\
\hline & 11-BAU-29 & 30,2 & 4,5 & 0,12 & 0,18 & 0,09 & 0,29 & 0,05 & 3,1 & 0,04 & 1,9 & 0,41 & $<1$ & 0,15 & 0,06 & 0,4 & 0,03 & 2 & 0,09 & 13,01 & 21 & 40,0 & 1,47 & 0,82 \\
\hline & 11-BAU-37 & 38,1 & 2,1 & 0,29 & 0,13 & 0,07 & 0,32 & 0,05 & 1,2 & 0,02 & 1,4 & 0,28 & $<1$ & 0,19 & 0,05 & 0,3 & 0,03 & 2,5 & 0,15 & 8,78 & 4,1 & 50,0 & 1,08 & 0,94 \\
\hline & 11-BAU-41 & 42,1 & 1 & 0,18 & 0,1 & 0,05 & 0,23 & 0,03 & 0,4 & 0,02 & 0,8 & 0,1 & $<1$ & 0,08 & 0,03 & $<0,2$ & $<0,01$ & 1,5 & 0,09 & 4,61 & 0,5 & 50,0 & 2,31 & 0,63 \\
\hline & 11-BAU-49 & 50,1 & 2,4 & 0,31 & 0,23 & 0,06 & 0,51 & 0,09 & 0,9 & 0,03 & 1,6 & 0,26 & $<1$ & 0,31 & 0,06 & $<0,2$ & 0,02 & 2,8 & $<0,05$ & 9,58 & 1,4 & 31,1 & 1,64 & 0,76 \\
\hline & 11-BAU-54 & 55,0 & 0,4 & 0,14 & 0,08 & $<0,02$ & 0,15 & $<0,02$ & 0,4 & 0,02 & $<0,3$ & 0,05 & $<1$ & 0,05 & 0,02 & $<0,2$ & $<0,01$ & 1,2 & 0,07 & 2,58 & 0,2 & - & - & 2,25 \\
\hline & 11-BAU-57 & 58,3 & 0,8 & 0,18 & 0,13 & 0,03 & 0,14 & $<0,02$ & 0,4 & $<0,01$ & $<0,3$ & 0,11 & $<1$ & 0,13 & 0,03 & $<0,2$ & 0,02 & 1,6 & 0,09 & 3,66 & 0,3 & - & - & 2,48 \\
\hline \multirow{11}{*}{ 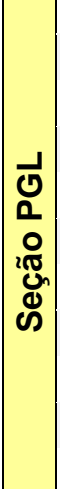 } & 11-PGL-03 & 2,0 & 0,9 & 0,14 & 0,12 & 0,07 & 0,23 & 0,05 & 0,7 & 0,05 & 0,4 & 0,14 & $<1$ & 0,15 & 0,05 & $<0,2$ & 0,03 & 1,8 & 0,15 & 4,98 & 1,8 & 36,0 & 0,53 & 1,37 \\
\hline & 11-PGL-05 & 4,0 & 3,4 & 0,37 & 0,17 & 0,13 & 0,53 & 0,08 & 1,9 & 0,04 & 2,6 & 0,52 & $<1$ & 0,58 & 0,08 & 0,3 & 0,04 & 2,3 & 0,15 & 12,89 & 3,3 & 28,8 & 0,94 & 0,99 \\
\hline & 11-PGL-11 & 10,4 & 2,3 & 0,35 & 0,18 & 0,11 & 0,39 & 0,07 & 1,7 & 0,04 & 1,7 & 0,39 & $<1$ & 0,4 & 0,07 & 0,2 & 0,04 & 2,4 & 0,15 & 10,29 & 2,3 & 34,3 & 0,74 & 1,12 \\
\hline & 11-PGL-13 & 12,9 & 2,4 & 0,18 & 0,18 & 0,09 & 0,37 & 0,08 & 1,4 & 0,04 & 1,5 & 0,33 & $<1$ & 0,33 & 0,06 & 0,4 & 0,04 & 2,3 & 0,06 & 9,36 & 2,8 & 28,8 & 0,96 & 1,00 \\
\hline & 11-PGL-18 & 17,9 & 4,5 & 0,39 & 0,24 & 0,17 & 0,74 & 0,14 & 2,7 & 0,04 & 3,9 & 0,76 & $<1$ & 0,62 & 0,11 & 0,3 & 0,05 & 3,8 & 0,17 & 18,33 & 3,9 & 27,1 & 0,88 & 1,00 \\
\hline & 11-PGL-23 & 23,2 & 5,2 & 0,39 & 0,3 & 0,16 & 0,66 & 0,13 & 3,1 & 0,05 & 3,6 & 0,79 & $<1$ & 0,84 & 0,11 & 0,5 & 0,04 & 3,5 & 0,14 & 19,01 & 6,9 & 26,9 & 0,87 & 1,04 \\
\hline & 11-PGL-27 & 27,6 & 0,7 & 0,09 & 0,07 & 0,03 & 0,14 & 0,04 & 0,4 & 0,03 & 0,6 & 0,08 & $<1$ & 0,08 & 0,03 & $<0,2$ & 0,02 & 1 & 0,12 & 3,43 & 1 & 25,0 & 1,90 & 0,68 \\
\hline & 11-PGL-33 & 33,6 & 9,7 & 0,66 & 0,49 & 0,18 & 0,74 & 0,15 & 5 & 0,07 & 4,1 & 1,12 & 2 & 0,78 & 0,15 & 1,7 & 0,06 & 4,4 & 0,3 & 27,9 & 21,6 & 29,3 & 0,92 & 1,04 \\
\hline & 11-PGL-35 & 35,6 & 2 & 0,22 & 0,14 & 0,1 & 0,38 & 0,08 & 1 & 0,04 & 1 & 0,27 & $<1$ & 0,36 & 0,06 & $<0,2$ & 0,03 & 2,4 & 0,13 & 8,21 & 1,4 & 30,0 & 0,79 & 1,12 \\
\hline & 11-PGL-41 & 42,0 & 2,1 & 0,21 & 0,12 & 0,06 & 0,37 & 0,05 & 1 & 0,03 & 1,1 & 0,25 & $<1$ & 0,29 & 0,05 & 0,2 & 0,03 & 1,7 & 0,1 & 7,46 & 2,9 & 34,0 & 1,07 & 0,96 \\
\hline & 11-PGL-43 & 44,1 & 4,2 & 0,47 & 0,22 & 0,1 & 0,41 & 0,07 & 1,9 & 0,04 & 1,8 & 0,43 & $<1$ & 0,49 & 0,07 & 0,5 & 0,04 & 3,2 & 0,21 & 13,65 & 6,7 & 45,7 & 1,18 & 0,92 \\
\hline
\end{tabular}


Seção BL
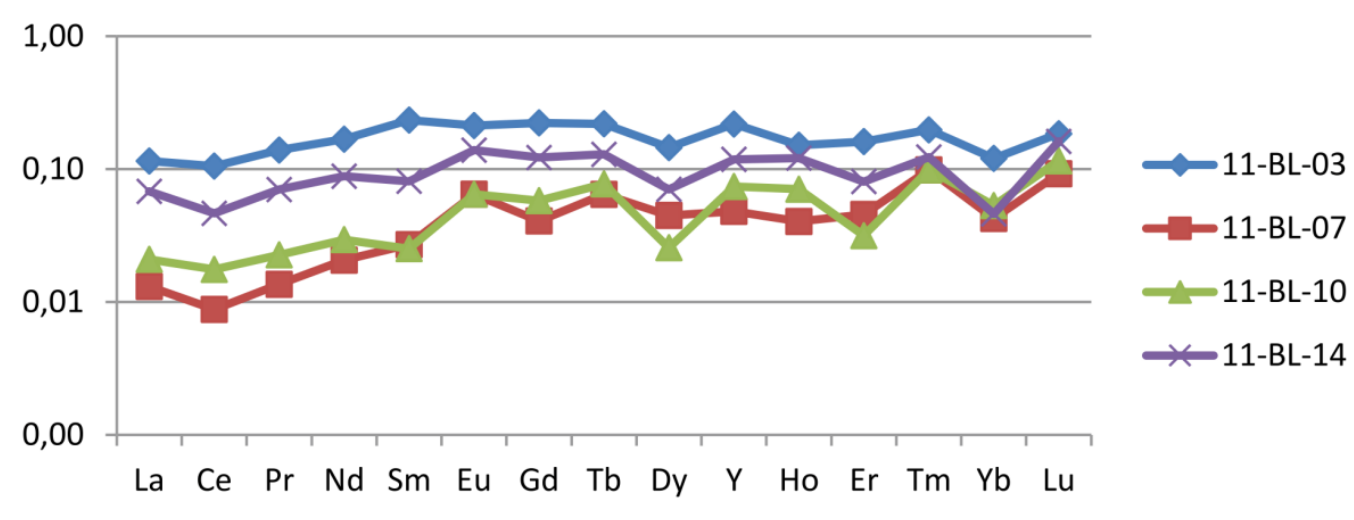

$-11-B L-07$

$-11-\mathrm{BL}-10$

$\leftarrow 11-\mathrm{BL}-14$

Seção BAU
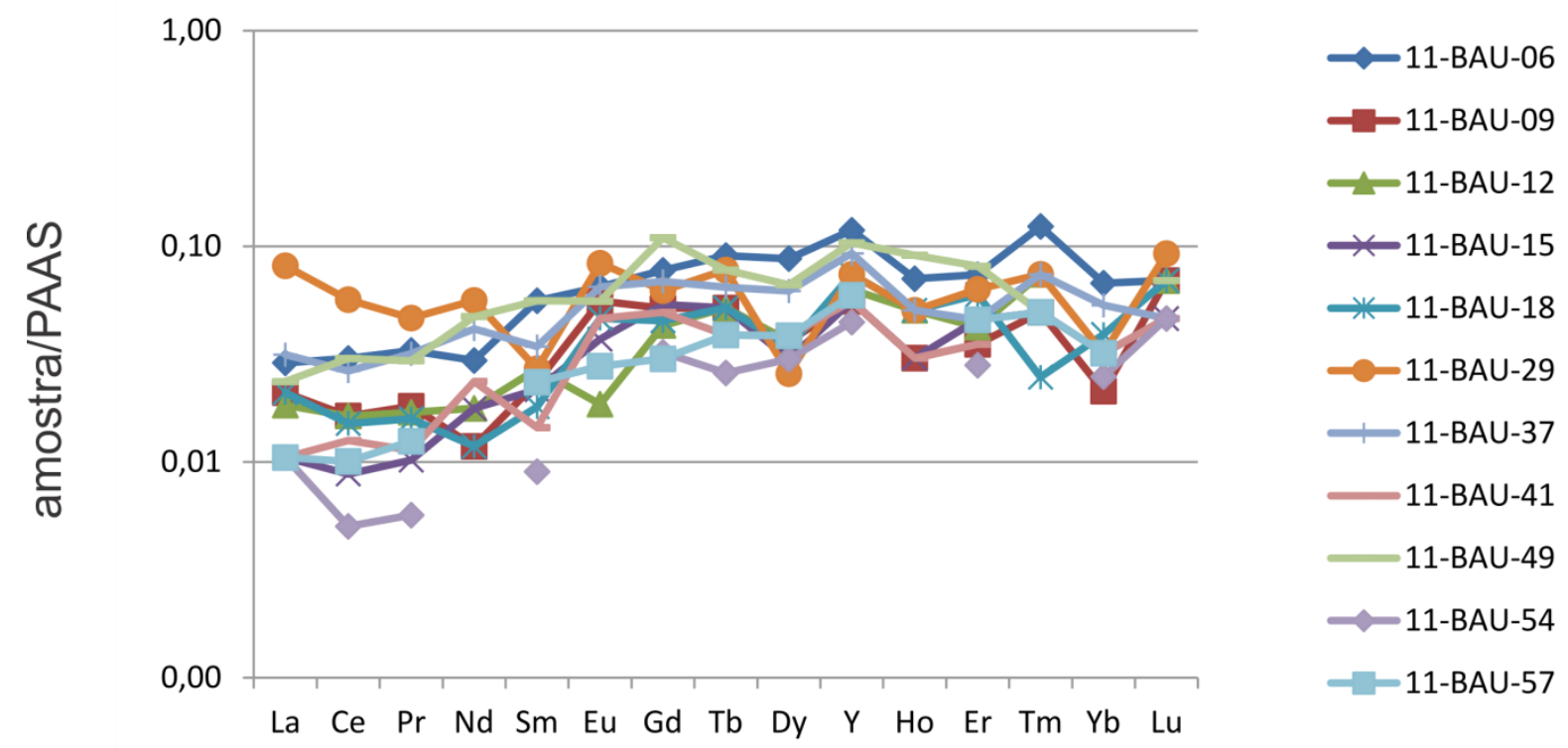

Seção PGL

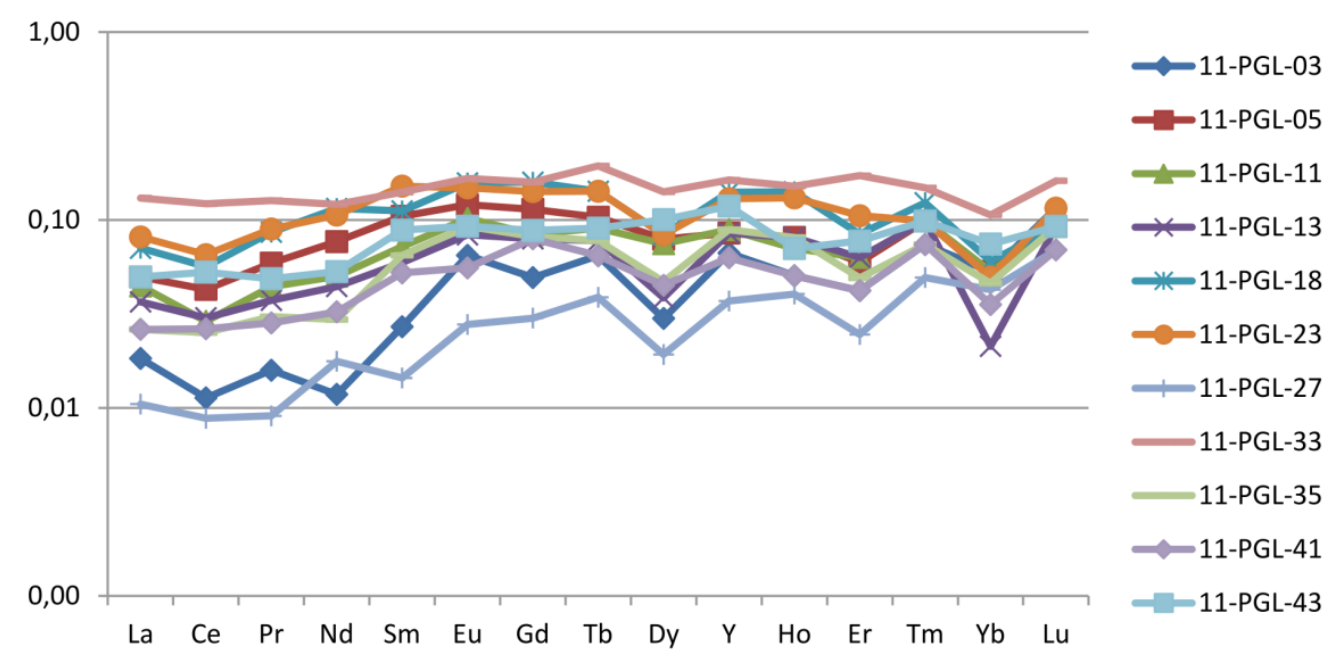

Fig. 20 - Distribuição normalizada de ETR em relação ao padrão PAAS obtidos em carbonatos da Formação Sete Lagoas das seções Bairro da Lapinha (BL), Pedra do Baú (BAU) e Parque da Gruta da Lapinha (PGL). 


\subsection{Isótopos de $\mathrm{C}, \mathrm{O}$ e $\mathrm{Sr}$}

Os dados isotópicos de $\mathrm{C}, \mathrm{O}$ e $\mathrm{Sr}$ são apresentados na Tabela 2 juntamente com as razões geoquímicas necessárias para análise da qualidade destes resultados. Com os valores de $\delta^{13} \mathrm{C}$ e $\delta^{18} \mathrm{O}$ foi elaborado um diagrama de dispersão (Fig. 21), no qual novamente se observa a mesma divisão da seções em dois grupos obtida com os dados de $\mathrm{Rb}$ e $\mathrm{Sr}$ (Fig. 19). O grupo 1, composto pelas seções AP e VS, tende a possuir composições isotópicas de C e O mais leves. O grupo 2, composto pelas seções BL, BAU e PGL, apresenta composições isotópicas mais pesadas.

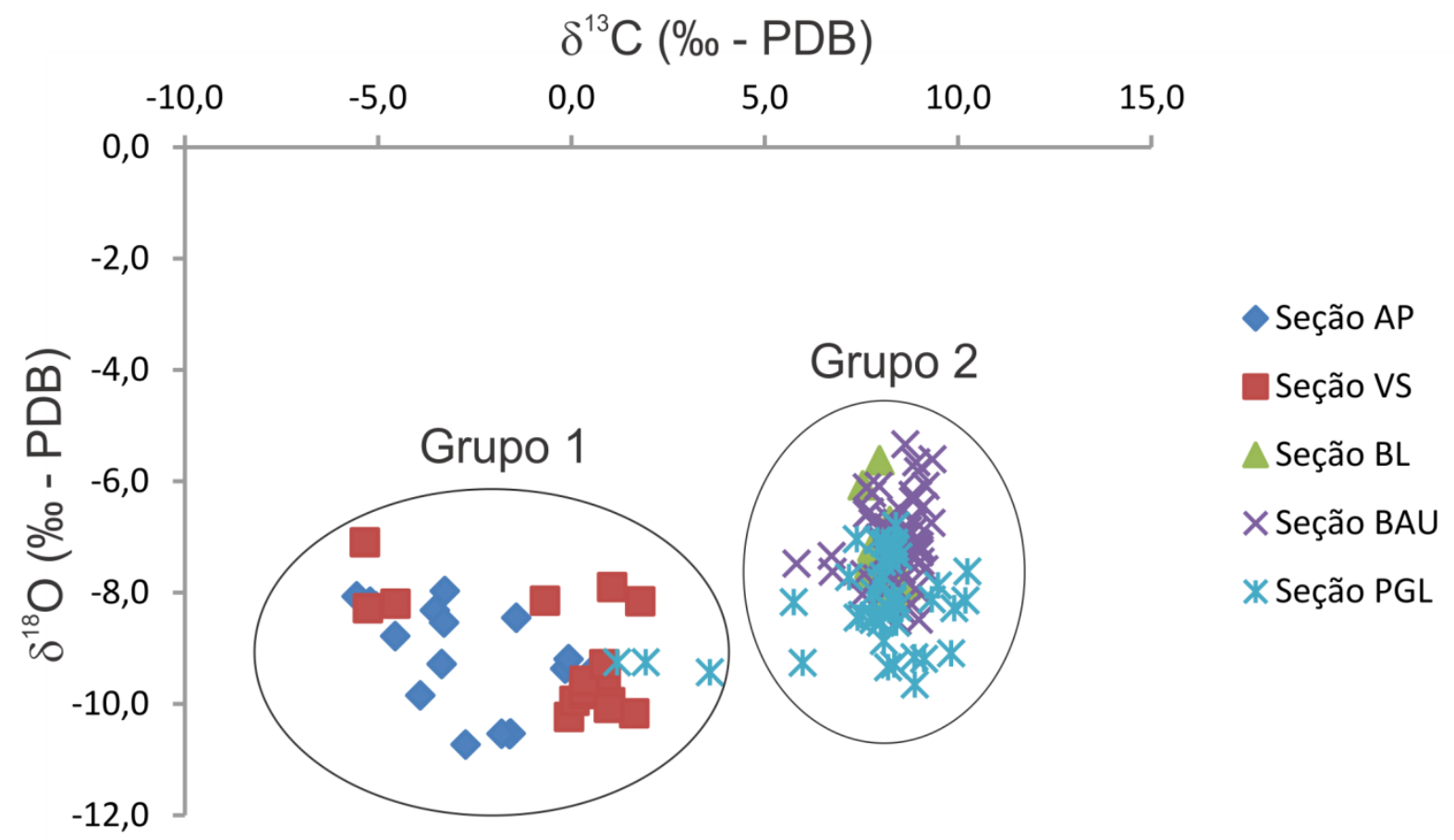

Fig. 21 - Gráfico de dispersão dos valores de $\delta^{13} \mathrm{C}$ e $\delta^{18} \mathrm{O}$, exibindo a distinção entre os carbonatos dos grupos 1 e 2. As amostras de calcário com lâminas de dolomita da seção PGL estão dentro da elipse do grupo 2, o que sugere alteração pós-deposicional.

\subsubsection{Seção Ana Paula}

Os valores de $\delta^{13} \mathrm{C}$ obtidos para a seção AP variam entre -5,6 e 0,5\%o (Tabela 2). Estes valores não apresentam qualquer padrão coerente da base para o topo e exibem uma grande variação ao longo da coluna estratigráfica (Fig. 9). As amostras de calcário com lâminas dolomíticas 11-AP-01 e 02, encontradas na base da seção apresentam certa coerência com valores constantes em -1,6\% . Algo semelhante é encontrado nas amostras de dolomitos do topo, 11-AP-19 a 21, para as quais foram obtidos valores de $\delta^{13} \mathrm{C}$ entre $-0,2$ e $0,5 \%$. As 
demais amostras apresentam valores completamente discrepantes quando comparadas àquelas imediatamente adjacentes.

A seção apresenta valores de $\delta^{18} \mathrm{O}$ entre $-10,7$ e $-8 \%$ que também variam bastante da base para o topo, ainda que de forma menos heterogênea que os isótopos de C. Novamente as amostras de calcários com lâminas dolomíticas da base e os dolomitos do topo apresentaram maior homogeneidade: os primeiros apresentam valores isotópicos de $\mathrm{O}$ iguais a $-10,5 \%$; os segundos, valores que variam entre $-9,4$ e $-9,2 \%$. As análises do diagrama $\delta^{18} \mathrm{O} v s . \delta^{13} \mathrm{C}$ (Fig. 21) e da coluna isotópica (Fig. 9) mostram que os isótopos de $\mathrm{C}$ e $\mathrm{O}$ variam de forma independente e sem correlação positiva.

A amostra 11-AP-14, com o maior teor de Sr da seção (533 ppm - Tabela 2), teve sua composição de isotópica de $\mathrm{Sr}$ determinada. A razão ${ }^{87} \mathrm{Sr} /{ }^{86} \mathrm{Sr}$ obtida foi $0,712122 \pm 0,000072$.

\subsubsection{Seção Vespasiano}

Os resultados isotópicos de C obtidos para a seção VS exibem diferentes padrões de acordo com o litotipo (Fig. 11). Os calcários encontrados nas porções de base e superior apresentam valores de $\delta^{13} \mathrm{C}$ que variam, da base para o topo, entre $-0,1$ e 1,6\%. Estes valores oscilam de forma coerente, sem grandes discrepâncias entre uma amostra e aquelas imediatamente adjacentes. Já os dolomitos da porção central possuem valores de $\delta^{13} \mathrm{C}$ entre 5,3 e 1,8\%o que apresentam ampla e incoerente oscilação, com altas discrepâncias entre amostras adjacentes.

Os isótopos de O também exibem diferenciação entre os litotipos. Os calcários das porções de base e superiores possuem composições isotópicas mais leves, com valores de $\delta^{18} \mathrm{O}$ entre $-10,2$ e $-9,3 \%$. Os dolomitos centrais apresentam composições isotópicas mais pesadas, com valores de $\delta^{18} \mathrm{O}$ entre $-8,3$ e $-7,1 \%$. Estas diferenças isotópicas também podem ser observadas no diagrama $\delta^{18} \mathrm{O} v s . \delta^{13} \mathrm{C}$ da Fig. 21.

As amostras 11-VS-01 e 16, com teores de Sr iguais a 531 e 397 ppm, respectivamente

(Tabela 2), tiveram suas composições isotópicas de $\mathrm{Sr}$ determinadas. As razões ${ }^{87} \mathrm{Sr} /{ }^{86} \mathrm{Sr}$ obtidas foram 0,709204 e 0,709840 , respectivamente.

\subsubsection{Seção Bairro da Lapinha}


Os valores de $\delta^{13} \mathrm{C}$ obtidos para a seção BL variam entre 7,5 e 8,6\%o (Tabela 2), com uma oscilação coerente e pouco discrepante quando se comparam amostras adjacentes (Figs. 13 e 21).

Já os valores de $\delta^{18} \mathrm{O}$ variam entre $-8,1$ e $-5,6 \%$. De maneira geral, estes valores também oscilam com coerência, à exceção das amostras 11-BL-01 e 10 que apresentam um pequeno desvio da curva isotópica de $\mathrm{O}$ obtida para a seção.

Foram selecionadas quatro amostras para análise isotópica de $\mathrm{Sr}$ com base em seus teores de Sr. Para as amostras 11-BL-03, 07 e 14 foram obtidas razões ${ }^{87} \mathrm{Sr} /{ }^{86} \mathrm{Sr}$ muito consistentes e dentro do intervalo 0,707547 e 0,707554. Dentre estas, o resultado ligeiramente menos radiogênico foi obtido na amostra 11-BL-03, que possui o maior teor de $\mathrm{Sr}$ da seção (3510 ppm). Para a amostra 11-BL-10 foi obtida a razão ${ }^{87} \mathrm{Sr} /{ }^{86} \mathrm{Sr}$ de 0,707122 , que destoa das demais por ser menos radiogênica. Curiosamente, esta é a mesma amostra que apresentou o menor valor de $\delta^{18} \mathrm{O}$ na seção, que também destoa das demais amostras, ainda que não haja qualquer desvio nos valores de $\delta^{13} \mathrm{C}$.

\subsubsection{Seção Pedra do Baú}

Para a seção BAU foram obtidos valores de $\delta^{13} \mathrm{C}$ entre 5,8 e 9,3\%o (Tabela 2), que apresentam oscilação coerente ao longo da seção (Figs. 15 e 21). A amostra 11-BAU-09 é a que apresenta o menor e mais discrepante valor, quando comparada às amostras adjacentes. Esta amostra apresenta lâminas submilimétricas compostas por dolomita.

Os valores de $\delta^{18} \mathrm{O}$ obtidos estão entre $-8,5$ e $-5,3 \%$ e variam coerentemente, ainda que de forma mais heterogênea que os isótopos de C.

Com base nos teores de $\mathrm{Sr}, 11$ amostras de carbonatos foram selecionadas para análises isotópicas de $\mathrm{Sr}$. As razões ${ }^{87} \mathrm{Sr} /{ }^{86} \mathrm{Sr}$ obtidas estão entre 0,707458 e 0,707934, sendo que a amostra com maior teor de $\mathrm{Sr}$ (11-BAU-06) apresentou razão igual 0,707618.

\subsubsection{Seção Parque da Gruta da Lapinha}

Os valores de $\delta^{13} \mathrm{C}$ obtidos para esta seção variam entre 1,2 e 10,2\%o (Tabela 2). Embora este intervalo seja bastante amplo, a análise de amostras adjacentes se mostra bastante coerente e os valores isotópicos de C são quase sempre superiores a 7\%o (Fig. 17). Exceção a esta coerência é feita para o trecho entre 32 e 36 m. Neste se encontram os mais baixos valores de $\delta^{13} \mathrm{C}$ que coincidem com o segmento composto por calcários com lâminas 
de dolomita acima da falha de empurrão e do boudin preenchido por calcita branca. A análise do diagrama de dispersão de $\delta^{18} \mathrm{O} v s . \delta^{13} \mathrm{C}$ (Fig. 21) mostra que as amostras deste trecho não se ajustam no campo do grupo 2, normal para esta seção. Estes argumentos sugerem uma alteração do registro isotópico de $\mathrm{C}$ e $\mathrm{O}$ para estes carbonatos por processos pósdeposicionais.

Os valores de $\delta^{18} \mathrm{O}$ variam entre -6,8 e -9,7\%o e de forma coerente, embora apresentem uma oscilação um pouco maior que os isótopos de C (Fig. 17). É curioso notar que no trecho composto por calcários com lâminas de dolomita, os isótopos de $\mathrm{O}$ não respondem de forma similar aos de C.

As razões ${ }^{87} \mathrm{Sr} /{ }^{86} \mathrm{Sr}$ obtidas para a seção PGL estão dentro do intervalo 0,70721 0,70859 , sendo que a amostra com maior teor de $\mathrm{Sr}$ apresentou razão ${ }^{87} \mathrm{Sr} /{ }^{86} \mathrm{Sr}$ igual a 0,70751 (Tabela 2). A razão mais radiogênica (amostra 11-PGL-35) foi obtida pouco acima do leito de calcários com valores de $\delta^{13} \mathrm{C}$ inferior a $2 \%$ e destoa completamente dos demais resultados isotópicos de Sr obtidos (Fig. 17).

\subsection{Dados geocronológicos}

Três amostras de marga foram selecionadas para análise de proveniência sedimentar baseada em dados geocronológicos $\mathrm{Sm}-\mathrm{Nd}$ em rocha total e $\mathrm{U}-\mathrm{Pb}$ em grãos de zircão detrítico, além da utilização do parâmetro isotópico $\varepsilon H f$ nos mesmos minerais. As amostras analisadas foram 11-AP-05, 11-VS-13 e 11-PGL-PEL, respectivamente das seções Ana Paula, Vespasiano e Parque da Gruta da Lapinha. As Tabelas 4, 5 e 6 exibem os resultados U-Pb, Sm-Nd e Hf, respectivamente.

Para grãos mais jovens que $800 \mathrm{Ma}$ foram consideradas as idades ${ }^{206} \mathrm{~Pb} /{ }^{238} \mathrm{U}$, enquanto que para os mais antigos, as idades ${ }^{207} \mathrm{~Pb} /{ }^{206} \mathrm{~Pb}$.

\subsubsection{Geocronologia U-Pb e Sm-Nd}

As Tabelas 4, 5 e 6 exibem os dados isotópicos de U-Pb obtidos em grãos de zircão detrítico e a Tabela 7, os dados isotópicos de $\mathrm{Sm}-\mathrm{Nd}$ obtidos em rocha total.

A amostra 11-AP-05 forneceu poucos grãos de zircão detrítico, de forma que apenas 13 foram analisados (Tabela 4). A petrografia sob lupa binocular permitiu observar grãos com características distintas: quatro grãos de granulometria silte médio apresentam cor amarelada e translúcida; nove grãos de fração areia muito fina apresentam coloração marrom e fosca. A análise de imagens de catodo luminescência (Fig. 22) revelou que a maioria dos grãos são 
prismáticos, com alguns poucos grãos de tendência ovoide. O grupo de zircões translúcidos apresenta metade dos grãos de zircão homogêneos escuros, um com zoneamento oscilatório e outro homogêneo claro. Já o de zircões foscos, dois grãos apresentam zoneamento oscilatório, ao passo que os demais, metade é homogêneo claro e metade é homogêneo escuro. As idades ${ }^{206} \mathrm{~Pb} /{ }^{238} \mathrm{U}$, com $100 \%$ de concordância, estão dentro do intervalo de 547-630 Ma, sendo que a maior concentração de idades está entre 620-560 Ma (77\% - Fig. 23). Curiosamente, apenas um grão apresentou idade ${ }^{206} \mathrm{~Pb} /{ }^{238} \mathrm{U}$ devoniana de 408 Ma que destoa do padrão, como mostra o diagrama concórdia de Tera \& Wasserburg (1972). A idade concórdia obtida para uma população representativa foi de 592,9 $\pm 1,7 \mathrm{Ma}$.

Da amostra da seção Vespasiano, 11-VS-13, 77 grãos de zircão detrítico foram analisados (Tabela 5). Sob a lupa binocular, observou-se que estes possuem granulometria predominantemente na fração silte $(<50 \mu \mathrm{m})$, com alguns grãos na fração areia muito fina (entre 63 e $80 \mu \mathrm{m}$ ), com coloração amarela esverdeada e translúcidos. As imagens de catodo luminescência (Fig. 24) exibem 30 grãos ovoides, 30 prismáticos, 16 fragmentos e um redondo. As principais populações de zircão possuem idades entre 950-1070 Ma ( 65\% dos grãos - Fig. 25 e Fig. 26). Outras populações importantes, mas de menor expressão, têm idades entre 870-930 Ma (6\% dos grãos), 1100 Ma (4\%) e entre 1200-1270 Ma (5\%). Um grão tem idade próxima a 1400 Ma e e outro próxima a 660 Ma. A população mais jovem é representada por dois grãos, um discordante com idade de 520 Ma e outro concordante de 537 Ma (Fig. 25). Ocorrem também grãos paleoproterozoicos e um grão arqueano concordante de 3,68 Ga.

A amostra 11-PGL-PEL forneceu 77 grãos de zircão detrítico para análise (Tabela 6). A descrição sob lupa binocular mostrou grãos com granulometria que varia de silte médio a areia muito fina (50 a $70 \mu \mathrm{m}$ ), com coloração amarela esverdeada e translúcidos. A análise de imagens de catodo luminescência (Fig. 27 e Fig. 28) revela que a grande maioria dos grãos são prismáticos e com zoneamento oscilatório ígneo. Os demais são ovoides com zoneamento oscilatório e apenas um redondo homogêneo escuro. As principais populações possuem idades entre 550 e $650 \mathrm{Ma}$ (89\% dos grãos), com destaque para aquela de $625 \mathrm{Ma}$ (63\%) (Fig. 29 e Fig. 30). Foram obtidos também dois grãos mais jovens: um de idade 543 Ma e outro de $506 \mathrm{Ma}$. Também foram analisados um zircão paleoproterozoico $(2,1 \mathrm{Ga})$ e um arqueano $(3,3$ $\mathrm{Ga})$.

As idades $\mathrm{T}_{\mathrm{DM}} \mathrm{Sm}-\mathrm{Nd}$ obtidas não necessariamente refletem as mesmas fontes sugeridas pelo método U-Pb. As amostras das seções VS e PGL têm idade $\mathrm{T}_{\mathrm{DM}}$ 1,8 Ga e $\varepsilon \mathrm{Nd}_{(0)}$ de $-13,1$ e $-13,6$ (Fig. 31), bastante semelhantes, embora a amostra do Parque da Gruta da Lapinha tenha predomínio de grãos de zircão criogenianos e ediacaranos e a amostra de 
Vespasiano, mesoproterozoicos e neoproterozoicos tonianos. A amostra da seção AP possui grãos de zircão com idades U-Pb similares às da principal população da amostra 11-PGLPEL, mas apresenta $\mathrm{T}_{\mathrm{DM}} 2,0 \mathrm{Ga}$ e $\varepsilon \mathrm{Nd}_{(0)}$-13. Os parâmetros $\varepsilon \mathrm{Nd}$ francamente negativos sugerem fontes com longa residência crustal para todas as amostras. 
Tabela 4 - Dados de LA-ICP-MS U/Pb dos grãos de zircão detríticos da amostra 11-AP-05.

\begin{tabular}{|c|c|c|c|c|c|c|c|c|c|c|c|c|}
\hline \multirow{2}{*}{ Amostra } & \multirow{2}{*}{ Spot } & \multicolumn{6}{|c|}{ Razões radiogênicas } & \multicolumn{4}{|c|}{ Idades (Ma) } & \multirow{2}{*}{$\begin{array}{c}\text { Conc. } \\
(\%)\end{array}$} \\
\hline & & ${ }^{207} \mathrm{~Pb} /{ }^{235} \mathrm{U}$ & $\pm \%$ & ${ }^{206} \mathrm{~Pb} /{ }^{238} \mathrm{U}$ & $\pm \%$ & ${ }^{207} \mathrm{~Pb} /{ }^{206} \mathrm{~Pb}$ & $\pm \%$ & ${ }^{206} \mathrm{~Pb} /{ }^{238} \mathrm{U}$ & \pm & ${ }^{207} \mathrm{~Pb} /{ }^{206} \mathrm{~Pb}$ & \pm & \\
\hline \multirow{13}{*}{$\begin{array}{l}20 \\
\vdots \\
\vdots \\
\vdots \\
=\end{array}$} & 1.1 & 0,8226 & 0,0133 & 0,1004 & 0,0009 & 0,0594 & 0,0005 & 617 & 5 & 575 & 18 & 107 \\
\hline & 2.1 & 0,8102 & 0,0131 & 0,0980 & 0,0009 & 0,0601 & 0,0005 & 603 & 5 & 602 & 18 & 100 \\
\hline & 3.1 & 0,7157 & 0,0148 & 0,0885 & 0,0009 & 0,0586 & 0,0009 & 547 & 5 & 544 & 33 & 100 \\
\hline & 4.1 & 0,7722 & 0,0123 & 0,0939 & 0,0009 & 0,0594 & 0,0005 & 578 & 5 & 576 & 18 & 100 \\
\hline & 5.1 & 0,7908 & 0,0124 & 0,0962 & 0,0009 & 0,0598 & 0,0005 & 592 & 5 & 590 & 18 & 100 \\
\hline & 6.1 & 0,8052 & 0,0127 & 0,0973 & 0,0009 & 0,0597 & 0,0005 & 599 & 5 & 585 & 17 & 102 \\
\hline & 7.1 & 0,7755 & 0,0122 & 0,0948 & 0,0009 & 0,0594 & 0,0005 & 584 & 5 & 576 & 17 & 101 \\
\hline & 8.1 & 0,8722 & 0,0151 & 0,1026 & 0,0011 & 0,0609 & 0,0005 & 630 & 6 & 631 & 18 & 100 \\
\hline & 9.1 & 0,5038 & 0,0101 & 0,0654 & 0,0008 & 0,0551 & 0,0006 & 408 & 5 & 410 & 22 & 100 \\
\hline & 10.1 & 0,7952 & 0,0125 & 0,0965 & 0,0009 & 0,0599 & 0,0005 & 594 & 5 & 593 & 18 & 100 \\
\hline & 11.1 & 0,8060 & 0,0126 & 0,0972 & 0,0009 & 0,0600 & 0,0005 & 598 & 5 & 596 & 18 & 100 \\
\hline & 12.1 & 0,8016 & 0,0124 & 0,0970 & 0,0009 & 0,0596 & 0,0005 & 597 & 5 & 582 & 17 & 102 \\
\hline & 13.1 & 0,7873 & 0,0121 & 0,0959 & 0,0009 & 0,0597 & 0,0005 & 591 & 5 & 588 & 17 & 100 \\
\hline
\end{tabular}

Nota: Erros são 1-sigma. 
Tabela 5 - Dados de LA-ICP-MS U/Pb dos grãos de zircão detríticos da amostra 11-VS-13.

\begin{tabular}{|c|c|c|c|c|c|c|c|c|c|c|c|c|}
\hline \multirow{2}{*}{ Amostra } & \multirow{2}{*}{ Spot } & \multicolumn{6}{|c|}{ Razões radiogênicas } & \multicolumn{4}{|c|}{ Idades (Ma) } & \multirow[b]{2}{*}{$\begin{array}{c}\text { Conc } \\
(\%)\end{array}$} \\
\hline & & ${ }^{207} \mathrm{~Pb} /{ }^{235} \mathrm{U}$ & $\pm \%$ & ${ }^{206} \mathrm{~Pb} /{ }^{238} \mathrm{U}$ & $\pm \%$ & ${ }^{207} \mathrm{~Pb} /{ }^{206} \mathrm{~Pb}$ & $\pm \%$ & ${ }^{206} \mathrm{~Pb} /{ }^{238} \mathrm{U}$ & \pm & ${ }^{207} \mathrm{~Pb} /{ }^{206} \mathrm{~Pb}$ & \pm & \\
\hline \multirow{25}{*}{$\begin{array}{l}\frac{m}{2} \\
\dot{n} \\
\vec{I}\end{array}$} & 1.1 & 0,9158 & 0,0230 & 0,1075 & 0,0009 & 0,0618 & 0,0014 & 658 & 5 & 661 & 50 & 100 \\
\hline & 2.1 & 7,2441 & 0,1813 & 0,3881 & 0,0034 & 0,1355 & 0,0031 & 2114 & 16 & 2166 & 38 & 98 \\
\hline & 3.1 & 1,4485 & 0,0349 & 0,1462 & 0,0008 & 0,0715 & 0,0016 & 880 & 4 & 972 & 47 & 91 \\
\hline & 4.1 & 1,6741 & 0,0399 & 0,1615 & 0,0011 & 0,0744 & 0,0017 & 965 & 6 & 1054 & 46 & 92 \\
\hline & 5.1 & 1,9055 & 0,0437 & 0,1804 & 0,0005 & 0,0768 & 0,0017 & 1069 & 2 & 1119 & 45 & 96 \\
\hline & 6.1 & 1,5556 & 0,0358 & 0,1593 & 0,0004 & 0,0708 & 0,0016 & 953 & 2 & 951 & 46 & 100 \\
\hline & 7.1 & 1,7942 & 0,0410 & 0,1753 & 0,0006 & 0,0741 & 0,0016 & 1041 & 3 & 1046 & 45 & 100 \\
\hline & 8.1 & 1,6732 & 0,0391 & 0,1672 & 0,0009 & 0,0723 & 0,0016 & 996 & 5 & 994 & 46 & 100 \\
\hline & 9.1 & 1,4870 & 0,0474 & 0,1514 & 0,0034 & 0,0712 & 0,0016 & 909 & 19 & 961 & 46 & 95 \\
\hline & 10.1 & 2,2463 & 0,0556 & 0,2030 & 0,0027 & 0,0799 & 0,0019 & 1192 & 14 & 1197 & 47 & 100 \\
\hline & 11.1 & 5,1319 & 0,1158 & 0,3264 & 0,0010 & 0,1140 & 0,0025 & 1821 & 5 & 1866 & 38 & 98 \\
\hline & 12.1 & 1,7038 & 0,0400 & 0,1704 & 0,0009 & 0,0728 & 0,0016 & 1014 & 5 & 1009 & 45 & 100 \\
\hline & 13.1 & 0,7032 & 0,0177 & 0,0868 & 0,0007 & 0,0584 & 0,0013 & 537 & 4 & 539 & 48 & 100 \\
\hline & 14.1 & 1,8197 & 0,0257 & 0,1721 & 0,0009 & 0,0771 & 0,0009 & 1024 & 5 & 1127 & 23 & 91 \\
\hline & 15.1 & 1,6080 & 0,0322 & 0,1625 & 0,0021 & 0,0738 & 0,0008 & 970 & 12 & 1038 & 23 & 94 \\
\hline & 16.1 & 1,9409 & 0,0276 & 0,1823 & 0,0009 & 0,0776 & 0,0009 & 1079 & 5 & 1139 & 23 & 95 \\
\hline & 17.1 & 1,6138 & 0,0224 & 0,1600 & 0,0008 & 0,0729 & 0,0008 & 957 & 4 & 1012 & 23 & 95 \\
\hline & 18.1 & 1,8337 & 0,0272 & 0,1741 & 0,0011 & 0,0787 & 0,0009 & 1034 & 6 & 1168 & 22 & 89 \\
\hline & 19.1 & 0,6741 & 0,0114 & 0,0839 & 0,0007 & 0,0589 & 0,0008 & 520 & 4 & 555 & 28 & 94 \\
\hline & 20.1 & 1,0519 & 0,0178 & 0,1079 & 0,0009 & 0,0705 & 0,0010 & 661 & 5 & 941 & 30 & 70 \\
\hline & 21.1 & 3,1970 & 0,0695 & 0,2249 & 0,0029 & 0,1044 & 0,0013 & 1308 & 15 & 1709 & 23 & 77 \\
\hline & 22.1 & 1,8459 & 0,0266 & 0,1750 & 0,0009 & 0,0770 & 0,0009 & 1040 & 5 & 1123 & 23 & 93 \\
\hline & 23.1 & 1,6113 & 0,0219 & 0,1639 & 0,0008 & 0,0717 & 0,0008 & 978 & 4 & 978 & 23 & 100 \\
\hline & 24.1 & 39,4729 & 0,5579 & 0,7660 & 0,0047 & 0,3750 & 0,0041 & 3666 & 17 & 3684 & -24 & 100 \\
\hline & 25.1 & 1,6116 & 0,0234 & 0,1628 & 0,0012 & 0,0720 & 0,0008 & 972 & 6 & 984 & 23 & 99 \\
\hline
\end{tabular}


Tabela 5 - Continuação.

\begin{tabular}{|c|c|c|c|c|c|c|c|c|c|c|c|c|c|c|}
\hline & \multirow{2}{*}{ Amostra } & \multirow{2}{*}{ Spot } & \multicolumn{6}{|c|}{ Razões radiogênicas } & & \multicolumn{4}{|c|}{ Idades (Ma) } & \multirow[b]{2}{*}{$\begin{array}{c}\text { Conc } \\
(\%)\end{array}$} \\
\hline & & & ${ }^{207} \mathrm{~Pb} /{ }^{235} \mathrm{U}$ & $\pm \%$ & ${ }^{206} \mathrm{~Pb} /{ }^{238} \mathrm{U}$ & $\pm \%$ & ${ }^{207} \mathrm{~Pb} /{ }^{206} \mathrm{~Pb}$ & $\pm \%$ & & ${ }^{206} \mathrm{~Pb} /{ }^{238} \mathrm{U}$ & \pm & ${ }^{207} \mathrm{~Pb} /{ }^{206} \mathrm{~Pb}$ & \pm & \\
\hline \multirow{26}{*}{$\begin{array}{l}\frac{a}{0} \\
\frac{1}{2} \\
\frac{1}{\Rightarrow}\end{array}$} & 26.1 & 2,2944 & 0,0375 & 0,2087 & 0,0019 & 0,0806 & 0,0009 & & 1222 & 10 & 1217 & 22 & 100 & \\
\hline & 27.1 & 1,8358 & 0,0245 & 0,1797 & 0,0008 & 0,0743 & 0,0009 & & 1065 & 4 & 1050 & 24 & 101 & \\
\hline & 28.1 & 1,7669 & 0,0221 & 0,1722 & 0,0005 & 0,0749 & 0,0009 & & 1024 & 3 & 1068 & 23 & 96 & \\
\hline & 29.1 & 1,4913 & 0,0204 & 0,1530 & 0,0007 & 0,0711 & 0,0008 & & 917 & 4 & 960 & 24 & 96 & \\
\hline & 30.1 & 1,7854 & 0,0228 & 0,1730 & 0,0006 & 0,0752 & 0,0009 & & 1029 & 3 & 1077 & 23 & 96 & \\
\hline & 31.1 & 1,8670 & 0,0255 & 0,1796 & 0,0010 & 0,0747 & 0,0008 & & 1065 & 6 & 1063 & 23 & 100 & \\
\hline & 32.1 & 5,6852 & 0,0770 & 0,3272 & 0,0013 & 0,1275 & 0,0015 & & 1825 & 6 & 2061 & 20 & 89 & \\
\hline & 33.1 & 1,2975 & 0,0204 & 0,1447 & 0,0007 & 0,0680 & 0,0009 & & 871 & 4 & 867 & 29 & 100 & \\
\hline & 34.1 & 6,0474 & 0,0922 & 0,3554 & 0,0016 & 0,1238 & 0,0016 & & 1960 & 8 & 2010 & 22 & 98 & \\
\hline & 35.1 & 1,8763 & 0,0243 & 0,1789 & 0,0007 & 0,0764 & 0,0009 & & 1061 & 4 & 1109 & 23 & 96 & \\
\hline & 36.1 & 1,5961 & 0,0276 & 0,1549 & 0,0016 & 0,0757 & 0,0010 & & 928 & 9 & 1088 & 27 & 85 & \\
\hline & 37.1 & 1,4233 & 0,0205 & 0,1422 & 0,0011 & 0,0730 & 0,0008 & & 857 & 6 & 1014 & 23 & 85 & \\
\hline & 38.1 & 2,4796 & 0,0574 & 0,2151 & 0,0033 & 0,0833 & 0,0011 & & 1256 & 17 & 1282 & 25 & 98 & \\
\hline & 39.1 & 1,5384 & 0,0190 & 0,1559 & 0,0004 & 0,0717 & 0,0008 & & 934 & 2 & 978 & 23 & 96 & \\
\hline & 40.1 & 1,7398 & 0,0351 & 0,1700 & 0,0018 & 0,0742 & 0,0011 & & 1012 & 10 & 1048 & 31 & 97 & \\
\hline & 41.1 & 5,4235 & 0,1080 & 0,3238 & 0,0032 & 0,1210 & 0,0018 & & 1808 & 16 & 1970 & 26 & 92 & \\
\hline & 42.1 & 17,0444 & 0,3426 & 0,5761 & 0,0059 & 0,2147 & 0,0032 & & 2933 & 24 & 2947 & 24 & 100 & \\
\hline & 43.1 & 1,7682 & 0,0357 & 0,1759 & 0,0018 & 0,0730 & 0,0011 & & 1045 & 10 & 1014 & 31 & 103 & \\
\hline & 44.1 & 1,6174 & 0,0323 & 0,1615 & 0,0016 & 0,0728 & 0,0011 & & 965 & 9 & 1009 & 31 & 96 & \\
\hline & 45.1 & 1,8221 & 0,0405 & 0,1783 & 0,0025 & 0,0745 & 0,0011 & & 1057 & 14 & 1055 & 30 & 100 & \\
\hline & 45.2 & 1,8952 & 0,0379 & 0,1820 & 0,0019 & 0,0751 & 0,0011 & & 1078 & 10 & 1074 & 30 & 100 & \\
\hline & 46.1 & 1,6608 & 0,0328 & 0,1671 & 0,0017 & 0,0723 & 0,0011 & & 996 & 9 & 994 & 31 & 100 & \\
\hline & 47.1 & 2,0667 & 0,0425 & 0,1920 & 0,0020 & 0,0769 & 0,0012 & & 1132 & 11 & 1121 & 30 & 101 & \\
\hline & 48.1 & 1,5689 & 0,0350 & 0,1598 & 0,0020 & 0,0711 & 0,0012 & & 956 & 11 & 961 & 33 & 100 & \\
\hline & 49.1 & 12,0899 & 0,2518 & 0,4788 & 0,0055 & 0,2184 & 0,0037 & & 2522 & 24 & 2975 & 27 & 85 & \\
\hline & 50.1 & 1,5832 & 0,0315 & 0,1617 & 0,0016 & 0,0715 & 0,0011 & & 966 & 9 & 971 & 31 & 100 & \\
\hline
\end{tabular}


Tabela 5 - Continuação.

\begin{tabular}{|c|c|c|c|c|c|c|c|c|c|c|c|c|}
\hline \multirow{2}{*}{ Amostra } & \multirow{2}{*}{ Spot } & \multicolumn{6}{|c|}{ Razões radiogênicas } & \multicolumn{4}{|c|}{ Idades (Ma) } & \multirow{2}{*}{$\begin{array}{r}\text { Conc } \\
(\%)\end{array}$} \\
\hline & & ${ }^{207} \mathrm{~Pb} /{ }^{235} \mathrm{U}$ & $\pm \%$ & ${ }^{206} \mathrm{~Pb} /{ }^{238} \mathrm{U}$ & $\pm \%$ & ${ }^{207} \mathrm{~Pb} /{ }^{206} \mathrm{~Pb}$ & $\pm \%$ & ${ }^{206} \mathrm{~Pb} /{ }^{238} \mathrm{U}$ & \pm & ${ }^{207} \mathrm{~Pb} /{ }^{206} \mathrm{~Pb}$ & \pm & \\
\hline \multirow{27}{*}{$\begin{array}{l}\frac{m}{7} \\
\dot{n} \\
\frac{1}{\Rightarrow}\end{array}$} & 51.1 & 5,6617 & 0,1652 & 0,3341 & 0,0070 & 0,1301 & 0,0033 & 1858 & 34 & 2096 & 43 & 89 \\
\hline & 52.1 & 1,6224 & 0,0202 & 0,1632 & 0,0009 & 0,0727 & 0,0008 & 974 & 5 & 1006 & 21 & 97 \\
\hline & 53.1 & 1,6739 & 0,0194 & 0,1680 & 0,0007 & 0,0726 & 0,0008 & 1001 & 4 & 1002 & 24 & 100 \\
\hline & 54.1 & 6,5888 & 0,0675 & 0,3632 & 0,0014 & 0,1313 & 0,0013 & 1997 & 7 & 2112 & 17 & 95 \\
\hline & 55.1 & 1,5953 & 0,0158 & 0,1618 & 0,0007 & 0,0719 & 0,0007 & 967 & 4 & 982 & 21 & 99 \\
\hline & 56.1 & 14,1589 & 0,1592 & 0,5312 & 0,0031 & 0,1895 & 0,0019 & 2746 & 13 & 2741 & 16 & 100 \\
\hline & 57.1 & 1,6975 & 0,0242 & 0,1691 & 0,0010 & 0,0729 & 0,0010 & 1007 & 6 & 1011 & 28 & 100 \\
\hline & 58.1 & 1,9247 & 0,0197 & 0,1846 & 0,0006 & 0,0757 & 0,0008 & 1092 & 3 & 1088 & 21 & 100 \\
\hline & 59.1 & 1,9132 & 0,0207 & 0,1832 & 0,0010 & 0,0756 & 0,0007 & 1085 & 6 & 1085 & 20 & 100 \\
\hline & 60.1 & 2,5069 & 0,0245 & 0,2181 & 0,0007 & 0,0831 & 0,0008 & 1272 & 4 & 1276 & 19 & 100 \\
\hline & 61.1 & 1,6263 & 0,0204 & 0,1674 & 0,0012 & 0,0726 & 0,0008 & 998 & 7 & 1002 & 22 & 100 \\
\hline & 62.1 & 1,7911 & 0,0176 & 0,1760 & 0,0006 & 0,0742 & 0,0007 & 1045 & 3 & 1048 & 20 & 100 \\
\hline & 63.1 & 1,9283 & 0,0227 & 0,1801 & 0,0011 & 0,0786 & 0,0008 & 1068 & 6 & 1165 & 20 & 92 \\
\hline & 64.1 & 16,6729 & 0,1607 & 0,5847 & 0,0018 & 0,2079 & 0,0020 & 2968 & 8 & 2896 & 16 & 102 \\
\hline & 65.1 & 1,3332 & 0,0192 & 0,1366 & 0,0014 & 0,0725 & 0,0010 & 825 & 8 & 999 & 28 & 83 \\
\hline & 66.1 & 5,8024 & 0,1014 & 0,3541 & 0,0036 & 0,1199 & 0,0026 & 1954 & 17 & 1954 & 37 & 100 \\
\hline & 67.1 & 1,6945 & 0,0225 & 0,1670 & 0,0014 & 0,0735 & 0,0010 & 996 & 8 & 1027 & 28 & 97 \\
\hline & 68.1 & 9,9853 & 0,5283 & 0,4287 & 0,0095 & 0,1978 & 0,0040 & 2300 & 43 & 2813 & 33 & 82 \\
\hline & 69.1 & 1,3984 & 0,0210 & 0,1512 & 0,0010 & 0,0714 & 0,0010 & 908 & 6 & 969 & 29 & 94 \\
\hline & 70.1 & 1,9995 & 0,0235 & 0,1899 & 0,0010 & 0,0768 & 0,0011 & 1121 & 6 & 1119 & 28 & 100 \\
\hline & 71.1 & 1,9366 & 0,0221 & 0,1878 & 0,0010 & 0,0764 & 0,0011 & 1109 & 5 & 1107 & 28 & 100 \\
\hline & 72.1 & 1,5828 & 0,0188 & 0,1596 & 0,0010 & 0,0728 & 0,0010 & 955 & 6 & 1009 & 28 & 95 \\
\hline & 73.1 & 2,9443 & 0,0360 & 0,2414 & 0,0016 & 0,0892 & 0,0012 & 1394 & 9 & 1414 & 26 & 99 \\
\hline & 74.1 & 11,6930 & 0,1786 & 0,4774 & 0,0038 & 0,1824 & 0,0025 & 2516 & 17 & 2677 & 23 & 94 \\
\hline & 75.1 & 1,5571 & 0,0645 & 0,1645 & 0,0055 & 0,0720 & 0,0028 & 982 & 31 & 986 & 78 & 100 \\
\hline & 76.1 & 1,6355 & 0,0196 & 0,1653 & 0,0010 & 0,0722 & 0,0010 & 986 & 5 & 990 & 29 & 100 \\
\hline & 77.1 & 1,6089 & 0,0294 & 0,1617 & 0,0020 & 0,0723 & 0,0010 & 966,4 & 11,2 & 993,1 & 28,7 & 97 \\
\hline
\end{tabular}

Nota: Erros são 1-sigma. 
Tabela 6 - Dados de LA-ICP-MS U/Pb dos grãos de zircão detríticos da amostra 11-PGL-PEL.

\begin{tabular}{|c|c|c|c|c|c|c|c|c|c|c|c|c|}
\hline \multirow{2}{*}{ Amostra } & \multirow{2}{*}{ Spot } & \multicolumn{6}{|c|}{ Razões radiogênicas } & \multicolumn{4}{|c|}{ Idades (Ma) } & \multirow{2}{*}{$\begin{array}{c}\text { Conc. } \\
(\%)\end{array}$} \\
\hline & & ${ }^{207} \mathrm{~Pb} /{ }^{235} \mathrm{U}$ & $\pm \%$ & ${ }^{206} \mathrm{~Pb} /{ }^{238} \mathrm{U}$ & $\pm \%$ & ${ }^{207} \mathrm{~Pb} /{ }^{206} \mathrm{~Pb}$ & $\pm \%$ & ${ }^{206} \mathrm{~Pb} /{ }^{238} \mathrm{U}$ & \pm & ${ }^{207} \mathrm{~Pb} /{ }^{206} \mathrm{~Pb}$ & \pm & \\
\hline \multirow{26}{*}{$\begin{array}{l}\overrightarrow{1} \\
\frac{5}{4} \\
\frac{1}{5} \\
\frac{1}{9}\end{array}$} & GL 1.1 & 0,9548 & 0,0178 & 0,1115 & 0,0012 & 0,0623 & 0,0009 & 682 & 7 & 678 & 32 & 100 \\
\hline & GL 1.2 & 0,7094 & 0,0163 & 0,0880 & 0,0010 & 0,0593 & 0,0012 & 543 & 6 & 574 & 42 & 95 \\
\hline & GL 2.1 & 7,2757 & 0,1331 & 0,4063 & 0,0043 & 0,1294 & 0,0019 & 2087 & 25 & 2087 & 25 & 105 \\
\hline & GL 3.1 & 0,8165 & 0,0162 & 0,0983 & 0,0010 & 0,0603 & 0,0010 & 605 & 6 & 607 & 35 & 100 \\
\hline & GL 4.1 & 0,8708 & 0,0186 & 0,1037 & 0,0011 & 0,0610 & 0,0011 & 636 & 7 & 633 & 38 & 100 \\
\hline & GL 5.1 & 0,9000 & 0,0172 & 0,1059 & 0,0012 & 0,0614 & 0,0010 & 649 & 7 & 649 & 34 & 100 \\
\hline & GL 6.1 & 2,0435 & 0,0417 & 0,1308 & 0,0016 & 0,1139 & 0,0017 & 792 & 9 & 1864 & 27 & 43 \\
\hline & GL 7.1 & 0,8072 & 0,0149 & 0,0962 & 0,0010 & 0,0608 & 0,0009 & 592 & 6 & 626 & 32 & 95 \\
\hline & GL 8.1 & 0,8386 & 0,0159 & 0,1007 & 0,0010 & 0,0608 & 0,0010 & 618 & 6 & 626 & 34 & 99 \\
\hline & GL 9.1 & 0,8560 & 0,0159 & 0,1025 & 0,0010 & 0,0609 & 0,0009 & 629 & 6 & 630 & 33 & 100 \\
\hline & GL 10.1 & 0,8893 & 0,0185 & 0,1054 & 0,0011 & 0,0624 & 0,0011 & 646 & 6 & 683 & 38 & 95 \\
\hline & GL 11.1 & 0,8251 & 0,0193 & 0,0989 & 0,0011 & 0,0602 & 0,0013 & 608 & 7 & 606 & 45 & 100 \\
\hline & GL 12.1 & 0,8769 & 0,0170 & 0,1039 & 0,0012 & 0,0611 & 0,0009 & 637 & 7 & 637 & 33 & 100 \\
\hline & 1.1 & 0,8547 & 0,0115 & 0,1024 & 0,0009 & 0,0607 & 0,0005 & 629 & 5 & 621 & 17 & 101 \\
\hline & 2.1 & 0,8602 & 0,0117 & 0,1013 & 0,0009 & 0,0613 & 0,0005 & 622 & 5 & 644 & 17 & 97 \\
\hline & 3.1 & 0,7618 & 0,0107 & 0,0911 & 0,0008 & 0,0606 & 0,0005 & 562 & 5 & 619 & 19 & 91 \\
\hline & 4.1 & 0,8583 & 0,0114 & 0,1021 & 0,0009 & 0,0608 & 0,0005 & 627 & 5 & 624 & 17 & 100 \\
\hline & 5.1 & 0,8766 & 0,0115 & 0,1038 & 0,0009 & 0,0609 & 0,0005 & 637 & 5 & 629 & 17 & 101 \\
\hline & 6.1 & 0,8845 & 0,0121 & 0,1048 & 0,0009 & 0,0612 & 0,0005 & 642 & 5 & 641 & 17 & 100 \\
\hline & 7.1 & 0,8576 & 0,0118 & 0,1027 & 0,0009 & 0,0610 & 0,0005 & 630 & 5 & 633 & 19 & 100 \\
\hline & 8.1 & 21,6644 & 0,4656 & 0,5868 & 0,0065 & 0,2742 & 0,0041 & 3325 & 23 & 3325 & 23 & 90 \\
\hline & 9.1 & 0,8652 & 0,0118 & 0,1022 & 0,0010 & 0,0608 & 0,0005 & 627 & 6 & 625 & 17 & 100 \\
\hline & 10.1 & 0,7646 & 0,0108 & 0,0924 & 0,0008 & 0,0600 & 0,0006 & 570 & 5 & 596 & 20 & 96 \\
\hline & 11.1 & 0,6550 & 0,0131 & 0,0769 & 0,0011 & 0,0605 & 0,0005 & 478 & 7 & 616 & 19 & 78 \\
\hline & 12.1 & 0,8148 & 0,0109 & 0,0985 & 0,0009 & 0,0602 & 0,0005 & 606 & 5 & 605 & 18 & 100 \\
\hline & 13.1 & 0,7842 & 0,0117 & 0,0939 & 0,0009 & 0,0604 & 0,0005 & 578 & 5 & 611 & 19 & 95 \\
\hline
\end{tabular}


Tabela 6 - Continuação.

\begin{tabular}{|c|c|c|c|c|c|c|c|c|c|c|c|c|}
\hline \multirow{2}{*}{ Amostra } & \multirow{2}{*}{ Spot } & \multicolumn{6}{|c|}{ Razões radiogênicas } & \multicolumn{4}{|c|}{ Idades (Ma) } & \multirow{2}{*}{$\begin{array}{c}\text { Conc } \\
(\%)\end{array}$} \\
\hline & & ${ }^{207} \mathrm{~Pb} /{ }^{235} \mathrm{U}$ & $\pm \%$ & ${ }^{206} \mathrm{~Pb} /{ }^{238} \mathrm{U}$ & $\pm \%$ & ${ }^{207} \mathrm{~Pb} /{ }^{206} \mathrm{~Pb}$ & $\pm \%$ & ${ }^{206} \mathrm{~Pb} /{ }^{238} \mathrm{U}$ & \pm & ${ }^{207} \mathrm{~Pb} /{ }^{206} \mathrm{~Pb}$ & \pm & \\
\hline \multirow{26}{*}{$\begin{array}{l}\text { 空 } \\
\frac{1}{3} \\
\frac{1}{3} \\
\frac{1}{2}\end{array}$} & 14.1 & 0,8357 & 0,0114 & 0,1007 & 0,0008 & 0,0606 & 0,0003 & 618 & 5 & 619 & 12 & 100 \\
\hline & 15.1 & 0,8278 & 0,0113 & 0,0986 & 0,0009 & 0,0610 & 0,0004 & 606 & 5 & 633 & 13 & 96 \\
\hline & 16.1 & 0,7959 & 0,0111 & 0,0956 & 0,0008 & 0,0601 & 0,0004 & 588 & 5 & 602 & 14 & 98 \\
\hline & 17.1 & 0,9109 & 0,0129 & 0,1073 & 0,0010 & 0,0617 & 0,0004 & 657 & 6 & 657 & 13 & 100 \\
\hline & 18.1 & 0,8740 & 0,0116 & 0,1038 & 0,0008 & 0,0607 & 0,0003 & 637 & 5 & 622 & 11 & 102 \\
\hline & 19.1 & 0,9243 & 0,0144 & 0,1084 & 0,0012 & 0,0618 & 0,0004 & 663 & 7 & 661 & 15 & 100 \\
\hline & 20.1 & 0,8638 & 0,0114 & 0,1024 & 0,0008 & 0,0609 & 0,0003 & 628 & 5 & 629 & 12 & 100 \\
\hline & 21.1 & 0,8550 & 0,0109 & 0,1021 & 0,0008 & 0,0609 & 0,0003 & 627 & 5 & 629 & 11 & 100 \\
\hline & 22.1 & 0,7284 & 0,0102 & 0,0898 & 0,0008 & 0,0604 & 0,0004 & 554 & 5 & 612 & 13 & 91 \\
\hline & 23.1 & 0,5682 & 0,0126 & 0,0716 & 0,0012 & 0,0572 & 0,0004 & 446 & 7 & 495 & 17 & 90 \\
\hline & 24.1 & 0,8531 & 0,0111 & 0,1016 & 0,0008 & 0,0610 & 0,0003 & 624 & 5 & 632 & 12 & 99 \\
\hline & 25.1 & 0,7663 & 0,0106 & 0,0923 & 0,0008 & 0,0599 & 0,0004 & 569 & 5 & 594 & 14 & 96 \\
\hline & 26.1 & 0,8941 & 0,0118 & 0,1060 & 0,0009 & 0,0612 & 0,0003 & 649 & 5 & 640 & 11 & 101 \\
\hline & 27.1 & 0,8714 & 0,0096 & 0,1046 & 0,0005 & 0,0607 & 0,0006 & 641 & 3 & 621 & 21 & 103 \\
\hline & 28.1 & 0,7405 & 0,0120 & 0,0903 & 0,0009 & 0,0598 & 0,0006 & 557 & 6 & 589 & 22 & 95 \\
\hline & 29.1 & 0,8363 & 0,0095 & 0,0991 & 0,0005 & 0,0611 & 0,0006 & 609 & 3 & 636 & 21 & 96 \\
\hline & 30.1 & 0,8701 & 0,0104 & 0,1036 & 0,0006 & 0,0611 & 0,0006 & 635 & 4 & 638 & 20 & 100 \\
\hline & 31.1 & 0,7397 & 0,0095 & 0,0892 & 0,0005 & 0,0599 & 0,0006 & 551 & 3 & 592 & 23 & 93 \\
\hline & 32.1 & 0,8608 & 0,0096 & 0,1025 & 0,0005 & 0,0609 & 0,0006 & 629 & 3 & 629 & 20 & 100 \\
\hline & 33.1 & 0,8052 & 0,0091 & 0,0955 & 0,0005 & 0,0609 & 0,0006 & 588 & 3 & 628 & 21 & 94 \\
\hline & 34.1 & 0,8942 & 0,0106 & 0,1074 & 0,0007 & 0,0611 & 0,0006 & 658 & 4 & 636 & 21 & 103 \\
\hline & 35.1 & 0,8647 & 0,0094 & 0,1026 & 0,0005 & 0,0615 & 0,0006 & 630 & 3 & 649 & 20 & 97 \\
\hline & 36.1 & 0,7908 & 0,0095 & 0,0940 & 0,0006 & 0,0600 & 0,0006 & 579 & 3 & 597 & 21 & 97 \\
\hline & 37.1 & 0,8343 & 0,0100 & 0,1005 & 0,0005 & 0,0605 & 0,0006 & 617 & 3 & 617 & 21 & 100 \\
\hline & 38.1 & 0,8905 & 0,0095 & 0,1051 & 0,0005 & 0,0611 & 0,0006 & 644 & 3 & 635 & 20 & 101 \\
\hline & 39.1 & 0,8737 & 0,0103 & 0,1030 & 0,0006 & 0,0616 & 0,0006 & 632 & 4 & 653 & 20 & 97 \\
\hline
\end{tabular}


Tabela 6 - Continuação.

\begin{tabular}{|c|c|c|c|c|c|c|c|c|c|c|c|c|}
\hline \multirow{2}{*}{ Amostra } & \multirow{2}{*}{ Spot } & \multicolumn{6}{|c|}{ Razões radiogênicas } & \multicolumn{4}{|c|}{ Idades (Ma) } & \multirow{2}{*}{$\begin{array}{c}\text { Conc. } \\
(\%)\end{array}$} \\
\hline & & ${ }^{207} \mathrm{~Pb} /{ }^{235} \mathrm{U}$ & $\pm \%$ & ${ }^{206} \mathrm{~Pb} /{ }^{238} \mathrm{U}$ & $\pm \%$ & ${ }^{207} \mathrm{~Pb} /{ }^{206} \mathrm{~Pb}$ & $\pm \%$ & ${ }^{206} \mathrm{~Pb} /{ }^{238} \mathrm{U}$ & \pm & ${ }^{207} \mathrm{~Pb} /{ }^{206} \mathrm{~Pb}$ & \pm & \\
\hline \multirow{26}{*}{ 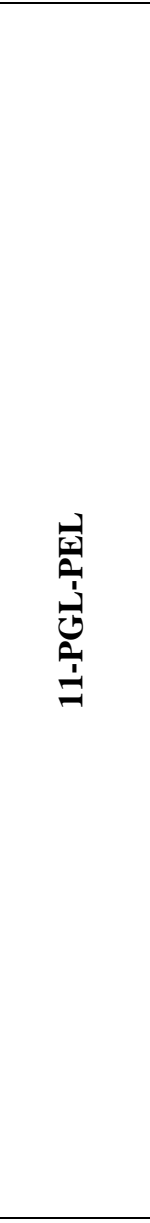 } & 40.1 & 0,7356 & 0,0123 & 0,0909 & 0,0009 & 0,0589 & 0,0009 & 561 & 6 & 559 & 33 & 100 \\
\hline & 41.1 & 0,8883 & 0,0104 & 0,1053 & 0,0008 & 0,0613 & 0,0007 & 645 & 5 & 643 & 26 & 100 \\
\hline & 42.1 & 0,7958 & 0,0094 & 0,0923 & 0,0007 & 0,0626 & 0,0007 & 569 & 4 & 689 & 26 & 83 \\
\hline & 43.1 & 0,9118 & 0,0123 & 0,1042 & 0,0009 & 0,0630 & 0,0008 & 639 & 5 & 704 & 27 & 91 \\
\hline & 44.1 & 0,8564 & 0,0112 & 0,1020 & 0,0010 & 0,0608 & 0,0008 & 626 & 6 & 627 & 27 & 100 \\
\hline & 45.1 & 0,7626 & 0,0120 & 0,0934 & 0,0010 & 0,0594 & 0,0008 & 575 & 6 & 576 & 28 & 100 \\
\hline & 46.1 & 0,8847 & 0,0113 & 0,1047 & 0,0010 & 0,0613 & 0,0007 & 642 & 6 & 643 & 26 & 100 \\
\hline & 47.1 & 0,6330 & 0,0153 & 0,0852 & 0,0013 & 0,0599 & 0,0017 & 527 & 8 & 595 & 61 & 89 \\
\hline & 48.1 & 0,7561 & 0,0113 & 0,0905 & 0,0009 & 0,0605 & 0,0008 & 559 & 5 & 615 & 29 & 91 \\
\hline & 49.1 & 0,8316 & 0,0115 & 0,1003 & 0,0009 & 0,0606 & 0,0009 & 616 & 5 & 618 & 30 & 100 \\
\hline & 50.1 & 0,8869 & 0,0109 & 0,1054 & 0,0009 & 0,0614 & 0,0007 & 646 & 5 & 646 & 26 & 100 \\
\hline & 51.1 & 0,8366 & 0,0100 & 0,0996 & 0,0008 & 0,0612 & 0,0007 & 612 & 5 & 640 & 26 & 96 \\
\hline & 52.1 & 4,6865 & 0,0707 & 0,2266 & 0,0025 & 0,1524 & 0,0018 & 1317 & 13 & 2368 & 21 & 56 \\
\hline & 53.1 & 0,7836 & 0,0057 & 0,0941 & 0,0003 & 0,0606 & 0,0004 & 580 & 2 & 619 & 13 & 94 \\
\hline & 54.1 & 0,8635 & 0,0044 & 0,1018 & 0,0002 & 0,0614 & 0,0003 & 625 & 1 & 647 & 10 & 97 \\
\hline & 55.1 & 0,8269 & 0,0072 & 0,0984 & 0,0006 & 0,0610 & 0,0003 & 605 & 4 & 632 & 12 & 96 \\
\hline & 56.1 & 0,8197 & 0,0048 & 0,0969 & 0,0003 & 0,0615 & 0,0003 & 596 & 2 & 651 & 10 & 92 \\
\hline & 57.1 & 0,8139 & 0,0048 & 0,0974 & 0,0002 & 0,0612 & 0,0004 & 599 & 1 & 639 & 12 & 94 \\
\hline & 58.1 & 0,8402 & 0,0052 & 0,1002 & 0,0003 & 0,0605 & 0,0003 & 616 & 1 & 616 & 12 & 100 \\
\hline & 59.1 & 0,8388 & 0,0046 & 0,0996 & 0,0003 & 0,0612 & 0,0003 & 612 & 2 & 640 & 11 & 96 \\
\hline & 60.1 & 0,8886 & 0,0091 & 0,1053 & 0,0004 & 0,0613 & 0,0006 & 645 & 3 & 646 & 19 & 100 \\
\hline & 61.1 & 0,7584 & 0,0048 & 0,0926 & 0,0003 & 0,0596 & 0,0004 & 571 & 2 & 582 & 13 & 98 \\
\hline & 62.1 & 0,6166 & 0,0102 & 0,0816 & 0,0008 & 0,0575 & 0,0006 & 506 & 4 & 504 & 22 & 100 \\
\hline & 63.1 & 0,8153 & 0,0063 & 0,0984 & 0,0005 & 0,0606 & 0,0003 & 605 & 3 & 620 & 12 & 98 \\
\hline & 64.1 & 0,8704 & 0,0047 & 0,1035 & 0,0003 & 0,0610 & 0,0003 & 635 & 2 & 633 & 11 & 100 \\
\hline & 65.1 & 0,8125 & 0,0051 & 0,0977 & 0,0003 & 0,0603 & 0,0004 & 601 & 2 & 610 & 14 & 99 \\
\hline
\end{tabular}

Nota: Erros são 1-sigma. 


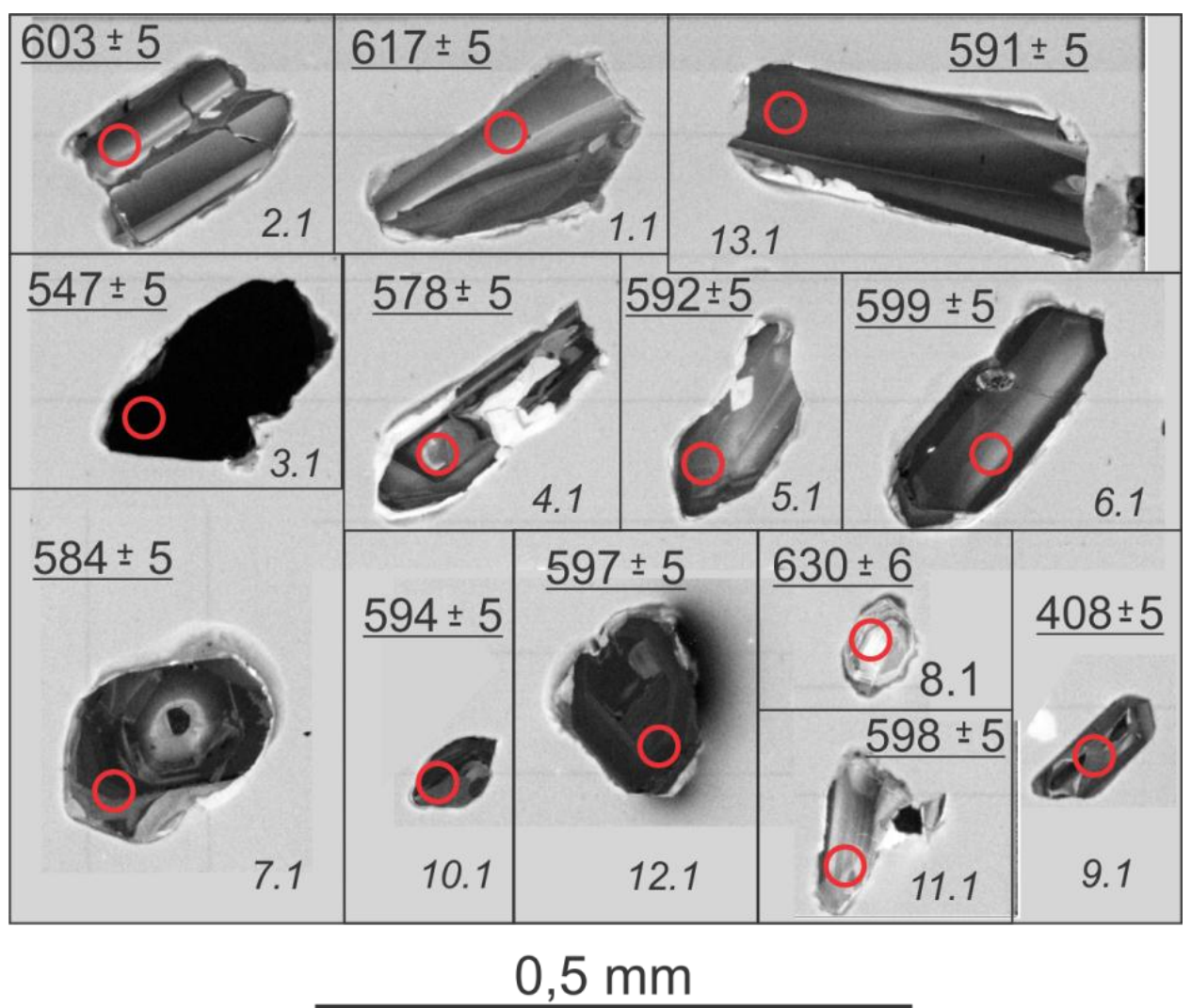

Fig. 22 - Imagens de catodoluminescência dos grãos de zircão detrítico obtidos da amostra 11-AP-05.

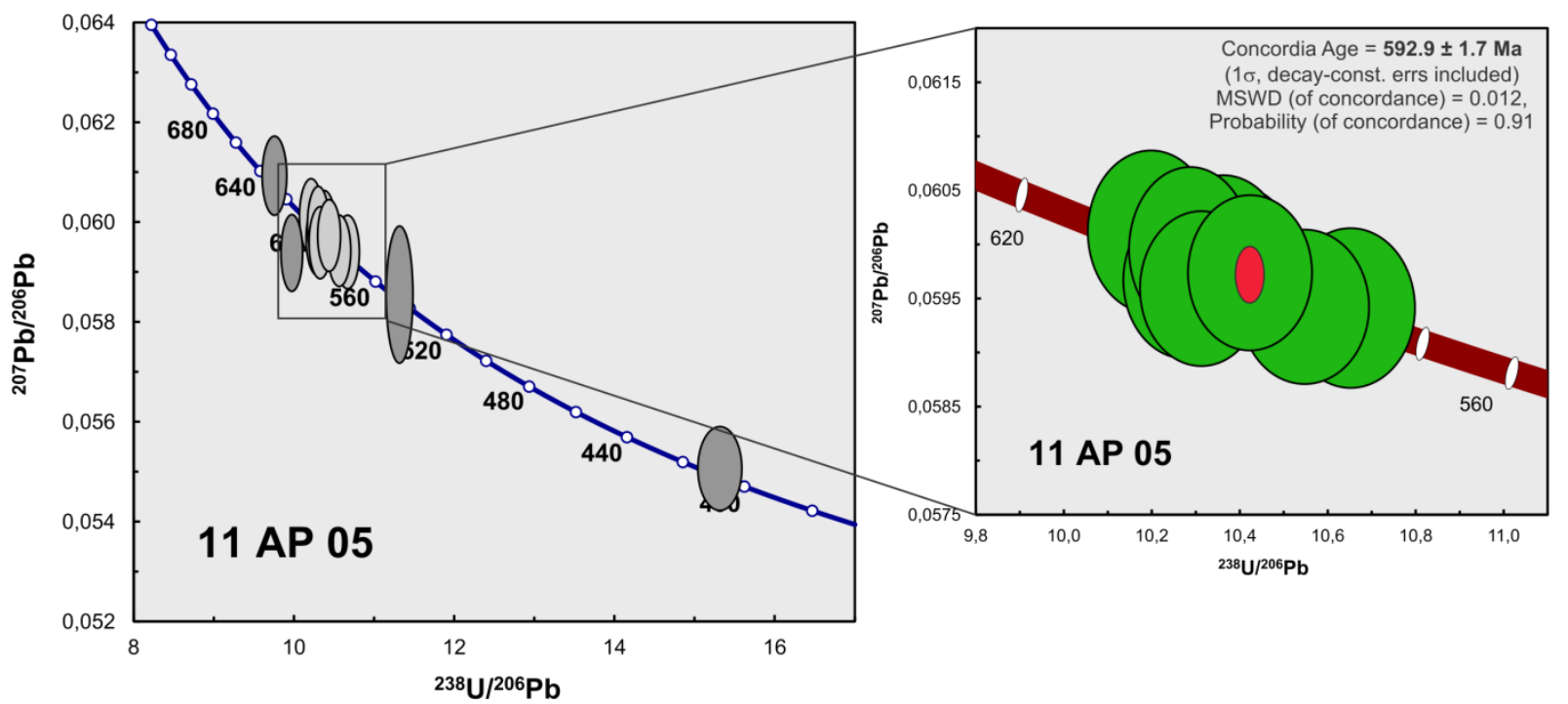

Fig. 23 - Diagrama Concórdia Tera \& Wasserburg (1972) para a amostra 11-AP-05, com detalhe para o intervalo entre 620-560 Ma, onde foi obtida a idade concórdia de 592,9 \pm 1,7 Ma. 


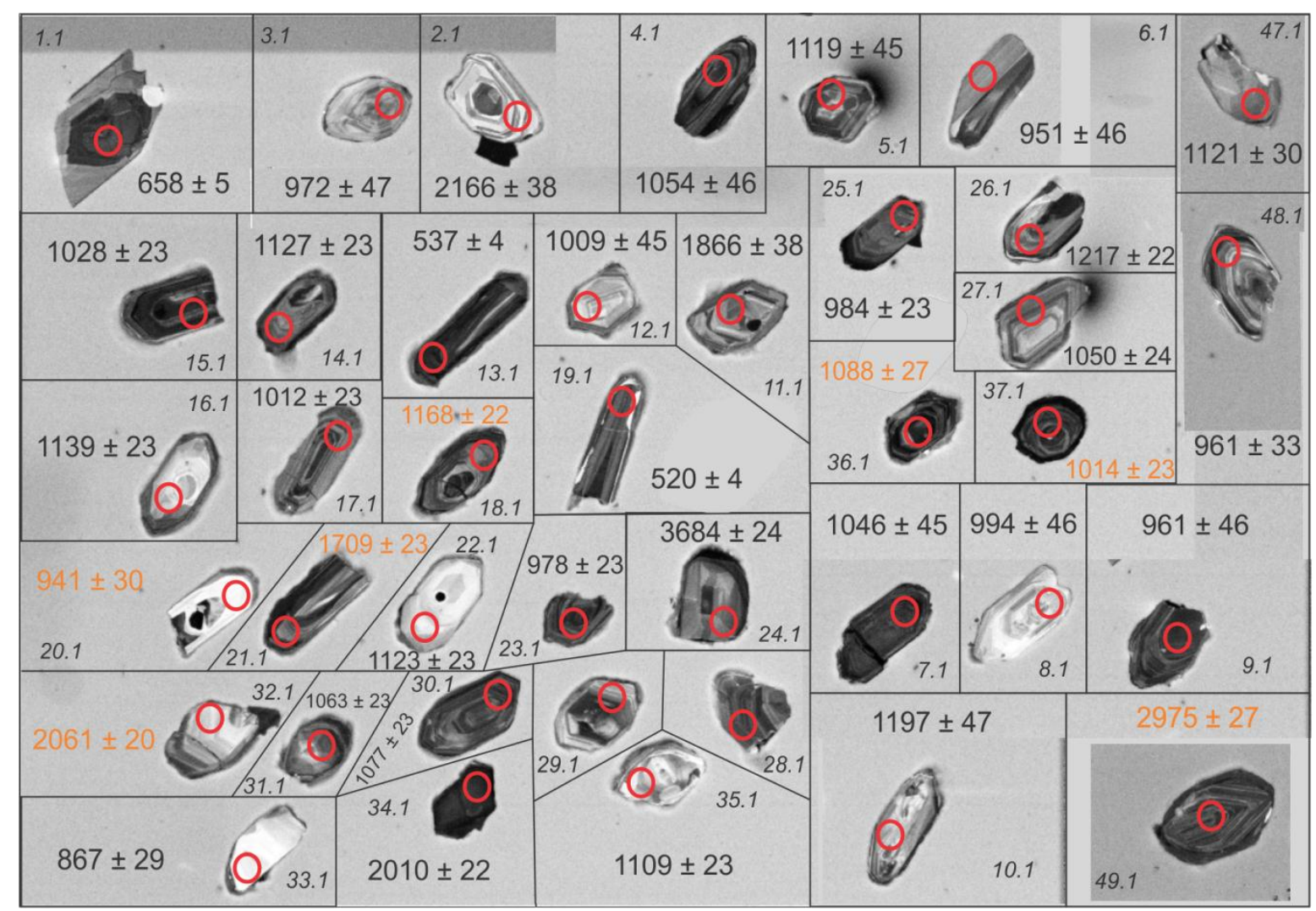

\section{$0,5 \mathrm{~mm}$}

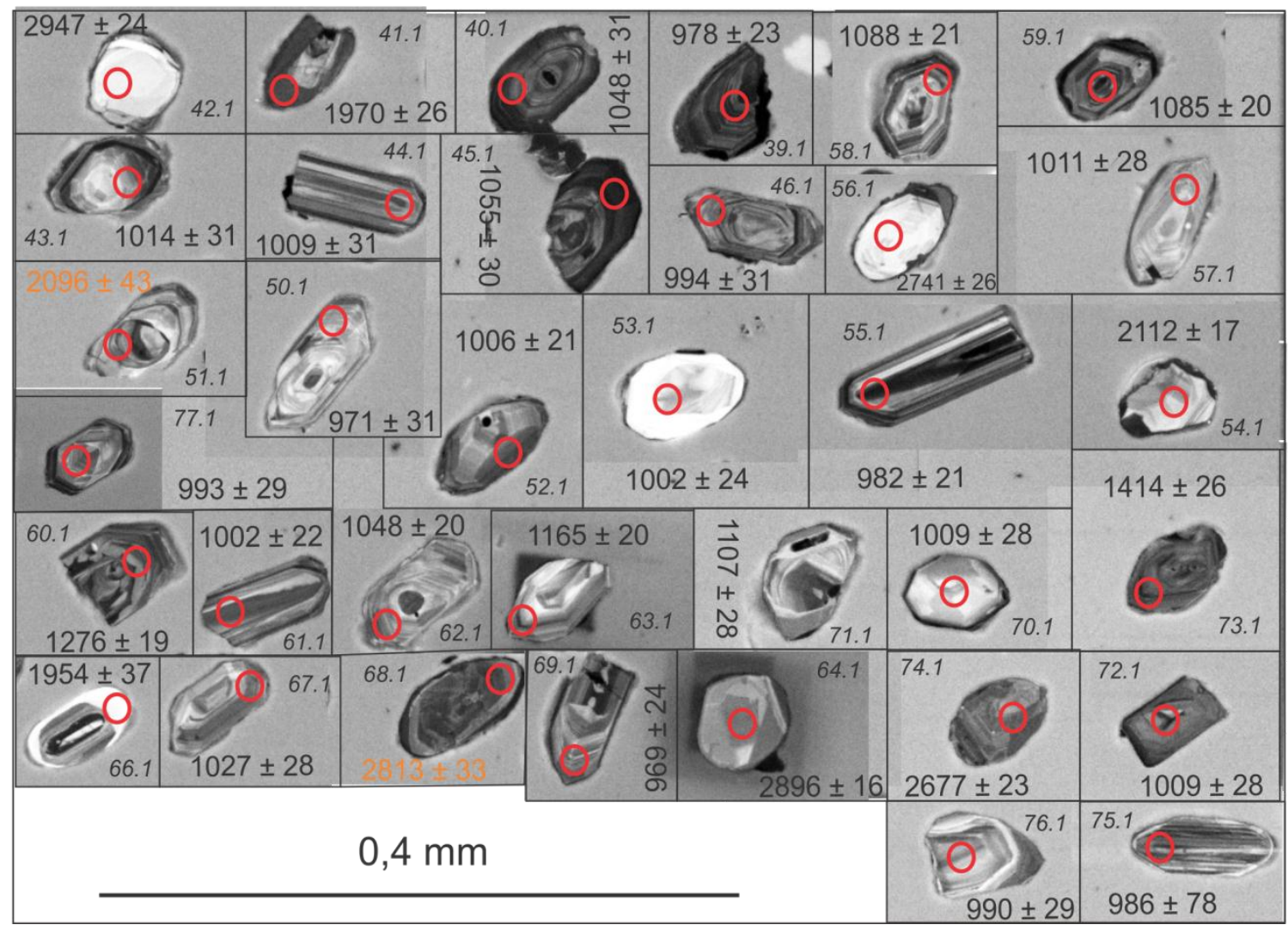

Fig. 24 - Imagens de catodoluminescência dos grãos de zircão detrítico obtidos da amostra 11-VS-13. 


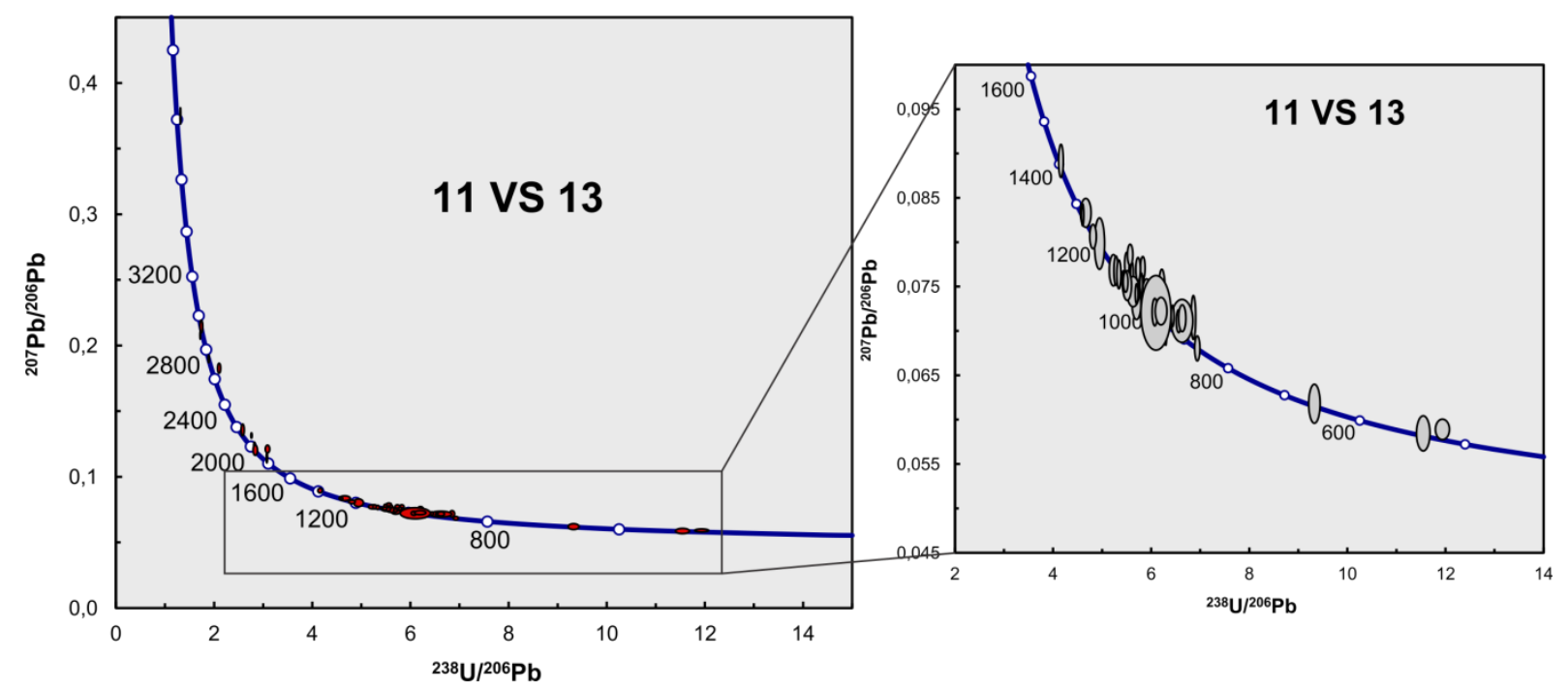

Fig. 25 - Diagrama Concórdia Tera \& Wasserburg (1972) para a amostra 11-VS-13 com detalhe para o intervalo entre 1600-400 Ma.

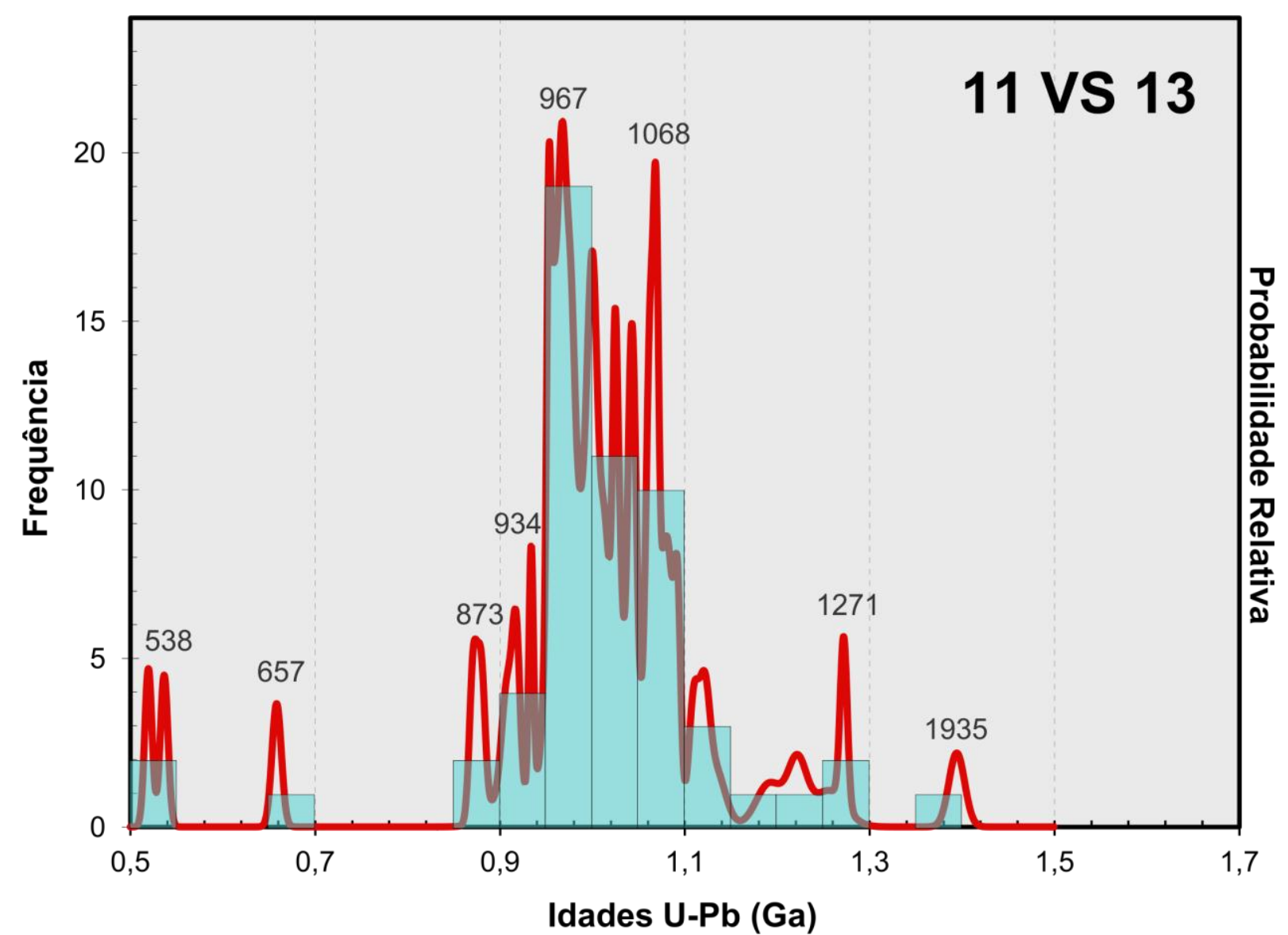

Fig. 26 - Histograma obtido com os dados geocronológicos de zircão detrítico da amostra 11-VS-13. Foram utilizadas somente idades ${ }^{207} \mathrm{~Pb} /{ }^{206} \mathrm{~Pb}$ com concordância entre $90-110 \%$. Não foram considerados os grãos de idade paleoproterozoica e arqueana. 

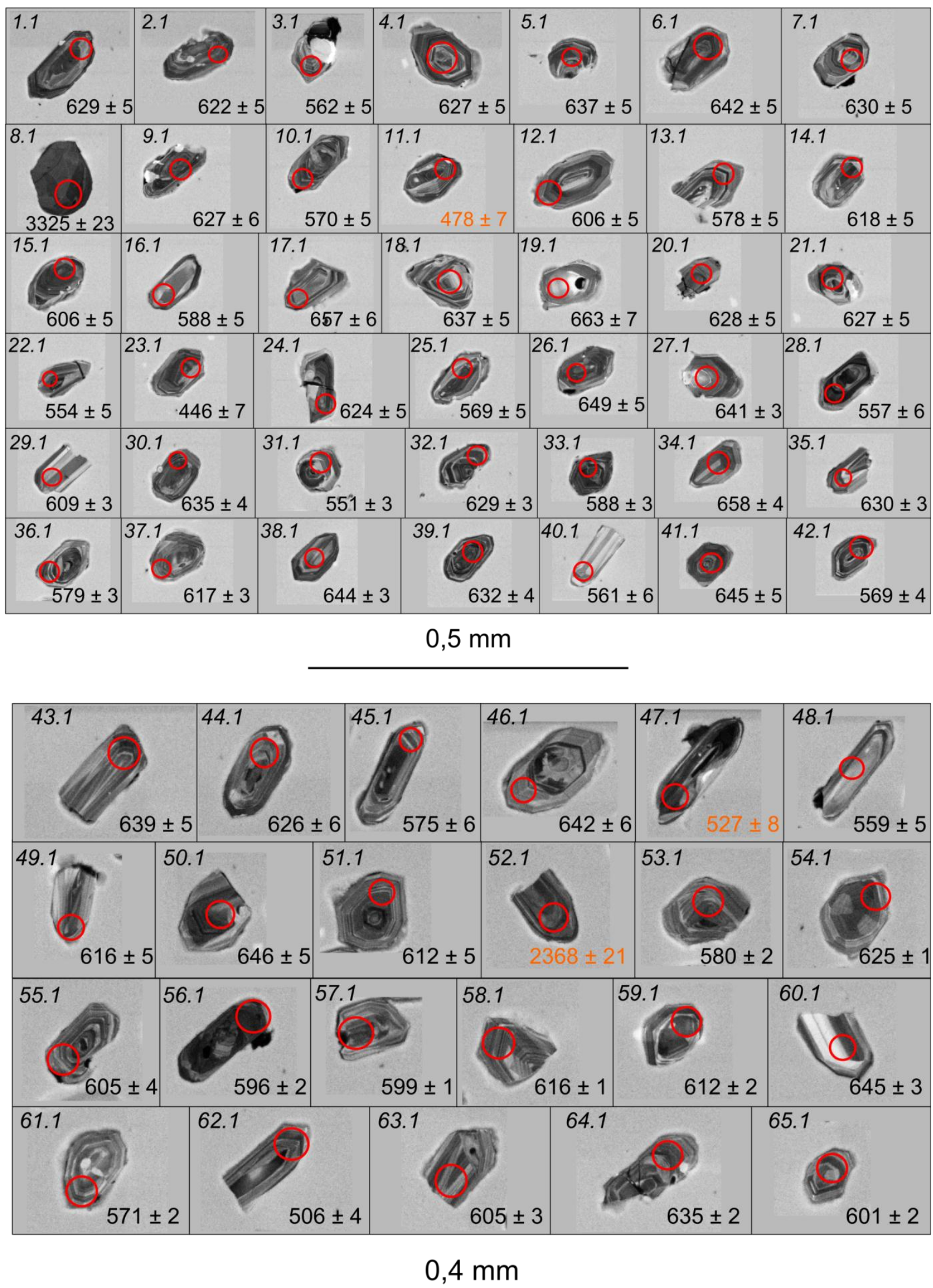

Fig. 27 - Imagens de catodoluminescência dos grãos de zircão detrítico obtidos da amostra 11-PGL-PEL. 


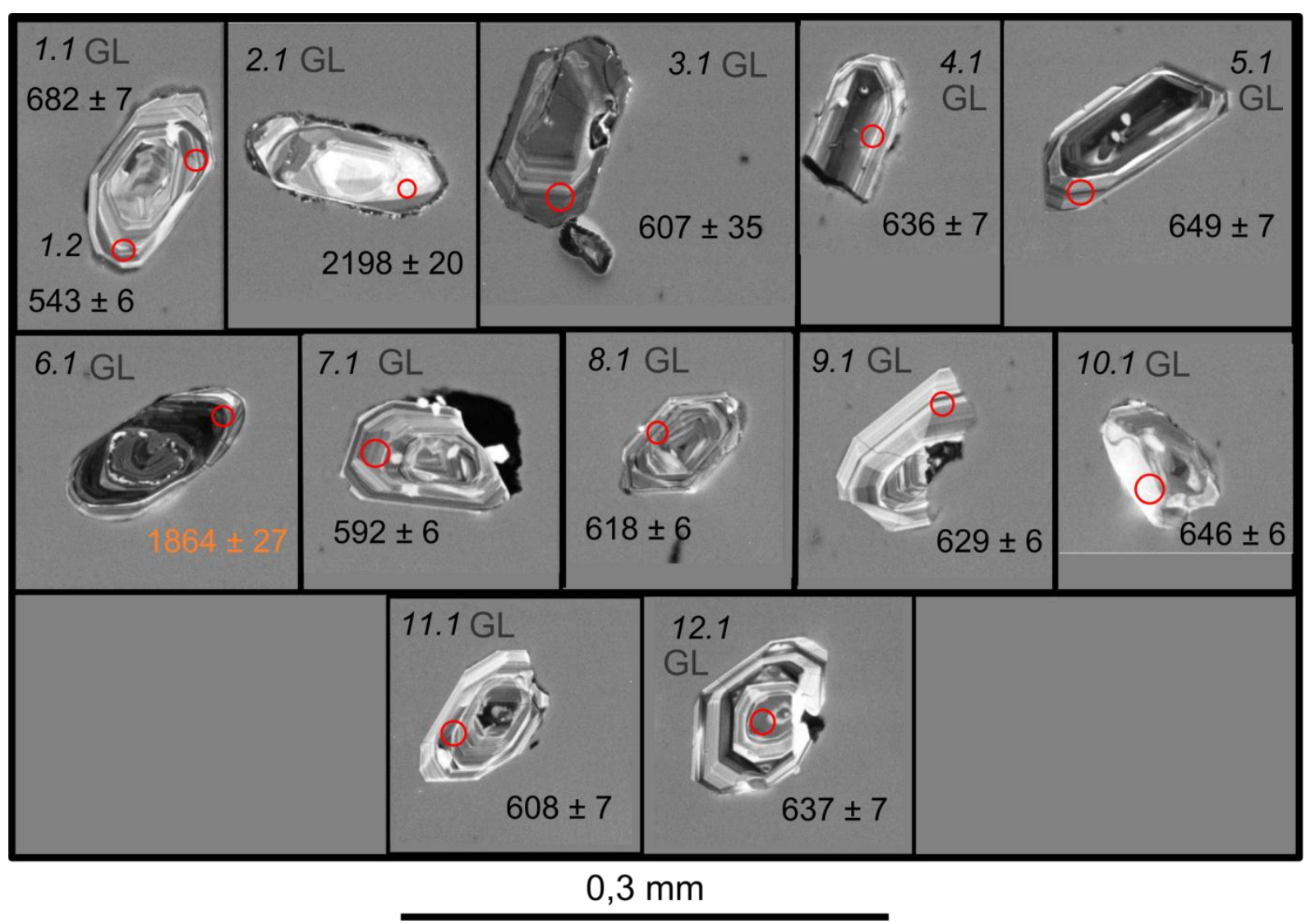

Fig. 28 - Imagens de catodoluminescência dos grãos de zircão detrítico obtidos da amostra 11-PGL-PEL.

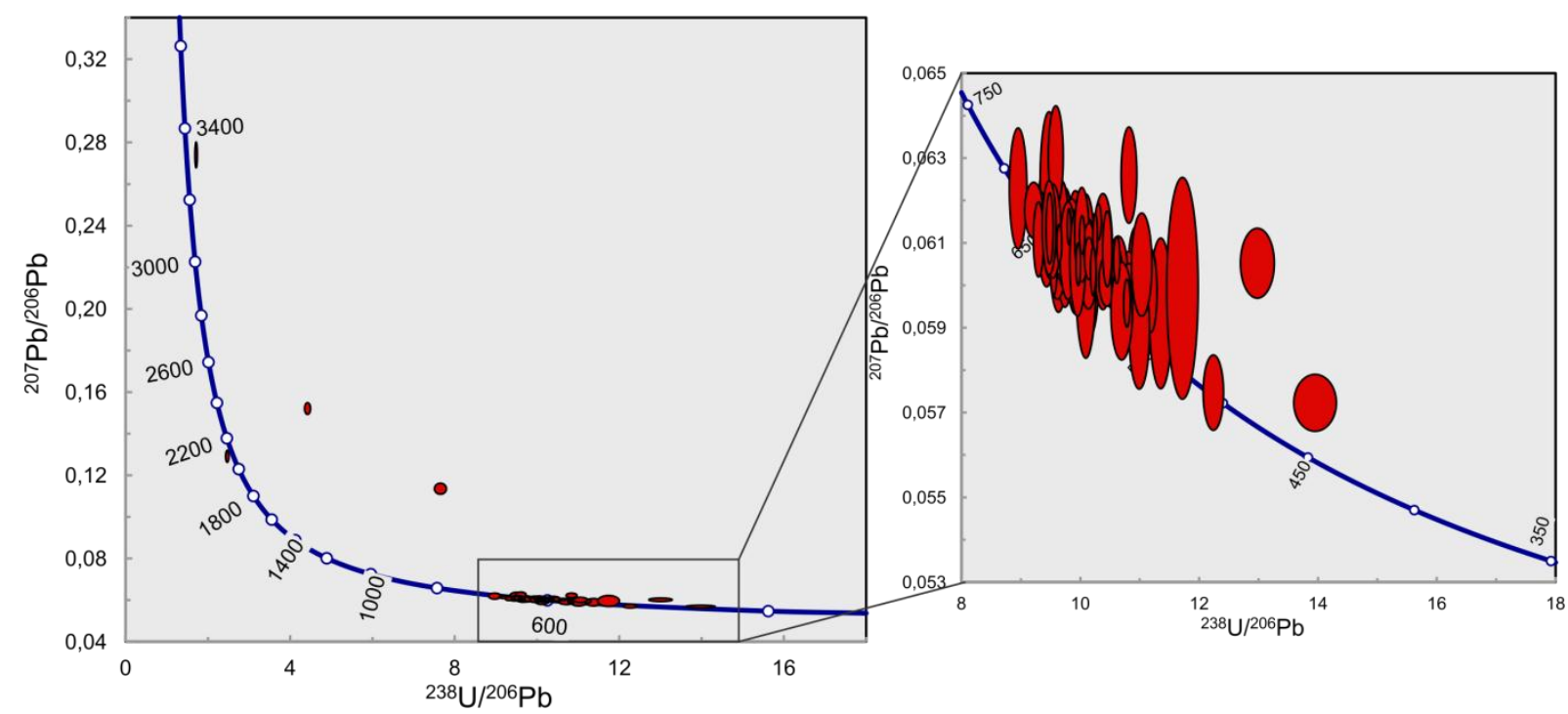

Fig. 29 - Diagrama Concórdia Tera \& Wasserburg (1972) para a amostra 11-PGL-PEL com detalhe para o intervalo entre 750-350 Ma. 


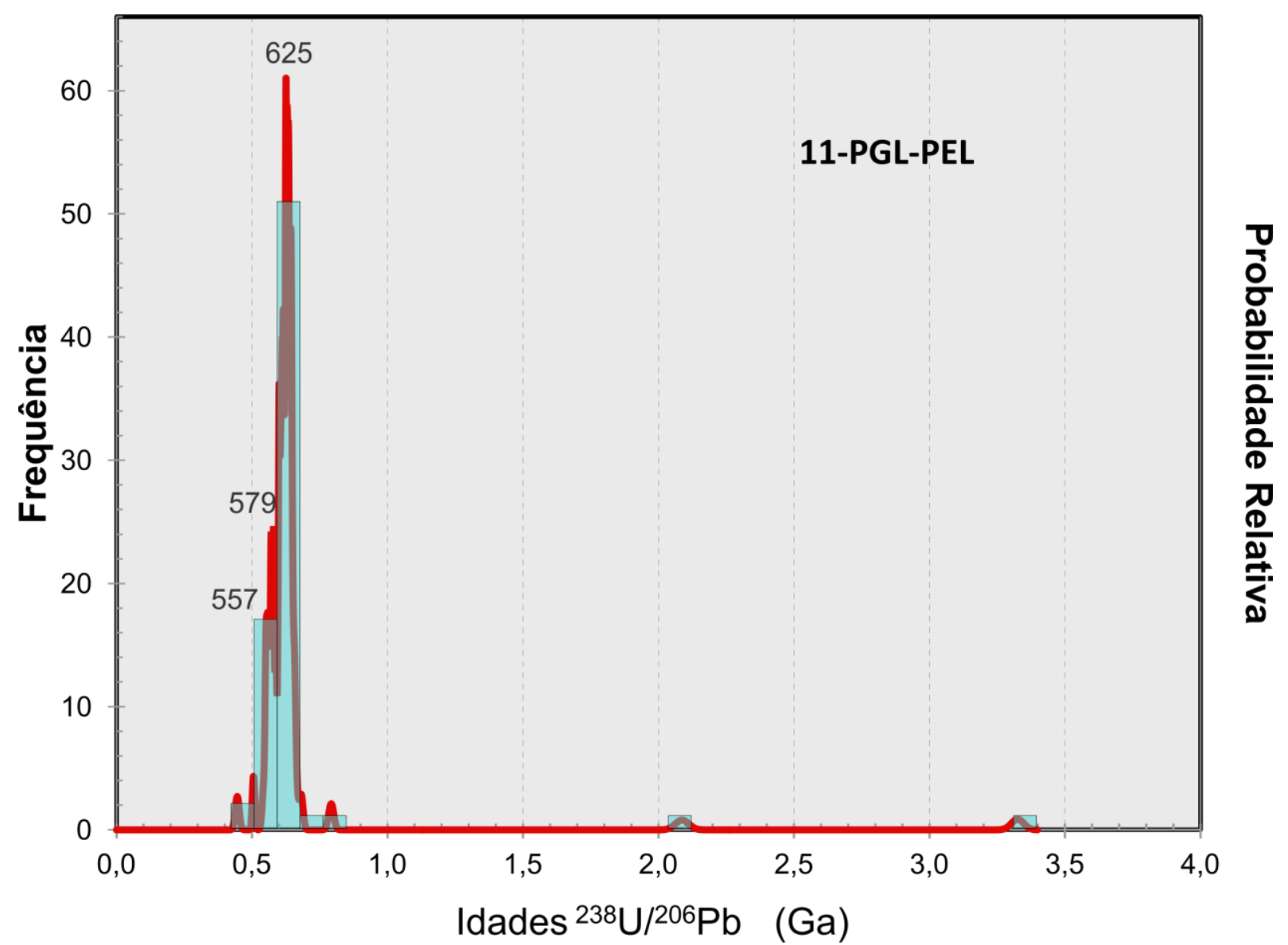

Fig. 30 - Histograma obtido com os dados geocronológicos de zircão detrítico da amostra 11-PGL-PEL. Foram utilizadas somente idades ${ }^{238} \mathrm{U} /{ }^{206} \mathrm{~Pb}$ com concordância entre 90-110\%. 
Tabela 7 - Dados isotópicos de Sm-Nd obtidos para as amostras de marga das seções AP, VS e PGL, Formação Sete Lagoas.

\begin{tabular}{|c|c|c|c|c|c|c|c|c|c|}
\hline Amostra & Sm (ppm) & Nd (ppm) & ${ }^{147} \mathrm{Sm} /{ }^{144} \mathrm{Nd}$ & Sigma-1 & ${ }^{143} \mathrm{Nd} /{ }^{144} \mathrm{Nd}$ & erro (2s) & $\mathbf{f}_{\mathrm{Sm} / \mathrm{Nd}}$ & $\mathrm{T}_{\mathrm{DM}}{ }^{1}(\mathrm{Ga})$ & $\operatorname{eNd}(0)$ \\
\hline 11-PGL-PEL & 1,425 & 7,191 & 0,1198 & 0,0007 & 0,511940 & 0,000014 & $-0,39$ & 1,8 & $-13,6$ \\
\hline 11-VS-13 & 2,305 & 11,405 & 0,1222 & 0,0007 & 0,511967 & 0,000013 & $-0,38$ & 1,8 & $-13,1$ \\
\hline 11-AP-05 & 1,769 & 8,203 & 0,1304 & 0,0008 & 0,511975 & 0,000013 & $-0,34$ & 2,0 & $-12,9$ \\
\hline
\end{tabular}

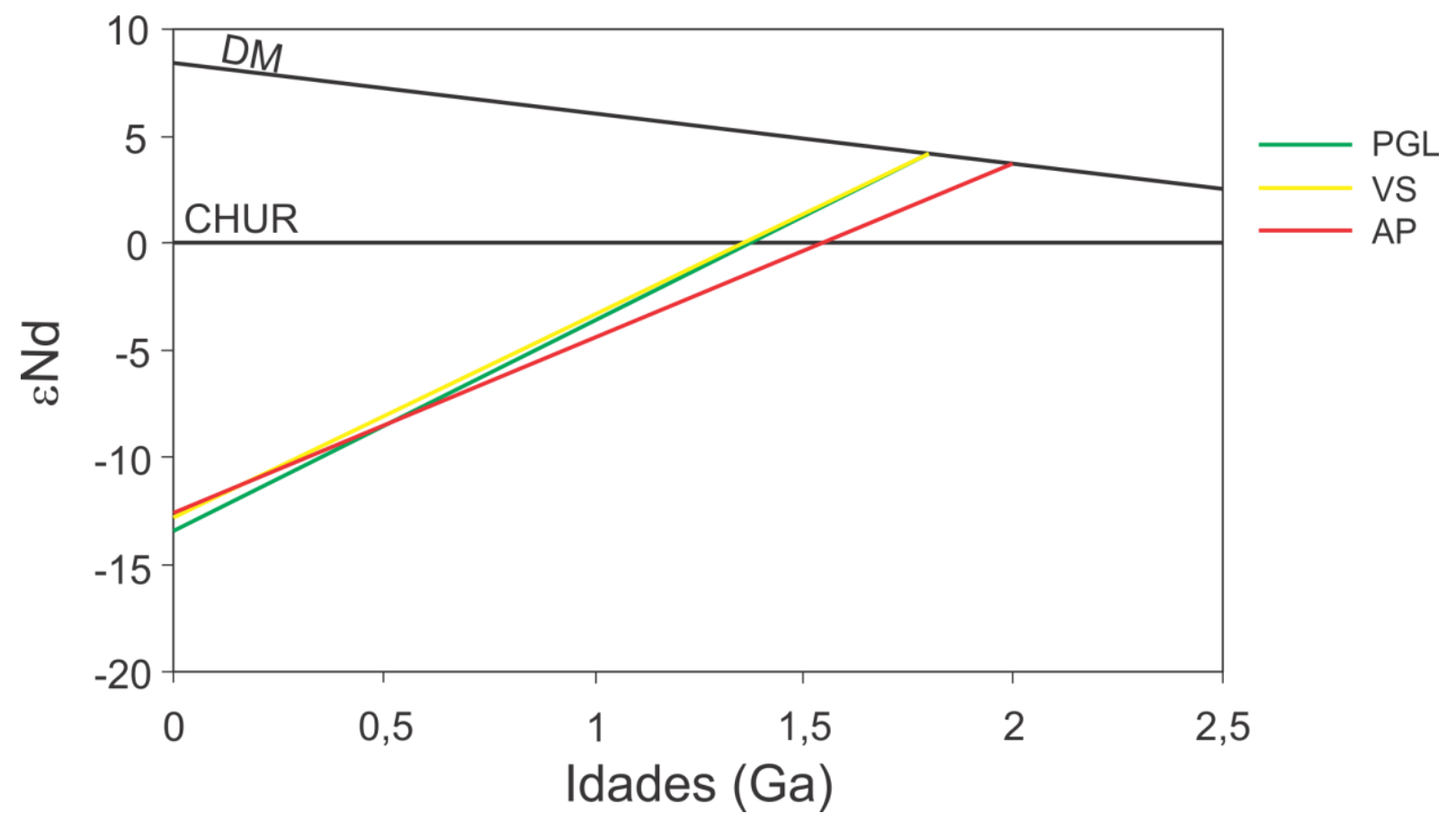

Fig. 31 - Idades Modelo Sm-Nd obtidas em análises de Rocha Total das amostras 11-AP-05, 11-VS-13, 11PGL-PEL.

\subsubsection{Dados isotópicos de Hf}

A Tabela 8 exibe as razões isotópicas, $\varepsilon H f$ e idades $\mathrm{T}_{\mathrm{DM}}$ obtidas com as análises isotópicas de Hf.

A maior parte dos grãos analisados da amostra 11-AP-05 apresentaram valores de $\varepsilon \mathrm{Hf}$ positivos. Dos cinco grãos que apresentaram $\varepsilon H f$ negativo, três possuem idades U-Pb entre 600-590 Ma ( $\varepsilon \mathrm{Hf}$ entre -0,2 e -5,7). Neste mesmo intervalo de idades, dois grãos apresentaram $\varepsilon H f$ positivo iguais a 1,8 e 6,8, que sugerem mais de uma fonte com mesma idade ou ampla variação isotópica de uma mesma fonte. Estes grãos ainda apresentaram diversidade de idades $\mathrm{T}_{\mathrm{DM}}$ entre 1,1 e 1,9 Ga. No grão mais antigo, de idade U-Pb 630 Ma, foi 
obtido valor de $\varepsilon \mathrm{Hf}$ igual a -7,6 e no mais jovem, de idade $547 \mathrm{Ma}$, (já desconsiderando o grão de $408 \mathrm{Ma})$, $\varepsilon H f$ levemente positivo e igual a 0,2 .

A amostra 11-VS-13 apresentou grãos com valores de $\varepsilon H f$ amplamente negativos. Alguns poucos grãos apresentaram valores positivos. Estes estão preferencialmente em uma faixa de idades $\mathrm{U}-\mathrm{Pb}$ entre 1050-950 Ma com idades $\mathrm{T}_{\mathrm{DM}}$ variando entre 1,4 e 1,8 Ga. Um grão de idade arqueana também apresentou $\varepsilon H f$ positivo $(2,5)$. No grão mais jovem, de idade $\mathrm{U}-\mathrm{Pb}$ igual a $537 \mathrm{Ma}$, foi obtido valor de $\varepsilon \mathrm{Hf}$ igual a -12,6 e idade $\mathrm{T}_{\mathrm{DM}}$ de 2,2 Ga que sugerem que a fonte é produto de retrabalhamento crustal de um protólito riaciano.

As análises isotópicas de $\mathrm{Hf}$ dos grãos da amostra 11-PGL-PEL foram bastante complicadas, visto que estes são bastante pequenos e muitos quebraram quando da incidência do feixe de laser. Conclui-se então a necessidade das datações U-Pb serem realizadas pela técnica SHRIMP, para evitar este tipo de problema em grãos menores e, consequentemente, mais finos. Nos grãos em que a análise foi bem sucedida, os valores de $\varepsilon H f$ obtidos foram negativos na maioria dos casos, com idades $\mathrm{T}_{\mathrm{DM}}$ entre 1,6 e 2,6 Ga. Apenas um grão de idade $\mathrm{U}-\mathrm{Pb} 579 \mathrm{Ma}$ apresentou $\varepsilon \mathrm{Hf}$ levemente positivo, igual a 0,3 , e idade $\mathrm{T}_{\mathrm{DM}} 1,5 \mathrm{Ga}$. 
Tabela 8 - Dados isotópicos de Hf obtidos nos grãos de zircão detrítico das amostras 11-AP-05, 11-VS-13 e 11-PGL-PEL.

\begin{tabular}{|c|c|c|c|c|c|c|c|c|c|c|c|c|c|}
\hline \multirow[t]{2}{*}{ Amostra } & \multirow[t]{2}{*}{ Spot } & \multirow[t]{2}{*}{${ }^{176} \mathrm{Hf} /{ }^{177} \mathrm{Hf}$} & \multirow[t]{2}{*}{ $\pm 2 \mathrm{se}$} & \multirow[t]{2}{*}{${ }^{176} \mathrm{Lu} /{ }^{177} \mathrm{Hf}$} & \multicolumn{2}{|r|}{ U-Pb } & $\varepsilon \mathbf{H f}(\mathbf{0})$ & ${ }^{176} \mathrm{Hf} /{ }^{177} \mathrm{Hf}$ & \multirow{2}{*}{$\begin{array}{l}\varepsilon \text { Hf } \\
\text { T1) }\end{array}$} & \multirow{2}{*}{$\begin{array}{c}{ }^{176} \mathrm{Hf} /{ }^{177} \mathrm{Hf} \\
\mathrm{DM}(\mathrm{T}) \\
\end{array}$} & \multirow{2}{*}{$\frac{\text { T DM }}{(\mathbf{G a})}$} & \multirow{2}{*}{$\frac{{ }^{176} \mathrm{Hf} /{ }^{177} \mathrm{Hf}}{\mathrm{DM}(\mathrm{T})}$} & \multirow{2}{*}{$\frac{\varepsilon \text { Hf }}{(\mathbf{T D M})}$} \\
\hline & & & & & & (T1) Ma & & (T1) & & & & & \\
\hline \multirow{12}{*}{ 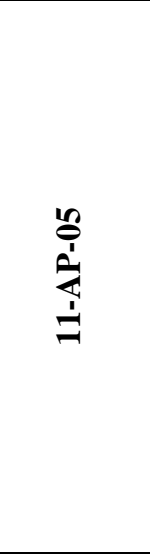 } & 1.1 & 0,282627 & 0,000024 & 0,000466 & 0,000040 & 603 & $-5,1$ & 0,282622 & 8,0 & 0,282789 & 1,0 & 0,282511 & 12,6 \\
\hline & 2.1 & 0,282511 & 0,000036 & 0,000767 & 0,000020 & 578 & $-9,2$ & 0,282503 & 3,2 & 0,282807 & 1,3 & 0,282301 & 11,6 \\
\hline & 4.1 & 0,282599 & 0,000038 & 0,000706 & 0,000004 & 599 & $-6,1$ & 0,282591 & 6,8 & 0,282792 & 1,1 & 0,282458 & 12,3 \\
\hline & 5.1 & 0,282480 & 0,000031 & 0,000797 & 0,000021 & 584 & $-10,3$ & 0,282472 & 2,3 & 0,282803 & 1,3 & 0,282252 & 11,3 \\
\hline & 6.1 & 0,282467 & 0,000037 & 0,001243 & 0,000011 & 594 & $-10,8$ & 0,282453 & 1,8 & 0,282796 & 1,4 & 0,282225 & 11,2 \\
\hline & 7.1 & 0,282408 & 0,000039 & 0,001330 & 0,000020 & 598 & $-12,9$ & 0,282393 & $-0,2$ & 0,282793 & 1,5 & 0,282127 & 10,7 \\
\hline & 8.1 & 0,282260 & 0,000062 & 0,001836 & 0,000046 & 597 & $-18,1$ & 0,282239 & $-5,7$ & 0,282793 & 1,9 & 0,281871 & 9,5 \\
\hline & 10.1 & 0,282509 & 0,000027 & 0,000790 & 0,000017 & 617 & $-9,3$ & 0,282500 & 4,0 & 0,282779 & 1,3 & 0,282314 & 11,6 \\
\hline & 11.1 & 0,282445 & 0,000041 & 0,000699 & 0,000009 & 547 & $-11,5$ & 0,282438 & 0,2 & 0,282830 & 1,4 & 0,282179 & 11,0 \\
\hline & 12.1 & 0,282191 & 0,000047 & 0,002295 & 0,000022 & 630 & $-20,5$ & 0,282164 & $-7,6$ & 0,282769 & 2,0 & 0,281762 & 8,9 \\
\hline & 13.1 & 0,282018 & 0,000050 & 0,002962 & 0,000018 & 408 & $-26,7$ & 0,281995 & $-18,5$ & 0,282931 & 2,5 & 0,281380 & 7,1 \\
\hline & 9.1 & 0,282285 & 0,000037 & 0,002368 & 0,000037 & 591 & $-17,2$ & 0,282259 & $-5,1$ & 0,282798 & 1,8 & 0,281902 & 9,6 \\
\hline
\end{tabular}

\begin{tabular}{|c|c|c|c|c|c|c|c|c|c|c|c|c|c|}
\hline \multirow{2}{*}{ Amostra } & \multirow{2}{*}{ Spot } & \multirow[t]{2}{*}{${ }^{176} \mathbf{H f} /{ }^{177} \mathrm{Hf}$} & \multirow[t]{2}{*}{ $\pm 2 \mathrm{se}$} & \multirow[t]{2}{*}{${ }^{176} \mathrm{Lu} /{ }^{177} \mathrm{Hf}$} & \multicolumn{3}{|c|}{ U-Pb } & \multirow{2}{*}{$\begin{array}{c}{ }^{176} \mathbf{H f} /{ }^{177} \mathbf{H f} \\
(\mathrm{T} 1) \\
\end{array}$} & \multirow{2}{*}{$\begin{array}{l}\varepsilon \text { Hf } \\
\text { (T1) }\end{array}$} & \multirow{2}{*}{ 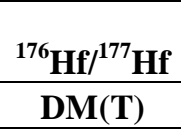 } & \multirow{2}{*}{$\frac{\text { T DM }}{(\mathbf{G a})}$} & \multirow{2}{*}{$\begin{array}{c}{ }^{176} \mathbf{H f} /{ }^{177} \mathrm{Hf} \\
\mathrm{DM}(\mathrm{T}) \\
\end{array}$} & \multirow{2}{*}{$\frac{\varepsilon \text { Hf }}{(\text { TDM })}$} \\
\hline & & & & & & (T1) Ma & & & & & & & \\
\hline \multirow{13}{*}{ 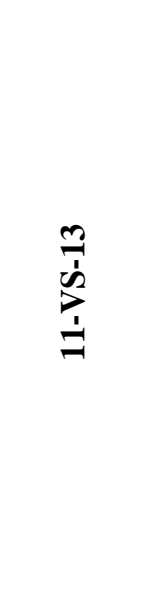 } & 1.1 & 0,282224 & 0,000038 & 0,001279 & 0,000018 & 658 & $-19,4$ & 0,282208 & $-5,4$ & 0,282749 & 1,9 & 0,281848 & 9,4 \\
\hline & 3.1 & 0,282116 & 0,000066 & 0,000680 & 0,000010 & 972 & $-23,2$ & 0,282103 & $-2,2$ & 0,282520 & 1,9 & 0,281822 & 9,2 \\
\hline & 5.1 & 0,281872 & 0,000047 & 0,002453 & 0,000043 & 1119 & $-31,8$ & 0,281820 & $-8,9$ & 0,282412 & 2,5 & 0,281418 & 7,3 \\
\hline & 6.1 & 0,282294 & 0,000029 & 0,000169 & 0,000002 & 951 & $-16,9$ & 0,282291 & 4,0 & 0,282535 & 1,5 & 0,282126 & 10,7 \\
\hline & 7.1 & 0,282157 & 0,000042 & 0,001829 & 0,000051 & 1046 & $-21,8$ & 0,282121 & 0,1 & 0,282466 & 1,8 & 0,281887 & 9,5 \\
\hline & 8.1 & 0,282329 & 0,000038 & 0,001235 & 0,000044 & 994 & $-15,7$ & 0,282306 & 5,5 & 0,282504 & 1,4 & 0,282172 & 10,9 \\
\hline & 9.1 & 0,282188 & 0,000032 & 0,001101 & 0,000043 & 961 & $-20,7$ & 0,282168 & $-0,1$ & 0,282528 & 1,8 & 0,281925 & 9,7 \\
\hline & 13.1 & 0,282108 & 0,000031 & 0,002582 & 0,000058 & 537 & $-23,5$ & 0,282082 & $-12,6$ & 0,282837 & 2,2 & 0,281583 & 8,1 \\
\hline & 14.1 & 0,282165 & 0,000123 & 0,001470 & 0,000021 & 1127 & $-21,5$ & 0,282134 & 2,4 & 0,282406 & 1,7 & 0,281949 & 9,8 \\
\hline & 17.1 & 0,282199 & 0,000028 & 0,001392 & 0,000023 & 1012 & $-20,3$ & 0,282173 & 1,2 & 0,282490 & 1,7 & 0,281958 & 9,9 \\
\hline & 19.1 & 0,281396 & 0,000044 & 0,003135 & 0,000041 & 520 & $-48,7$ & 0,281365 & $-38,3$ & 0,282849 & 3,8 & 0,280384 & 2,2 \\
\hline & 22.1 & 0,281709 & 0,000027 & 0,000988 & 0,000040 & 1123 & $-37,6$ & 0,281688 & $-13,5$ & 0,282409 & 2,7 & 0,281197 & 6,2 \\
\hline & 24.1 & 0,280162 & 0,000084 & 0,000386 & 0,000009 & 3684 & $-92,3$ & 0,280135 & $-9,7$ & 0,280483 & 4,5 & 0,279870 & $-0,3$ \\
\hline
\end{tabular}




\begin{tabular}{|c|c|c|c|c|c|c|c|c|c|c|c|c|}
\hline 26.1 & 0,281373 & 0,000124 & 0,003390 & 0,000095 & 1217 & $-49,5$ & 0,281295 & $-25,3$ & 0,282340 & 3,6 & 0,280581 & 3,2 \\
\hline 29.1 & 0,281829 & 0,000033 & 0,001908 & 0,000052 & 960 & $-33,4$ & 0,281794 & $-13,4$ & 0,282529 & 2,6 & 0,281299 & 6,7 \\
\hline 30.1 & 0,281624 & 0,000028 & 0,000934 & 0,000013 & 1077 & $-40,6$ & 0,281605 & $-17,5$ & 0,282443 & 3,0 & 0,281037 & 5,4 \\
\hline 33.1 & 0,282072 & 0,000026 & 0,000951 & 0,000040 & 867 & $-24,8$ & 0,282056 & $-6,2$ & 0,282597 & 2,1 & 0,281693 & 8,6 \\
\hline 35.1 & 0,281632 & 0,000027 & 0,001005 & 0,000017 & 1109 & $-40,3$ & 0,281611 & $-16,5$ & 0,282419 & 2,9 & 0,281063 & 5,5 \\
\hline 38.1 & 0,281850 & 0,000237 & 0,001429 & 0,000034 & 1282 & $-32,6$ & 0,281815 & $-5,4$ & 0,282292 & 2,4 & 0,281488 & 7,6 \\
\hline 39.1 & 0,281965 & 0,000046 & 0,001906 & 0,000081 & 978 & $-28,6$ & 0,281929 & $-8,2$ & 0,282515 & 2,3 & 0,281534 & 7,8 \\
\hline 42.1 & 0,280997 & 0,000032 & 0,000580 & 0,000021 & 2947 & $-62,8$ & 0,280964 & 2,5 & 0,281047 & 3,1 & 0,280904 & 4,8 \\
\hline 46.1 & 0,282049 & 0,000033 & 0,001176 & 0,000012 & 994 & $-25,6$ & 0,282027 & $-4,4$ & 0,282504 & 2,1 & 0,281705 & 8,7 \\
\hline 48.1 & 0,281849 & 0,000081 & 0,001141 & 0,000019 & 961 & $-32,7$ & 0,281828 & $-12,2$ & 0,282528 & 2,5 & 0,281356 & 7,0 \\
\hline 50.1 & 0,282158 & 0,000043 & 0,001147 & 0,000049 & 971 & $-21,7$ & 0,282137 & $-1,0$ & 0,282520 & 1,8 & 0,281879 & 9,5 \\
\hline 53.1 & 0,282312 & 0,000290 & 0,001454 & 0,000079 & 1002 & $-16,3$ & 0,282285 & 4,9 & 0,282498 & 1,5 & 0,282141 & 10,8 \\
\hline 66.1 & 0,281041 & 0,000030 & 0,000373 & 0,000014 & 1954 & $-61,2$ & 0,281027 & $-18,2$ & 0,281794 & 3,7 & 0,280485 & 2,7 \\
\hline 67.1 & 0,281437 & 0,000043 & 0,001473 & 0,000009 & 1027 & $-47,2$ & 0,281409 & $-25,5$ & 0,282479 & 3,4 & 0,280684 & 3,7 \\
\hline 60.1 & 0,281579 & 0,000026 & 0,001856 & 0,000046 & 1276 & $-42,2$ & 0,281535 & $-15,5$ & 0,282297 & 3,0 & 0,281013 & 5,3 \\
\hline 63.1 & 0,281691 & 0,000033 & 0,001516 & 0,000035 & 1165 & $-38,2$ & 0,281658 & $-13,6$ & 0,282378 & 2,8 & 0,281167 & 6,0 \\
\hline 59.1 & 0,281798 & 0,000069 & 0,002078 & 0,000084 & 1085 & $-34,4$ & 0,281756 & $-12,0$ & 0,282437 & 2,6 & 0,281293 & 6,7 \\
\hline 58.1 & 0,281802 & 0,000097 & 0,001498 & 0,000016 & 1088 & $-34,3$ & 0,281771 & $-11,3$ & 0,282435 & 2,6 & 0,281320 & 6,8 \\
\hline 52.1 & 0,282010 & 0,000034 & 0,001285 & 0,000015 & 1006 & $-26,9$ & 0,281986 & $-5,6$ & 0,282495 & 2,2 & 0,281642 & 8,4 \\
\hline 62.1 & 0,282013 & 0,000037 & 0,000701 & 0,000007 & 1048 & $-26,8$ & 0,281999 & $-4,1$ & 0,282464 & 2,1 & 0,281685 & 8,6 \\
\hline 55.1 & 0,282087 & 0,000045 & 0,001011 & 0,000042 & 982 & $-24,2$ & 0,282068 & $-3,2$ & 0,282512 & 2,0 & 0,281768 & 9,0 \\
\hline 70.1 & 0,282087 & 0,000028 & 0,000828 & 0,000004 & 1107 & $-24,2$ & 0,282070 & $-0,3$ & 0,282421 & 1,9 & 0,281832 & 9,3 \\
\hline
\end{tabular}


Tabela 8 - Continuação.

\begin{tabular}{|c|c|c|c|c|c|c|c|c|c|c|c|c|c|}
\hline \multirow{2}{*}{ Amostra } & \multirow[t]{2}{*}{ Spot } & \multirow[t]{2}{*}{${ }^{176} \mathrm{Hf} /{ }^{177} \mathrm{Hf}$} & \multirow[t]{2}{*}{ $\pm 2 \mathrm{se}$} & \multirow[t]{2}{*}{${ }^{176} \mathbf{L u} /{ }^{177} \mathbf{H f}$} & $\pm 2 \mathrm{se}$ & U-Pb & $\varepsilon \mathbf{H f}(\mathbf{0})$ & ${ }^{176} \mathrm{Hf} /{ }^{177} \mathrm{Hf}$ & \multirow{2}{*}{$\begin{array}{l}\varepsilon \text { Hf } \\
\text { (T1) }\end{array}$} & \multirow{2}{*}{$\begin{array}{c}{ }^{176} \mathrm{Hf} /{ }^{177} \mathbf{H f} \\
\mathrm{DM}(\mathrm{T})\end{array}$} & \multirow{2}{*}{$\frac{\text { T DM }}{(\mathbf{G a})}$} & \multirow{2}{*}{$\begin{array}{c}{ }^{176} \mathbf{H f} /{ }^{177} \mathbf{H f} \\
\mathrm{DM}(\mathrm{T}) \\
\end{array}$} & \multirow{2}{*}{$\frac{\varepsilon \text { Hf }}{(\text { TDM })}$} \\
\hline & & & & & & (T1) Ma & & (T1) & & & & & \\
\hline \multirow{18}{*}{ 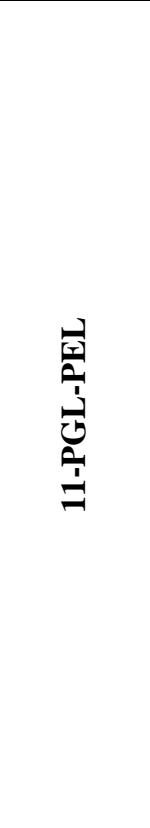 } & GL 1.1 & 0,282949 & 0,000109 & 0,001043 & 0,000008 & 682 & 6,3 & 0,282936 & 20,9 & 0,282731 & 0,2 & 0,283073 & 15,3 \\
\hline & GL 1.2 & 0,282922 & 0,000104 & 0,001049 & 0,000012 & 543 & 5,3 & 0,282911 & 16,9 & 0,282833 & 0,4 & 0,282964 & 14,8 \\
\hline & GL 2.1 & 0,281869 & 0,000070 & 0,001120 & 0,000044 & 2198 & $-31,9$ & 0,281822 & 15,7 & 0,281612 & 1,7 & 0,281973 & 10,0 \\
\hline & GL 3.1 & 0,283331 & 0,000120 & 0,001622 & 0,000025 & 605 & 19,8 & 0,283312 & 32,5 & 0,282788 & $-0,6$ & 0,283661 & 18,1 \\
\hline & GL 5.1 & 0,283189 & 0,000146 & 0,001547 & 0,000051 & 649 & 14,7 & 0,283170 & 28,4 & 0,282756 & $-0,3$ & 0,283446 & 17,1 \\
\hline & GL 6.1 & 0,282161 & 0,000125 & 0,001511 & 0,000021 & 792 & $-21,6$ & 0,282138 & $-4,9$ & 0,282651 & 2,0 & 0,281795 & 9,1 \\
\hline & GL 7.1 & 0,283061 & 0,000129 & 0,001212 & 0,000008 & 592 & 10,2 & 0,283048 & 22,8 & 0,282797 & 0,0 & 0,283214 & 16,0 \\
\hline & GL 8.1 & 0,282962 & 0,000107 & 0,001341 & 0,000009 & 618 & 6,7 & 0,282946 & 19,8 & 0,282778 & 0,2 & 0,283058 & 15,2 \\
\hline & GL 9.1 & 0,282995 & 0,000097 & 0,001580 & 0,000040 & 629 & 7,9 & 0,282976 & 21,1 & 0,282770 & 0,2 & 0,283113 & 15,5 \\
\hline & GL 11.1 & 0,283002 & 0,000131 & 0,001459 & 0,000023 & 608 & 8,1 & 0,282986 & 21,0 & 0,282785 & 0,1 & 0,283119 & 15,5 \\
\hline & GL 12.1 & 0,283272 & 0,000131 & 0,001839 & 0,000014 & 637 & 17,7 & 0,283250 & 31,0 & 0,282764 & $-0,5$ & 0,283574 & 17,7 \\
\hline & 9.1 & 0,282250 & 0,000102 & 0,001654 & 0,000012 & 627 & $-18,5$ & 0,282231 & $-5,3$ & 0,282772 & 1,9 & 0,281871 & 9,5 \\
\hline & 10.1 & 0,282367 & 0,000129 & 0,001177 & 0,000003 & 570 & $-14,3$ & 0,282354 & $-2,2$ & 0,28281297 & 1,6 & 0,282050 & 10,3 \\
\hline & 36.1 & 0,282432 & 0,000087 & 0,001126 & 0,000005 & 579 & $-12,0$ & 0,282420 & 0,3 & 0,28280643 & 1,5 & 0,282163 & 10,9 \\
\hline & 37.1 & 0,282063 & 0,000083 & 0,001365 & 0,000015 & 617 & $-25,1$ & 0,282047 & $-12,0$ & 0,282779 & 2,3 & 0,281561 & 8,0 \\
\hline & 40.1 & 0,281934 & 0,000093 & 0,001490 & 0,000010 & 561 & $-29,6$ & 0,281918 & $-17,9$ & 0,282820 & 2,6 & 0,281321 & 6,8 \\
\hline & 41.1 & 0,282048 & 0,000166 & 0,002283 & 0,000028 & 645 & $-25,6$ & 0,282020 & $-12,4$ & 0,282758 & 2,3 & 0,281529 & 7,8 \\
\hline & 6.1 & 0,282161 & 0,000125 & 0,001511 & 0,000021 & 792 & $-21,6$ & 0,282138 & $-4,9$ & 0,282651 & 2,0 & 0,281795 & 9,1 \\
\hline
\end{tabular}




\section{CAPÍTULO 5}

\section{DISCUSSÃO DOS RESULTADOS}

\subsection{Alterações do registro isotópico dos carbonatos}

O reconhecimento de processos pós-deposicionais que possam modificar o registro isotópico dos carbonatos estudados é de fundamental importância para garantir a confiabilidade da aplicação da quimioestratigrafia isotópica, fato já levantado por diversos pesquisadores na literatura (e.g. Melezhik et al., 2001). Isto é especialmente importante para rochas carbonáticas pré-cambrianas e até para as do Cambriano que, pela longa residência crustal, estiveram sujeitas a tais processos. Estas rochas também não contêm carbonatos biogênicos inalterados, como foraminíferos e outros fósseis marinhos, considerados ideais para obtenção de dados isotópicos representativos do ambiente de deposição (Frimmel, 2010). Um passo essencial para aquisição destes dados é a seleção criteriosa das regiões a serem recolhidas as alíquotas de carbonato para análise. Isto foi realizado neste trabalho por meio de polimento de seções das amostras, análise petrográfica minuciosa e amostragem por microdrill, a fim de evitar regiões com recristalização mais intensa, vênulas, veios e outras estruturas. Mesmo assim, este procedimento sozinho não é capaz de garantir a originalidade do registro isotópico.

O procedimento mais comum para identificar processos pós-deposicionais é por meio de razões geoquímicas. Isto porque a interação de carbonatos com fluidos intersticiais durante a diagênese, dolomitização ou metamorfismo leva a um incremento nas razões $\mathrm{Mn} / \mathrm{Sr}, \mathrm{Fe} / \mathrm{Sr}$, $\mathrm{Rb} / \mathrm{Sr},{ }^{87} \mathrm{Sr} /{ }^{86} \mathrm{Sr}$ bem como a um decréscimo nos valores de $\delta^{13} \mathrm{C}$ e $\delta^{18} \mathrm{O}$ (Brand \& Veizer, 1980; Banner \& Hanson, 1990). Diversos parâmetros empíricos, baseados nestas razões, são apresentados por diferentes autores. Como os carbonatos das seções BL, BAU e PGL foram submetidos a análises mais completas, a discussão para estas seções será feita de forma diferente das seções AP e VS.

Em geral, os isótopos de C são mais resistentes às alterações pós-deposicionais que os de $\mathrm{Sr}$, visto que os primeiros são constituintes majoritários de minerais carbonáticos ao passo que o $\mathrm{Sr}$ ocorre como elemento traço. Os valores de $\delta^{13} \mathrm{C}$ também são menos afetados que os de $\delta^{18} \mathrm{O}$, pois fluidos aquosos diagenéticos ou metamórficos são empobrecidos em $\mathrm{C}$ (Frimmel, 2010). Mesmo assim, dependendo do grau de interação entre fluido e rocha, pode ocorrer modificação do registro isotópico de $\mathrm{C}$ e $\mathrm{O}$ durante a diagênese que poderia ser 
reconhecida por uma correlação positiva em diagramas $\delta^{18} \mathrm{O} v s . \delta^{13} \mathrm{C}$ (Derry, 2010). A análise de tal diagrama para as seções AP e VS não aponta para esta interpretação (Fig. 21), mas a ampla oscilação dos valores de $\delta^{13} \mathrm{C}$ observado para a Seção AP (Fig. 9) e para a porção central da seção VS (Fig. 11) com grandes discrepâncias entre as amostras adjacentes são bastante sugestivas de que estes resultados não são representativos da água do mar na época da deposição dos carbonatos.

Tanto a seção AP quanto a porção central da VS são caracterizados por ocorrências importantes de dolomitos de coloração bege e lâminas de mesma cor compostas por dolomita, quase sempre associadas a estruturas tectônicas como dobras, brechas, boudins e falhas de empurrão. À luz deste fato, assume-se que estes litotipos são produtos de dolomitização tectônica. Tal processo deveria levar a um decréscimo dos valores de $\delta^{13} \mathrm{C}$ e $\delta^{18} \mathrm{O}$, conforme já citado.

A análise disto é complicada para a seção AP, na qual não há nenhum intervalo em que se tenha absoluta certeza de que o registro isotópico seja original. Na base desta seção observa-se certa coerência com valores de $\delta^{13} \mathrm{C}$ de cerca de $-1,5 \%$ e de $\delta^{18} \mathrm{O}$ ao redor de $10,5 \%$. No topo, também ocorre uma tendência coerente de valores de $\delta^{13} \mathrm{C}$ próximos a $0 \%$ e de $\delta^{18} \mathrm{O}$ próximos a $-9 \%$. Se estes valores são assumidos como representativos do ambiente deposicional, nota-se que os demais carbonatos possuem valores de $\delta^{13} \mathrm{C}$ mais negativos, mas de $\delta^{18} \mathrm{O}$ menos negativos.

A seção VS permite um teste melhor desta hipótese. As porções de base e topo apresentam valores de $\delta^{13} \mathrm{C}$ e $\delta^{18} \mathrm{O}$ coerentes quando se comparam os resultados obtidos com as amostras adjacentes. Além disto, não possuem porções significativamente dolomitizados, mas sim calcários com algumas lâminas compostas por dolomita. Com base nisso, consideram-se os resultados isotópicos de $\mathrm{C}$ e $\mathrm{O}$ destas porções originais e representativos da água do mar na época da deposição. Isto fornece uma base sólida para avaliar o efeito da dolomitização na porção central. Esta apresenta valores de $\delta^{13} \mathrm{C}$ mais negativos, em geral, e valores de $\delta^{18} \mathrm{O}$ menos negativos, de forma semelhante aos carbonatos da seção AP. Isto confirma o efeito de decréscimo dos valores isotópicos de $\mathrm{C}$ descrito por Brand \& Veizer (1980) e Banner \& Hanson (1990), mas não para os isótopos de O. Tal observação pode ser explicada pela interação dos carbonatos destas seções com fluidos ricos em ${ }^{12} \mathrm{C}$ e ${ }^{18} \mathrm{O}$. Os principais fluidos diagenéticos naturais são isotopicamente leves, como por exemplo água meteórica e de degelo, ou pesados, como as salmouras (Kah, 2000). Visto que a composição inferida dos fluidos estudados difere destes, considera-se isto mais uma evidência de que estes são de origem tectônica. Conclui-se então que os efeitos de uma interação carbonato/fluido 
nem sempre tem um único resultado possível. Mais ainda, as alterações isotópicas que podem ocorrer são dependentes da composição de tal fluido. É importante ressaltar que o fluido em questão também não corresponde ao que preencheu falhas e os veios concordantes a $S_{0}$, visto que estes são relativamente enriquecidos em ${ }^{13} \mathrm{C}$ e ${ }^{16} \mathrm{O}$. Isto é compatível com a petrografia que indicou que estes são pós-tectônicos.

Outra característica interessante da porção central da seção VS é que os valores de $\delta^{13} \mathrm{C}$ oscilam bastante. Em contrapartida, os de $\delta^{18} \mathrm{O}$ são bastante homogêneos. Explica-se tal fato pela maior susceptibilidade dos isótopos de $\mathrm{O}$ às alterações pós-deposicionais. A quantidade de fluido que interagiu com os carbonatos depende da permissividade dos estratos à percolação dos mesmos. Tal permissividade pode ter ocorrido durante o deslize interestratal observado pelas lineações E-W. Como o pacote rochoso é heterogêneo, o comportamento reológico dos diferentes estratos deve ter sido particular a cada um destes, resultando em diferentes permissividades. Os valores isotópicos de $\mathrm{C}$ decrescem de forma diretamente proporcional à razão fluido/rocha durante os processos tectônicos (quanto maior a razão, maior o decréscimo). Dado que os isótopos de O são mais facilmente modificados, estes se equilibram de forma mais fácil com os fluidos que os isótopos de C, ou seja, de maneira menos independente em relação à razão fluido/rocha.

As razões ${ }^{87} \mathrm{Sr} /{ }^{86} \mathrm{Sr}$ obtidas em 3 amostras de carbonatos do grupo 1 são bastante radiogênicas, superiores a 0,7090. Tais amostras apresentam teores de $\mathrm{Sr}$ superiores a 300 ppm que, de acordo com Halverson et al. (2007), as fazem qualificadas para análises isotópicas de Sr. Mesmo assim, seus teores (<600 ppm - Tabela 2) são bem inferiores aos dos carbonatos do grupo 2. Isto, em conjunto com o elevado grau de dolomitização observado nas seções AP e VS, sugere que as razões ${ }^{87} \mathrm{Sr} /{ }^{86} \mathrm{Sr}$ destes carbonatos não são primárias. É provável que durante a dolomitização, o $\mathrm{Sr}$ original das rochas tenha sido lixiviado e $\mathrm{Sr}$ radiogênico de um fluido, incorporado a rocha.

Ao contrário dos carbonatos do grupo 1, os do grupo 2 foram submetidos a análises geoquímicas mais completas. Isto porque após a petrografia, as rochas das seções BL, BAU e PGL se mostraram mais propícias para análises isotópicas de $\mathrm{Sr}$, dado o menor conteúdo de sedimentos continentais e menor grau de dolomitização. Desta forma, é possível fazer uma análise de representatividade dos dados de maneira mais precisa, tanto sob o aspecto quantitativo quanto gráfico. Como já mencionado no item 2.3.4, serão utilizados os parâmetros de monitoramento de alterações pós-deposicionais propostos por Fölling \& Frimmel (2002), visto que estes são mais rigorosos para os isótopos de Sr. 
Inicialmente, analisando os isótopos de $\mathrm{C}$ e $\mathrm{O}$, observa-se que os dados das seções do grupo 2 são bastante coerentes, o que sugere que estes são representativos da composição isotópica original dos carbonatos. Algumas poucas exceções são notadas.

$\mathrm{Na}$ amostra 11-BL-10 o valor de $\delta^{18} \mathrm{O}$ é ligeiramente maior que o das demais amostras (Fig. 13). A amostra 11-BAU-09 possui valor $\delta^{13} \mathrm{C}$ um pouco menor que as demais e apresenta finas lâminas dolomíticas intercaladas no calcário (Fig. 15). O caso mais curioso ocorre na seção PGL. As amostras 11-PGL-32 e 33 possuem valores de $\delta^{13} \mathrm{C}$ francamente menores se comparados às demais. Nota-se também que as adjacências destas amostras apresentam valores isotópicos de C levemente menores. Não são visíveis diferenças significativas dos valores $\delta^{18} \mathrm{O}$ desta região, embora exista uma tendência destes serem um pouco mais negativos. Assim como nas seções AP e VS, este intervalo apresenta finas lâminas composta por dolomita e está acima de uma falha de empurrão e de um boudin, o que novamente sugere que a dolomitização é de origem tectônica.

De acordo com Fölling \& Frimmel (2002), rochas carbonáticas que guardam a composição isotópica original possuem razões $\mathrm{Mn} / \mathrm{Sr}<10$ e Fe/ $\mathrm{Sr}<50$. Todos os carbonatos analisados do grupo 2 se enquadram nesta situação, inclusive a amostra 11-PGL-33 (Tabela 2). Tal amostra possui razão $\mathrm{Mn} / \mathrm{Sr}$ igual a 0,5 e Fe/Sr igual a 16,65, ambos maiores que das demais amostras. Como é notável que o registro isotópico de $\mathrm{C}$ desta não é original, percebese que estes parâmetros não são eficientes para este estudo.

A análise gráfica dos carbonatos permite a mesma interpretação realizada pela análise das colunas isotópicas. O gráfico $\mathrm{Mg} / \mathrm{Ca} v s . \delta^{13} \mathrm{C}$ e $\delta^{18} \mathrm{O}$ mostra que a alteração dos valores isotópicos de $\mathrm{C}$ está diretamente ligada a um aumento na razão $\mathrm{Mg} / \mathrm{Ca}$ (Fig. 32). De forma semelhante, também está ligada a um incremento na razão $\mathrm{Mn} / \mathrm{Sr}$. A análise do gráfico de $\mathrm{Mg} / \mathrm{Ca}$ vs. Mn/Sr (Fig. 33) também sugere que os incrementos de ambas razões estão ligados. De fato, a interação de carbonatos marinhos com fluidos diagenéticos (água doce, meteórica, de degelo ou salmoura) acarreta na lixiviação do $\mathrm{Sr}$ e com concomitante incorporação de $\mathrm{Mn}$ nestes litotipos (Brand \& Veizer, 1980; Veizer et al., 1983). Um raciocínio simples baseado neste conceito poderia indicar que o incremento conjunto entre $\mathrm{Mn} / \mathrm{Sr}$ e $\mathrm{Mg} / \mathrm{Ca}$ na amostra alterada é resultado diagenético. Entretanto, uma análise mais criteriosa revela o contrário.

Dado que o Ca é mais resistente que o Sr à lixiviação, por ser constituinte majoritário de rochas carbonáticas, um processo de alteração pós-deposicional acarretaria em rápido decréscimo da razão $\mathrm{Sr} / \mathrm{Ca}$. Isto seria acompanhado pela incorporação de Mn na química dos carbonatos, conforme discutido. A análise do gráfico $\mathrm{Sr} / \mathrm{Ca}$ vs. Mn (Fig. 34) mostra claramente que o decréscimo desta razão não é acompanhado pela incorporação de $\mathrm{Mn}$. De fato, o teor de Mn da amostra 11-PGL-33 não difere das demais (Tabela 1). Visto que o 
processo de alteração pós-deposicional observado na amostra em questão difere do apresentado para diagênese na literatura, considera-se isto mais um argumento a favor de uma dolomitização tectônica. Nota-se, entretanto, que o fluido de interação difere daqueles observados para as seções do grupo 1 , já que sua composição aparenta ser rica em ${ }^{12} \mathrm{C} \mathrm{e}{ }^{16} \mathrm{O}$. Tal fato pode ser explicado pela presença de diferentes fluidos durante os processos tectônicos sofridos pelas rochas da Formação Sete Lagoas ou pelas distintas interações fluido/rocha em cada pacote rochoso.
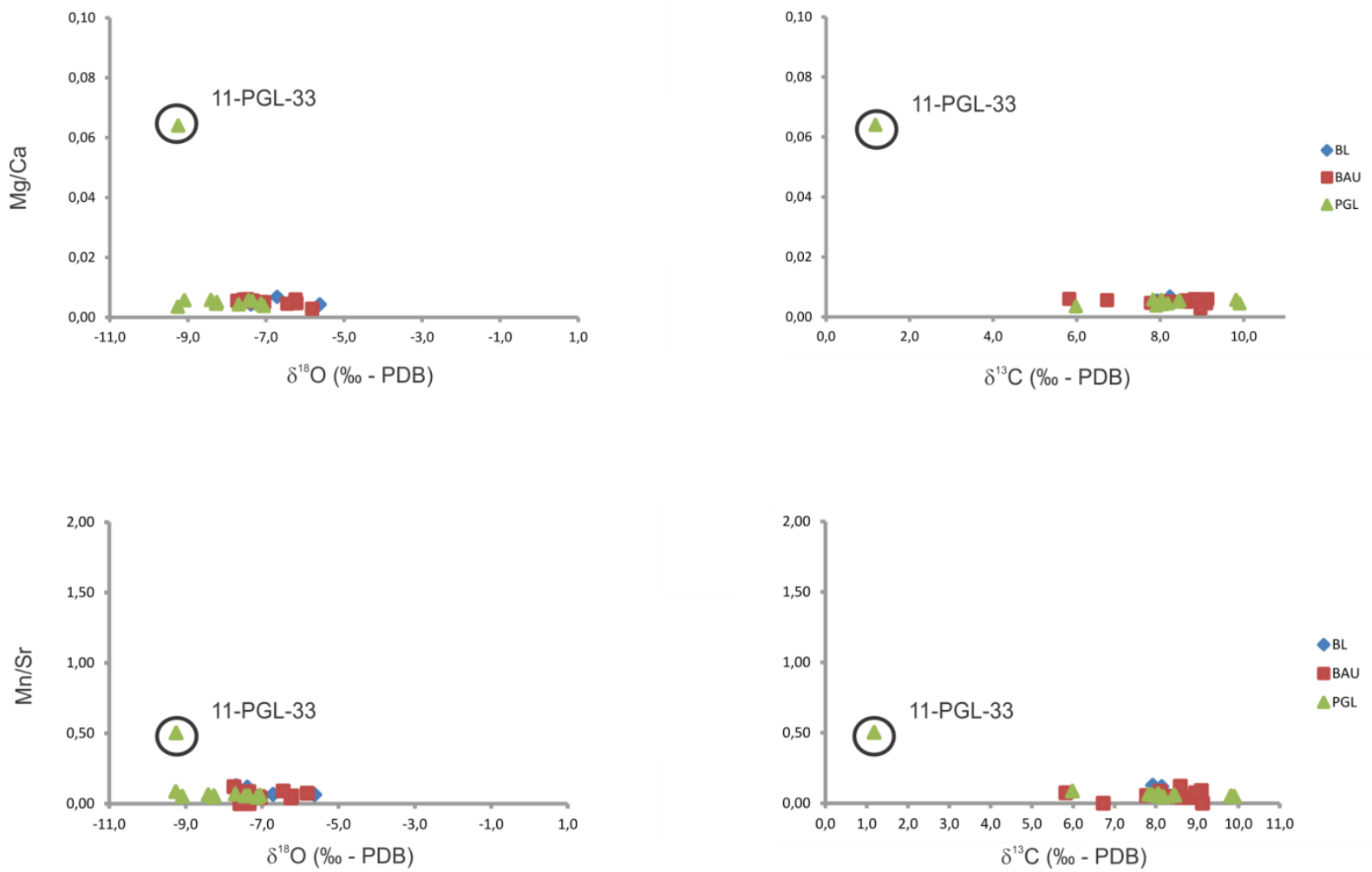

Fig. 32 - Gráficos de dispersão entre $\mathrm{Mg} / \mathrm{Ca}$ e $\mathrm{Mn} / \mathrm{Sr}$ vs. $\delta^{13} \mathrm{C}$ e $\delta^{18} \mathrm{O}$. Nota-se que amostra 11-PGL-33 difere geoquimicamente das demais. 


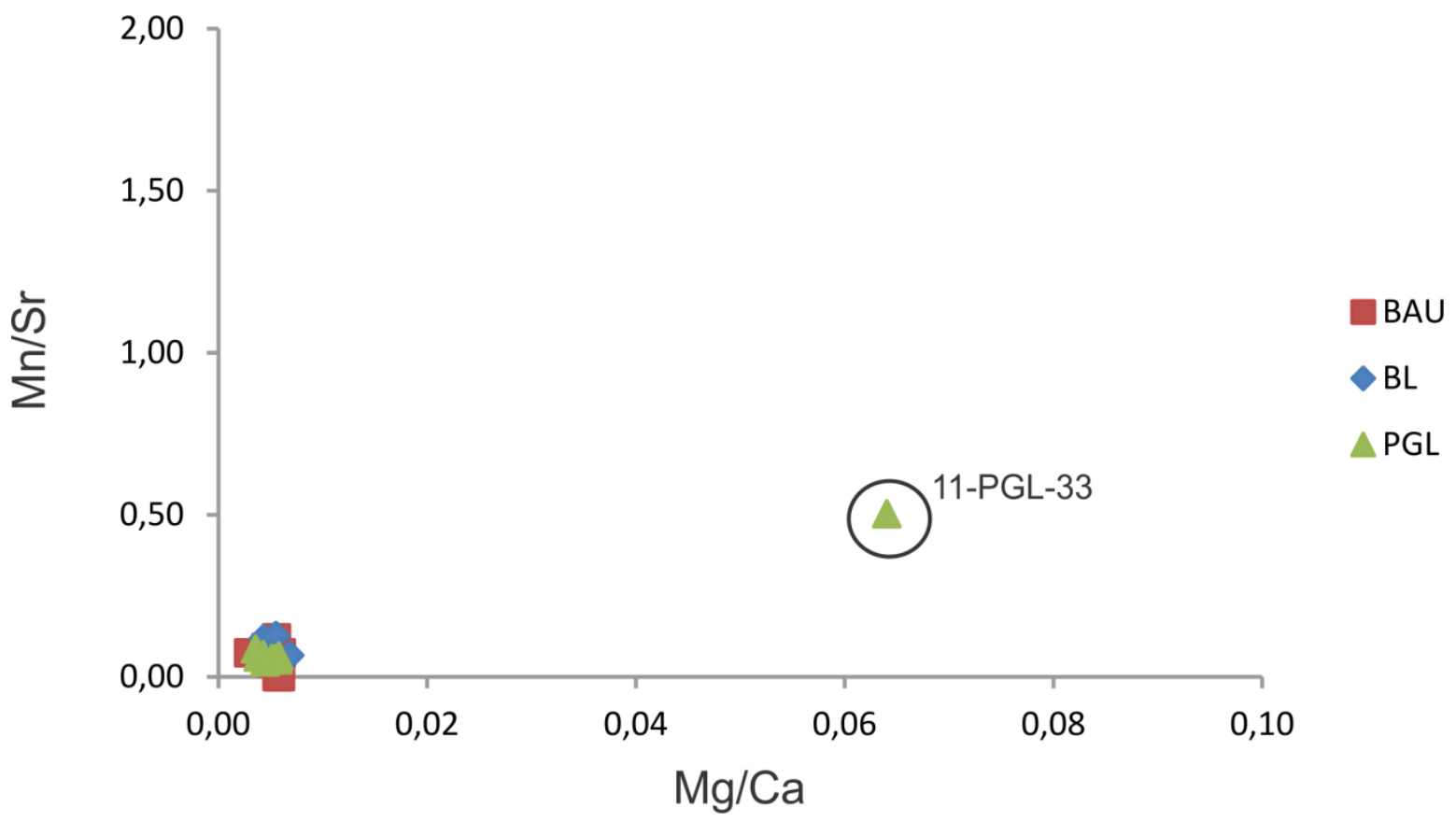

Fig. 33 - Gráfico de dispersão entre as razões $\mathrm{Mn} / \mathrm{Sr}$ vs. $\mathrm{Mg} / \mathrm{Ca}$ das amostras de carbonatos.

Passando a verificação da representatividade dos isótopos de $\mathrm{Sr}$, nota-se que três das quatro razões ${ }^{87} \mathrm{Sr} /{ }^{86} \mathrm{Sr}$ obtidas para a seção BL são bastante consistentes e próximas a 0,7075 . A razão discordante é igual a 0,7071. De acordo com Fölling \& Frimmel (2002), carbonatos que guardam a composição isotópica da água do mar na época da deposição possuem razões $\mathrm{Rb} / \mathrm{Sr}<0,001, \mathrm{Mn} / \mathrm{Sr}<0,5, \mathrm{Fe} / \mathrm{Sr}<3, \mathrm{Sr} / \mathrm{Ca}>0,001$ e valores de $\delta^{18} \mathrm{O}>-10 \%$ o (PDB). As amostras de calcários desta seção se enquadram nestes parâmetros com exceção das razões $\mathrm{Rb} / \mathrm{Sr}$ (Tabela 2), mas como a interferência de ${ }^{87} \mathrm{Sr}$ radiogênico foi removida (conforme equação no item 3.3.) isto não caracteriza um problema. As amostras também apresentaram altos teores de Sr, acima do limite de 300 ppm proposto por Halverson et al. (2007) de confiabilidade dos resultados. A razão menos radiogênica foi obtida na amostra 11-BL-10 que também possui valor de $\delta^{18} \mathrm{O}$ discordante das amostras adjacentes. Os argumentos acima endossam a consideração de que a razão ${ }^{87} \mathrm{Sr} /{ }^{86} \mathrm{Sr} 0,7075$ é a mais representativa da composição isotópica do ambiente marinho deposicional. Soma-se a estes, o fato de que amostra com maior teor de Sr (11-BL-03) também apresentou esta razão. 


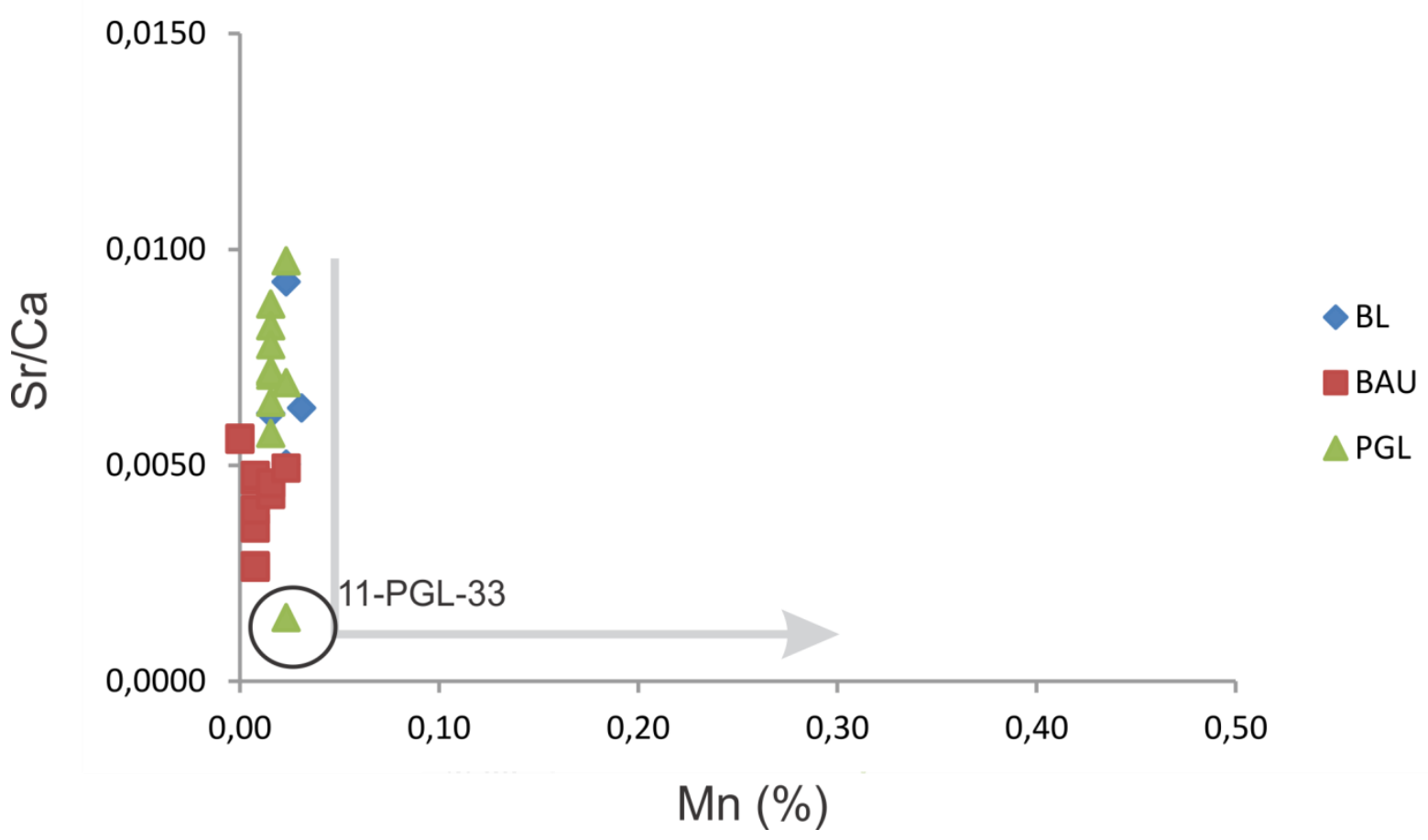

Fig. 34 Gráfico de dispersão entre os teores de Sr/Ca vs. Mn. Nota-se que a diminuição das razões Sr/Ca não é acompanhada de incorporação de Mn na química dos carbonatos.

As amostras da seção BAU atendem aos parâmetros de Fölling \& Frimmel (2002) e de Halverson et al. (2007). Exceção novamente é feita às razões Rb/Sr (Tabela 2), mas como já discutido, isto não caracteriza um problema. A amostra 11-BAU-09, com valor de $\delta^{13} \mathrm{C}$ menor que as demais e com lâminas dolomíticas, possui os menores teores de $\mathrm{Sr}$ da seção e sua razão ${ }^{87} \mathrm{Sr} /{ }^{86} \mathrm{Sr}$ pode ser considerada a menos representativa, ainda que não destoe das demais amostras. A diminuição deste teor de Sr pode ter ocorrido durante a dolomitização tectônica que lixiviou o $\mathrm{Sr}$, conforme já discutido. As amostras 11-BL-06 e 11-BL-37 possuem os maiores teores de $\mathrm{Sr}$ da seção BAU e suas razões ${ }^{87} \mathrm{Sr} /{ }^{86} \mathrm{Sr}$, respectivamente iguais a 0,70762 e 0,70753, são as mais representativas do ambiente deposicional na época da deposição. Os demais carbonatos não necessariamente guardam razões isotópicas de Sr modificadas pósdeposição, visto que estão dentro dos limites geoquímicos de confiabilidade. No caso das mais radiogênicas, 11-BAU-12 e 49, as razões Y/Ho são as mais baixas da seção (Tabela 3) e próximas daquelas obtidas para a crosta superior (Kamber et al., 2005). Tal observação sugere que estes carbonatos podem ter sido depositados em períodos mais úmidos, de maior intemperismo da crosta continental, com maior contribuição de águas fluviais portadoras de Sr mais radiogênico.

Para a seção PGL também foram obtidas razões geoquímicas e teores de $\mathrm{Sr}$ que atendem aos padrões de confiabilidade utilizados neste trabalho, inclusive com grande parte das amostras apresentando razões $\mathrm{Rb} / \mathrm{Sr}$ igual a 0,001 (Tabela 2). A amostra 11-PGL-33 
corresponde ao intervalo interpretado como alterado por dolomitização tectônica e possui o menor teor de Sr, que corrobora o processo de lixiviação deste elemento. A razão ${ }^{87} \mathrm{Sr} /{ }^{86} \mathrm{Sr}$ mais radiogênica $(0,7086$; amostra $11-\mathrm{PGL}-35)$ foi obtida acima deste carbonato, em uma amostra que possui valor de $\delta^{13} \mathrm{C}$ pouco menor que as obtidas para o topo da seção. Embora possa indicar uma zona ainda afetada pelo tectonismo, não há evidências petrográficas e geoquímicas disto, já que a amostra 11-PGL-35 possui altos teores de $\mathrm{Sr}$ e razões geoquímicas semelhantes às demais rochas carbonáticas inalteradas da seção. Novamente a amostra com maior teor de $\mathrm{Sr}(11-\mathrm{PGL}-23)$ apresenta razão ${ }^{87} \mathrm{Sr} /{ }^{86} \mathrm{Sr}$ igual a 0,7075 , considerada a mais representativa da composição isotópica do ambiente marinho na época da deposição.

É interessante notar que as razões consideradas as mais representativas para as seções deste estudo, são semelhantes às apresentadas por outros autores em diversas localidades da Bacia do São Francisco. Kuchenbecker (2011) obteve razões ${ }^{87} \mathrm{Sr} /{ }^{86} \mathrm{Sr}$ representativas ao redor de 0,7075 para a primeira sequência da Formação Sete Lagoas na região de Arcos (MG), sul do CSF; Alvarenga et al. (2007) obtiveram as mesmas razões para as duas sequências na região dos municípios de Formosa, Bezerra e Cabeceiras (GO), próximo do limite do cráton com a Faixa Brasília; Misi et al. (2007) determinaram razões 0,7076 em carbonatos da primeira sequência.

\subsection{Representatividade dos dados de Elementos Terras Raras}

De modo semelhante ao feito com os dados isotópicos, é necessário avaliar os casos em que os resultados de ETR obtidos são representativos da água do mar na época da deposição ou de outros processos e elementos estranhos a este ambiente. Embora os carbonatos dificilmente tenham suas composições de ETR modificadas durante a diagênese (Banner \& Hanson, 1990; Webb et al., 2009), os sedimentos detríticos presentes em suas constituições podem causar enriquecimento nestes elementos nos lixiviados analíticos.

Os sedimentos siliciclásticos são mais enriquecidos em ETR que os carbonáticos, fato que pode ser averiguado pela comparação dos dados do padrão PAAS (Taylor \& McLennan, 1985) com os apresentados para rochas carbonáticas na literatura (e.g. Frimmel, 2009; Zhao et al., 2009; Ling et al., 2011) e neste trabalho (Tabela 3). Isto faz com que, durante os processos analíticos de ataque ácido, a dissolução de minerais terrígenos libere aos lixiviados quantidades apreciáveis de ETR. Tal processo pode ser observado nos gráficos da Fig. 35. Nota-se uma correlação positiva entre os teores de $\mathrm{Al}$ e $\mathrm{Zr}$, oriundos da mineralogia detrítica dos carbonatos, e o conteúdo total de ETR das amostras analisadas. Tal correlação evidencia 
que o aumento dos teores de ETR estão ligados à presença de minerais não carbonáticos nas amostras. De acordo com Frimmel et al. (2006), a mesma relação deveria ser observada em gráficos de teores de Th $v s$. Al e Sc vs. Al. De fato há correlação positiva entre os teores de Th e Al que corrobora a indicação da contaminação por terrígenos. Como os teores de $\mathrm{Sc}$ invariavelmente são menores que o limite de detecção da metodologia aplicada (Tabela 3), não foi possível verificar a mesma relação em um diagrama Sc vs. Al.
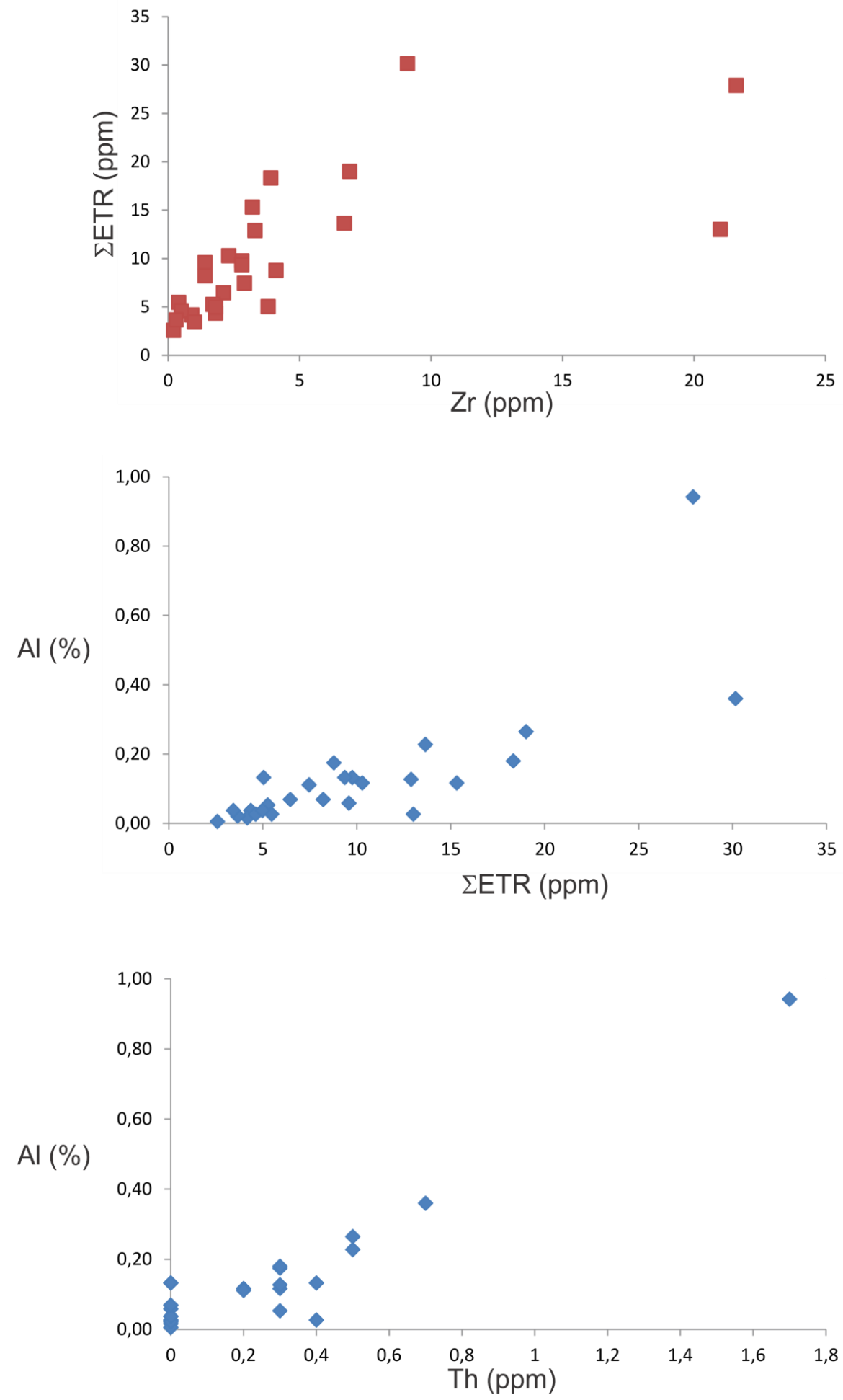

Fig. 35 - Diagramas de teores $\Sigma$ ETR vs. Zr, Al vs. ETR e Al vs.Th, nos quais se observa correlação positiva entre os constituintes de minerais terrígenos e o conteúdo de ETR dos carbonatos analisados. 
Uma vez verificado que o conteúdo de sedimentos detríticos influencia os resultados obtidos, é necessária a realização de uma triagem para averiguar quais amostras são representativas do ambiente deposicional marinho. Isto foi realizado por meio de parâmetros disponíveis na literatura. Ling et al. (2011) consideram teores de $\mathrm{Al}<0,35 \%$, Fe < 0,45\%, Th $<0,5 \mathrm{ppm}, \mathrm{Sc}<2 \mathrm{ppm}, \Sigma \mathrm{ETR}<12 \mathrm{ppm}$ e razões $\mathrm{Y} / \mathrm{Ho}>36$ como limites para se considerar uma amostra de carbonato com composição de ETR representativa da água do mar na época de sua deposição. Frimmel (2009) considera um parâmetro mais simples: teores de $\mathrm{Zr}<4$ ppm. Neste trabalho foram combinados ambos os parâmetros para aumentar o rigor da seleção e garantir a escolha de amostras representativas. Apenas 8 das 26 amostras analisadas podem ter suas composições de ETR consideradas representativas do ambiente deposicional: 11PGL-03, 11-BAU-06, 09, 15, 18, 41, 54 e 57. Nenhuma amostra da seção BL possui os parâmetros exigidos pela triagem.

Os diagramas de distribuição dos ETR normalizados ao padrão PAAS para as amostras acima citadas são exibidos na Fig. 36. Observa-se um empobrecimento em ETR leves em relação aos médios e pesados e empobrecimento geral ETR em relação ao padrão em todas as amostras, como ocorre em sedimentos marinhos atuais (Zhang \& Nozaki, 1996). Entretanto, as demais características dos oceanos modernos não são observadas em todos os carbonatos analisados. A amostra 11-PGL-03 apresenta leve enriquecimento em La e leve anomalia negativa em $\mathrm{Ce}$, mas não apresenta uma marcada anomalia positiva de $\mathrm{Y}$ e exibe uma pronunciada anomalia negativa de Dy, de caráter desconhecido e não reportada em nenhum dos trabalhos já citados nesta dissertação. As amostras 11-BAU-09, 15 e 18 também apresentam distribuições normalizadas semelhantes, com uma pequena ressalva para a última amostra citada que apresenta anomalia positiva de Y. A amostra 11-BAU-06 guarda apenas a anomalia positiva de Y como característica comum aos oceanos atuais. Seu diagrama de distribuição normalizado mostra um padrão plano para os ETR leves, inclusive com um leve empobrecimento em La, e uma anomalia positiva de Tm também não mencionada na literatura. A amostra 11-BAU-41 exibe leve anomalia positiva de Ce e outra pronunciada de $\mathrm{Nd}$, novamente não mencionada nos trabalhos pesquisados. As amostras 11-BAU-54 e 57 são aquelas que apresentam distribuições mais semelhantes aos sedimentos marinhos atuais. As razões Y/Ho variam entre 36 e 50, menores as dos atuais oceanos entre 60 e 90 (Lawrence et $a l .$, 2006), mas semelhantes às apresentadas na literatura para carbonatos neoproterozoicos e cambrianos de outras seções do globo (Frimmel, 2009; Zhao et al., 2009; Ling et al., 2011).

A análise do parâmetro $\mathrm{Ce} / \mathrm{Ce}^{*}$ também mostra bastante variabilidade entre as amostras (Tabela 3). Para garantir a validade deste parâmetro, além da triagem já mencionada, foram consideradas somente amostras com o parâmetro $\operatorname{Pr} / \operatorname{Pr} *$ entre 0,95 e 1,05, em acordo 
com Ling et al. (2011). As amostras 11-PGL-03 e 11-BAU-09 apresentaram Ce/Ce* igual a 0,53 e 0,59, respectivamente. Considerando o comportamento geoquímico do Ce já discutido no item 2.4, estes valores estão dentro do intervalo encontrado na superfície de oceanos atuais e sugerem oxigenação das águas marinhas durante a deposição da Formação Sete Lagoas. Ling et al. (2011) observaram uma redução dos valores de $\mathrm{Ce} / \mathrm{Ce}^{*}$ de 0,9 para 0,4 da base para o topo da Formação Denjying, na China, e interpretaram isto como um evento importante de oxigenação dos oceanos no limite Ediacarano-Cambriano, que coincide com a diversificação da assembleia fossilífera. Embora não tenham sido encontrados fósseis, os carbonatos da Formação Sete Lagoas apresentam alto teor de matéria orgânica e elevados valores de $\delta^{13} \mathrm{C}$ que sugerem alta bioprodutividade no ambiente deposicional. As amostras 11BAU-06 e 11-BAU-18 apresentaram valores do parâmetro Ce/Ce* iguais a 0,82 e 0,71, respectivamente, que de acordo com Ling et al. (2011), sugerem condições paleoambientais subóxicas a óxicas. As amostras 11-BAU-54 e 57 apresentam valores de $\mathrm{Ce} / \mathrm{Ce}$ * muito próximos a 0 , mas como estes podem ser resultado dos baixos teores de $\operatorname{Pr}$ (ver metodologia em 3.4), serão desconsiderados por representarem possível enviesamento dos cálculos. Estes dados são bastante sugestivos de que o aumento da bioprodutividade observado nas seções BL, BAU e PGL pode estar ligado a um evento de oxigenação do ambiente marinho. Entretanto as amostras 11-BAU-15 e 11-BAU-41 apresentaram valores de $\mathrm{Ce} / \mathrm{Ce}^{*}$ iguais a 1,50 e 2,31, respectivamente, que sugerem condições paleoambientais anóxicas a euxínicas (Ling et al., 2011). Estes dados bastante contrastantes demonstram que o baixo número de amostras confiáveis pode não ser representativo o suficiente do ambiente de deposição da Formação Sete Lagoas.

De qualquer forma, a grande variabilidade dos padrões de distribuição normalizada e mesmo dos valores de $\mathrm{Ce} / \mathrm{Ce}^{*}$ levam a duas possíveis interpretações. A primeira é de que os parâmetros indicadores de confiabilidade apresentados na literatura não são válidos para os carbonatos deste estudo e que muitas das amostras analisadas neste trabalho não são representativas da água do mar na época da deposição dos sedimentos carbonáticos. Isto é cabível porque tanto os parâmetros de Ling et al. (2011) quanto de Frimmel (2009) são empíricos e não necessariamente iguais para todas a sucessões carbonáticas espalhadas pelo planeta. A outra interpretação possível é de que o ambiente marinho da Formação Sete Lagoas foi diferente de outros oceanos contemporâneos e sua composição química esteve sujeita a variações de curto tempo, visto que alguns ETR como Ce, Pr e Eu possuem tempo de residência no mar inferior ao do C (Alibo \& Nozaki, 1999). Esta última interpretação é a mais plausível à luz da idade máxima de deposição obtida para a Formação Sete Lagoas neste trabalho. Isto será discutido nos itens 5.4 e 5.5. 
Os diagramas de distribuição normalizada de ETR das amostras consideradas não representativas da composição da água marinha na época da deposição são apresentados na Fig. 37. Para a seção BAU não se observa qualquer tipo de padrão destas distribuições, inclusive com algumas amostras se assemelhando às representativas (11-BAU-12, 37 e 49). Para as seções PGL e BL notam-se características que as diferem da seção anterior. Há uma tendência generalizada das distribuições serem planares (exceção à amostra 11-PGL-27) e de as amostras serem mais enriquecidas em ETR comparadas ao padrão PAAS. Além disso, estas amostras apresentaram baixas razões Y/Ho, quase todas dentro do intervalo 27-30, típicas da crosta superior (Kamber et al., 2005). Estas características sugerem grande influência de águas fluviais no ambiente marinho de deposição e é encontrado em carbonatos de fácies proximais (Frimmel 2009, 2010). Interessante notar que as seções PGL e BL se encontram mais a E da seção BAU (Fig. 6). 


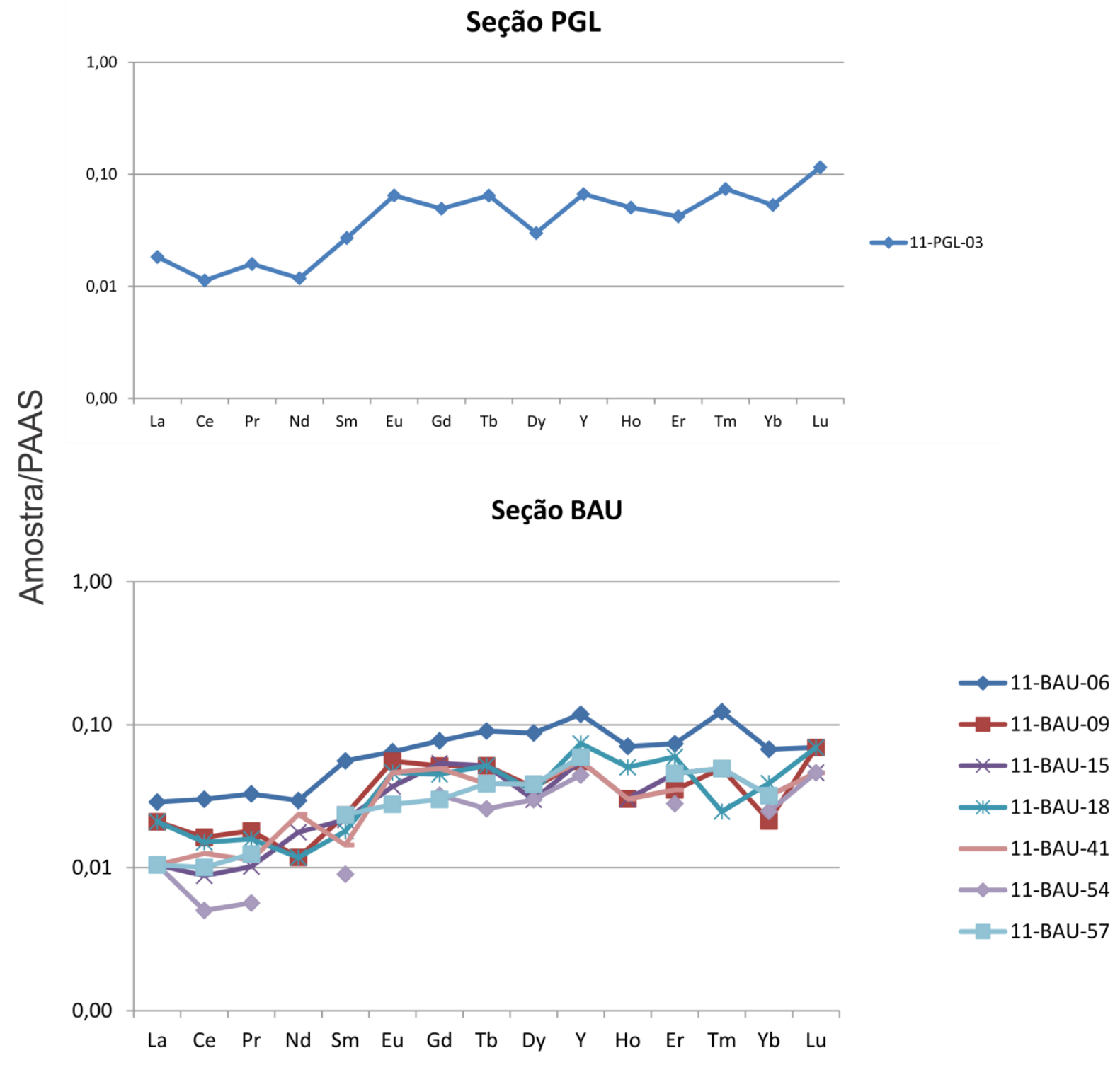

Fig. 36 - Diagramas de distribuição normalizada das amostras de carbonatos considerados representativos da composição de ETR do ambiente de deposição. 


\section{Seção BL}

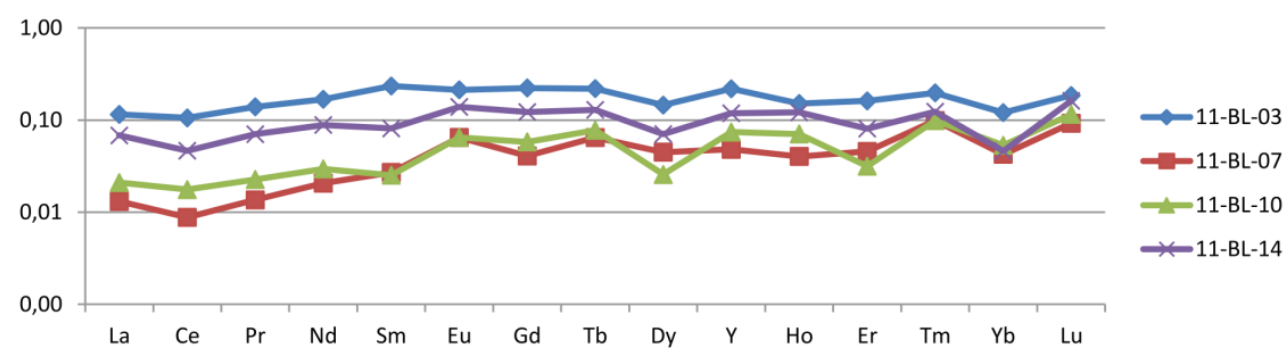

Seção BAU

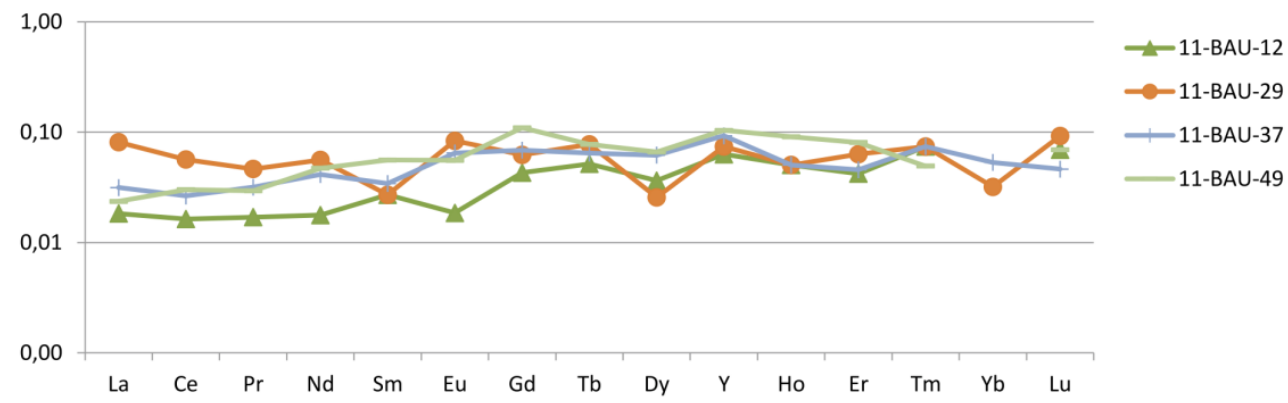

Seção PGL

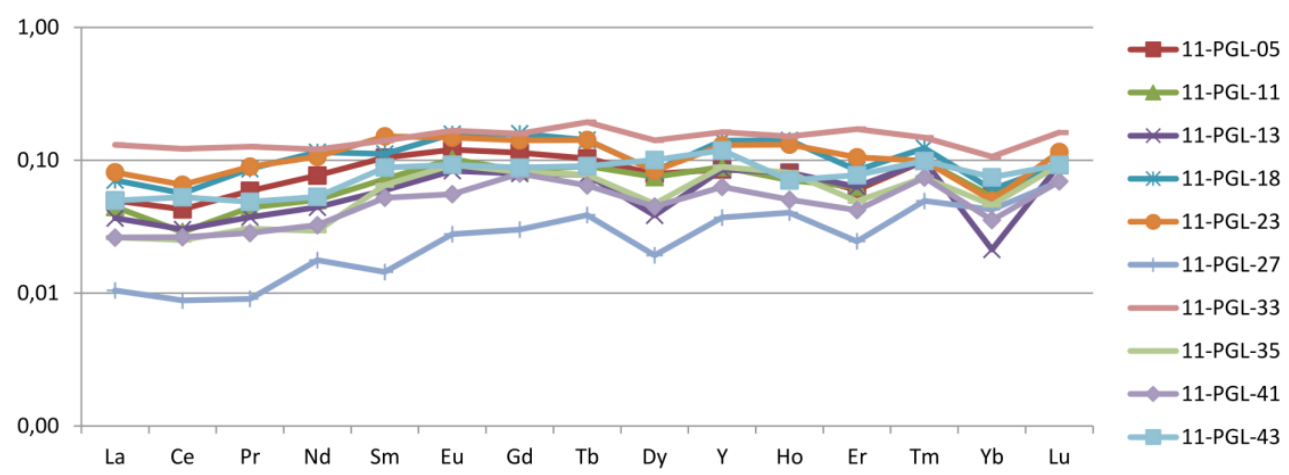

Fig. 37 - Diagramas de distribuição normalizada das amostras de carbonatos considerados não representativos da composição de ETR do ambiente de deposição.

\subsection{Quimioestratigrafia isotópica}

O objetivo desta dissertação é determinar as idades das duas sequências deposicionais da Formação Sete Lagoas propostas na literatura (Vieira et al., 2007a, b) e avaliar a representatividade temporal do salto isotópico comumente observado entre estas (Kuchenbecker, 2011; Santos et al., 2000, 2004; Vieira et al., 2007b). Para atingi-lo, é de suma importância posicionar cada seção estudada na estratigrafia da unidade geológica alvo. Dada a grande extensão física da Bacia do São Francisco, deve haver um número muito grande de sistemas deposicionais que representam variações laterais de um mesmo conjunto de rochas contemporâneas. Os isótopos de C também estão sujeitos a esta variação lateral devido ao seu baixo tempo de residência nos oceanos (Frimmel, 2010) e as razões ${ }^{87} \mathrm{Sr} /{ }^{86} \mathrm{Sr}$ 
registram variações de longo tempo, além de serem muito homogêneas ao longo da bacia com valores ao redor de 0,7075 (Alvarenga et al., 2007; Babinski et al., 2007; Caxito et al., 2012; Kuchenbecker, 2011; Misi et al., 2007; Santos et al., 2000, 2004; Vieira et al., 2007b), pouco distinto entre as diferentes porções da Formação Sete Lagoas. À luz destes possíveis elementos de complicação, este trabalho utiliza em conjunto dados sedimentares e isotópicos para posicionamento estratigráfico refinado das seções e dá preferência à correlação com outros trabalhos realizados nas proximidades desta área de estudo (Projeto VIDA, 2003; Vieira et al., 2007a, b; Schöll, 1976), a fim de evitar eventuais erros induzidos pela grande extensão bacinal.

Em uma primeira análise das seções levantadas, chama a atenção a grande diferença sedimentar, geoquímica e isotópica dos carbonatos do grupo 1 (seções AP e VS) e 2 (BL, BAU, PGL). O grupo 1 é constituído por calcários e dolomitos com altos teores de sedimentos siliciclásticos (em especial a seção AP), baixos teores de matéria orgânica, maiores teores de $\mathrm{Rb}$ e menores de $\mathrm{Sr}$ se comparados ao segundo grupo. Também apresentam estruturas sedimentares de águas rasas, provavelmente geradas em ambiente de planície de maré, tais quais laminação rítmica, que alterna areias calcárias recobertas por argila, laminações irregulares truncadas e laminações com cavalgamento supercrítico (climbing ripples). Estas características são bastante diagnósticas do Membro Pedro Leopoldo descrito nos trabalhos de Schöll (1976) e Projeto VIDA (2003) e que corresponde à base da Formação Sete Lagoas. De fato, a localização geográfica das seções do grupo 1 está em regiões mapeadas como tal membro (Projeto VIDA, 2003 - Fig. 6). As rochas das seções AP e VS também se assemelham àquelas agrupadas na primeira sequência desta unidade geológica por Vieira et al. (2007a) em especial às associações de fácies AF3 e 4. A AF4 é caracterizada como de ambiente raso dominado por maré e ocorre exclusivamente na Pedreira Paraíso (E do Município de Sete Lagoas - MG), o que pode sugerir pouca continuidade lateral. A associação de fácies AF3 do mesmo trabalho é caracterizada por depósitos de ambiente dominado por tempestades, com carbonatos sem matéria orgânica e impuros que apresentam até $10 \%$ de terrígenos. As seções AP e VS são interpretadas como uma variação lateral da AF4 depositadas mais próximas à linha de costa que estaria mais a $\mathrm{E}$ da área, com menor influência de tempestades e predomínio de processos dominados por maré. A redução da granulometria e do teor dos terrígenos, a progressiva melhora da seleção e aumento do grau de arredondamento dos mesmos de E para W (AP para VS - Fig. 6), também suportam uma linha de costa a $\mathrm{E}$ da área.

Os valores de $\delta^{13} \mathrm{C}$ mais representativos do ambiente marinho de deposição obtidos para os carbonatos do grupo 1 se encontram em uma faixa ao redor de $0 \%$. A base da seção 
AP apresenta valores de $\delta^{13} \mathrm{C}$ iguais a $-1,6 \%$. As porções de base e de topo da seção VS apresenta valores isotópicos de $\mathrm{C}$ pouco negativos (base) que passam a valores levemente positivos próximos a $2 \%$. Estes valores são claramente correlacionáveis àqueles obtidos por Vieira et al. (2007b) para a porção superior da primeira sequência, acima da capa carbonática com excursão negativa de C, observada nas seções Lontra (LO), Sambra (SA), Paraíso (PA), Tatiana (TA) e Cauê (CE) daquele trabalho (Fig. 38). As curvas de C obtidas para as seções VS e AP apresentam semelhança com segmentos do Grupo Bambuí abaixo do salto isotópico descritos por Santos et al. (2004) em Alvorada (GO), Serra de São Domingos e Mina da Bocaina (MG) e por Kuchenbecker (2011) na região de Arcos (MG - Fig. 39).

Baseado nestas correlações estratigráficas e quimioestratigráficas, conclui-se que as rochas das seções AP e VS pertencem à primeira sequência deposicional da Formação Sete Lagoas, posicionadas abaixo do salto isotópico de $\mathrm{C}$ e acima da base desta unidade, representada pelos carbonatos de capa com valores bastante negativos de $\delta^{13} \mathrm{C}$. Este intervalo marca um estágio no qual o CSF esteve banhado por águas marinhas rasas, com baixa bioprodutividade fotossintética, marcada pelos valores de $\delta^{13} \mathrm{C}$ próximos a $0 \%$, e influência de sedimentação continental, que na área de estudo apresenta decréscimo de E para W.

Já os carbonatos do grupo 2 são dominantemente constituídos por calcários de coloração cinza escura a negra, ricos em matéria orgânica, pobres em sedimentos siliciclásticos, com baixos teores de Rb e altos teores de Sr. A estrutura dominante destas rochas é a laminação plano-paralela com algumas ocorrências de laminação planar truncada, sugestivas de um ambiente mais profundo e menos sujeito à influência de correntes de maré ou tempestades. Estas características são bastante semelhantes às apresentadas na literatura para o Membro Lagoa Santa, que representa a porção superior da Formação Sete Lagoas (Schöll, 1976; Projeto VIDA, 2003). O mapa da Fig. 6 mostra que as seções BL, BAU e PGL localizam-se a NW do município de Lagoa Santa, onde predominam afloramentos do Membro homônimo. Os carbonatos destas seções também são bastante semelhantes aos agrupados nas associações de fácies AF5 e 6 do trabalho de Vieira et al. (2007a). Estas associações incluem pelitos depositados sobre o limite de sequências, dentro da Formação Sete Lagoas após o afogamento da bacia, seguido pelo início da deposição de calcários negros.

Os resultados de isótopos de $\mathrm{C}$ considerados representativos para as seções BL, BAU e PGL mostram valores de $\delta^{13} \mathrm{C}$ francamente positivos que ultrapassam os $10 \%$. Em uma abordagem quimioestratigráfica comparativa com o trabalho de Vieira et al. (2007b), as seções estudadas para esta dissertação podem ser correlacionadas ao topo da seção Canaã (CA), grande parte da seção Mata Grande (MG) e ao topo da seção da Pedreira Cauê (CE), todas estas acima do salto isotópico característico da Formação Sete Lagoas (Fig. 40). As 
seções com carbonatos do grupo 2 também apresentam valores isotópicos de C correlacionáveis ao topo da Formação Sete Lagoas na Serra de São Domingos, Jequitaí, Serra do Cabral e Sete Lagoas (Santos et al., 2004 - Fig. 41).

Estas observações sedimentológicas e quimioestratigráficas claramente posicionam as seções BL, BAU e PGL na segunda sequência da Formação Sete Lagoas, acima do salto isotópico. Neste segundo estágio evolutivo da unidade em questão, houve uma segunda transgressão marinha com águas mais profundas e menos energéticas. Os valores de $\delta^{13} \mathrm{C}$ bastante positivos são comuns a toda bacia e representam processos bioquímicos de ampla distribuição no ambiente marinho, ainda que os valores absolutos sejam um pouco distintos. Tal característica isotópica pode ser explicada por diversos processos tais como altas taxas de soterramento de compostos orgânicos (Knoll et al.,1986), alta bioprodutividade fotossintética, altas taxas de evaporação (Frimmel, 2010), metanogênese relacionada à fermentação, redução direta do $\mathrm{CO}_{2}$ (Whithicar et al., 1986) e redução de sulfatos acompanhada de geração de sulfetos sob condições anaeróbicas (Claypool \& Kaplan, 1974; Pierre, 1989). É bastante provável que o registro isotópico da Formação Sete Lagoas seja resultado de mais de um processo que podem ter reflexos em escala local ou bacinal. Depósitos evaporíticos não são conhecidos no Grupo Bambuí, de forma que é possível descartar processos de evaporação. Como já apontado por Santos et al. (2000), existem ocorrências de gás natural e de sulfetos, que sugerem importância dos processos de metanogênese e de redução de sulfatos, mas em escala local. Em escala bacinal, os mesmos autores propõem que os altos valores isotópicos de $\mathrm{C}$ são decorrentes principalmente da fixação de ${ }^{12} \mathrm{C}$ por processos fotossintéticos e com menor contribuição de uma estagnação da bacia, visto que esta excursão positiva é característica de outras seções carbonáticas neoproterozoicas espalhadas pelo globo. Os novos dados de ETR obtidos neste estudo parecem convergir para esta hipótese.

As anomalias negativas de Ce observadas em alguns dos calcários com composições de ETR representativas da água do mar sugerem oxigenação do ambiente. De acordo com Ling et al. (2011), se esta anomalia é encontrada num carbonato, quer dizer que ao menos uma parte da lâmina d'água acima do ponto a partir do qual este precipitou foi oxigenada. Se isto estiver correto, é possível que os níveis mais rasos do mar que recobriu o CSF neste estágio tenham sofrido oxigenação durante os processos de interação com a atmosfera, possibilitando a diversificação da biota marinha. Isto teria culminado com o aumento da bioprodutividade e geração de matéria orgânica que em ambientes mais profundos e redutores (sugeridos pela presença de pirita autigênica) seria preservada junto com os sedimentos carbonáticos. O mesmo processo é aventado por Ling et al. (2011) para a Formação Denjying (China) do limite do Ediacarano-Cambriano, sugerindo se tratar de um processo em escala 
global. Baseado nestes dados, concorda-se com Santos et al. (2000) no aspecto de que as excursões positivas $\delta^{13} \mathrm{C}$ registradas na Formação Sete Lagoas são resultados de um aumento da bioprodutividade aliado a processos de menor importância de escala local. É importante salientar que poucos dados de ETR representativos foram obtidos e que algumas amostras apresentaram valores de $\mathrm{Ce} / \mathrm{Ce}^{*}$ positivos, que sugerem redução do ambiente. Fica evidente a necessidade de mais estudos neste tema para averiguar esta hipótese.

Como mencionado no início deste item, as razões ${ }^{87} \mathrm{Sr} /{ }^{86} \mathrm{Sr}$ comumente reportadas para a Formação Sete Lagoas ao longo da bacia são bastante homogêneas e não constituem um eficiente balizador estratigráfico intrabacinal. Esta constância contrasta com a leve variação observada nos valores de $\delta^{13} \mathrm{C}$ entre diferentes seções estudadas no CSF, o que sugere uma capacidade da circulação termohalina em homogeneizar a composição isotópica do ambiente marinho em períodos de tempo superiores ao de residência do C (433 anos - Frimmel, 2010), mas inferiores ao do $\mathrm{Sr}$ ( 2,4 Ma - Jones \& Jenkyns, 2001). Isto é algo observado nos oceanos modernos em que este período de homogeneização é da ordem de $10^{5}$ anos (Jacobsen \& Kaufman, 1999). 


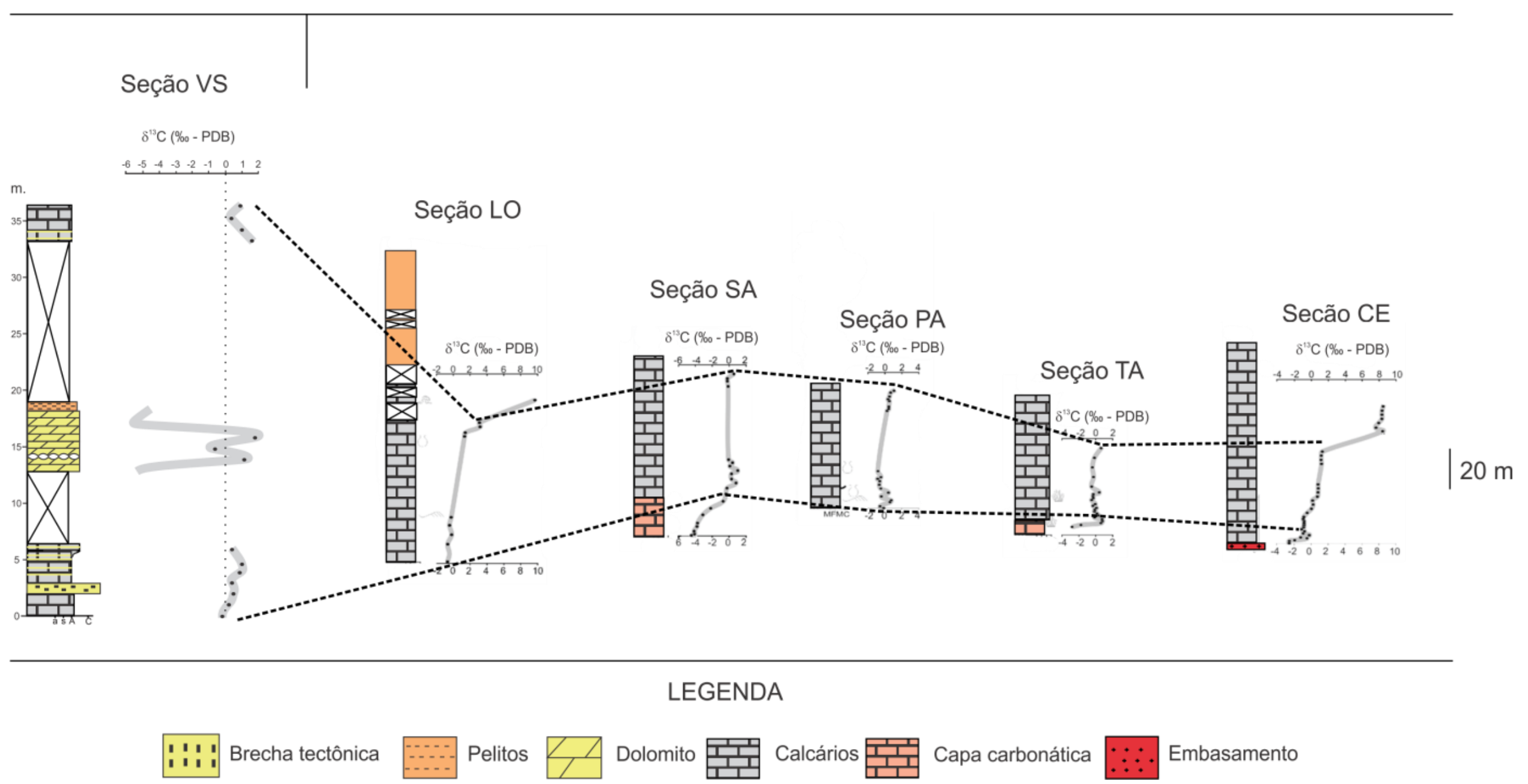

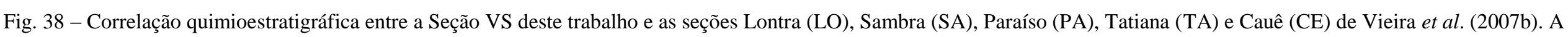
seção AP foi posicionada abaixo do salto isotópico da Formação Sete Lagoas por estratigrafia convencional. 


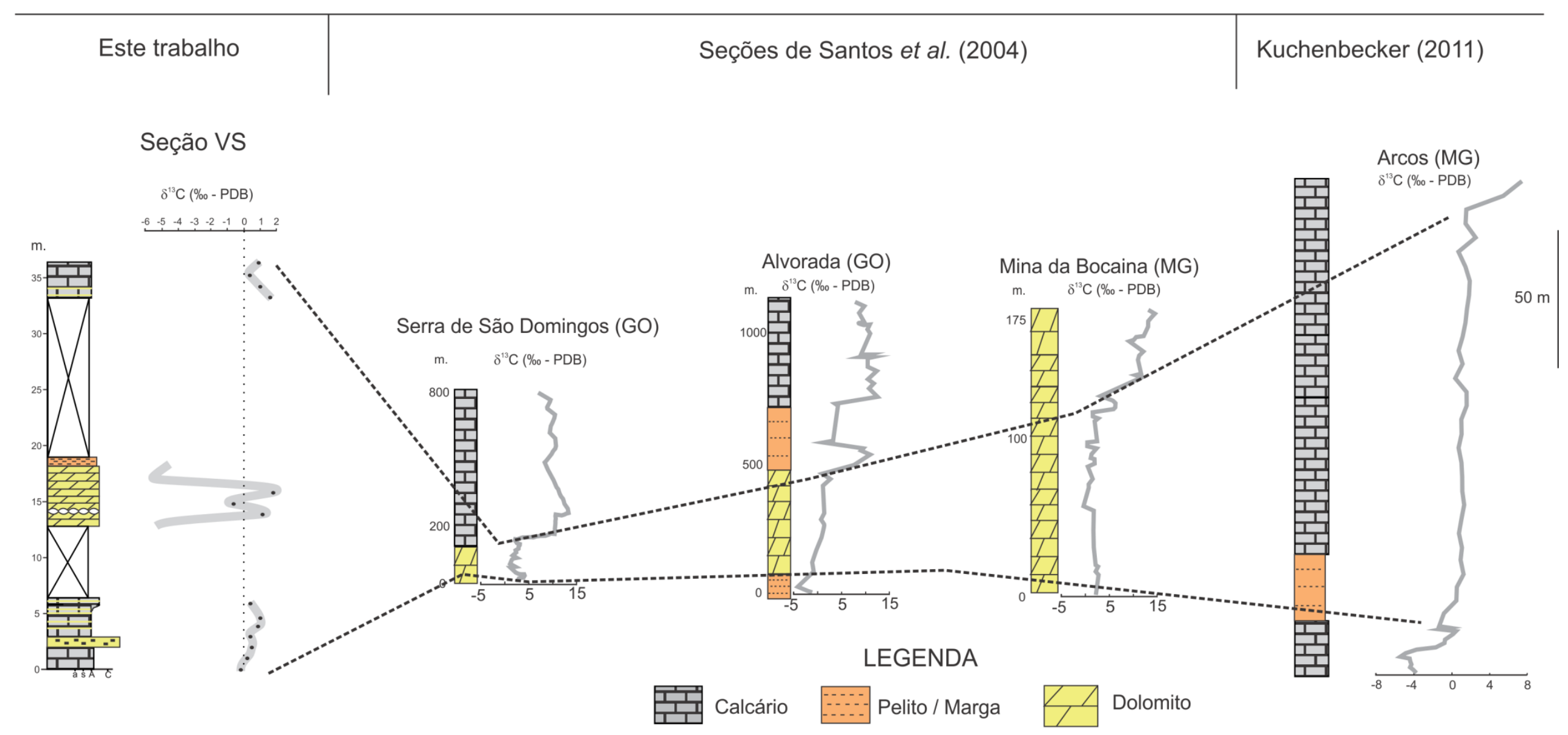

Fig. 39 - Correlação quimioestratigráfica entre a Seção VS deste trabalho e as seções de Santos et al. (2004) e Kuchenbecker (2011). 
Este trabalho

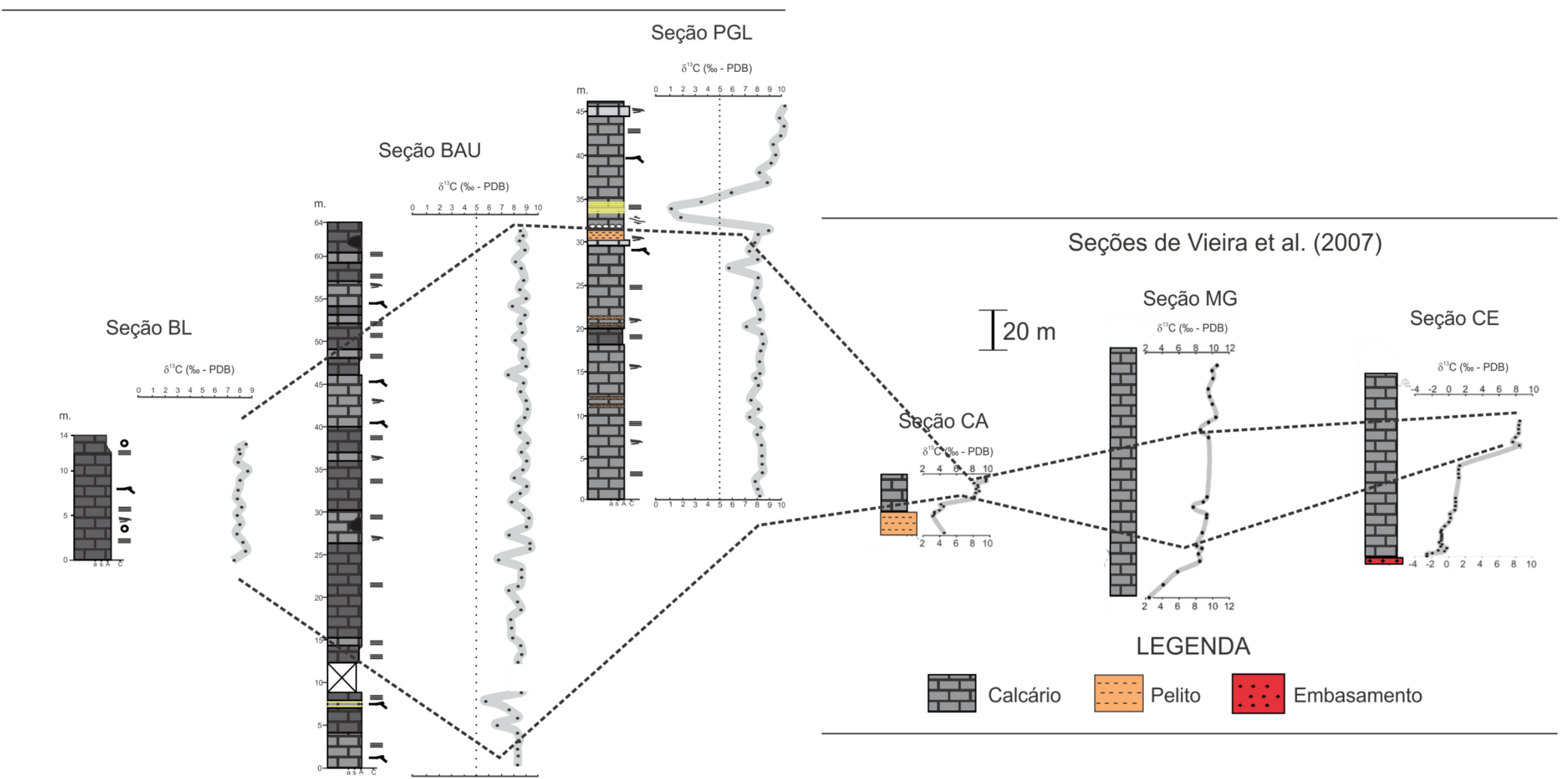

Fig. 40 - Correlação quimioestratigráfica entre a Seçốes BL, BAU e PGL deste trabalho e as seções Canaã (CA), Mata Grande (MG) e Cauê (CE) do trabalho de Vieira et al. (2007b). 


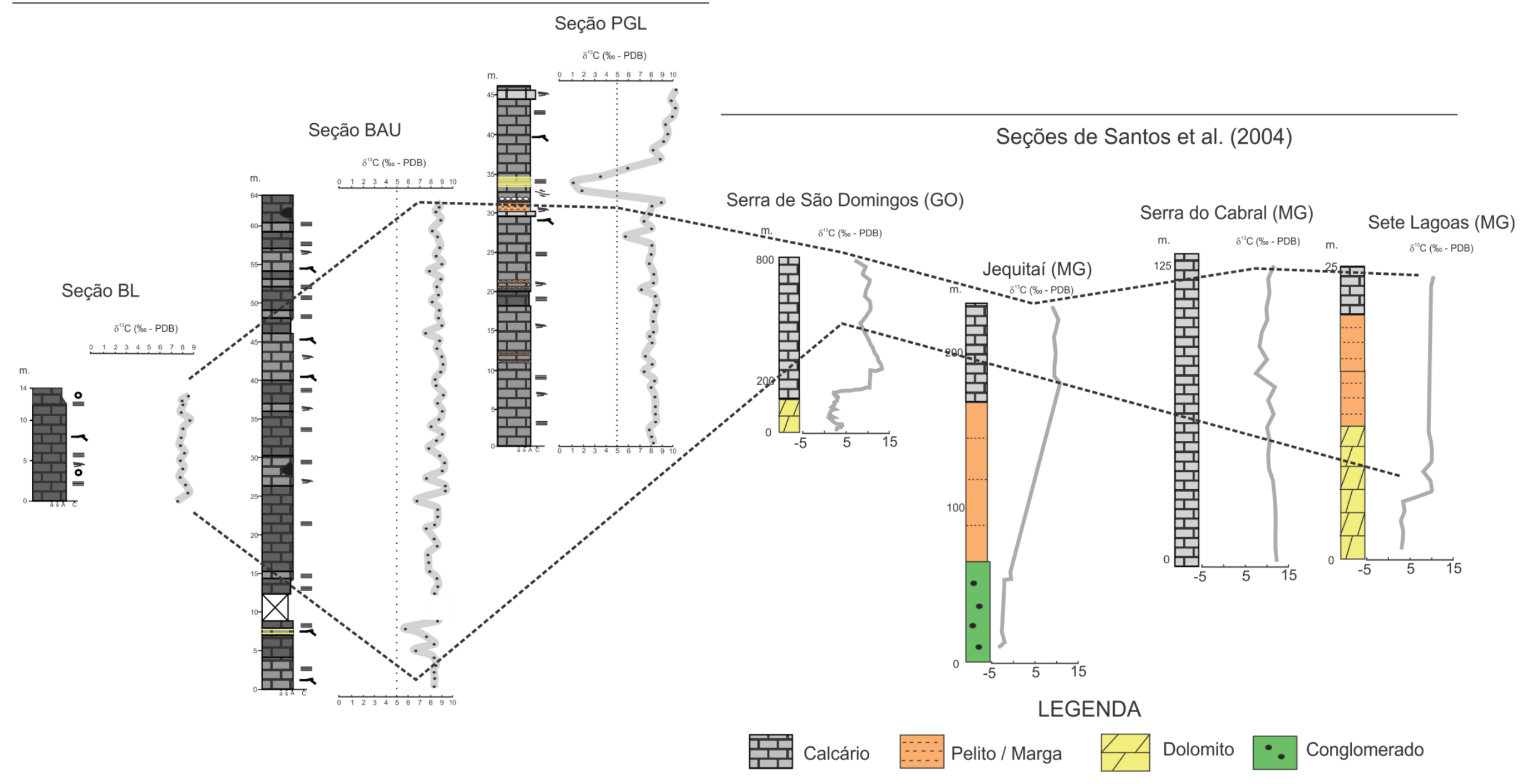

Fig. 41 - Correlação quimioestratigráfica entre a Seções BL, BAU e PGL deste trabalho e as seções de Santos et al. (2004). 


\subsection{Proveniência sedimentar e idade deposicional da Formação Sete Lagoas}

Os dados petrográficos, geoquímicos e isotópicos dos carbonatos permitiram posicionar as seções AP e VS abaixo do salto isotópico registrado pelos valores de $\delta^{13} \mathrm{C}$, mas acima da capa carbonática, e as seções BL, BAU e PGL, acima deste salto. Amostras de marga das seções da primeira sequência (11-AP-05 e 11-VS-13) e da segunda sequência (11PGL-PEL) da Formação Sete Lagoas tiveram seus grãos de zircão detrítico datados pelo método $\mathrm{U}-\mathrm{Pb}$, o que representa uma excelente oportunidade para discutir o significado temporal da abrupta mudança na curva isotópica de $\mathrm{C}$ desta unidade, bem como sua idade deposicional. Uma observação importante é que quase não há dados de isótopos de Hf disponíveis na literatura para o CSF e suas faixas móveis adjacentes. Desta forma, os resultados de Hf obtidos neste trabalho são de difícil interpretação e pouco representativos na tentativa de rastrear mais precisamente a fonte dos sedimentos. Mesmo assim, fornecem uma visão preliminar quanto à origem destas fontes, podendo ser produtos de acresções juvenis ou retrabalhamento crustal.

Os dados petrográficos (de lâminas delgadas e imagens de catodo luminescência) mostram progressiva redução da granulometria, aumento do grau de arredondamento e melhora da seleção dos grãos terrígenos de $\mathrm{E}$ para $\mathrm{W}$ na área de estudo. Isto sugere que grande parte dos sedimentos não-autigênicos da Formação Sete Lagoas na região de Lagoa Santa é proveniente de fontes a E do CSF. Esta possibilidade fica ainda mais plausível quando as idades U-Pb obtidas são comparadas com as idades disponíveis na literatura para as rochas da Faixa Araçuaí, situada a E do CSF.

Cerca de 75\% do grãos datados da amostra 11-AP-05 têm idades entre 630-584 Ma. Este intervalo de idade sugere que a fonte destes grãos são as rochas ígneas da supersuíte G1 (630-585 Ma) da Faixa Araçuaí definida por Pedrosa Soares et al. (2011). Tal supersuíte consiste de tonalitos a granodioritos, com enclaves máficos, de assinatura geoquímica característica de arco-magmático continental, pré-colisional em relação ao choque entre o CSF e o Cráton do Congo que resultou no fechamento do oceano Adamastor durante o Neoproteozoico-Cambriano. Um grão de idade 578 Ma poderia ser proveniente da supersuíte G2 (585-560 Ma - Pedrosa Soares et al., 2008, 2011 e referências destes trabalhos), constituída principalmente por granitos tipo $\mathrm{S}$ sin-colisionais. O grão de idade $547 \mathrm{Ma}$, se considerado seu erro de 5 Ma para mais ou para menos, pode ser oriundo da supersuíte tardicolisional G3 (545-525 Ma - Pedrosa Soares et al., 2008, 2011). Não existem fontes para o grão de idade devoniana no CSF e suas faixas móveis adjacentes. Esta idade pode representar um caso de perda de $\mathrm{Pb}$ em trajetória sobre a concórdia ou erro analítico. A amostra 11-AP-05 
apresentou idade $\mathrm{T}_{\mathrm{DM}} \mathrm{Sm}-\mathrm{Nd}$ de 2,0 Ga e $\varepsilon \mathrm{Nd}_{(0)}-13$ que sugerem fontes de longa residência crustal e oriundas de protólitos dominantemente paleoproterozoicos. Estes dados estão em acordo com os apresentados para a supersuíte G1 (Pedrosa Soares et al., 2008, 2011) e reforçam esta como a principal fonte. Contrário a isto, os isótopos de Hf sugerem uma fonte predominantemente juvenil com idades modelo mesoproterozóicas para a marga da seção AP. Como não há dados de Hf para a Faixa Araçuaí e os resultados isotópicos de Hf são bastante incoerentes nesta amostra, é difícil interpretar o significado geológico destes dados.

Já a amostra 11-VS-13 apresenta populações distintas com importantes picos mesoproterozoicos da curva gaussiana de distribuição de idades (Fig. 42). Os parâmetros $\varepsilon N d$ e $\varepsilon H f$ são dominantemente negativos e sugerem fontes de longa residência crustal para a amostra. O histograma de distribuição das idades com as fontes dos principais picos é apresentado na Fig. 42. Para os picos de idade entre 1400-1050 Ma não foram encontradas fontes no CSF e nem nas faixas móveis que o circundam. O problema para identificar estas fontes também foi encontrado por Pedrosa-Soares et al. (2000), Rodrigues (2008) e Babinski et al. (2012) para rochas glaciogênicas da sequência Macaúbas nas Faixas Araçuaí e Brasília. Babinski et al. (2012) argumentam que esta fonte pode estar na África ou até mesmo na Faixa Brasília. As análises petrográficas sugerem que as fontes da Formação Sete Lagoas na área de estudo são provenientes principalmente da Faixa Araçuaí, a E do CSF. Assim considera-se menos provável que as fontes mesoproterozoicas não identificadas estejam na Faixa Brasília. Ao invés disto, os grãos de zircão deste intervalo devem ser provenientes de ressedimentação das rochas glaciogênicas do Grupo Macaúbas ou de fontes não identificadas que estão na África. A análise das imagens de catodoluminescência dos grãos de zircão da seção VS mostra uma considerável variedade destes que podem ser prismáticos, fragmentados e ovoides e com zoneamento oscilatório ígneo ou homogêneos claros (Fig. 24). Tal observação leva à suposição de haver mais de uma fonte dos grãos do intervalo 1400-1050 Ma, cujos dados isotópicos de Hf sugerem se tratar de rochas de longa residência crustal ( $\mathrm{HH}$ negativos Tabela 8). Iizuka et al. (2010) encontraram zircões desta faixa de idades em sedimentos atuais do Rio do Congo, situado no Cráton homônimo, o que reforça a possibilidade das fontes repousarem sobre o continente Africano.

Outra faixa de idade importante obtida para a amostra 11-VS-13 é a de 1000-900 Ma. Possíveis fontes a E da área de estudo com estas idades estão na Faixa West Congo, contraparte do orógeno Araçuaí na África. Rochas vulcânicas e granitos associados dos Grupos Mayumbian e Zanadinian foram datados entre $912 \pm 7$ Ma e $999 \pm 7$ por Tack et al. (2001). Rochas deste intervalo de idades ocorrem apenas como diques máficos no CSF e na 
Faixa Araçuaí (Machado et al., 1989; D’Agrella Filho et al., 1990) que costumam apresentar poucos ou nenhum grão de zircão.

Outras populações de menor expressão (inferiores a 5\% do total dos grãos analisados) são paleoproterozoicas e arqueanas presentes no embasamento cratônico ou retrabalhadas na Faixa Araçuaí, além de fontes neoproterozoicas. Um pico de idade toniana (873 Ma) pode ter como fonte os granitos tipo A datados em $875 \pm 9$ Ma presentes no CSF e orógenos a $\mathrm{E}$ (Silva et al., 2008). Um pico de 656 Ma possui fonte desconhecida. É possível que esta seja representada por uma geração de rochas ígneas um pouco mais antigas que as da supersuíte G1 da Faixa Araçuaí. O valor negativo de $\varepsilon H f$ obtida no grão/spot 1.1 da amostra 11-VS-13 (Tabela 8) sugere uma fonte de retrabalhamento crustal de um protólito paleoproterozoico, semelhante às características da supersuíte G1 (Pedrosa-Soares et al., 2011), mas como já discutido, estes resultados são de difícil comparação e interpretação. Já os dois picos mais jovens de idades 538 e 519 Ma podem ser atribuídos aos leucogranitos não foliados da supersuíte G3 (545-525 Ma) e aos granitos tipo S pós-colisionais da supersuíte G4 (530-500 Ma - Pedrosa-Soares et al., 2011).

De maneira geral, o que se observa é que as fontes de sedimentos detríticos da seção VS estão situados a E da área, embora as fontes mesoproterozoicas e tonianas nesta sejam mais expressivas que na $\mathrm{AP}$, onde predominam fontes criogenianas e ediacaranas. $\mathrm{O}$ grão $100 \%$ concordante mais jovem obtido para estas seções foi datado em $537 \pm 4$ Ma (Tabela 5), e pode representar idade máxima de deposição para os carbonatos da primeira sequência da Formação Sete Lagoas, posicionados acima da capa carbonática. Entretanto, é necessário cautela, visto que poucos grãos apresentam idades do limite Ediacarano/Cambriano e não há uma população expressiva com esta idade. Mesmo assim, é bom salientar que a idade concórdia próxima a 593 Ma, obtida com os dados geocronológicos da amostra 11-AP-05, é mais jovem que as encontradas na literatura e apóia a idéia de que a primeira sequência da FSL teve sua deposição iniciada próxima ao fim do Ediacarano.

A geocronologia da segunda sequência está representada pela amostra 11-PGL-PEL (Tabela 6; Fig. 42). Nesta amostra observa-se a predominância (70\% dos grãos) de uma fonte neoproterozoica de $625 \mathrm{Ma}$ que pode ser atribuída às rochas ígneas da supersuíte G1 (630-585 Ma - Pedrosa-Soares et al., 2011). A dominância desta fonte é similar àquela apresentada pela amostra 11-AP-05 que, no entanto, não apresentou grãos suficientes para se considerar suas populações representativas. A segunda população mais expressiva (27\% dos grãos) tem idade de 557 Ma. A fonte destes grãos é atribuída aos granitos tipo S sin-colisionais da supersuíte G2 (585-560 Ma). A contribuições menores de fontes arqueanas e paleoproterozoicas, situadas no CSF ou na Faixa Araçuaí, além de fontes mais jovens do limite Ediacarano- 
Cambriano representadas pelas supersuítes pós-colisionais G4 e G5. O grão 100\% concordante mais jovem obtido foi datado em $506 \pm 4 \mathrm{Ma}$, cuja fonte provavelmente é um dos corpos ígneos da supersuíte G5 (520-480 Ma - Pedrosa-Soares et al., 2011). Novamente, as fontes identificadas para a seção PGL estão a E da área de estudo, na Faixa Araçuaí. Tal idade poderia representar a idade máxima de deposição da segunda sequência, mas visto que foi obtida em apenas um grão, será considerada a idade de 557 Ma, da população expressiva mais jovem.

Com as idades obtidas o quadro estratigráfico e geocronológico da Formação Sete Lagoas fica como o representado pela Fig. 43. Os grãos mais jovens da primeira e da segunda sequência possuem idades que diferem da literatura e sugerem uma evolução sedimentar da Formação Sete Lagoas no limite Ediacarano-Cambriano, com possibilidade de ser francamente Cambriana. Estas idades também refutam a possibilidade de haver um hiato de 130 M.y. entre as sequências deposicionais, proposta na literatura (Babinski et al., 2012). Admitindo-se a idade concórdia de cerca de 590 Ma para a primeira sequência e a idade de cerca de 560 Ma da população expressiva mais jovem da segunda, o hiato máximo admitido é da ordem de $30 \mathrm{Ma}$. Porém, dada a semelhança entre as razões ${ }^{87} \mathrm{Sr} /{ }^{86} \mathrm{Sr}$ de ambas sequências (ao redor de 0,7075) é bem provável que este hiato seja ainda mais curto, como já discutido por Caxito et al. (2012). Esta argumentação é ainda reforçada se considerarmos que a idade de $506 \pm 4$ Ma da seção PGL foi obtida em apenas um zircão e que o controle de distribuição das fontes parece ter uma variabilidade horizontal significativa, já que as amostras das seções AP e VS estão situadas aproximadamente no mesmo nível estratigráfico e possuem populações distintas. Desta forma, a ausência desta fonte Cambriana nas seções de base pode se ser decorrente de uma mera distribuição diferenciada das fontes ao longo da bacia do São Francisco. O tipo de limite de sequências proposto por Vieira et al. (2007a), se verdadeiro, também não endossa a existência de um hiato significativo nesta porção da Formação Sete Lagoas. Estes autores afirmam que o limite entre as sequências de base e topo desta unidade se deu por afogamento da bacia. Como esta permaneceu submersa após o fim da primeira sequência, é de se imaginar uma continuidade da sedimentação. Um período de não deposição neste momento necessitaria de um cessamento combinado da produção da fábrica carbonática e do aporte de terrígenos na bacia. Esta situação parece ser um pouco mais difícil de ocorrer, especialmente se considerarmos que um orógeno está sendo exumado na borda E do CSF nesta época.

Outro ponto que chama a atenção é que as idades máximas obtidas são significativamente mais jovens que a de $740 \pm 22$ obtida para a capa carbonática na base da Formação Sete Lagoas (Babinski et al. 2007). Isto levanta a hipótese de que se um hiato 
realmente existe na unidade basal do Grupo Bambuí, ele está posicionado em um nível estratigráfico mais abaixo do que outrora proposto e é da ordem de 200 M.y.. Neste caso, assumindo a definição de sequência deposicional de Van Wagoner (1995), três seriam as sequências deposicionais de terceira ordem da Formação Sete Lagoas: (i) a basal constituída pelos carbonatos de capa com valores de $\delta^{13} \mathrm{C}$ negativos; (ii) uma segunda constituída por carbonatos pobres em matéria orgânica e com valores de $\delta^{13} \mathrm{C}$ ao redor de $0 \%$; (iii) uma terceira de topo, constituída por carbonatos ricos em matéria orgânica e valores de $\delta^{13} \mathrm{C}$ bastante positivos.

Mas esta nova subdivisão estratigráfica baseada em estratigrafia de sequências fica condicionada à existência de uma discordância entre os carbonatos de capa e o restante da Formação Sete Lagoas, o que é absolutamente inconclusivo até o momento. Alguns argumentos a favor de sua existência podem ser levantados. Primeiro, existe uma diferença de idade considerável entre as seções mais basais deste trabalho e os diamictitos glaciais da sequência Macaúbas. Os sedimentos glaciogênicos possuem idades máximas entre 900-850 Ma (Pedrosa-Soares et al., 2000; Rodrigues, 2008; Babinski et al., 2012), que sugerem que estes foram depositados antes da existência dos granitos da Faixa Araçuaí (ca. 630 Ma Pedrosa-Soares et al., 2011). Se consideramos o início deste magmatismo como um limite adicional para a idade desta sedimentação, abstraindo a idade da capa, ainda restariam cerca de 130 M.y. de hiato entre a glaciação e a deposição dos carbonatos das seções AP e VS. Se os carbonatos Sturtianos de fato capeiam os diamictitos, é possível admitir esta discordância. Outro argumento são os dados de geofísica apresentados por Zalán \& Romero (2007). Em estudos de sísmica, estes autores interpretaram um refletor existente na base da Formação Sete Lagoas como uma discordância erosiva.

Entretanto, argumentos contra também podem ser enumerados. O primeiro deles é que as relações de campo entre a capa carbonática datada e os sedimentos glaciais, embasamento e carbonatos superiores inexistem, o que complica análises com maior grau de confiabilidade. Além disso, não se tem notícia de uma superfície de discordância expressiva ao longo da Bacia São do Francisco condizente com um hiato desta magnitude. A ausência total de grãos de zircão em intercalações de pelitos em carbonatos imediatamente acima da capa carbonática (pedreira Paraíso - Sete Lagoas, MG), também dificulta optar por uma hipótese. Por fim, as razões ${ }^{87} \mathrm{Sr} /{ }^{86} \mathrm{Sr}$ obtidas por Babinski et al. (2007) são constantes ao redor de 0,7075. Estes dados não suportam a existência de um hiato expressivo entre a capa Sturtiana e o restante do Grupo Bambuí, mas sim sugerem uma deposição relativamente contemporânea entre estes. Mas a interpretação dos dados isotópicos de Sr neste caso é mais complicada, como será discutido no item 5.6. 
Como os argumentos pró e contra esta discordância não permitem uma definição segura de sua existência ou não, assume-se aqui que a melhor evidência são as idades absolutas apresentadas até agora. Assim, considera-se que a capa carbonática da base da Formação Sete Lagoas de fato é mais antiga que o restante da unidade e, por isso, há uma discordância. Seria desejável, no entanto, que estudos mais avançados, em especial de subsuperfície, confirmassem a existência de uma superfície de descontinuidade erosiva expressiva na base do Grupo Bambuí.

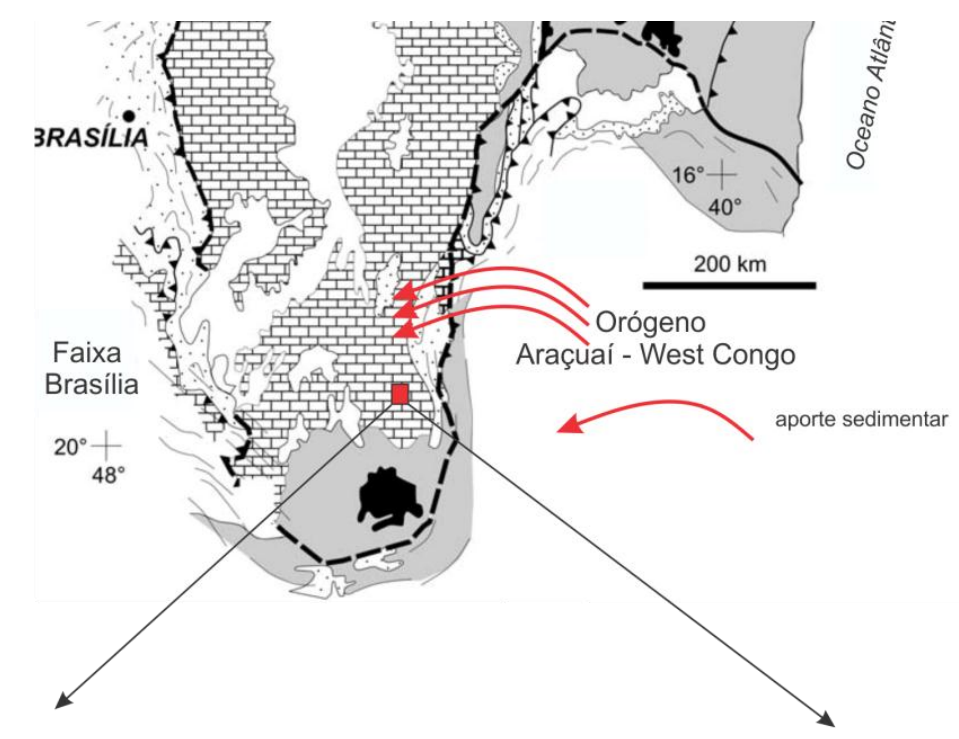

11-VS-13
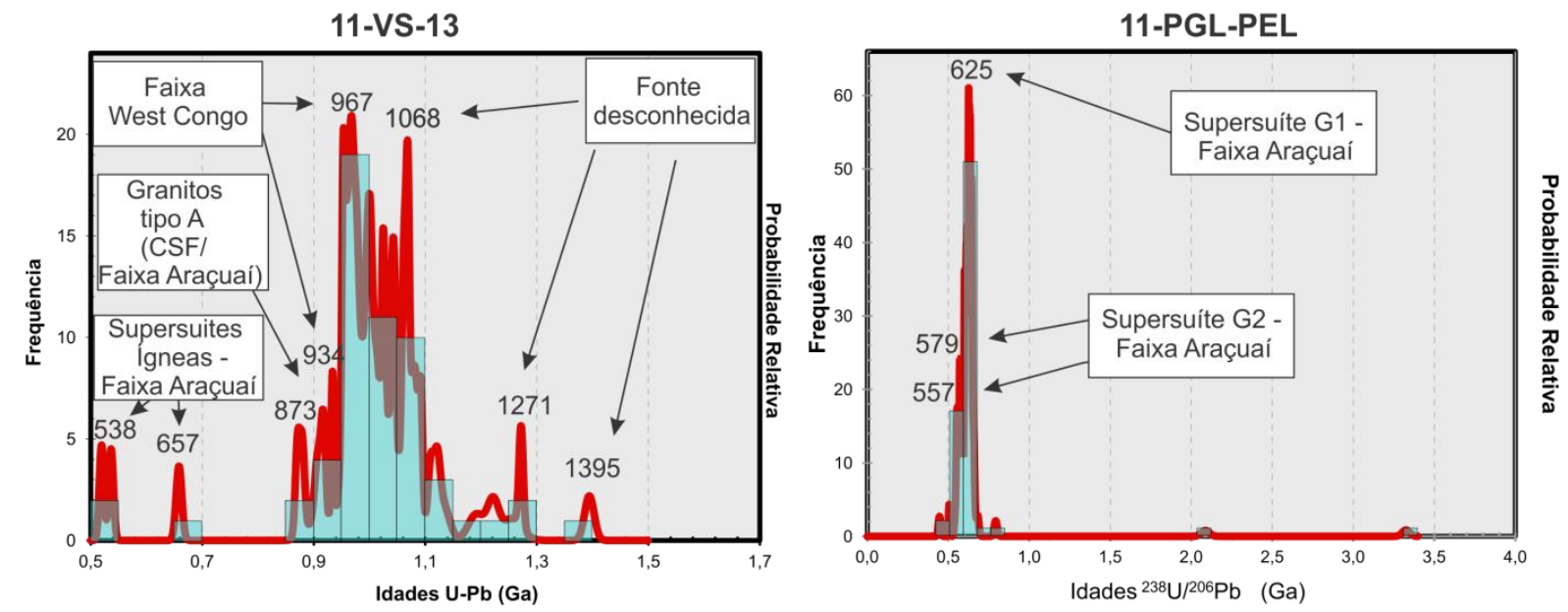

Fig. 42 - Histogramas de distribuição das idades para as amostras 11-VS-13 e 11-PGL-PEL com as prováveis fontes dos sedimentos terrígenos. 


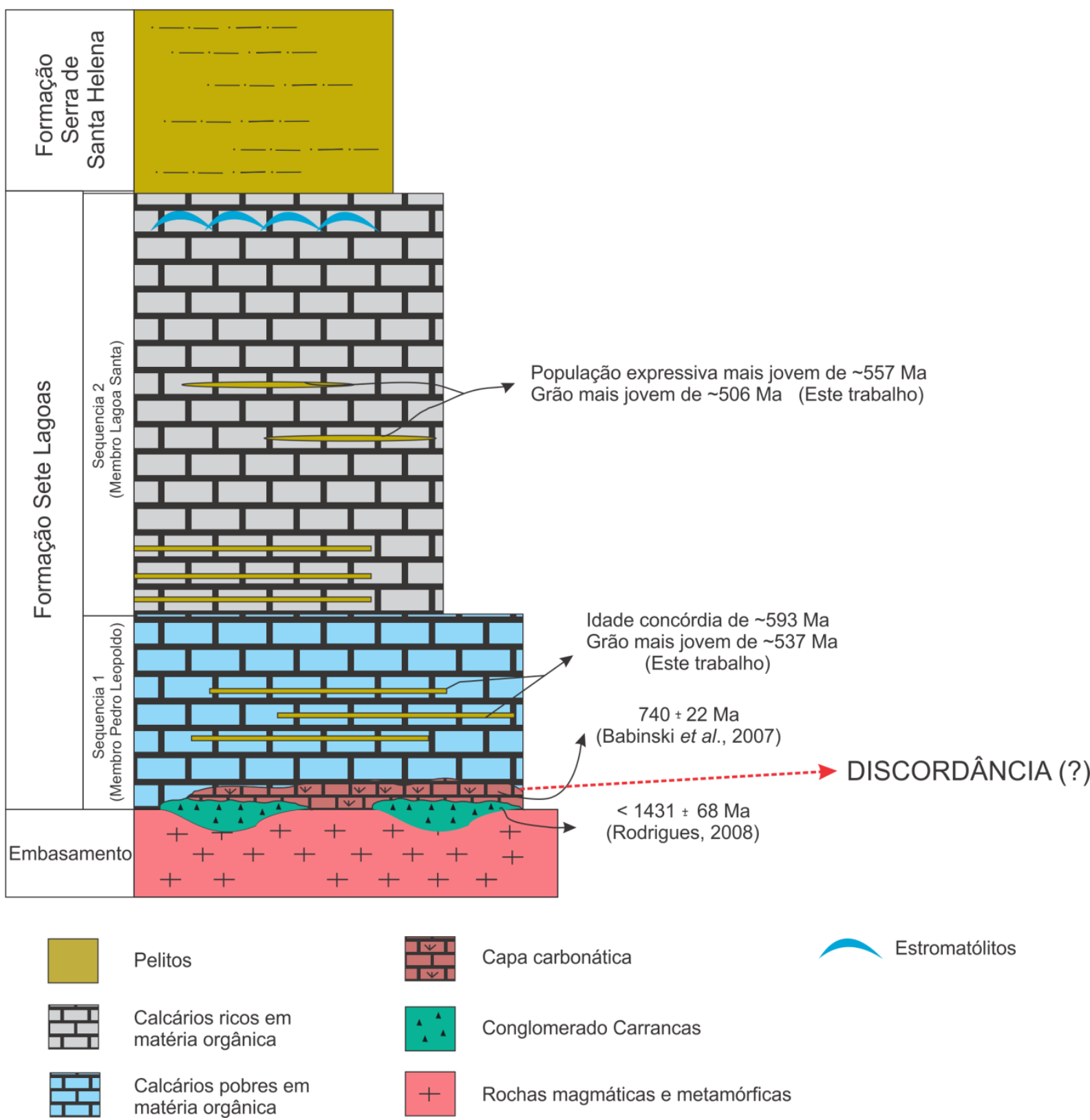

Fig. 43 - Esquema estratigráfico e geocronológico da Formação Sete Lagoas baseado em dados disponíveis na literatura e obtidos neste trabalho.

\subsection{Implicações geotectônicas e paleoambientais das idades obtidas}

Além de uma nova visão para a estratigrafia da Formação Sete Lagoas, as idades mais jovens obtidas sugerem uma configuração tectônica diferente sob a qual esta unidade foi depositada. Para melhor visualização deste cenário é necessário uma análise da evolução tectônica do CSF entre 750-530 Ma proposta por Martins-Neto (2009), como representado na Fig. 44.

Durante o Criogeniano, O CSF esteve separado do Cráton do Congo pelo oceano Adamastor. Os dados geocronológicos existentes sugerem que ao menos a capa carbonática da Formação Sete Lagoas foi depositada neste período (740 \pm 22 Ma - Babinski et al., 2007). 
Em um segundo estágio, durante o Ediacarano, inicia-se o processo de convergência e subducção da paleoplaca São Francisco sob a do Congo, com geração de um arco magmático representado pela supersuíte G1 da Faixa Araçuaí (Pedrosa-Soares et al., 2011). No final do Ediacarano / início do Cambriano, o oceano Adamastor foi completamente consumido e a Faixa Araçuaí, edificada a E do CSF, como sugerido pelas supersuítes pós-colisionais G4 e G5 (Pedrosa-Soares et al., 2011).

A idade máxima obtida de 610 Ma por Rodrigues (2008) para a Formação Sete Lagoas e reinterpretada como pós-Marinoana por Caxito et al. (2012) implica que o Grupo Bambuí teria sido depositado no Ediacarano, durante os primeiros estágios de formação do Orógeno Araçuaí - Oeste Congo e com o Oceano Adamastor ainda existente. As idades de $537 \pm 4 \mathrm{Ma}$ e $506 \pm 6$ obtidas neste trabalho para a primeira e segunda sequência da FSL, respectivamente, apoiadas pelas idades concórdia de cerca de 593 Ma e da população mais jovem de 557Ma, sugerem que a deposição do Grupo Bambuí se iniciou no limite EdiacaranoCambriano, após o fechamento daquele oceano. Neste momento, tanto a Faixa Brasília (W do CSF) como a Faixa Araçuaí (E) já estariam edificadas às margens do CSF (Fig. 44). A Faixa Sergipana também margeava o NE do Cráton neste período (Oliveira et al., 2010). Desta forma, propõe-se que o Grupo Bambuí foi depositado em uma bacia tipo foreland, na qual um mar epicontinental restrito submergiu o CSF quando as faixas móveis que hoje o circundam estavam completamente edificadas.

Seções sísmicas sugerem que o Grupo Bambuí foi depositado em uma bacia de antepaís (foreland), com subsidência flexural induzida principalmente pela carga litosférica exercida pela Faixa Brasília (Zalán \& Romero, 2007; Martins-Neto, 2009; Alkmim \& Martins-Neto, 2012). Entretanto, algumas observações deste trabalho endossam a tese de que a Faixa Araçuaí também pode ter exercido influência semelhante na deposição da cobertura cratônica (Fig. 45). As características dos sedimentos terrígenos misturados à matriz carbonática da Formação Sete Lagoas sugerem uma fonte proximal a E da área de estudo. Isto é evidenciado pela progressiva diminuição da granulometria, melhora da seleção, diminuição do teor e aumento do grau de arredondamento dos sedimentos detríticos de E para W. O estudo de proveniência sedimentar por datação de grãos de zircão detríticos confirma isto, demonstrando que o Orógeno Araçuaí - Oeste Congo foi a fonte sedimentar das seções do Grupo Bambuí na região de Lagoa Santa (MG). Ainda que preliminar, os dados de ETR convergem para a mesma direção. As seções BL e PGL com tendência de distribuição planar em diagramas normalizados e menores razões Y/Ho ocorrem mais a E que a seção BAU, com distribuição e razão Y/Ho mais semelhantes a de ambientes marinhos (Fig. 44). Isto sugere uma influência progressivamente menor de água doce de $\mathrm{E}$ para $\mathrm{W}$, provavelmente 
proveniente de rios que drenavam os terrenos da Faixa Araçuaí e atingiam uma linha de costa próxima ao limite geográfico entre esta e o CSF. Como argumento final, Vieira et al. (2007a, b) apontam subsidência da bacia para E-SE da região de Sete Lagoas (MG), o que pode representar deformação flexural da litosfera da porção E do Cráton por carga do Orógeno Araçuaí - Oeste Congo.

As idades deposicionais obtidas neste trabalho também permitem algumas interpretações paleoambientais. A oxigenação do ambiente marinho sugerida pelas anomalias negativas de Ce pode representar um evento importante em escala global. Ling et al. (2011) observou esta anomalia na Formação Denjying, China, que data do limite do EdiacaranoCambriano. Visto que grande parte do Grupo Bambuí apresenta evolução sedimentar que data deste limite, as anomalias negativas de Ce podem demonstrar um evento de oxigenação global dos oceanos deste período que coincide com a diversificação da biota, no caso chinês, e com o aumento da bioprodutividade verificado nos carbonatos ricos em matéria orgânica e com valores bastante positivos de $\delta^{13} \mathrm{C}$ da segunda sequência da Formação Sete Lagoas. Isto sugere um novo foco de pesquisa para a passagem Neoproterozoico-Cambriano, quando é observada a "explosão de vida do Cambriano". O efeito de "gargalo" evolucionário das glaciações proposto na hipótese Snowball Earth (Hoffman et al., 1998) parece não proceder, como demonstrado por Corsetti et al. (2006) em análises de assembleias fossilíferas pré-, sine pós-glaciais. Se o evento de oxigenação marinha observada neste trabalho é de fato global, este pode ser uma das causas que levaram a tal explosão de vida que propiciou o surgimento dos organismos mais complexos observados no Fanerozoico. Entretanto, é importante salientar que esta é uma ideia embrionária e que necessita de estudos mais aprofundados.

Voltando o foco para a bacia do São Francisco, o confronto das idades ediacaranas/cambrianas obtidas com dados geoquímicos e isotópicos apresentado neste trabalho e na literatura revela outro aspecto do ambiente marinho de deposição da Formação Sete Lagoas. Esta unidade apresenta razões ${ }^{87} \mathrm{Sr} /{ }^{86} \mathrm{Sr}$ bastante homogêneas ao redor de 0,7075 por toda a bacia (e.g. Misi et al. (2007); Alvarenga et al. (2007); Kuchenbecker (2011); este trabalho). Os dados geocronológicos obtidos neste trabalho indicam que estas razões foram registradas em rochas depositadas na bacia no período compreendido entre o final do Ediacarano e início do Cambriano. Se comparados à curva de evolução isotópica de $\mathrm{Sr}$ dos oceanos durante o Neoproterozoico e Cambriano proposta por Halverson et al. (2010), os resultados obtidos são amplamente discordantes (Fig. 46). No período de deposição da Formação Sete Lagoas, tal curva apresenta razões ${ }^{87} \mathrm{Sr} /{ }^{86} \mathrm{Sr}$ superiores a 0,7085 . Isto reforça que o mar epicontinental que banhou o CSF de fato era restrito, como sugerido pela análise geotectônica. Provavelmente havia pouca troca de águas entre este mar e os oceanos 
cambrianos, o que impossibilitou a homogeneização isotópica entre estes. A restrição do ambiente também pode estar indicada nos dados de ETR mais representativos obtidos na seção BAU. Os diagramas de distribuição normalizada (Fig. 36) mostram semelhanças com ambientes marinhos modernos e do Cambriano (comparar com Ling et al., 2011), mas apresentam anomalias não observadas nos mesmos.

A hipótese de restrição do ambiente marinho quebra uma premissa importante para aplicação da quimioestratigrafia isotópica como ferramenta de correlação global do Grupo Bambuí com outras sucessões carbonáticas contemporâneas do planeta. A atribuição de uma idade pós-marinoana ao Grupo através de quimioestratigrafia por Caxito et al. (2012) é considerada inadequada, dada a situação observada. Da mesma forma, é pouco seguro atribuir uma idade marinoana aos depósitos glaciais encontrados no CSF e Faixa Araçuaí, visto que deve ser considerada a existência de uma discordância entre a capa carbonática e as porções superiores da Formação Sete Lagoas, que possibilitaria uma situação tectônica diferenciada com homogeneização isotópica entre a bacia e oceanos externos. Esta discordância ainda é uma hipótese e é sugerida pela idade isocrônica $\mathrm{Pb}-\mathrm{Pb}$ de $740 \pm 22 \mathrm{Ma}$ (Babinski et al., 2007), que por sua vez contradiz a idade marinoana.

Algo que pode ser indagado é como as razões ${ }^{87} \mathrm{Sr} /{ }^{86} \mathrm{Sr}$ são homogêneas ao longo da bacia se não há trocas de água com oceanos externos. A verdade é que isto independe desta troca, visto que o papel de homogeneização é desempenhado pela circulação termohalina. A própria análise do termo mostra que esta circulação depende exclusivamente de temperatura e salinidade e é alheia a qualquer fluxo externo de águas. Desta forma, é possível imaginar uma circulação deste tipo dentro da bacia que homogeneizava a composição isotópica de suas águas.

Outro ponto importante a ser mencionado é que os grãos de idade cambriana são escassos, não aparecendo em mais de três exemplares por amostra analisada. Isto abre a possibilidade de estes grãos terem sido cristalizados ou afetados por processos hidrotermais mais jovens que a deposição. Entretanto, tais processos não são conhecidos nas rochas do Grupo Bambuí. Também foi demonstrado no item 5.4. que existem fontes para estes grãos na Faixa Araçuaí, adjacente a área de estudo. Além disso, foi observada uma importante população, com cerca de 18 grãos que define o pico de idade $557 \mathrm{Ma}$ (Fig. 42), que por si só já sugere uma deposição da FSL após os estágios colisionais que consumiram o oceano Adamastor. Tal população sustenta a ideia de uma idade de deposição Ediacarana / Cambriana para a unidade de estudo. Mesmo assim, estudos acerca da composição geoquímica de ETR dos grãos mais jovens tornam-se necessários para confirmação das idades. 


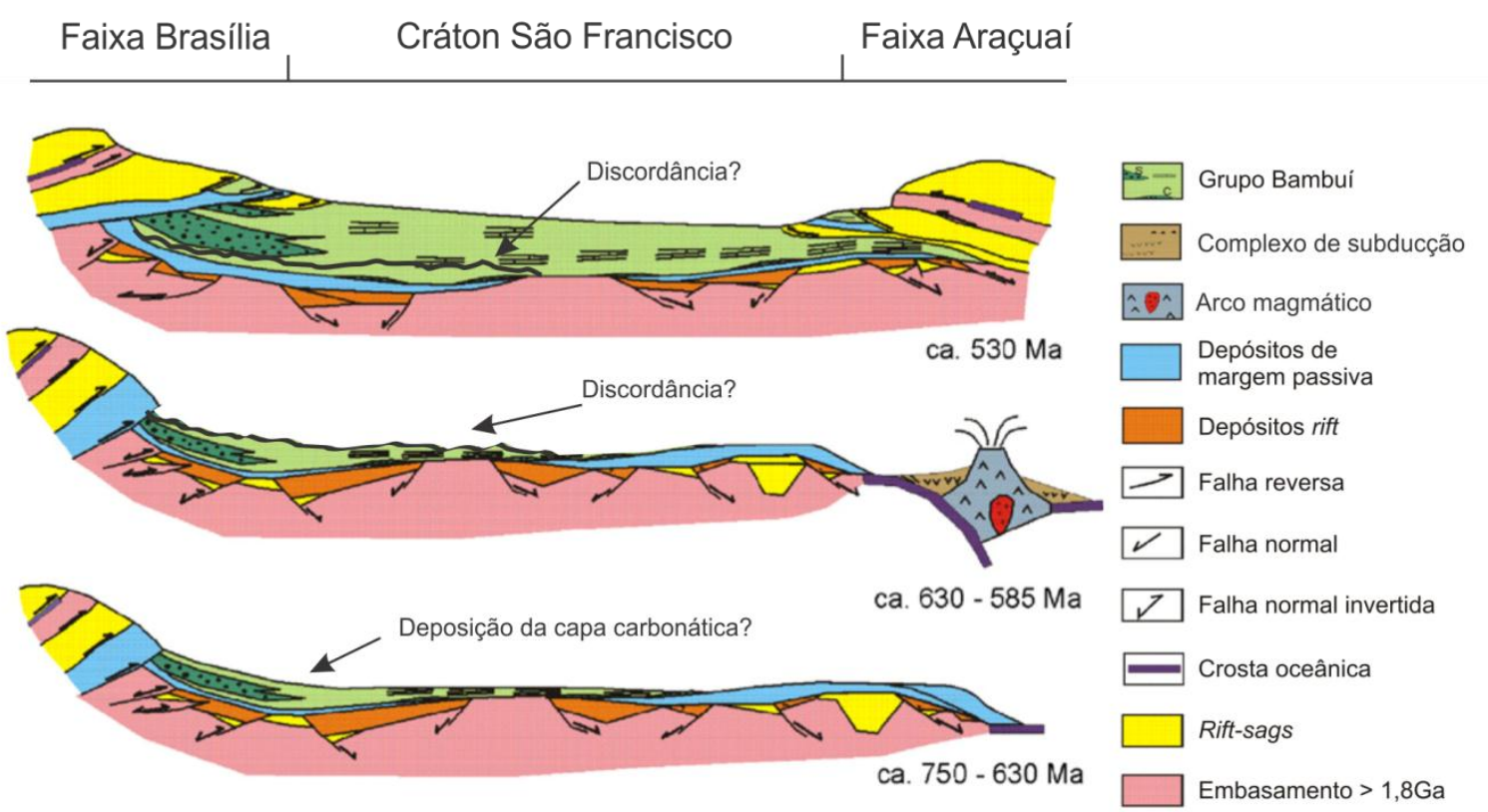

Fig. 44 - Esquema da evolução tectônica do CSF entre 750-530 Ma com a deposição do Grupo Bambuí neste intervalo (modificado de Martins-Neto, 2009 e Kuchenbecker, 2011).

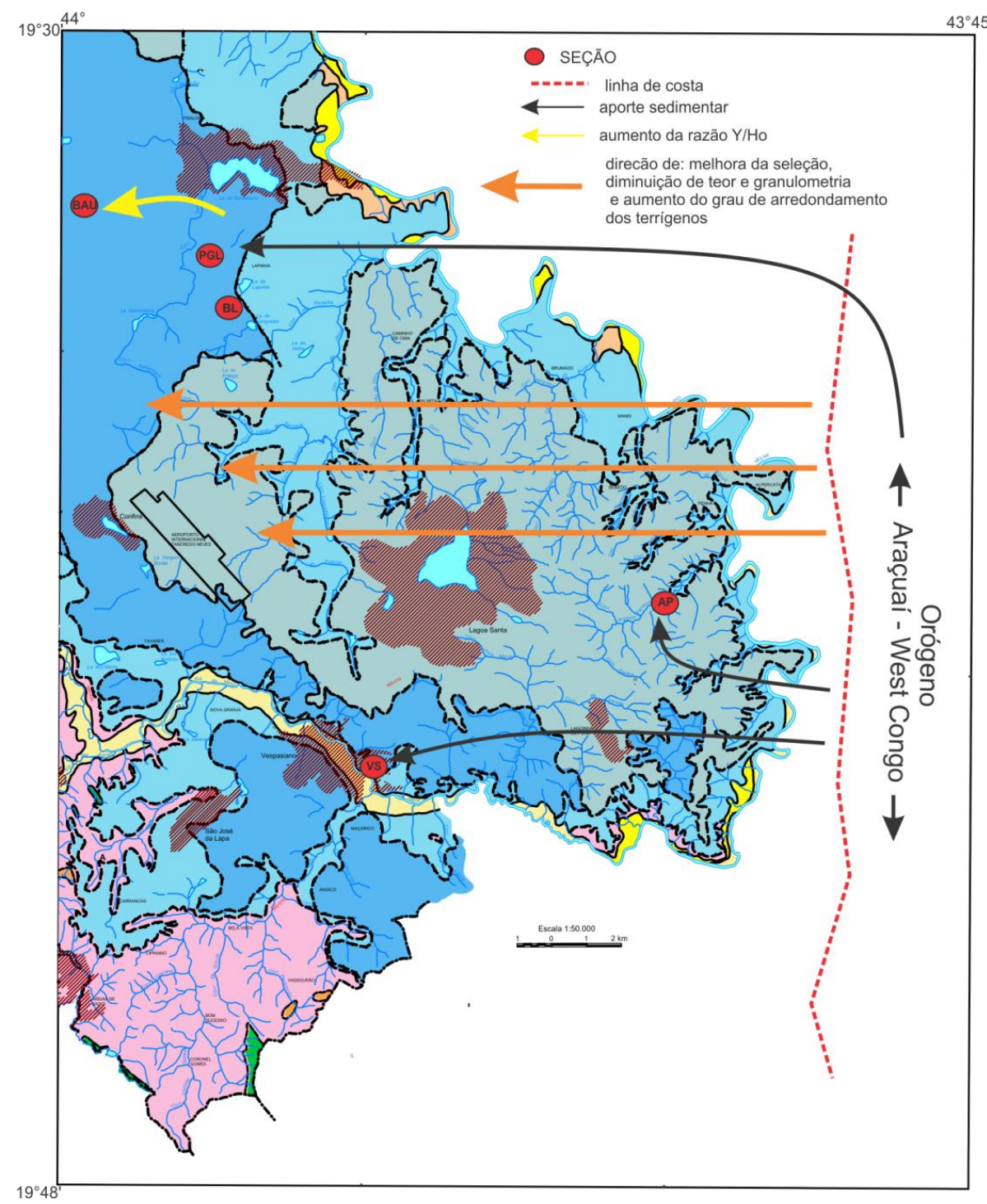

Fig. 45 - Mapa da área de estudo com indicação dos elementos que sugerem que a Faixa Araçuaí estava edificada a E durante a deposição do Grupo Bambuí e atuou como fonte dos sedimentos detríticos desta unidade. 


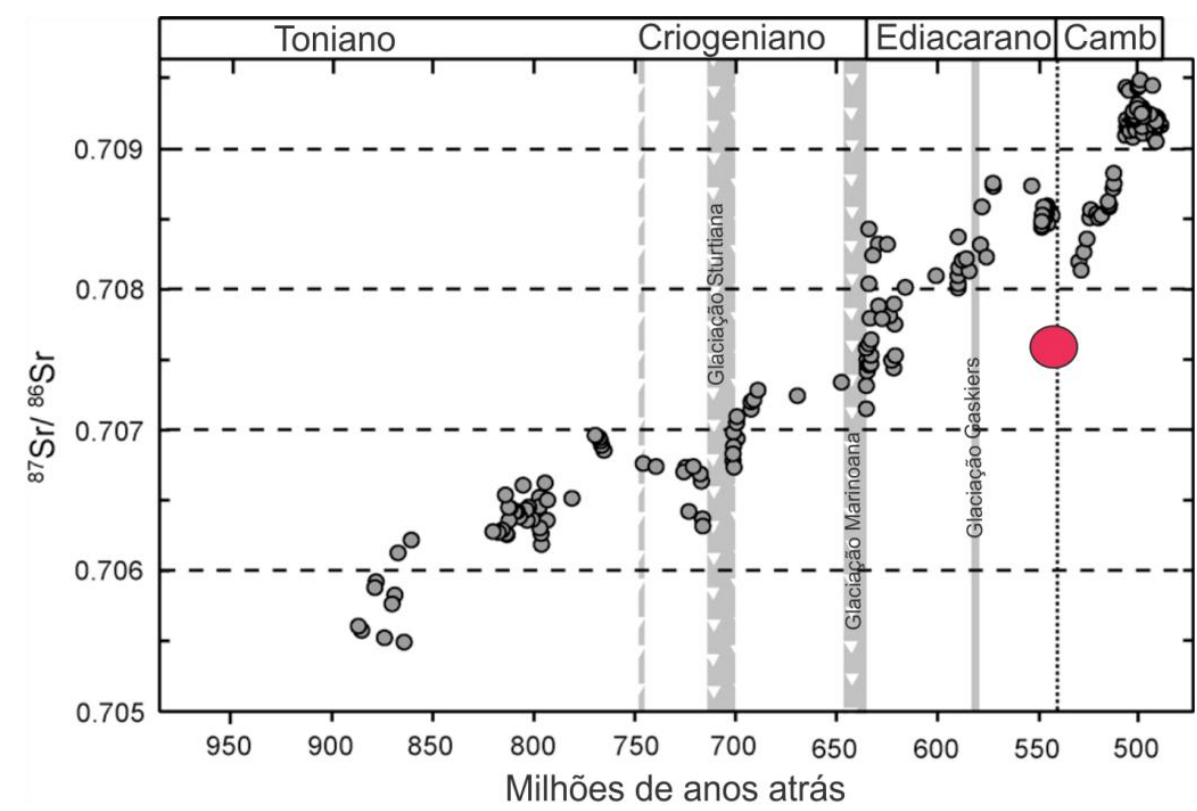

Fig. 46 - Curva de evolução da composição isotópica de $\mathrm{Sr}$ dos oceanos durante o Neoproterozoico e Cambriano. A elipse vermelha indica a faixa de razões ${ }^{87} \mathrm{Sr} /{ }^{86} \mathrm{Sr}$ mais representativas obtidas para a Formação Sete Lagoas (modificado de Halverson et al., 2010).

\subsection{Significado das razões ${ }^{87} \mathrm{Sr} /{ }^{86} \mathrm{Sr}$ nos carbonatos do Grupo Bambuí}

Após a constatação de que as razões ${ }^{87} \mathrm{Sr} /{ }^{86} \mathrm{Sr}$ obtidas para o Grupo Bambuí diferem daquelas dos oceanos contemporâneos a sua deposição, torna-se necessário compreender o significado destas. De acordo com Melezhik et al. (2001), um ambiente marinho restrito cercado por crosta continental tende a receber $\mathrm{Rb}$ lixiviado desta crosta. Desta forma, este mar se enriqueceria em ${ }^{87} \mathrm{Rb}$ (comum nas rochas crustais potássicas) que decai para ${ }^{87} \mathrm{Sr}$. Sem uma conexão com mar aberto que permitisse homogeneização isotópica, os carbonatos precipitados neste ambiente possuiriam uma razão ${ }^{87} \mathrm{Sr} /{ }^{86} \mathrm{Sr}$ mais radiogênica que os de um oceano contemporâneo.

Esta situação paleoambiental se assemelha muito àquela proposta para o Grupo Bambuí neste trabalho. As rochas desta unidade teriam sido depositadas em um mar epicontinental, restrito pelas faixas móveis neoproterozoicas que circundavam o CSF já naquela época. Pelo raciocínio acima, um mar rodeado por crosta continental soerguida (representada pelos cinturões orogênicos) e que não homogeneizava sua composição isotópica com outros oceanos deveria apresentar razões ${ }^{87} \mathrm{Sr} /{ }^{86} \mathrm{Sr}$ mais elevadas que estes. Entretanto, não é isso que se observa pela análise da Fig. 46, que demonstra que as razões isotópicas de Sr são menos radiogênicas. Então fica necessário buscar uma explicação para este fato, visto que o modelo proposto por Melezhik et al. (2001) é generalista e não se ajusta ao caso. 
Palmer \& Edmond (1989) determinaram por meio de análises quantitativas que o fluxo de Sr de rios para o mar é o principal fator controlador da razão ${ }^{87} \mathrm{Sr} /{ }^{86} \mathrm{Sr}$ dos oceanos modernos ( 0,7092). Este fluxo responde por $75 \%$ do $\mathrm{Sr}$ inserido nos oceanos, enquanto que os $25 \%$ restantes são decorrentes da atividade hidrotermal nas dorsais meso-oceânicas e pelo retrabalhamento de carbonatos mais antigos na plataforma continental. Se transportarmos esta situação para o início do Cambriano no CSF, podemos supor que o fluxo de $\mathrm{Sr}$ dos rios deve ter tido um papel ainda mais importante no controle da composição isotópica do ambiente deposicional do Grupo Bambuí. Isto porque não há registro de atividade hidrotermal na bacia. Além disso, a influência de água doce na composição química dos carbonatos da Formação Sete Lagoas é evidenciada pelas razões Y/Ho próximas à da crosta superior e tendências planares observadas em diagramas de distribuição normalizada de ETR (Kuchenbecker, 2011; Fig. 37). Se este pensamento for assumido como correto, analisar os fatores que controlam a composição isotópica de $\mathrm{Sr}$ dos rios pode auxiliar a compreender porque as razões ${ }^{87} \mathrm{Sr} /{ }^{86} \mathrm{Sr}$ do Grupo Bambuí podem ser menores que dos oceanos contemporâneos.

As composições isotópicas de $\mathrm{Sr}$ dos rios é resultado da mistura do $\mathrm{Sr}$ oriundo do intemperismo de carbonatos com aquele derivado de rochas siliciclásticas (Wadleigh et al., 1985; Palmer \& Edmond, 1989). As primeiras rochas são caracterizadas por serem facilmente intemperisadas, conterem altos teores de $\mathrm{Sr}$ e razões ${ }^{87} \mathrm{Sr} /{ }^{86} \mathrm{Sr}$ baixas (menores que o oceano moderno). As segundas são caracterizadas por serem resistentes ao intemperismo, conterem baixos teores de $\mathrm{Sr}$ e razões ${ }^{87} \mathrm{Sr} /{ }^{86} \mathrm{Sr}$ elevadas (maiores que o oceano moderno). A razão ${ }^{87} \mathrm{Sr} /{ }^{86} \mathrm{Sr}$ de um rio depende da geologia das áreas que drena, bem como do curso do mesmo onde esta é medida.

Palmer \& Edmond (1992) realizaram um estudo sobre as composições ${ }^{87} \mathrm{Sr} /{ }^{86} \mathrm{Sr}$ dos rios atuais. Dentre os pontos discutidos mais importantes, está o fato de que o alto curso dos rios, geralmente em regiões topograficamente elevadas, tende a apresentar razões isotópicas de $\mathrm{Sr}$ mais baixas que os cursos médio e baixo. Bons exemplos disto são os rios que compõem a bacia hidrográfica do rio Amazonas. Na região da Cordilheira dos Andes (alto curso), estes rios drenam áreas cuja geologia é composta de folhelhos, calcários, dolomitos, evaporitos, embasamento pré-cambriano e alguns granitos. Suas águas intemperisam preferencialmente os carbonatos, mais suscetíveis a este processo, de forma que são caracterizadas por uma geoquímica rica em $\mathrm{Ca}$, com altos teores de $\mathrm{Sr}$ e razões ${ }^{87} \mathrm{Sr} /{ }^{86} \mathrm{Sr}$ mais baixas que os oceanos modernos (entre 0,706-0,709 - ver dados em Palmer \& Edmond, 1992). Situação semelhante é observada no rio Orinoco que corre pela Venezuela e Colômbia. À medida em que estes rios atingem o curso médio em regiões mais baixas, o intemperismo de rochas siliciclásticas começa a se tornar importante e as águas passam a ficar mais ricas em $\mathrm{K}$ e $\mathrm{Na}$ (derivados de 
feldspatos) e com menores teores de $\mathrm{Sr}$ e razões ${ }^{87} \mathrm{Sr} /{ }^{86} \mathrm{Sr}$ mais altas, se comparadas ao alto curso. Este processo se intensifica no baixo curso, onde os rios percorrem terrenos antigos (Cráton Amazônico) constituídos de rochas ricas em ${ }^{87} \mathrm{Sr}$ radiogênico e, consequentemente, com altas razões ${ }^{87} \mathrm{Sr} /{ }^{86} \mathrm{Sr}$. Desta forma, as águas fluviais aumentam sua razão isotópica de $\mathrm{Sr}$ gradualmente até atingirem o oceano Atlântico com razões superiores a deste. Todo este processo está esquematizado na Fig. 47.

A geologia das áreas elevadas Andinas é bastante semelhante a dos cinturões orogênicos neoproterozoicos que circundam o $\mathrm{CSF}$. Estes são constituídos de metassedimentos do tipo QPC (quartzitos, pelitos e calcários), além de granitos e blocos mais antigos (arqueanos, paleo e mesoproterozoicos) e crosta oceânica presos nas faixas móveis durante os eventos orogênicos. O CSF é constituído de rochas antigas com altas razões ${ }^{87} \mathrm{Sr} /{ }^{86} \mathrm{Sr}$, de maneira semelhante ao Cráton Amazônico. Em uma situação semelhante a da bacia hidrográfica do rio Amazonas, um rio com nascente situada em uma faixa móvel teria seu alto curso caracterizado por águas ricas em $\mathrm{Sr}$ e com razões ${ }^{87} \mathrm{Sr} /{ }^{86} \mathrm{Sr}$ menores que dos oceanos contemporâneos. Ao atingir os médio e baixo cursos, na região cratônica, suas águas teriam progressivamente maiores razões ${ }^{87} \mathrm{Sr} /{ }^{86} \mathrm{Sr}$.

Entretanto, no limite Ediacarano/Cambriano, o CSF esteve encoberto por um mar epicontinental e as regiões do médio e baixo cursos dos rios estavam submersas. Na situação geotectônica proposta neste trabalho para a época, as linhas de costa provavelmente se encontravam próximas do limite entre as cadeias montanhosas (representadas pelas faixas móveis) e o cráton. Assim, o mar que encobria o CSF recebia águas oriundas diretamente do alto curso dos rios, com altos teores de $\mathrm{Sr}$ e razões ${ }^{87} \mathrm{Sr} /{ }^{86} \mathrm{Sr}$ menores que dos oceanos Ediacaranos/Cambrianos (Fig. 47). Águas doces com estas características poderiam adentrar o ambiente marinho vindo de todos os cinturões orogênicos que já estavam adjacentes ao Cráton. Como as águas deste mar não se homogeneizavam com as dos oceanos de mesma idade, suas razões isotópicas de $\mathrm{Sr}$ tenderiam a diminuir e não aumentar, como esperado pelo raciocínio de Melezhik et al. (2001). Consequentemente, os carbonatos da Formação Sete Lagoas depositados neste ambiente registraram razões ${ }^{87} \mathrm{Sr} /{ }^{86} \mathrm{Sr}$ menores que as de outras sucessões contemporâneas. Esta situação perdurou além da deposição desta unidade, visto que carbonatos da Formação Lagoa do Jacaré também possuem baixas razões ${ }^{87} \mathrm{Sr} /{ }^{86} \mathrm{Sr}(0,7074$ Misi et al., 2007).

Este cenário ilustra como a aplicação da quimioestratigrafia deve ser pautada em estudos extremamente rigorosos. Além de petrografia, geoquímica e idades absolutas (Melezhik et al., 2001), uma análise geotectônica da bacia deve preceder qualquer tentativa de correlação global ou posicionamento temporal da sucessão carbonática em estudo usando a 
quimioestratigrafia isotópica. Os casos em que não há dados de geocronologia absoluta são especialmente mais complicados, pois o posicionamento temporal das unidades carbonáticas, em geral, é realizado por curvas isotópicas de C. Isto pode induzir a erros, como salientado por Frimmel (2010), e resultar em correlações errôneas. Mais que isto, pode levar à reconstrução imprecisa das curvas de evolução de $\mathrm{Sr}$ para os oceanos neoproterozoicos e cambrianos pela utilização de dados provenientes de seções mal posicionadas no tempo, em função de dados de isótopos de C. 


\section{Bacia Hidrográfica do rio Amazonas - Atualmente}

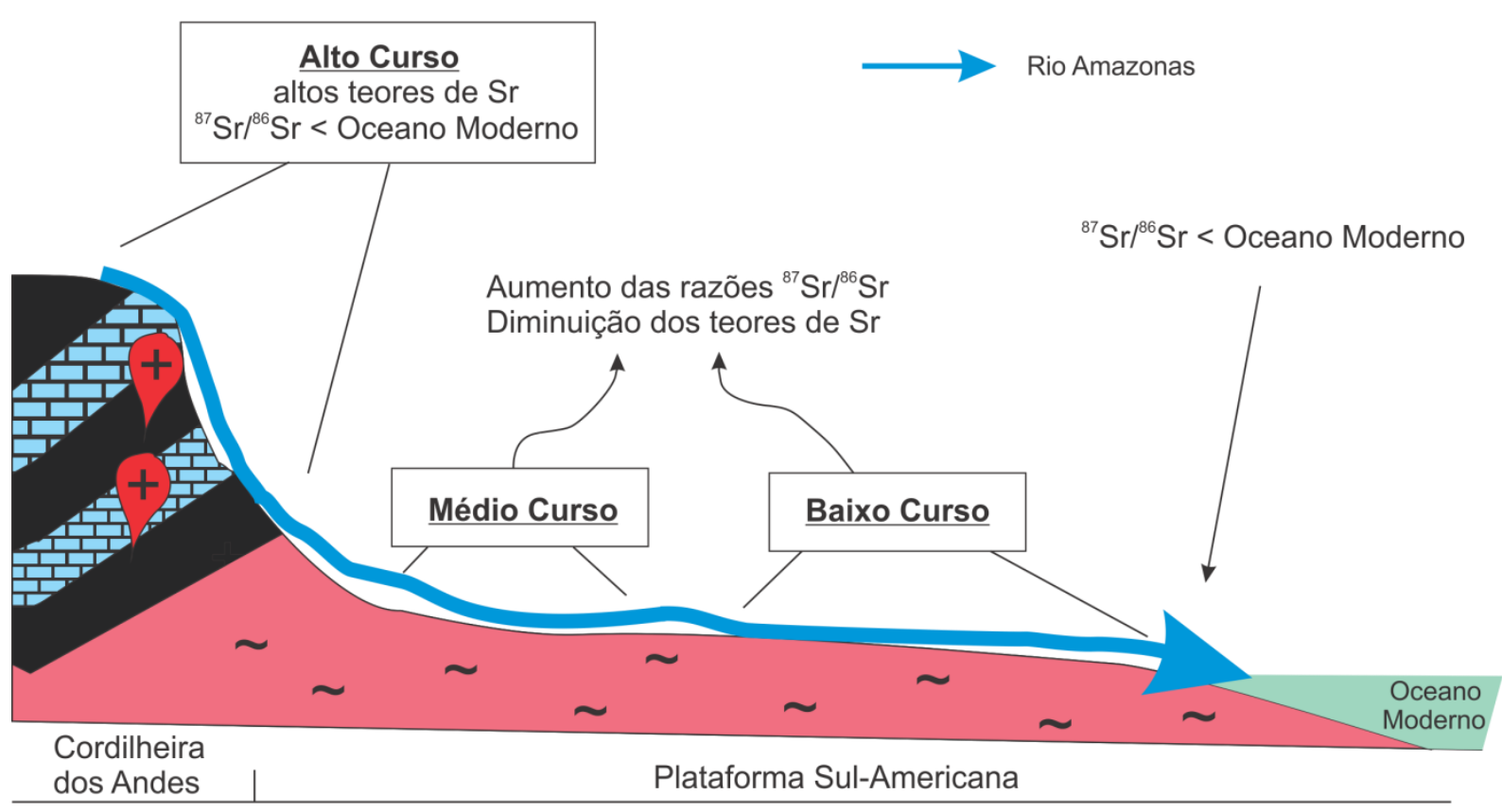

\section{Cráton São Francisco - Início do Cambriano}

Rios
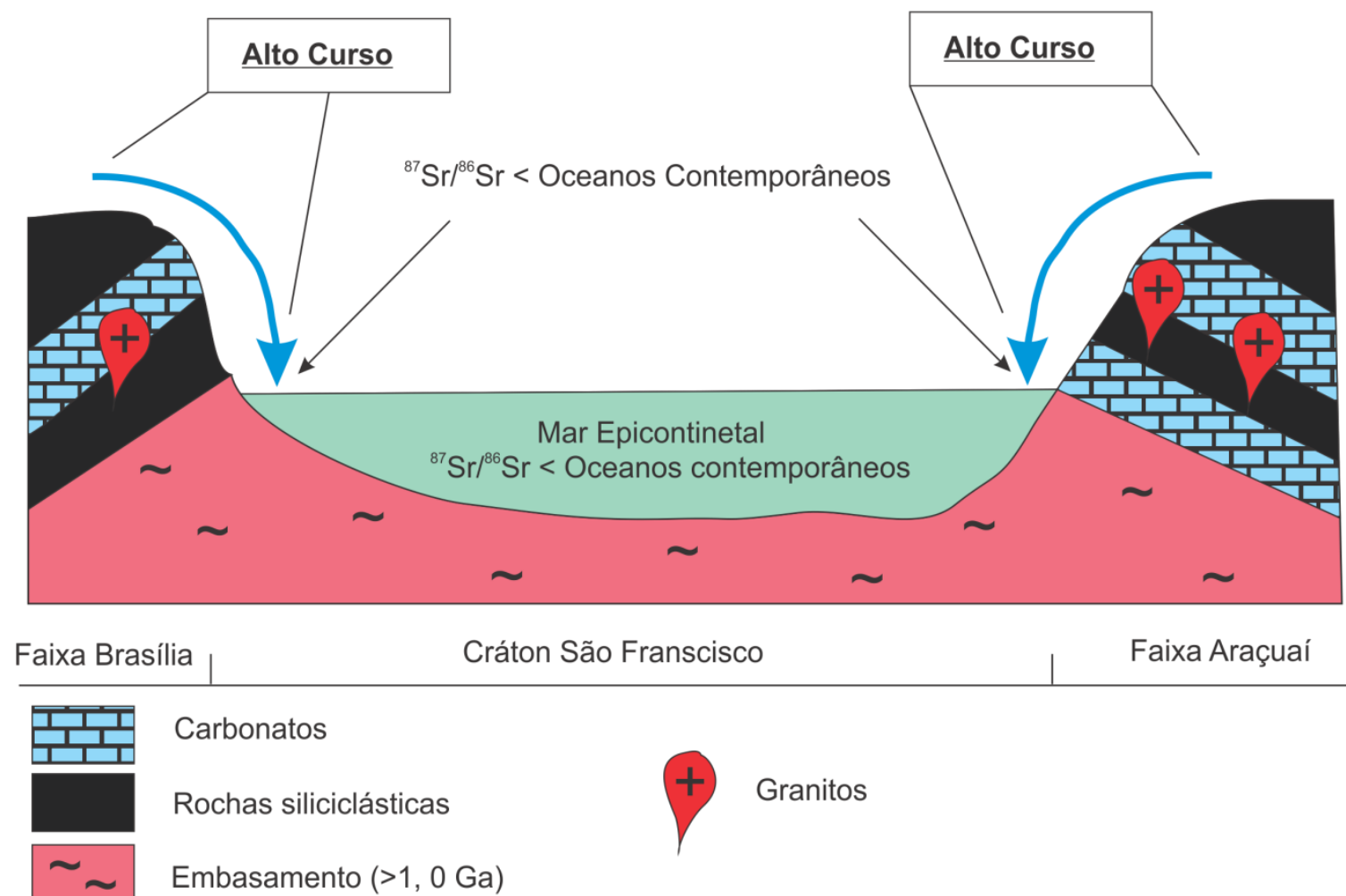

Fig. 47 - Esquema do fluxo de Sr fluvial para os mares nos dias atuais (baseado em Palmer \& Edmond, 1992) e no CSF no início do Cambriano. 


\section{CAPÍTULO 6}

\section{CONCLUSÕES}

Os dados geoquímicos, isotópicos e geocronológicos obtidos neste trabalho forneceram uma nova visão sobre a idade deposicional e evolução sedimentar da Formação Sete Lagoas, bem como sobre o momento geotectônico do CSF em que foi depositada. Além disso, permitiram estabelecer novas linhas de pesquisa para Grupo Bambuí em diversas áreas do conhecimento geológico. No escopo do trabalho, o levantamento de seções representantes das duas sequências deposicionais proposta por Vieira et al. (2007a, b) foi fundamental no cumprimento do objetivo proposto para este projeto.

Cinco seções geológicas da Formação Sete Lagoas foram descritas entre os municípios de Vespasiano e Lagoa Santa (MG). Os carbonatos coletados foram submetidos a análises petrográficas, geoquímicas (elementos maiores, traço e ETR) e isotópicas (C, O e Sr) e três amostras de marga foram coletadas para estudos geocronológicos (U-Pb, $\mathrm{Sm}-\mathrm{Nd}$ e Hf).

As seções VS e AP são constituídas de calcários de coloração cinza clara e dolomitos de coloração bege, com altos teores de sedimentos terrígenos, pobres em matéria orgânica e depositados em ambientes rasos de planície de maré. Os valores de $\delta^{13} \mathrm{C}$ obtidos nos calcários da seção VS variam de pouco negativos a pouco positivos, dentro de uma faixa de valores ao redor de 0\%. A seção AP apresentou valores isotópicos de $\mathrm{C}$ incoerentes e não representativos do ambiente deposicional. Diversas porções destas seções apresentam dolomitização tectônica, evidenciada pela estreita relação entre dolomitos e estruturas como falhas de empurrão e zonas brechadas. Os resultados isotópicos de $\mathrm{C}$ e $\mathrm{O}$ destas porções apresentam ampla oscilação e destoam das demais amostras. Estes carbonatos também apresentaram baixos teores de $\mathrm{Sr}$, sugerindo que suas razões ${ }^{87} \mathrm{Sr} /{ }^{86} \mathrm{Sr}$ bastante radiogênicas (ao redor de 0,7100) também não são representativas do ambiente deposicional. Mesmo assim, os dados petrográficos e isotópicos confiáveis permitem posicionar estas duas seções na primeira sequência deposicional da Formação Sete Lagoas, acima da capa carbonática Sturtiana (Criogeniano Médio).

As seções BL, BAU e PGL são constituídas dominantemente de calcários cinza escuros a negros, pobres em sedimentos siliciclásticos, ricos em matéria orgânica e depositados em ambiente moderadamente profundo e pouco sujeito à influência de ondas e tempestades. Os valores de $\delta^{13} \mathrm{C}$ obtidos nestes carbonatos são bastante positivos, em geral maiores que $6 \%$, e as razões ${ }^{87} \mathrm{Sr} /{ }^{86} \mathrm{Sr}$ mais representativas do ambiente marinho de deposição 
estão ao redor de 0,7075. Estes dados permitem posicionar estas seções na segunda sequência deposicional da Formação Sete Lagoas, acima do salto isotópico de C característico desta unidade. Os altos valores de $\delta^{13} \mathrm{C}$ representam um estágio de alta bioprodutividade do ambiente marinho, que pode ter sido induzida por um evento de oxigenação das águas. Isto é sugerido pelos dados preliminares de ETR que exibem anomalias negativas de $\mathrm{Ce}$ em algumas das amostras com composição representativa do ambiente de deposição obtidas na seção BAU.

Duas amostras de marga da primeira sequência (11-AP-05 e 11-VS-13) e uma da segunda (11-PGL-PEL) apresentaram idades $\mathrm{T}_{\mathrm{DM}} \mathrm{Sm}-\mathrm{Nd}$ entre 1,8 e 2,0 Ga e $\varepsilon \mathrm{Nd}_{(0)}$ bastante negativos, que sugerem fontes de protólitos paleoproterozoicos e de longa residência crustal. Isto também é sugerido pelos valores de $\varepsilon \mathrm{Hf}$ dos grãos de zircão datados que são dominantemente negativos, com apenas alguns exemplares apresentando valores positivos. As datações U-Pb em grãos de zircão detrítico sugerem o Orógeno Araçuaí - West Congo (E do CSF) como principal fonte dos sedimentos terrígenos da Formação Sete Lagoas na área de estudo. As amostras 11-AP-05 e 11-PGL-PEL possuem fontes dominantemente ediacaranas (625-557 Ma), representadas pelas supersuites ígneas encontradas na Faixa Araçuaí. A amostra 11-VS-13 possui sedimentos detríticos provenientes principalmente de rochas mesoproterozoicas e tonianas (1400-875 Ma), com menor contribuição de fontes arqueanas, paleoproterozoicas e ediacaranas/cambrianas. Não foram encontradas fontes ígneas para os grãos mesoproterozoicos. As fontes tonianas são os Grupos Mayumbian e Zanadinian encontrados na Faixa Oeste Congo, e em menor parte granitos anorogênicos encontrados no CSF e Faixa Araçuaí. As fontes dos grãos mais jovens são as supersuítes pós-colisionais da Faixa Araçuaí. Outros elementos petrográficos e geoquímicos suportam o Orógeno Araçuaí West Congo como fonte da Formação Sete Lagoas na porção SE do CSF. São estes a diminuição da granulometria e do teor, melhora na seleção e aumento do grau de arredondamento dos grãos terrígenos de E para W. Além disso, observa-se que seções mais a E (BL e PGL) possuem sua composição de ETR influenciada por água doce, enquanto que mais a W (BAU) há carbonatos com composições representativas do ambiente marinho, o que sugere fluxo de água doce oriundo do E.

A população de grãos de zircão expressiva mais jovem de 557 Ma determina a idade máxima de deposição para a segunda sequência da FSL e para grande parte do Grupo Bambuí. Embora nenhuma população de mais de 2 grãos tenha apresentado idade parecida, a idade concórdia de cerca de 593 Ma obtida na amostra da seção AP fornece uma estimativa para a idade das rochas sotopostas à capa carbonática desta sequência. Além disso, foram obtidos grãos de zircão mais jovens datados em $537 \pm 4$ Ma para a primeira sequência e de 
$506 \pm 4$ Ma para a segunda. Estes dados sugerem uma evolução sedimentar iniciada no limite Ediacarano - Cambriano e perdurada durante o Cambriano para a Formação Sete Lagoas. Os resultados geocronológicos também refutam a possibilidade de existir um hiato deposicional da ordem de 130 M.y. entre as duas sequências. Se existe uma discordância nesta unidade, ela deve estar posicionada entre a capa carbonática basal, com valores de $\delta^{13} \mathrm{C}$ negativos e os demais carbonatos sobrepostos a esta. O principal argumento em prol desta discordância é a grande diferença de idades entre a capa (740 \pm Ma - Babinski et al., 2007) e as porções mais superiores estudadas neste trabalho. Entretanto, chama atenção a ausência de uma superfície discordante compatível com um hiato de quase 200 M.y.. Estes dados demonstram a necessidade de mais estudos sobre o tema.

As idades ediacarana/cambrianas implicam que grande parte do Grupo Bambuí foi depositado em uma bacia do tipo foreland, após o fechamento do oceano Adamastor que culminou com a edificação da Faixa Araçuaí a E do CSF. A deposição das unidades marinhas ocorreu em um mar epicontinental restrito que não homogeneizava sua composição isotópica com os oceanos contemporâneos. Esta hipótese é suportada pela grande diferença entre as razões ${ }^{87} \mathrm{Sr} /{ }^{86} \mathrm{Sr}$ comumente obtidas para o Grupo Bambuí (ao redor de 0,7075) e aquelas apresentadas por Halverson et al. (2010) para os oceanos do Cambriano (>0,7085). As razões menos radiogênicas podem ser explicadas pela configuração geotectônica do cráton nesta época. Como o CSF estava completamente bordejado pelas cadeias de montanhas dos orógenos, o mar que o invadiu também esteve limitado pelas mesmas entidades geomorfológicas. Desta forma, o ambiente marinho recolhia águas diretamente do alto curso de rios que drenavam as áreas elevadas, que continham carbonatos mais antigos. Estas águas seriam caracterizadas por altos teores de $\mathrm{Sr}$ e razões ${ }^{87} \mathrm{Sr} /{ }^{86} \mathrm{Sr}$ mais baixas que dos oceanos da época. Sem homogeneização com oceanos globais, a composição isotópica de $\mathrm{Sr}$ do mar epicontinental tornou-se progressivamente menos radiogênica. Esta situação representa a quebra de uma premissa fundamental para aplicação da quimioestratigrafia isotópica, de maneira que correlações globais ou posicionamento temporal do Grupo Bambuí, por meio desta ferramenta, se mostram inadequadas. 


\section{REFERÊNCIAS BIBLIOGRÁFICAS}

Alibo, D.S. \& Nozaki, Y., 1999. Rare earth elements in seawater: Particle association, shalenormalization and Ce oxidation. Geochimica et Cosmochimica Acta, 63:363-372.

Alkmim, F.F., 2004. O que faz de um Cráton um Cráton? O Cráton São Francisco e as revelações Almeidanas ao delimitá-lo. In: Mantesso-Neto, V., Bartorelli, A., Carneiro, C.D.R., BritoNeves, B.B. (eds.) Geologia do Continente Sul-Americano: Evolução da Obra de Fernando Flávio Marques de Almeida. São Paulo, editora Beca, p. 17-35.

Alkmim, F.F. \& Marshak, S., 1998. Transamazonian Orogeny in the Southern São Francisco Craton Region in Minas Gerais, Brazil: evidence for Paleoproterozoic collision and collapse in the Quadrilátero Ferrífero. Precambrian Research, 90:29-58.

Alkmim, F.F., Chemale Jr., F., Endo, I., 1996. A deformação das coberturas proterozoicas do Craton do São Francisco e o seu significado tectônico. Revista da Escola de Minas, 49(1):22-38.

Alkmin, F.F. \& Martins-Neto, M.A., 2012. Proterozoic first-order sedimentary sequences of the São Francisco cráton, eastern Brazil. Marine and Petroleum Geology, 33(1):127-139.

Alvarenga, C.J.S., Santos, R.V., Dantas, E.L., 2004. C-O-Sr isotopic stratigraphy of cap carbonates overlying Marinoan-age glacial diamictites in the Paraguay Belt, Brazil. Precambrian Research, 131:1-21.

Alvarenga, C.J.S., Della Giustina, M.E.S., Silva N.G.C., Santos R.V.S., Gioia S.M.C.L., Guimarães, E.M., Dardenne, M.A., Sial A.N., Ferreira V.P., 2007. Variações dos isótopos de C e Sr em carbonatos pré e pós-glaciação Jequitaí (Esturtiano) na região de Bezerra-Formosa, Goiás. Revista Brasileira de Geociências, 37(4):147-155.

Alvarenga, C.J.S., Dardenne, M.A., Santos, R.V., Brod, E.R., Gioia, S.M.C.L., Sial, A.N., Dantas, E.L., Ferreira, V.P., 2008. Isotope stratigraphy of Neoproterozoic cap carbonates in the Araras Group, Brazil. Gondwana Research, 13:469-479.

Babinski, M., Brito Neves, B.B., Machado, N., Noce, C.M., Uhlein, A., Van Schmus, W.R., 1994. Problemas da metodologia U/Pb em zircões de vulcânicas continentais: caso do Grupo Rio dos Remédios, Supergrupo Espinhaço, no Estado da Bahia. In: Sociedade Brasileira de Geologia, Congresso Brasileiro de Geologia, 42, Balneário Camboriú, Anais, v.2, p. 409-410.

Babinski, M., Van Schmus, W.R. and Chemale, F., 1999. $\mathrm{Pb}-\mathrm{Pb}$ dating and $\mathrm{Pb}$ isotope geochemistry of Neoproterozoic carbonate rocks from the São Francisco basin, Brazil: implications for the mobility of $\mathrm{Pb}$ isotopes during tectonism and metamorphism. Chemical Geology, 160:175-199.

Babinski, M., Vieira, L.C., Trindade, R.I.F., 2007. Direct dating of Sete Lagoas cap carbonate (Bambuí Group, Brazil) and implications for the Neoproterozoic glacial events. Terra Nova, 19:401-406.

Babinski, M., Pedrosa-Soares, A.C., Trindade, R.I.F., Martins, M., Noce, C.M., Liu, D., 2012. Neoproterozoic glacial deposits from the Araçuaí orogen, Brazil: Age, provenance and correlations with the São Francisco craton and West Congo belt. Gondwana Research, 21:451465 .

Banner, J.L. \& Hanson, G.N., 1990. Calculation of simultaneous isotopic and trace element variations during water-rock interaction with application to carbonate diagenesis. Geochimica et Cosmochimica Acta 54:3123-3137. 
Bau, M. \& Dulski, P., 1996. Distribution of yttrium and rare-earth elements in the Penge and Kuruman Iron-Formations, Transvaal Supergroup South Africa. Precambrian Research, 79:37-55.

Bau, M., Koschinsky, A., Dulski, P., Hein, J.R., 1996. Comparison of the partitioning behaviours of yttrium, rare earth elements, and titanium between hydrogenetic marine ferromanganese crusts and seawater. Geochimica et Cosmochimica Acta, 60:1709-1725.

Bekker, A., Sial, A.N., Karhu, J.A., Ferreira, V.P., Noce, C.M., Kaufman, A.J., Romano, A.W., Pimentel, M.M., 2003. Chemostratigraphy of carbonates from the Minas Supergroup, Quadrilátero Ferrífero (Iron Quadrangle), Brazil: A stratigraphic record of Early Proterozoic atmospherical, biogeochemical and climate change. American Journal of Science, 303:865-904.

Brand, U., \& Veizer, J., 1980. Chemical diagenesis of a multicomponent carbonate system-1: Trace elements. Journal of Sedimentary Petrology, 50:1219-1236.

Brito-Neves, B.B., Campos-Neto, M.C., Fuck, R.A., 1999. From Rodínia to Western Gondwana: An approach to the Brasiliano-Pan African Cycle and orogenic collage. Episodes, 22:155-166.

Buchwaldt, R., Toulkeridis, T., Babinski, M., Santos, R., Noce, C.M., Martins-Neto, M.A., Hercos, C.M. 1999. Age determination and age-related provenance analysis of the Proterozoic glaciation event in central-eastern Brazil. In: South American Symposium on Isotope Geology, 2, Cordoba, Argentina, Actas, p. 387-390.

Buick, R., Des Marais, D.J., Knoll, A.H., 1995. Stable isotope compositions from the Mesoproterozoic Bangemall Group, northwestern Australia. Chemical Geology, 123:153-171.

Campos-Neto, M.C., 2000. Orogenic systems from southwestern Gondwana. An approach to Brasilano-Pan African Cycle and orogenic collage in southeastern Brazil. In: Cordani, U.G., Milani, E.J., Thomaz-Filho, A., Campos, D.A. (eds.) Tectonic Evolution of South America. 31st International Geology Congress, Rio de Janeiro, p. 335-365.

Caxito, F.A., Halverson, G.P., Uhlein, A., Stevensson, R., Dias, T.G., Uhlein, G.J., 2012. Marinoan glaciation in east Central Brazil. Precambrian Research, 200-203:38-58.

Cherniak, D.J. \& Watson, E.B., 2000. Pb diffusion in zircon. Chemical Geology, 172:5-24.

Claypool, G.E., Kaplan, I.R., 1974. The origin and distribution of methane in marine sediments. In: Kaplan, I.R. (Ed.) Natural Gases in Marine Sediments. Plenum, New York, p. 99-139.

Coelho, J.C.C., Martins-Neto, M.A., Marinho, M., 2008. Estilos estruturais e evolução tectônica da porção mineira da bacia proterozoica do São Francisco. Revista Brasileira de Geociências, 38 (2):149-165.

Corsetti, F.A., Olcott, A.N., Bakermans, C., 2006. The biotic response to Neoproterozoic snowball Earth. Paleogeography, Paleoclimatology, Paleoecology, 232:114-130.

Cruz, S.C.P. \& Alkmim. F.F., 2004. The tectonic interaction between the Paramirim Aulacogen and the Araçuaí Belt, São Francisco Craton region, Eastern Brazil. Anais da Academia Brasileira de Ciências, 1:151-173.

D'Agrella Filho, M.S., Pacca, I.I.G., Trindade, R.I.F., Teixeira, W., Raposo, M.I.B, Onstott,T.C., 1990. Paleomagnetism of Middle Proterozoic (1.01 to $1.08 \mathrm{Ga}$ ) mafic dykes in southeastern Bahia State- São Francisco craton, Brazil. Earth and Planetary Science Letters, 101:332-348.

Danderfer, A., De Waele, B., Pedreira, A., Nalini, H.A., 2009. New geochronological constraints on the geological evolution of Espinhaço basin within the São Francisco craton - Brazil. Precambrian Research, 170:116-128. 
Dardenne, M.A., 1978. Síntese sobre a estratigrafia do Grupo Bambuí no Brasil Central. In: SBG, Congresso Brasileiro de Geolologia, 30, Recife, Anais, v. 2, p. 597-610.

De Paolo, D., 1981. Neodymium isotopes in the Colorado Front Range and crust-mantle evolution in the Proterozoic. Nature, 291:193-196.

Derry, L.A., 2010. A burial diagenesis origin for the Ediacaran Shuram-Wonoka carbon isotope anomaly. Earth and Planetary Science Letters, 294:152-162.

Dias, P.H.A, Noce, C.M., Pedrosa-Soares, A.C., Seer, H.J., Dussin, I.A., Valeriano, C.M., Kuchenbecker, M., 2011. O Grupo Ibiá (Faixa Brasília Meridional): evidências isotópicas Sm$\mathrm{Nd}$ e U-Pb de bacia colisional tipo flysch. Geonomos, 19(2):90-99.

Evans, D.A.D., 2000. Stratigraphic, geochronological, and paleomagnetic constraints upon the Neoproterozoic climatic paradox. American Journal of Science, 300:347- 433.

Eyles, N. \& Januszczak, N., 2004. 'Zipper-rift': a tectonic model for Neoproterozoic glaciations during the breakup of Rodinia after 750 Ma. Earth-Science Reviews, 65:1-73.

Faure, G. \& Mensing, T.M. (eds.) 2005. Isotopes: Principles and Applications. $3^{\text {rd }}$ edition, New Jersey, John Wiley \& Sons, 897 p.

Figueiredo, M.F., 2006. Quimioestratigrafia das rochas ediacarianas do extremo norte da Faixa Paraguai, Mato Grosso. Dissertação de Mestrado, Instituto de Geociências da Universidade de São Paulo, São Paulo, 105 p.

Figueiredo, M.F., Babinski, M., Alvarenga, C.J.S., Pinho, F.E.C., 2008. Nova unidade litoestratifráfica registra Glaciação Ediacariana em Mato Grosso: Formação Serra Azul. Geologia USP Série Científica, 2 (8):65-75.

Figueiredo, M.F., 2010. Quimioestratigrafia isotópica (C, O, S e Sr), geocronologia ( $P b-\mathrm{Pb}$ e $\mathrm{K}$-Ar) e proveniência $(\mathrm{Sm}-\mathrm{Nd})$ das rochas da Faixa Paraguai Norte, Mato Grosso. Tese de Doutoramento, Instituto de Geociências da Universidade de São Paulo, São Paulo, 200 p.

Figueiredo, F.T., Almeida, R.P., Tohver, E., Babinski, M., Liu, D., Fanning, C.M., 2009. Neoproterozoic glacial dynamics revealed by provenance of diamictites of the Bebedouro Formation, São Francisco Craton, Central Eastern Brazil. Terra Nova, 21:375-385.

Fölling, P.G. \& Frimmel, H.E., 2002. Chemostratigraphic correlation of carbonate successions in the Gariep and Saldania Belts, Namibia and South Africa. Basin Research, 14:69-88.

Frimmel, H.E., Tack, L., Basei, M.S., Nutman, A.P., 2006. Provenance and chemostratigraphyof the Neoproterozoic West Congolian Group in the Democratic Republic of Congo. Journal of African Earth Sciences, 46:221-239.

Frimmel, H.E., 2009. Trace element distribution in Neoproterozoic carbonates as palaeoenvironmental indicator. Chemical Geology, 258:338-353.

Frimmel, H.E., 2010. On the reliability of stable carbon isotopes for Neoproterozoic chemostratigraphic correlation. Precambrian Research, 182(4):239-253.

Grotzinger, J.P. \& Knoll, A.H., 1995. Anomalous carbonate precipitates: is the Precambrian the key to the Permian? Palaios, 10:578-596.

Halverson, G.P., Hoffman, P.F., Schrag, D.P., Maloof, A.C., Rice, A.H., 2005. Toward a Neoproterozoic composite carbon-isotope record. GSA Bulletin, 117:1181-1207. 
Halverson, G.P., Dudás, F.O., Maloof, A.C., Bowring, S.A., 2007. Evolution of the ${ }^{87} \mathrm{Sr} /{ }^{86} \mathrm{Sr}$ composition of Neoproterozoic seawater. Palaeogeography, Palaeoclimatology, Palaeoecology, 256 (3-4):103-129.

Halverson, G.P., Wade, B.P., Hurtgen, M.T., Barovich, K.M., 2010. Neoproterozoic chemostratigraphy. Precambrian Research, 182:337-350.

Hawkesworth, C.J. \& Kemp, A.I.S., 2006. Using hafnium and oxygen isotopes in zircons to unravel the record of crustal evolution. Chemical Geology, 226:144-162.

Hoffman, P.F., Kaufman, A.J., Halverson, G.P., Schrag, D.P. 1998. A Neoproterozoic Snowball Earth. Science, 281:1342-1346.

Hoffman, P.F., Schrag, D.P., 2002. The Snowball Earth hypothesis: testing the limits of global change. Terra Nova, 14:129-155.

Houghton, R.A., 2005. The contemporary carbon cycle. In: Schlesinger, W.H. (Ed.), Biogeochemistry. Treatise on Geochemistry, vol. 8. Elsevier-Pergamon, Oxford, p. 473-513.

Hyde, W.T., Crowley, T.J., Baum, S.K., Peltier, W.R., 2000. Neoproterozoic 'Snowball Earth' simulations with a coupled climate/ice-sheet model. Nature, 405:425-429.

Iglesias, M. \& Uhlein, A., 2009. Estratigrafia do Grupo Bambuí e coberturas fanerozoicas no vale do rio São Francisco, norte de Minas Gerais. Revista Brasileira de Geociências, 39(2):256-266.

Iyer, S.S., Babinski, M., Krouse, H.L., Chemale, F., 1995. Highly ${ }^{13} \mathrm{C}$ enriched carbonate and organic matter in the Neoproterozoic sediments of the Bambuí Group, Brazil. Precambrian Research, 73: $271-282$.

Iizuka, T., Komiya, T., Rino, S., Maruyama, S., Hirata, T., 2010. Detrital zircon evidence for Hf isotopic evolution of granitoid crust and continental growth. Geochimica et Cosmochimica Acta, 74:2450-2472.

Jacobsen, S.B. \& Kaufman, A.J., 1999. The Sr, C and O isotopic evolution of Neoproterozoic seawater, Chemical Geology, 161:37-57.

Jones, C.E. \& Jenkyns, 2001. Seawater strontium isotopes, oceanic anoxic events, and seafloor hydrothermal activity in the Jurassic and Cretaceous. American Journal of Science, 301:112149.

Kah, L.C., 2000. Depositional $\delta^{18} \mathrm{O}$ signatures in Proterozoic dolostones: constraints on seawater chemistry and early diagenesis. In: Grotzinger, J.P. \& James, N.P. (eds.). Carbonate sedimentation and diagenesis in the involving Precambrian World. Society for Sedimentary Geology, Special Publication 67, p. 345-359.

Kamber, B.S., Greig, A., Collerson, K.D., 2005. A new estimate for the composition of weathered young upper continental crust from alluvial sediments, Queensland, Australia. Geochimica et Cosmochimica Acta, 69:1041-1058.

Kaufman, A.J., Hayes, J.M., Knoll, A.H., Germs, G.J.B., 1991. Isotopic composition of carbonates and organic carbon from upper Proterozoic successions in Namibia: stratigraphic variation and the effects of diagenesis and metamorphism. Precambrian Research, 49: 301-327.

Kaufman, A.J. \& Knoll, A.H., 1995. Neoproterozoic variations in the C-isotopic composition of seawater: stratigraphic and biogeochemical implications. Precambrian Research, 73:27-49. 
Kaufman, A.J., Knoll, A.H., Narbonne, G.M., 1997. Isotopes, ice ages, and terminal Proterozoic Earth history. National Academy Sciences Proceedings, 94:600-605.

Kennedy, M.J., 1996. Stratigraphy, sedimentology,and isotope geochemistry of Australian Neoproterozoic postglacial cap dolostones: deglaciation, $\delta^{13} \mathrm{C}$ excursions, and carbonate precipitation. Journal of Sedimentology Research, 66:1050-1064.

Kirschvink, J.L., 1992. Late Proterozoic low latitude glaciations: the snowball Earth. In: Schopf J.W. \& Klein C, (eds.) The Proterozoic Biosphere: A Multidisciplinary Study. Cambridge, Cambridge University Press, p. 51-52.

Knoll, A.H., Hayes, J.M., Kaufman, A.J., Swett, K., Lambert I.B., 1986. Secular variation in carbon isotope ratios from upper Proterozoic successions of Svalbard and East Greenland. Nature, 321:832-837.

Knoll, A.H. \& Walter, M.R., 1992. Latest Proterozoic stratigraphy and Earth history, Nature, 356:673678.

Kuchenbecker, M., 2011. Quimioestratigrafia e proveniência sedimentar da porção basal do Grupo Bambuí em Arcos (MG). Dissertação de Mestrado, Instituto de Geociências da Universidade Federal de Minas Gerais, Belo Horizonte, 91p.

Lawrence, M.G., Greig, A., Collerson, K.D., Kamber, B.S., 2006. Rare earth element and yttrium variability in South East Queensland waterways. Aquatic Geochemistry, 12:39-72.

Ling, H.-F., Chen, X., Li, D., Wang, D., Shields-Zhou, G.A., Zhu, M., 2011. Cerium anomaly variations in Ediacaran-earliest Cambrian carbonates from the Yangtze Gorges area, South China: Implications for oxygenation of coeval shallow seawater. Precambrian Research, in press, doi:10.1016/j.precamres.2011.10.011.

Machado, N., Schrank, A., Abreu, F.R., Knauer, L.G., Almeida-Abreu, P.A., 1989. Resultados preliminares da geocronologia U-Pb na Serra do Espinhaço Meridional. In: Simpósio de Geologia do Núcleo MG, 5, Simpósio de Geologia do Brasília, 1, Resumos, 10: 171-174.

Magalhães, P. M., 1989. Análise Estrutural das rochas do Grupo Bambuí, na porção sudoesteda Bacia do São Francisco. Dissertação de Mestrado, UFOP, Ouro Preto, 100 p.

Marshak, S. \& Alkmim, F.F., 1989. Proterozoic contraction/extension tectonics of the southern São Francisco region, Minas Gerais, Brazil. Tectonics, 8(3):555-571.

Martins-Neto, M.A., Pedrosa-Soares, A.C., Lima, S.A.A., 2001. Tectono-sedimentary evolution of sedimentary basis from Late Paleoproterozoic to Late Neoproterozoic in the São Francisco craton and Araçuaí fold belt, eastern Brazil. Sedimentary Geology, 142:343-370.

Martins-Neto, M.A. 2009. Sequence stratigraphic framework of Proterozoic successions in eastern Brazil. Marine and Petroleum Geology, 26:163-176.

McLennan, S.M., 1989. Rare-earth elements in sedimentary rocks - influence of provenance and sedimentary processes. Reviews in Mineralogy, 21:169-200.

Melezhik, V.A., Gorokhov, I.M., Kuznetsov, A.B., Fallick, A.E., 2001. Chemostratigraphy of Neoproterozoic carbonates: implications for "blind dating". Terra Nova, 13:1-11. 
Misi, A., Kaufman, A.J., Veizer, J., Powis, K., Azmy, K., Boggiani, P.C., Gaucher, C., Teixeira J.B.G., Sanchez, A.L., Iyer, S.S.S., 2007. Chemostratigraphic correlation of Neoproterozoic successions in South America. Chemical Geology, 237:143-167.

Noce, C.M., Teixeira, W., Quéméneur, J., Martins, V.T.S., Bolzachini, E., 2000. Isotopic signatures of Proterozoic granitoids from the Southern São Francisco Craton and implications for the evolution of the Transamazonian Orogeny. Journal of South American Earth Sciences, 13:225239.

Oliveira, E.P., Windley, B.F., Araújo, M.N.C., 2010. The Neoproterozoic Sergipano Belt, NE Brazil: A complete plate tectonic cycle in western Gondwana. Precambrian Research, 181(1):64-84.

Palmer, M.R., \& Edmond, J.M., 1989. The strontium isotope budget of the modern ocean. Earth and Planetary Science Letters, 92:11-26.

Palmer, M.R., \& Edmond, J.M., 1992. Controls over the strontium isotope composition of river water. Geochimica et Cosmochimica Acta, 56:2099-2111.

Patchett, P.J. \& Tatsumoto, M., 1980. Lu-Hf total-rock isochron for the eucrite meteorites. Nature, 288:571-574.

Pedrosa-Soares, A.C., Cordani, U.G., Nutman, A., 2000. Constraining the age of Neoproterozoic Glaciation in Eastern Brazil: first U-Pb (SHRIMP) data for detrital zircons. Revista Brasileira de Geociêcias, 30:58-61.

Pedrosa-Soares, A.C., Alkmim, F.F., Tack, L., Noce, C.M., Babinski, M., Silva, L.C., Martins-Neto, M., 2008. Similarities and differences between the Brazilian and African counterparts of the Neoproterozoic Araçuaí-West Congo Orogen. In: Pankhurst, J.R., Trouw, R.A.J., Brito-Neves, B.B., De Wit, M.J. (Eds.) West Gondwana: Pre-Cenozoic Correlations across the South Atlantic Region. Geological Society of London Special Publications, 294:153-172.

Pedrosa-Soares, A.C., De Campos, C.P., Noce, C., Silva, L.C., Novo, T., Roncato, J., Medeiros, S., Castañeda, C., Queiroga, G., Dantas, E., Dussin, I., Alkmim, F.F., 2011. Late NeoproterozoicCambrian granitic magmatism in the Araçuaí orogen (Brazil), the Eastern Brazilian Pegmatite Province and related mineral resources. Geological Society of London Special Publications, 350:25-51.

Pierre, C., 1989. Sedimentation and diagenesis in restricted marine basins. In: Fritz, P., Fontes, J.C.H. (Eds.) Handbook of Environmental Isotope Geochemistry, v.3 The Marine Environment. A. Elsevier, Amsterdam, p. 257-315.

Pimentel, M.M., Rodrigues, J.B., Della Giustina, M.E.S., Junges, S., Matteini, M., Armstrong, R., 2011. The tectonic evolution of the Neoproterozoic Brasília Belt, central Brazil, based on SHRIMP and LA-ICPMS U-Pb sedimentary provenance data: a review. Journal of South America Earth Sciences, 31:345-357.

PROJETO VIDA. CPRM - Serviço Geológico do Brasil. 2003. Mapeamento Geológico Região de Sete Lagoas, Pedro Leopoldo, Matozinhos, Lagoa Santa, Vespasiano, Capim Branco, Prudente de Morais, Confins e Funilândia. Mapa Geológico, escala 1:50.000.

Rocha-Campos, A C., Hasui, Y., 1981. Tillites of the Macaúbas Group (Proterozoic) in central Minas Gerais and southern Bahia, Brazil. In: Hambrey, M. J., Harland, W. B. (Eds) Earth's pre-Pleistocene Glacial Record. Cambridge University Press, p. 933-939.

Rodrigues, J.B., 2008. Proveniência de sedimentos dos grupos Canastra, Ibiá, Vazante e Bambuí - um estudo de zircões detríticos e Idades Modelo Sm-Nd. Tese de Doutoramento, Instituto de Geociências, Universidade de Brasília, Brasília, 128 p. 
Santos, R.V., Alvarenga, C.J.S., Dardenne, M.A., Sial, A.N., Ferreira, V.P., 2000. Carbon and oxygen isotope profiles across Meso-Neoproterozoic limestones from central Brazil: Bambuí and Paranoá Groups. Precambrian Research, 104:107-122.

Santos, R.V., Alvarenga, C.J.S., Babinski, M., Ramos, M.L.S, Cukrov, N., Fonseca, M.A., Sial, A.N., Dardenne, M.A., Noce, C.M., 2004. Carbon isotopes of Mesoproterozoic-Neoproterozoic sequences from Southern São Francisco cráton and Araçuaí Belt, Brazil: Paleogeographic implications. Journal of South American Earth Sciences, 18: 27-39.

Schmidt, P.W. \& Williams, G.E., 1995. The Neoproterozoic climactic paradox: equatorial palaeolatitude for Marinoan glaciations near sea level in South Australia. Earth Planetary Science Letters, 134: 107-124.

Schobbenhaus, C., Hoppe, A., Baumann, A., Lork, A., 1994. Idade U/Pb do vulcanismo Rio dos Remédios, Chapada Diamantina, Bahia. In: Congresso Brasileiro de Geologia, 38, Balneário Camboriú, SC, Resumos Expandidos, v.2, p. 397-399.

Schöll, W.U., 1976. Sedimentologia e geoquímica do Grupo Bambuí na parte sudeste da Bacia do São Francisco. In: Congresso Brasileiro de Geologia,29, Ouro Preto, Anais, p. 207-231.

Silva, L.C., Pedrosa-Soares, A.C., Teixeira, L.R., Armstrong, R., 2008. Tonian rift-related A-type continental plutonism in the Araçuaí Orogen, eastern Brazil: new evidence for the breakup stage of the São Francisco-Congo Paleocontinent. Gondwana Research, 13:527-537.

Tack, L., Wingate, M.T.D., Liégeois, J.P., Fernandez-Alonso, M., Deblond, A., 2001. Early Neoproterozoic magmatism (1000-910 Ma) of the Zadinian and Mayumbian Groups (BasCongo): Onset of Rodinian rifting at the western edge of the Congo craton. Precambrian Research, 110:277-306.

Taylor, S.R. \& McLennan, S.M. (eds.) 1985. The Continental Crust: Its Composition and Evolution. Blackwell, Oxford, $312 \mathrm{p}$.

Teixeira, W. \& Figueiredo, H.M.C., 1991. Na outline of Early Proterozoic crustal evolution in the São Franscisco craton, Brazil: a review. Precambrian Research, 53:1-22.

Teixeira, W., Sabaté, P., Barbosa, J., Noce, C.M., Carneiro, M.A., 2000. Archean and Paleoproterozoic tectonic evolution of the São Francisco craton, Brazil. In: Cordani, U.G., Milani, E.J., Thomaz-Filho, A., Campos, D.A. (eds.) Tectonic Evolution of South America. 31st International Geology Congress, Rio de Janeiro, p. 101-137.

Tera, F. \& Wasserburg, G.J., 1972. U-Th-Pb systematics in three Apollo 14 basalts and the problem of initial $\mathrm{Pb}$ in Lunar rocks. Earth and Planetary Science Letters, 14:281-304.

Van Wagoner, J.C., 1995. Sequence stratigraphy and Marine to Nonmarine Facies Architecture of Foreland Basin Strata, Book Cliffs, Utah, U.S.A. In: Van Wagoner, J.C. \& Bertram, G.T. (eds.) Sequence Stratigraphy of Foreland Basin Deposits - Outcrop and Subsurface Examples from the Cretaceous of North America. American Association of Petroleum Geologists Memoir, 64:137-223.

Veizer,J., Compston, W., Clauer, N., Schidlowski, M., 1983. ${ }^{87} \mathrm{Sr} /{ }^{86} \mathrm{Sr}$ in Late Proterozoic carbonates: Evidence for a mantle event at $900 \mathrm{Ma}$ ago. Geochimica et Cosmochimica Acta, 47:295-302.

Veizer, J., Hoefs, J., Ridler, R.H., Jensen, L.S., Lowe, D.R., 1989. Geochemistry of Precambrian carbonates: I. Archean hydrothermal systems. Geochimica et Cosmochimica Acta, 53:845-857. 
Veizer, J., Ala, D., Azmy, K., Brukschen, P., Buhl, D., Bruhn, F., Carden, G.A.F., Diener, A., Ebneth, S., Godderis, Y., Jasper, T., Korte, C., Pawellek, F., Podlaha, O.G., Strauss, H., $1999 .{ }^{87} \mathrm{Sr} /{ }^{86} \mathrm{Sr}$, $\delta^{13} \mathrm{C}$ and $\delta^{18} \mathrm{O}$ evolution of Phanerozoic seawater. Chemical Geology, 161:59-88.

Vieira, L.C., Almeida, R.P., Trindade, R.I.F., Nogueira, A.C.R., Janikian, L., 2007a. Formação Sete Lagoas em sua área-tipo: fácies, estratigrafia e sistemas deposicionais. Revista Brasileira de Geociências, 37 (4):1-14.

Vieira, L.C., Trindade, R.I.F, Nogueira, A.C.R., Ader, M., 2007b. Identification of a Sturtian cap carbonate in the Neoproterozoic Sete Lagoas carbonate plataform, Bambuí Group, Brazil. $C$. $R$. Geoscience, 339:240-258.

Wadleigh, M.A., Veizer, J., Brooks, C., 1985. Strontium and its isotopes in Canadian rivers: Fluxes and global implications. Geochimica et Cosmochimica Acta, 49:1727-1736.

Webb, G.E., Nothdurft, L.D., Kamber, B.S., Kloprogge, J.T., Zhao, J.-X., 2009. Rare earth element geochemistry of scleractinian coral skeleton during meteoric diagenesis: a sequence through neomorphism of aragonite to calcite. Sedimentology, 56:1433-1463.

Whithicar, M.J., Faber, E., Schoell, M., 1986. Biogenic methane formation in marine and freshwater environments: $\mathrm{CO}_{2}$ reduction versus acetate fermentation? Isotope evidence. Geochimica et Cosmochimica Acta, 50:693-709.

Williams, G.E., 1975. Late Precambrian glacial climate and the Earth's obliquity. Geological Magazine, 112:441-465.

Zalán P. V. \& Romeiro-Silva P.C. 2007. Proposta de mudança significativa na coluna estratigráfica da Bacia do São Francisco. In: Simpósio de Geologia de Minas Gerais, 14, Simpósio de Geologia do Sudeste, 10, Diamantina, MG, Anais, p. 79.

Zhang, J., Nozaki, Y., 1996. Rare earth elements and yttrium in seawater: ICP-MS determinations in the East Caroline, Coral Sea, and South Fiji basins of the western South Pacific Ocean. Geochimica et Cosmochimica Acta, 60:4631-4644.

Zhao, Y., Zheng, Y., Chen, F., 2009. Trace element and strontium isotope on sedimentary environment of Ediacaran carbonates in southern Anhui, South China. Chemical Geology, 265:345-362. 